Aus dem Fachgebiet Pflanzenpathologie und Pflanzenschutz

des Department für Nutzpflanzenwissenschaften der Georg-August-Universität Göttingen

\title{
Einflussfaktoren der Mykotoxinbildung durch Ährenbefall mit Fusarium spp. in verschiedenen Winterweizenfruchtfolgen
}

\author{
Dissertation \\ zur Erlangung des Doktorgrades \\ der Fakultät für Agrarwissenschaften \\ der Georg-August-Universität Göttingen
}

vorgelegt von

Ruben Gödecke

geboren in Göttingen

Göttingen, im November 2010 
D 7

1. Referent : Prof. Dr. Andreas von Tiedemann

2. Referent : Prof. Dr. Petr Karlovsky

Tag der mündlichen Prüfung: 09.11.2010 
Put your confidence in us. Give us your faith and your blessing, and, under providence, all will be well. We shall not fail or falter; we shall not weaken or tire. Neither the sudden shock of battle, nor the long-drawn trials of vigilance and exertion will wear us down. Give us the tools, and we will finish the job!

Winston Churchill, 09.02.1941 


\section{Inhaltsverzeichnis}

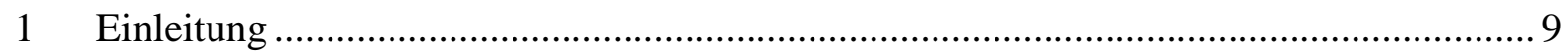

1.1 Partielle Weißährigkeit im Weizen................................................................. 9

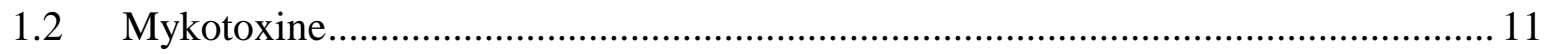

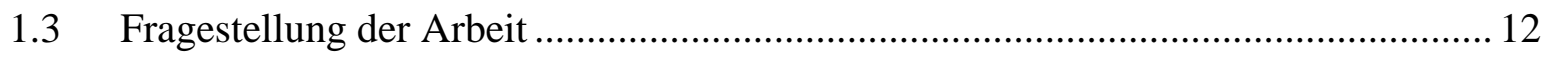

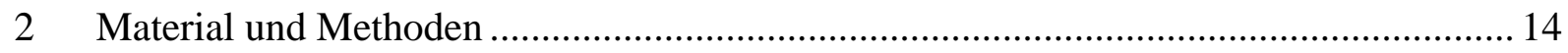

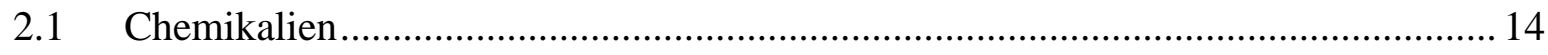

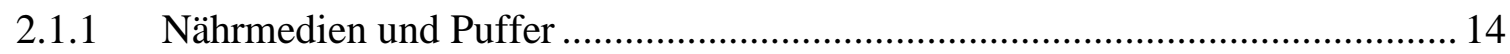

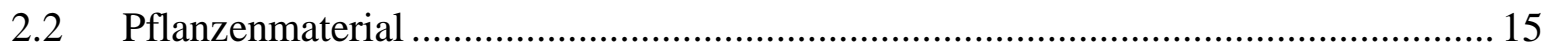

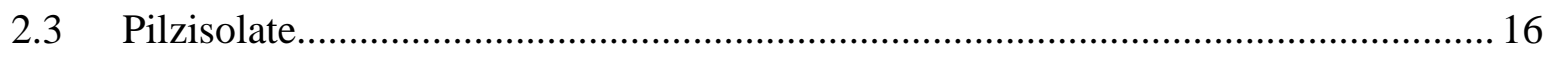

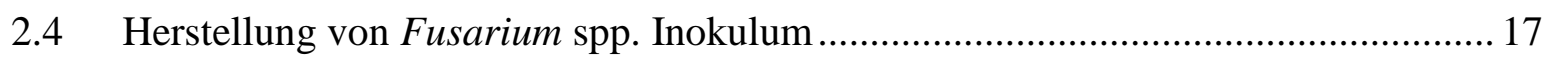

2.4.1 Inokulumherstellung auf Haferkörnern .................................................... 17

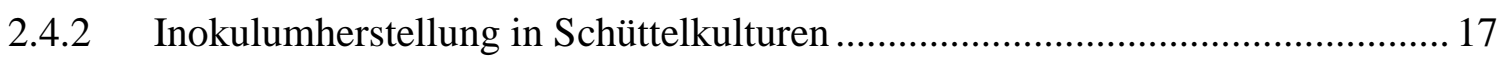

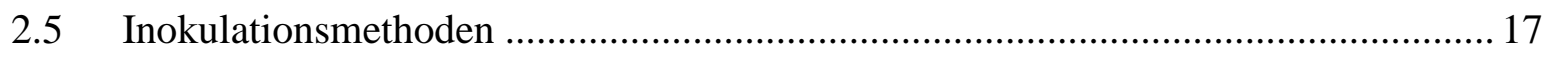

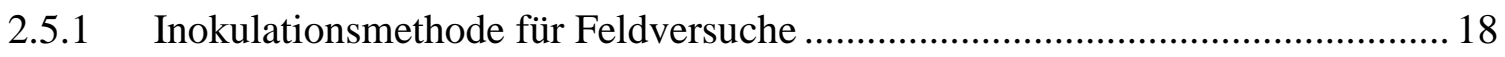

2.5.2 Inokulationsmethoden für Gewächshausversuche ..................................... 18

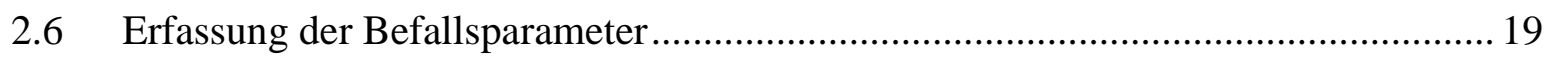

2.6.1 Visuelle Bonitur im Feldversuch................................................................... 19

2.6.2 Visuelle Bonitur im Gewächshaus ................................................................. 20

2.7 Analysen der Proben aus Feld- und Gewächshausversuchen ................................. 21

2.7.1 Probennahme und Probenaufbereitung ................................................... 21

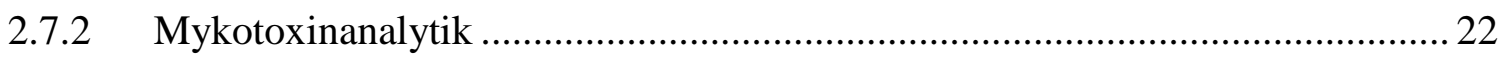

2.7.2.1 ELISA (Enzyme-linked-immunosorbent-assay)................................... 22

2.7.2.2 HPLC (High performance liquid chromagraphy) ................................... 23

2.7.3 Quantitative PCR (Polymerase chain reaction) ............................................ 23

2.8 Isolierung und Identifikation von Fusarium-Arten aus dem Erntegut des FAEN Feldversuches 
2.9 Erfassung des Fusarium spp. Sporenfluges im FAEN Feldversuch ......................... 25

2.10 Erfassung des Blühverlaufs in Gewächshaus- und Feldversuchen .......................25

2.11 Bestimmung von fungiziden Restmengen in Pflanzenmaterial .......................... 26

2.12 Erfassung des Abreifeverlaufs von Weizenähren ............................................ 27

2.13 Messung der Gujakolperoxidaseaktivität im Spelzengewebe von Winterweizen . 27

2.14 Erfassung weiterer Parameter an Kornproben ................................................ 28

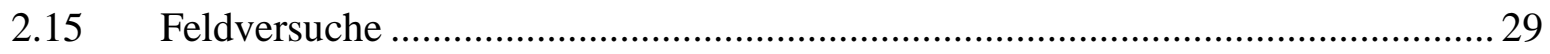

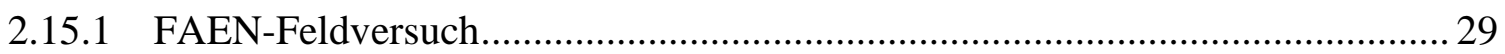

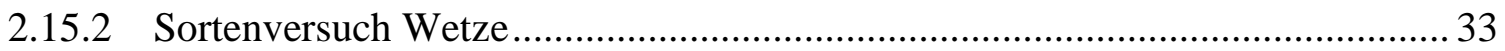

2.15.3 Abreife- und Enzymaktivitätsversuch Weendelsbreite .................................... 33

2.15.3.1 Halbfreilandversuch zum Abreifeverlauf am Standort Weendelsbreite ..... 34

2.15.3.2 Feldversuch zur Enzymaktivität am Standort Weendelsbreite ................... 34

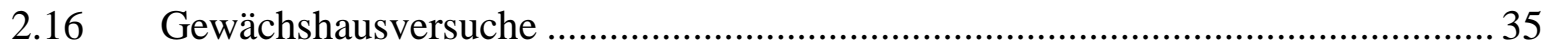

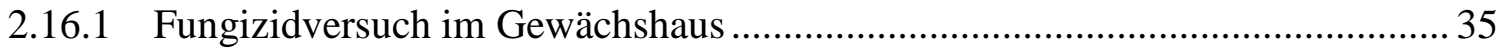

2.16.2 Sortenversuch mit Einzelährchen- und Sprühinokulation............................... 36

2.16.3 Klimakammerversuche zum Einfluss von Witterungsparametern .................... 37

2.16.4 Pathogenitätstest an Weizen mit Fusarium-Isolaten aus Zuckerrüben und deren

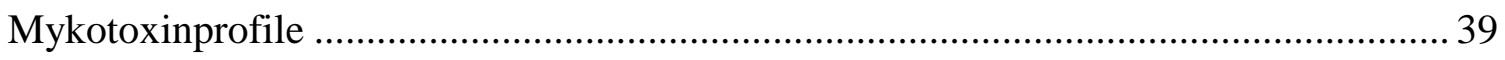

2.16.5 Untersuchungen zum „Black Point“ Symptom an Weizen ................................ 39

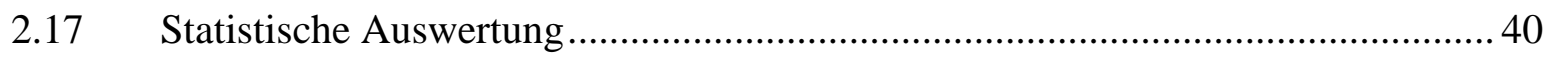

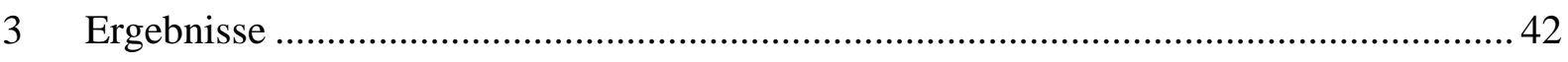

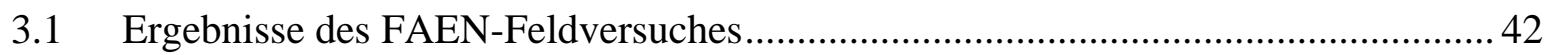

3.1.1 Meteorologische Daten und Sporenmessungen ........................................ 42

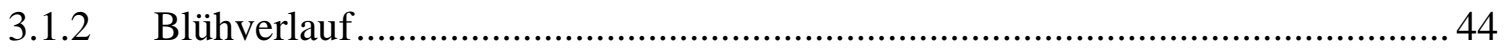

3.1.3 Befallshäufigkeit der partiellen Weißährigkeit ................................................ 45

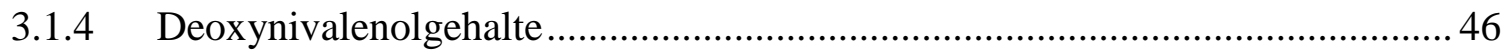

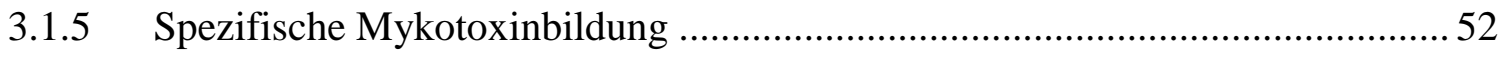

3.1.6 Artenspektrum von Fusarium spp.......................................................... 55 


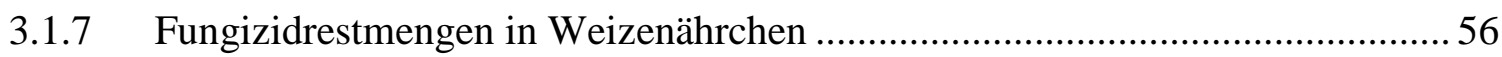

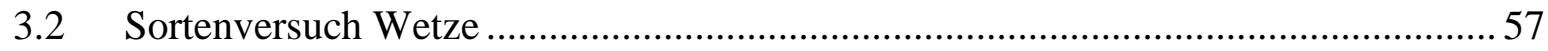

3.3 Abreife- und Enzymaktivitätsversuche Weendelsbreite.........................................59

3.3.1 Halbfreilandversuch zum Abreifeverlauf am Standort Weendelsbreite ............59

3.3.2 Feldversuch zur Enzymaktivität am Standort Weendelsbreite ......................... 60

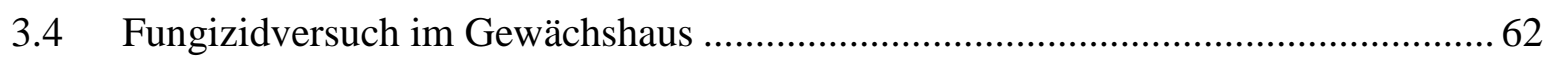

3.5 Sortenversuch mit Einzelährchen- und Sprühinokulation ..................................... 63

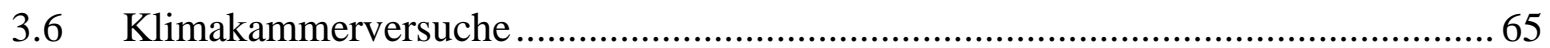

3.7 Pathogenitätsversuch an Weizen mit aus Zuckerrüben isolierten Fusarium-Isolaten

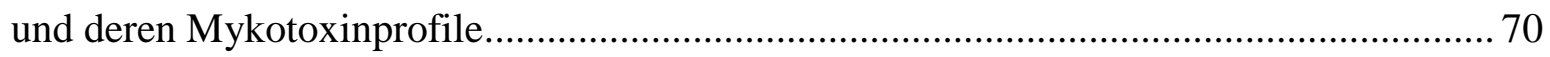

3.8 Untersuchungen zum „Black Point“ Symptom .................................................... 74

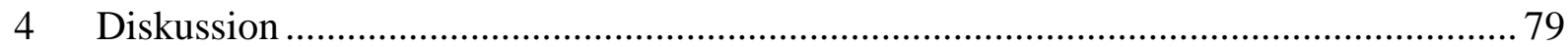

4.1 Methodische Fragestestellungen zu Versuchen mit FHB im Feld und Gewächshaus ..

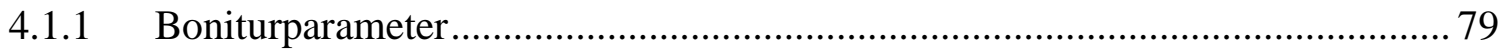

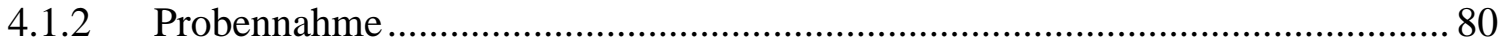

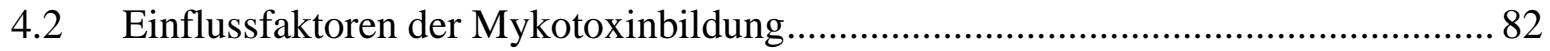

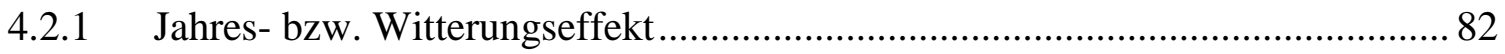

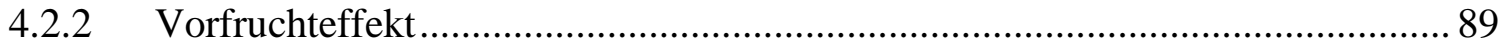

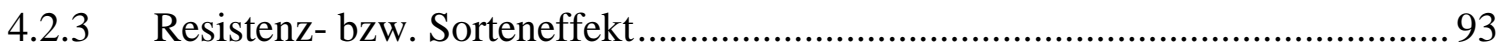

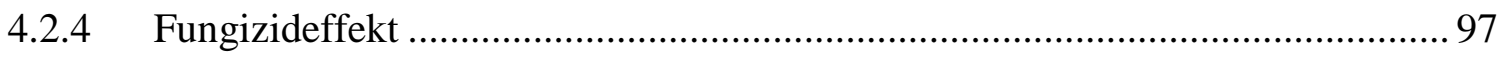

4.3 Artenspektrum von Fusarium spp. am Erntegut des FAEN-Versuches................... 104

4.4 Pathogenität der aus Zuckerrüben isolierten Fusarium-Isolaten und das „Black

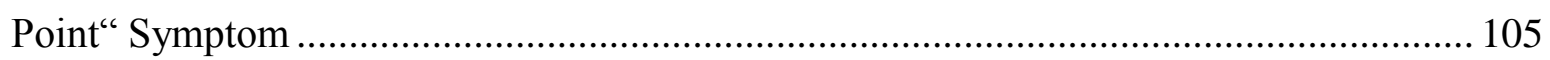

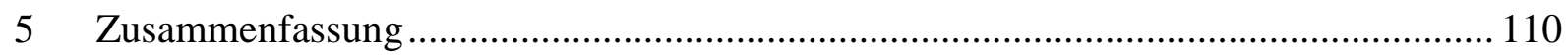

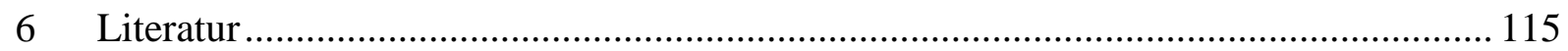

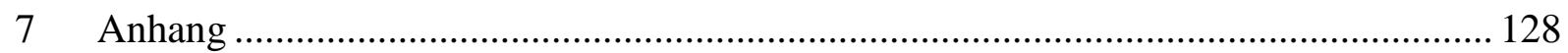


Abkürzungen und Symbole

Abb.

Abbildung

$15-\mathrm{A}-\mathrm{DON}$

15-Acetyldeoxynivalenol

2-AOD-3-ol

2-Amino-14,16-Dimethyloctadecan-3-ol

3-ADON

3-Acetyldeoxynivalenol

AVENA

Avenacein Y (syn. Antibiotic Y)

$\mathrm{BBCH}$

Codierung der phänotypischen Entwicklungsstadien von

Getreide

BEAU

Beauvericin

bzw.

beziehungsweise

${ }^{\circ} \mathrm{C}$

Grad Celsius

ca.

zirka

$\mathrm{cm}$

Zentimeter

DAS

Diacetoxyscirpenol

DNA

Desoxyribonukleinsäure

DON

Deoxynivalenol

dpi

Days post inoculation

ELISA

Enzyme linked immunosorbent assay

ENNI

Enniatin

EQUI

Equisetin

FHB

Fusarium Head Blight

FUS $X$

Fusarenon X (syn. 4-Acetylnivalenol)

g

Gramm

h

Stunde

ha

Hektar

HPLC-MS/MS

Hochdruckflüssigkeitschromatographie mit TandemMassenspektrometrie

i.d.R

in der Regel

$\mathrm{kg}$

Kilogramm

$\mathrm{km}$

Kilometer

1

Liter 
$\mathrm{m}$

$\mathrm{m}^{2}$

MAS

Min

$\mathrm{mm}$

MON

NIV

PCR

n.s.

OD

PCR

rel.

rpm

Tab.

TKG

z.B.

$\mu g$

$\mathrm{W}: \mathrm{V}$

Wdh

$\%$

ZEA
Meter

Quadratmeter

Monoacetoxyscirpenol

Minute

Millimeter

Moniliformin

Nivalenol

Polymerasekettenreaktion

nicht signifikant

Optische Dichte

Polymerase Chain Reaction

relativ

Umdrehungen pro Minute

Tabelle

Tausendkorngewicht

zum Beispiel

Mikrogramm

weight per volume (Gewichtsanteil zu Volumenanteil)

Wiederholung

Prozent

Zearalenon 


\section{$1 \quad$ Einleitung}

\subsection{Partielle Weißährigkeit im Weizen}

Die partielle Weißährigkeit bzw. Fusarium Head Blight (FHB) kann von mehreren Pathogenen verursacht werden, die verschiedenen Arten angehören und trotzdem ähnliche Symptome verursachen, so dass eine visuelle Unterscheidung an der Pflanze nahezu unmöglich ist. Der FHB-Komplex besteht aus bis zu 19 Spezies (Liddell, 2003) von denen vor allem das Pathogen Fusarium graminearum Schwabe [teleomorph Gibberella zeae (Schweinitz) Petch] weltweit als der Hauptverursacher in Weizen angesehen wird (Goswami \& Kistler, 2004). FHB wurde das erste Mal 1884 in England von W.G. Smith an Weizen beschrieben und wird seit den neunziger Jahren, nach mehreren Epidemien, vor allem auf dem amerikanischen Kontinent, weltweit als der limitierende Hauptfaktor in der Weizenproduktion angesehen (Stack, 1999). Aufgrund allein dieses Pathogens kam es in den USA zwischen 1998-2000 zu geschätzten Verlusten im Agrarsektor von bis zu 2,7 Mrd \$ (Nganje et al., 2002). Ertragsverluste, hauptsächlich durch die Verringerung des Tausendkorngewichtes hervorgerufen, können in Abhängigkeit vom Epidemieverlauf unter natürlichen Befallsbedingungen zwischen 2-30\% liegen, bei künstlichen Inokultionsexperimenten wurden sogar Ertragsausfälle von bis zu 70\% beobachtet (Parry et al., 1995).

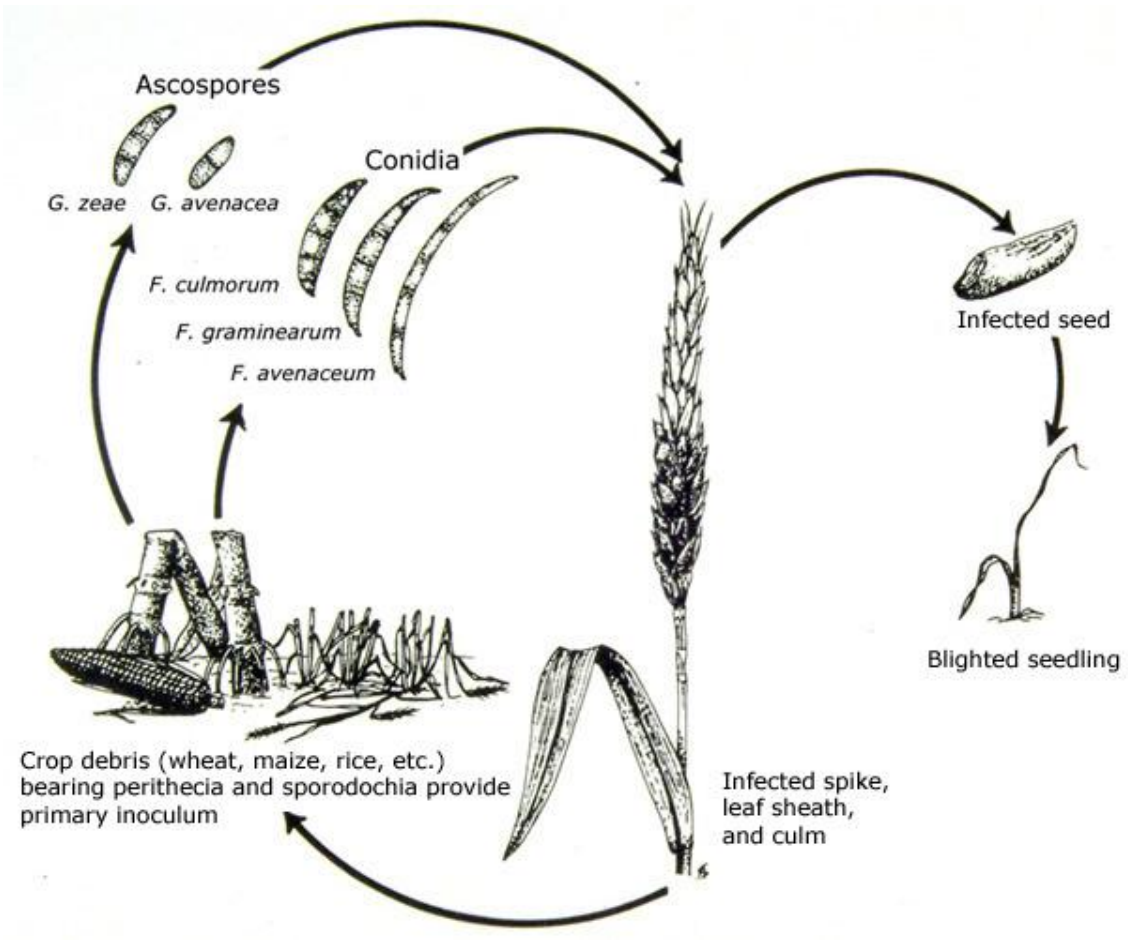

Abb. 1: Entwicklungszyklus verschiedener am FHB-Komplex beteiligter Fusarium-Arten, nach A. Schilder \& G. Bergstrom (www.apsnet.org/education/LessonsPlantPath/Fusarium/discycle.htm) 
Als primäre Inokulumquelle werden die vom Pathogen besiedelten Stoppelreste der Vorfrucht angesehen, die zwischen den wachsenden Weizenpflanzen auf der Erde verbleiben und auf denen F. graminearum als saproyhytisches Myzel überwintern kann (Sutton, 1982; Beck \& Lepschy, 2000). Im Frühjahr bzw. im beginnenden Sommer führt auf den pflanzlichen Resten eine feuchtwarme Witterung zur Bildung von Konidienlagern und zur Reifung von Perithezien (Abb. 1). Weizenpflanzen sind besonders im Entwicklungsstadium der Vollblüte (BBCH 65) anfällig für Ähreninfektion durch F. graminearum (Pugh et al., 1933). Eine Koinzidenz mit einer ausreichenden Menge an Askosporen oder Konidien, die durch Niederschläge in die Luft gewirbelt wurden, kann unter günstigen Witterungsumständen zu einem großflächigen Auftreten der partiellen Weißährigkeit führen (Obst, 2000). Sobald das Pathogen die Ähre erreicht hat, kommt es zu einem Hyphenwachstum, was ein dünnes Myzelnetzwerk um und zwischen den Vor-, Hüll- und Deckspelzen bildet. Dies erscheint notwendig, da der Pilz nicht die Fähigkeit besitzt, direkt durch die Epidermis zu wachsen, er muss somit anfälligere Gewebebereiche, wie z.B. die Stomataöffnungen (Kang \& Buchenauer, 2000a) des Ährchens erreichen, um diese als Eintrittspforten zu nutzen. Durch diese kann das Pathogen bis in das photoynthetisch aktive Assimilatparenchym vordringen und sich dort ausbreiten (Bushnell et al., 2003). Nekrotisiertes und kollabiertes Collenchym in den Hüll- und Deckspelzen infizierter Ähren deutet darauf hin, dass diese Gewebeschicht $F$. graminearum zur Passage von auBen nach innen in die Blütenanlage dient. Einen weiteren möglichen Infektionsweg sollen Antheren bilden. Diese können während der Blüte zwischen den Spelzen hängen bleiben, und eine direkte Brücke für das Pathogen in die Blüte darstellen. Darüberhinaus wurden in ihnen die Substanzen Betain und Cholin identifiziert, die in vitro das Wachstum von $F$. graminearum förderten (Strange et al., 1978). Jedoch zeigten auch Versuche mit emaskulierten Ähren vergleichbare Infektionsverläufe wie normale Ähren, so dass die Antherenpassage wahrscheinlich erscheint aber nicht notwendig ist (Bushnell et al., 2003). Unabhängig davon wie Sporen in das Ährchen gelangen, sobald das Pathogen dieses erreicht hat, ist eine Ähreninfektion höchst wahrscheinlich. Innerhalb von zwei Tagen werden in der Blüte zuerst der Fruchtknoten, die Schwellkörper und die Staubbeutel besiedelt (Tu, 1950). Mittels zellwandabbauender Enzymen wie Cellulase, Xylanasen und Pektinasen (Kang \& Buchenauer, 2000b) dringen Penetrationshyphen in das Gewebe am Kelchgrund ein, und wachsen von dort in die Ährchenachse bis sie die Spindel erreichen. Über das Xylem und Phloem kann F. graminearum basipetal nacheinander, systemisch weitere Ährchen besiedeln und bis in das obere Halminternodium vordringen (Weinert \& Wolf, 1995). Oberhalb der Primärinfektion führt die Unterbrechung der Leitgewebe in der Spindel zu einer Chlorose, da 
weniger Nährstoffe in diese Abschnitte transportiert werden. Unterhalb dieses Abschnittes bilden sich auf den Spelzen bei entsprechender Witterung rötlich lachsfarbene Sporenlager. Das Ergebniss einer vollständigen Krankheitsentwicklung von $F$. graminearum an einer Weizenähre sind Kümmerkörner, die aus den chlorotischen oberen Bereichen geerntet werden können und weißlich oder rötlich verpilzte, teils beulige Körner aus den unteren Bereichen. Typische Symptome der partiellen Weißährigkeit treten zu Beginn der Milchreife (BBCH 75) auf, mit einzelnen oder mehreren aufgehellten Ährchen, sowie chlorotischen Ährenabschnitte, in einer ansonsten normalen grünen Ähre (Weinert \& Wolf, 1995).

\section{$1.2 \quad$ Mykotoxine}

Toxinproduzierende Pilze werden grundsätzlich in zwei distinkte Gruppen eingeteilt. Die erste Gruppe infiziert Pflanzen während des Wachstums und produziert Toxine vor der Ernte, hingegen die zweite Gruppe, die sogenannten Lagerpilze, beginnen mit der Toxinproduktion erst nach der Ernte (Miller, 2008). Das Pathogen Fusarium graminearum gehört zu der ersten Gruppe und kann neben der Quantität auch die Qualität des Ernteguts von Weizen durch die Bildung von Mykotoxinen nachhaltig beeinflussen. $\mathrm{Zu}$ diesen Mykotxinen gehören vor allem die B-Trichothecene Deoxynivalenol (DON), Nivalenol (NIV), Zearalenon (ZEA) mit ihren jeweiligen Derivatformen, darüberhinaus wurde auch die Bildung von Aurofusarin, Chlamydosporol und Culmorin beschrieben (Desjardins, 2006). Kontaminationen von Weizen und Gerste mit diesen Trichothecenen führte nach Verzehr, von den fünziger bis in die siebziger Jahre in Japan immer wieder zum Aufflackern von Intoxikationen bei Mensch und Tier, der sogenannten „Akakabi-Byo“ bzw. „red mold disease“. Vergleichbare Symptome wurden bereits in in den dreiziger Jahren in den USA festgestellt, wo 1928 nach einem Starkbefall mit F. graminearum und der Nutzung des Getreides als Futter bei Schweinen ein Futterverweigerungssyndrom beobachtet wurde, welches mit Erbrechen einherging und dazu führte, dass DON auch als sogenanntes Vomitoxin bekannt wurde (Vesonder \& Hesseltine, 1981). Darüberhinaus zeichnet sich DON in in vitro Untersuchungen als potenter Inhibitor der Proteinbiosynthese aus, wobei die Konsequenzen dieses Effekte im System Tier bzw. Mensch noch unbekannt sind (Tiemann \& Dänicke, 2007). ZEA besitzt eine hohe Affinität zu dem 17ßÖstradiol des menschlichen Organismus, welches als eines der wichtigsten Hormone in den Ovarien gebildet wird und somit direkten Einfluss auf die Fruchtbarkeit des Individuums hat. Übermäßiger Konsum von mit ZEA belastetem Getreide führte bei Schweinen zum sogenannten „Östrogensyndrom“. Besonders junge Sauen vor dem ersten Wurf reagieren bereits bei 
geringen Mengen (50-100 $\mu \mathrm{g} \mathrm{ZEA} \mathrm{kg}^{-1}$ ) sehr sensitiv auf diese Intoxikation, was zu Veränderungen bei der Fötusentwicklung, zu Scheinrauschen und zu geringeren Wurfgrößen führen kann (Mirocha et al., 1977). Als Konsequenz dieser möglichen Folgen von Intoxikationen mit verschiedenen Mykotoxinen verabschiedete die Europäische Union im Sinne des Verbraucherschutzes Grenzwerte für DON (1250 $\mu \mathrm{g} \mathrm{kg}^{-1}$ für unverarbeitet Getreideprodukte) und ZEA (100 $\mu \mathrm{g} \mathrm{kg}^{-1}$ für unverarbeite Getreideprodukte), die seit dem 01.07.2006 in Kraft sind (Anonymus, 2005). Getreidepartien, die diese Grenzwerte überschreiten, dürfen nicht als Lebensmittel in Verkehr gebracht werden, es gilt ein Verschneidungs- und Entgiftungsverbot mittels chemischer Behandlungen. Landwirte, die ihr Getreide als Lebensmittel weiter vermarkten wollen, müssen seitdem ihre Produktionstechnik darauf abstimmen, dass das $\mathrm{Zu}$ sammenwirken aller agronomischen Faktoren die Wahrscheinlichkeit für einen Befall mit Fusarium graminearum und somit für eine erhöhte Mykotoxinbelastung im Erntegut minimiert.

\subsection{Fragestellung der Arbeit}

Die Mykotoxinbelastung von Getreidekörnern hängt unmittelbar mit der Besiedelung der Pflanzen mit dem Ährenpathogen Fusarium graminearum zusammen. Im Rahmen des Forschungsverbundes Agrar- und Ernährungswissenschaften Niedersachsen (FAEN) wurden daher Feldversuche in Südniedersachsen angelegt, in denen bekannte ackerbauliche Risikofaktoren der Mykotoxinbildung bestätigt und quantifiziert werden sollten: (i) Fruchtfolgen mit Weizen nach Mais, (ii) Anbau anfälliger Sorten, (iii) pfluglose Stoppel- bzw. Bodenbearbeitung und (iv) eine Verzögerung der Abreife durch hohes Düngungsniveau (Edwards, 2004). Zusätzlich werden erstmals in dieser Arbeit die Einflüsse von physiologischen bzw. indirekten Fungizideffekten auf den Mykotoxin- und den Pilzbiomassegehalt überprüft, da in der Vergangenheit bei der Blattapplikation von physiologisch hochreaktiven Fungiziden wie den Strobilurinen immer wieder erhöhte Mykotoxinakkumulationen festgestellt wurden (Ellner, 2005).

Eine der zentralen Fragestellungen dieser Dissertation ist die spezifische Mykotoxinbildung der Ährenfusariosen d.h. die Menge Mykotoxin die pro Einheit $F$. graminearum DNA gebildet werden kann. Bisherige Untersuchungen stellten zwischen verschiedenen Versuchsjahren, große Schwankungsbreiten dieses Parameters fest, die bisher allein mit den unterschiedlichen Witterungseinflüssen erklärt wurden. Es ist jedoch unbekannt, warum in einem Jahr mehr Mykotoxine im Vergleich zur Pilzbiomasse und in einem anderen Jahr weniger gebildet wer- 
den. Welcher der vielfältigen Faktoren, wie z.B. die Temperatur oder die Dauer von Feuchtinkubationsperioden hauptsächlich für die Pathogenese und welcher für die Mykotoxinakkumulation von Bedeutung ist, soll im Laufe dieser Arbeit unter natürlichen und artifiziellen Umwelten identifiziert und verifiziert werden. Neben der bloßen Identifizierung soll aber auch eine quantitaive Bewertung der einzelnen Versuchsfaktoren mittels Varianzkomponentenanalysen durchgeführt werden, so dass für den Klimaraum Niedersachsen mögliche Risikorichtwerte bei entsprechenden Infektionssituationen abgeleitet werden können.

Ferner bieten vor allem die Kooperationen mit dem Institut für Zuckerrübenforschung (IFZ) und der Abteilung Qualität pflanzlicher Erzeugnisse im FAEN-Verbundprojekt Möglichkeiten, die bislang noch unbekannten Infektionswege von verschiedenen Fusarium-Arten in $\mathrm{Zu}$ ckerrübenfruchtfolgen und die Entwicklung qualitativer Parameter während der Pathogenentwicklung detaillierter zu untersuchen. 


\section{Material und Methoden}

\subsection{Chemikalien}

Agar-Agar

Gelextraktionssäule (PD-10)

Kartoffel-Glukose-Agar (PDA)

Polyvinylpolypyrrolidone (PVPP)

Polyethermodifiziertes Trisiloxan

Tween 20
Merck, Darmstadt

Sephadex, GE Healthcare, München

Fluka Analytical, Buchs/Schweiz

Serva, Heidelberg

Spiess Urania, Hamburg

Scharlau, Barcelona, Spanien

\subsubsection{Nährmedien und Puffer}

Der pH-Wert, der unten aufgelisteter Nährmedien, wurde vor dem Autoklavieren (15 min bei $121^{\circ} \mathrm{C}$ mit $\mathrm{NaOH}$ bzw. $\mathrm{HCl}$ eingestellt. Alle Puffer wurden in Aqua bidest. angesetzt.

Für die Identifizierung der Fusarium-Arten wurden folgende Medien verwendet:

Kartoffel-Glukose-Agar (PDA): pH 5,5

PDA

Aqua bidest.

Strohextrakt Agar 2\%-ig (SEA): pH 5,5

Unbehandeltes Weizenstroh $(2 \mathrm{~mm})$

Agar-Agar

Aqua bidest.

Strohextrakt Agar 0,2\%-ig (1/10 SEA): pH 5,5

Unbehandeltes Weizenstroh (2 mm)

Agar-Agar

Aqua bidest.
$39 \mathrm{~g}$

Ad $1000 \mathrm{ml}$

$15 \mathrm{~g}$

Ad $1000 \mathrm{ml}$

$2 \mathrm{~g}$

$15 \mathrm{~g}$

Ad $1000 \mathrm{ml}$ 
Für die Messung der Enzymkinetik wurden folgende Puffer verwendet:

Extraktionspuffer zur Analyse der Gujakolperoxidase

$\begin{array}{ll}\mathrm{K}_{2} \mathrm{HPO}_{4} & 0,1 \mathrm{M}\end{array}$

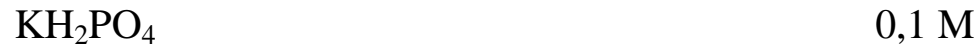

$\begin{array}{ll}\text { Triton } X & 1,5 \%\end{array}$

$\mathrm{pH} 7,8$

Elutionspuffer zur Analyse der Gujakolperoxidase
$\mathrm{K}_{2} \mathrm{HPO}_{4}$
$0,05 \mathrm{M}$
$\mathrm{KH}_{2} \mathrm{PO}_{4}$
$0,05 \mathrm{M}$

$\mathrm{pH} 7,8$

\subsection{Pflanzenmaterial}

Die im Rahmen dieser Arbeit verwendeten Winter- und Sommerweizensorten sind in Tab. 1 aufgeführt.

Tab. 1 Verwendete Weizensorten aus Feld- und Gewächshausversuchen, Anfälligkeit gegenüber Ahrenfusarium ist den Beschreibenden Sortenlisten 2006-2009 entnommen (Anonymus, 2006 \& 2009).

\begin{tabular}{cccc}
\hline Sorte & Typ & $\begin{array}{c}\text { Anfälligkeit für } \\
\text { Ährenfusarium }\end{array}$ & Züchter \\
\hline Centrum & Winterweizen & 2 & Diekmann Seed GmbH \\
Ritmo & Winterweizen & 7 & LG Seed \\
Julius & Winterweizen & 5 & KWS-Lochow GmbH \\
KWS Pius & Winterweizen & 5 & KWS-Lochow GmbH \\
KWS Erasmus & Winterweizen & 4 & KWS-Lochow GmbH \\
SW Kadrilj & Sommerweizen & 5 & SW Seed AG \\
Tybalt & Sommerweizen & 6 & Saatenunion GmbH \\
\hline
\end{tabular}




\subsection{Pilzisolate}

Bei allen Fusarium-Arten die in Gewächshaus- und Feldversuchen eingesetzt wurden, handelte es sich um Einzelsporenisolate (Tab. 2) die auf nährstoffarmen $2 \%$ SEA-Medium bei $8^{\circ} \mathrm{C}$ im Kühlraum gelagert wurden. Die Herkunft der Isolate ist in Tabelle 2 aufgeführt.

Tab. 2 Verwendete Einzelsporisolate von Fusarium spp. aus Gewächshaus- und Feldversuchen

\begin{tabular}{|c|c|c|c|}
\hline Art & Isolatbezeichnung & Herkunft & Isoliert aus \\
\hline F. graminearum & Fg142 & Stammsammlung APP & Winterweizen \\
\hline F. graminearum & Fg143 & Stammsammlung APP & Winterweizen \\
\hline F. graminearum & Fg144 & Stammsammlung APP & Winterweizen \\
\hline F. graminearum & $\mathrm{O} 14$ & $\begin{array}{c}\text { Institut für } \\
\text { Zuckerrübenforschung (IFZ) }\end{array}$ & Zuckerrübe \\
\hline F. culmorum & $\mathrm{Fc} 34$ & Stammsammlung APP & Winterweizen \\
\hline F. culmorum & $\mathrm{Fc} 35$ & Stammsammlung APP & Winterweizen \\
\hline F. culmorum & $\mathrm{Fc} 36$ & Stammsammlung APP & Winterweizen \\
\hline F. culmorum & $\mathrm{O} 29$ & IFZ & Zuckerrübe \\
\hline F. cerealis & $\mathrm{O} 45$ & IFZ & Zuckerrübe \\
\hline F. equiseti & O19 & IFZ & Zuckerrübe \\
\hline F. equiseti & $\mathrm{O} 20$ & IFZ & Zuckerrübe \\
\hline F. equiseti & O90 & IFZ & Zuckerrübe \\
\hline F. tricinctum & O63 & IFZ & Zuckerrübe \\
\hline F. tricinctum & $\mathrm{O} 35$ & IFZ & Zuckerrübe \\
\hline F. tricinctum & $\mathrm{O} 32$ & IFZ & Zuckerrübe \\
\hline$F$. redolens & O1 & IFZ & Zuckerrübe \\
\hline F. redolens & $\mathrm{O} 4$ & IFZ & Zuckerrübe \\
\hline F. redolens & $\mathrm{O} 7$ & IFZ & Zuckerrübe \\
\hline F. oxysporum & $\mathrm{O} 38$ & IFZ & Zuckerrübe \\
\hline F. oxysporum & O39 & IFZ & Zuckerrübe \\
\hline F. oxysporum & $\mathrm{O} 40$ & IFZ & Zuckerrübe \\
\hline
\end{tabular}




\subsection{Herstellung von Fusarium spp. Inokulum}

\subsubsection{Inokulumherstellung auf Haferkörnern}

Zweifach autoklavierte Haferkörner wurden in Inkubationsbeutel (Mycelia, Microsacs, Belgien) mit Segmenten aus PDA Kulturen der Isolate Fc34/35/36 von Fusarium culmorum beimpft. Die Beutel wurden täglich durchmischt um Luftmyzelbildung zu unterbinden (verändert nach Bockmann, 1962). Nach ca. 21 Tagen bildeten sich orangefarbene Sporodochien auf den Haferkörnern. Nachdem diese die gesamten Körner überwuchsen, wurden sie zum trocknen ausgelegt. Die trockenen Haferkörner wurden in Plastikbeutel bei $8^{\circ} \mathrm{C}$ im Kühlraum eingelagert und können für mehrere Jahre für eine Inokulumherstellung genutzt werden. Sobald sie mit Wasser in Kontakt kamen, wurden die Konidien von den Sporodochien abgespült, somit entstand eine infektionsfähige Konidiensuspension. Die Menge an Haferkörnern pro Liter Inokulationslösung war abhängig vom Sporodochienbewuchs und musste separat berechnet und ausgezählt werden, um eine einheitliche Konidiendichte zu gewährleisten.

\subsubsection{Inokulumherstellung in Schüttelkulturen}

Die Inokulumherstellung aller Fusarium spp. außer Fusarium culmorum erfolgte in einem zweiprozentigen Stroh-Wasser-Gemisch, dass zuvor zweimal autoklaviert wurde. Jeder Kolben, der $500 \mathrm{ml}$ Suspension enthielt, wurde mit fünf $1 \mathrm{~cm}^{2}$ großen Segmenten von besiedelten PDA-Platten beimpft und vierzehn Tage bei $23^{\circ} \mathrm{C}$ auf einem Schüttelinkubator (100rpm) im Dunkeln inkubiert. Nach der Inkubation wurden das Stroh und alle Schwebstoffe durch Filtration entfernt und die Sporen gewonnen. Mit Hilfe einer Fuchs-Rosenthal-Zählkammer wurde deren Menge bestimmt und durch Zugabe von Aqua bidest. auf eine Dichte von 2 x $10^{5}$ Sporen/ml eingestellt. Die Konidienformen der verschiedenen Fusarium-Arten unterscheiden sich teilweise erheblich. Darüber hinaus bilden einige Arten, neben Makrokonidien auch noch Meso- und Mikrokonidien, was bei der Einstellung der Sporendichte Berücksichtigung finden muss.

\subsection{Inokulationsmethoden}

Für Infektionsversuche mit Fusarieninokulum wurde sowohl in Gewächshaus- als auch in Feldversuchen die Konidiendichte auf 2 x $10^{5}$ Sporen/ml festgelegt. Um eine optimale Verteilung der Sporensuspension auf der Ähre zu gewährleisten wurde das Benetzungsmittel 
Silwet@ Gold (Spiess Urania) mit 0,1\% zugesetzt. Dieser Superbenetzer hat keinen Einfluss auf die Keimfähigkeit der Fusarienkonidien (eigene Daten). Die Inokulation erfolgte im Entwicklungsstadium BBCH 63-65 (Lancashire et al., 1991), sobald ca. 30\% der Antheren pro Ähre sichtbar waren. Inokulierte Pflanzen wurden in Gewächshausversuchen mit einem farbigen Etikett oberhalb des Fahnenblattes versehen, auf dem das jeweilige Inokulationsdatum eingetragen wurde.

\subsubsection{Inokulationsmethode für Feldversuche}

Die Inokulation der Feldversuche wurde mit einem, an einer Rückenspritze befestigten, Handspritzbalken (2,5 m) durchgeführt. Bei einem Druck von 5 bar wurden $100 \mathrm{ml}$ Sporensuspension pro $\mathrm{m}^{2}$ (siehe Kapitel 2.5) auf den Weizenbestand appliziert (verändert nach Bockmann, 1962). Eine einmalige Applikation zum Zeitpunkt der Blüte (BBCH 63-65) war ausreichend für einen gleichmäßigen Infektionserfolg, Diese sollte in den frühen Morgenstunden bzw. späten Abendstunden erfolgen um die infektionsfördernde Wirkung der Taubildung auszunutzen.

\subsubsection{Inokulationsmethoden für Gewächshausversuche}

Sprühinokulation: Ein Standardhandsprüher wurde ausgelitert und beide Spindelachsen so lange besprüht bis $2 \mathrm{ml}$ der Sporensuspension gleichmäßig auf der gesamten Ähre aufgetragen waren(Abb. 2a) (verändert nach Schroeder \& Christensen, 1963).

Punktinokulation: Mit einer Insulinspritze (Microfine U40/29G x 1/2, Becton Dickinson) wurden ca. $25 \mu 1$ der Sporensuspension am Kelchgrund durch Hüll- und Deckspelze in die Blütenanlage der Weizenpflanzen injiziert (verändert nach Engle et al. 2003). Die Inokulation erfolgte in der linken und rechten Ährenanlage eines Ährchens und wurde auf der gegenüberliegenden Spindelseite wiederholt (Abb. 2b).

Um in den Gewächshausversuchen eine umweltunabhängige und gleichmäßige Infektion zu gewährleisten, wurden die inokulierten Ähren für 48 h von einem Polyethylenbeutel (60 mm x $130 \mathrm{~mm}$ ) umhüllt (verändert nach Stein et al. 2009), in dem nahezu 100\% Luftfeuchtigkeit herrschten. Die Inkubation der Weizenpflanzen wurde in einem Raum mit stabilen Umweltbedingungen (Tag/Nacht: $20^{\circ} \mathrm{C} / 16^{\circ} \mathrm{C}$ ) durchgeführt. 


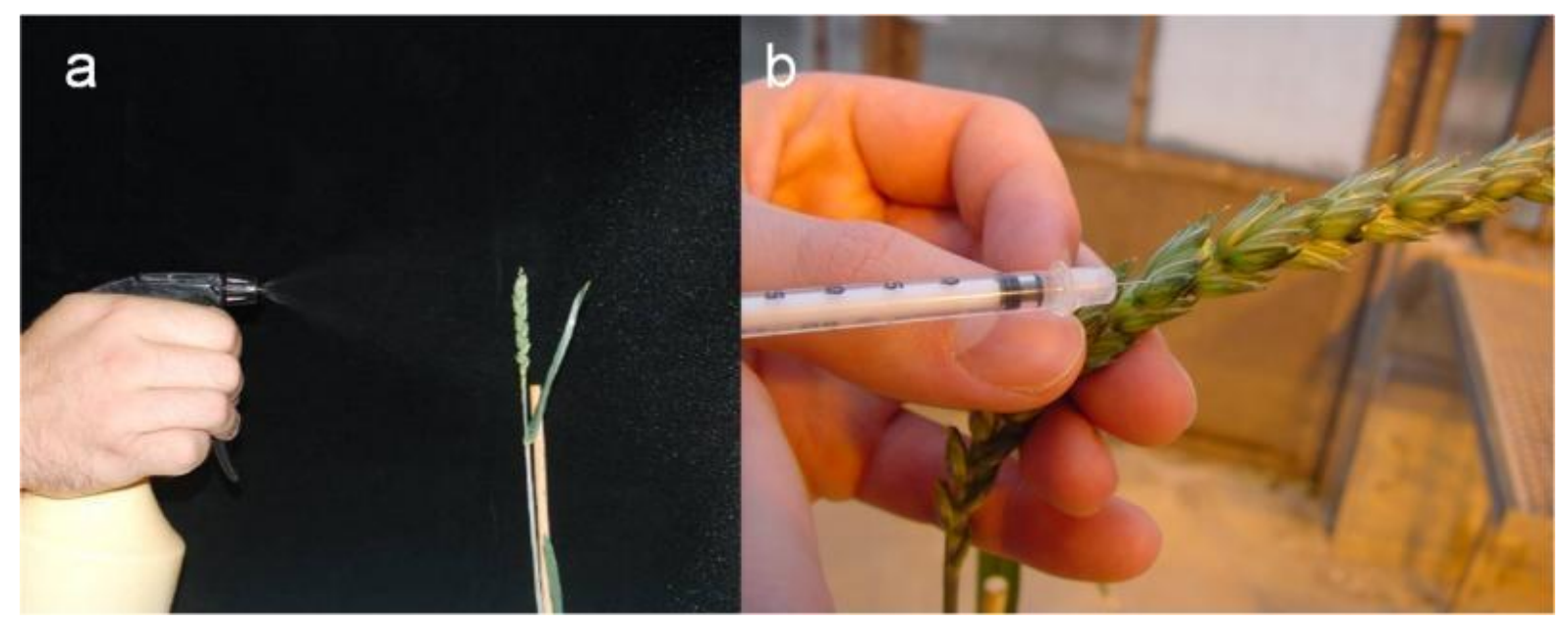

Abb. 2 Inokulationstechniken in Gewächshausversuchen a) Sprühinokulation der gesamten Ähre mit einem Handsprüher zur Induktion multipler Primärinfektionen b) Punktinokulation in einem Ährchen der Ähre mit einer Spritze zur Induktion einer gezielten Primärinfektion

\subsection{Erfassung der Befallsparameter}

\subsubsection{Visuelle Bonitur im Feldversuch}

Die visuelle Befallsermittlung von Fusarium spp. im Winterweizen erfolgte in Abhängigkeit von der Witterung ca. 15-20 Tagen nach der Vollblüte (BBCH 65) zum Zeitpunkt der mittleren Milchreife in BBCH 72-75. In den Parzellen wurde die Befallshäufigkeit derjenigen Ähren bestimmt, die Symptome der Partiellen Weißährigkeit aufwiesen (Anzahl symptomatischer Ähren pro $\mathrm{m}^{2}$ ). Zusätzlich wurde in Abhängigkeit von der jeweiligen Bestandesdichte die prozentuale Befallshäufigkeit berechnet (prozentuale Anteil symptomatische Ähren pro $\mathrm{m}^{2}$ ). In den Jahren 2007 und 2009 wurden ca. 50\% jeder Parzellenfläche für die Befallserhebung untersucht, im Jahr 2008 wurde aufgrund des minimalen Befalls mit Fusarium spp. die gesamte Parzellenfläche ausgewertet. Die Befallsstärke (\% symptomatische Ährchen pro Einzelähre) in den einzelnen Parzellen wurde mit Hilfe von zwanzig zufällig ausgewählten infizierten Weizenähren bestimmt (verändert nach Culler et al., 2007). Deren prozentualer Anteil symptomatischer Ährchen pro Einzelähre wurde in 5\%-igen Boniturschritten ermittelt (verändert nach Stack et al., 1998) und über alle 20 Ähren verrechnet (Abb. 3a/b/c). Die Erhebung der Befallsstärke ist nur in Jahren mit mindestens mittlerem bis starkem Befall möglich, daher wurde dieser Parameter in den Feldversuchen mit natürlichen Infektionsbedingungen nur 2007 ermittelt.

Der Fusarium Head Blight Index (FHB-Index) ist das Produkt aus der Befallshäufigkeit und der Befallstärke. Dieser kennzeichnet das Infektionsgeschehen bei mittlerem und stärkerem 
Fusariumbefall wie im Jahr 2007 realistischer, als die beiden jeweils einzelnen Befallsparameter (Wilcoxson et al., 1992).

$$
\begin{aligned}
& \text { FHB - Index (\% pro Parzelle) } \\
& =\frac{\text { Befallshäufigkeit }(50-100 \% \text { Parzellenfläche })}{100} \times \frac{\text { Befallsstärke (20 infizierter Ähren) }}{100} \times 100
\end{aligned}
$$
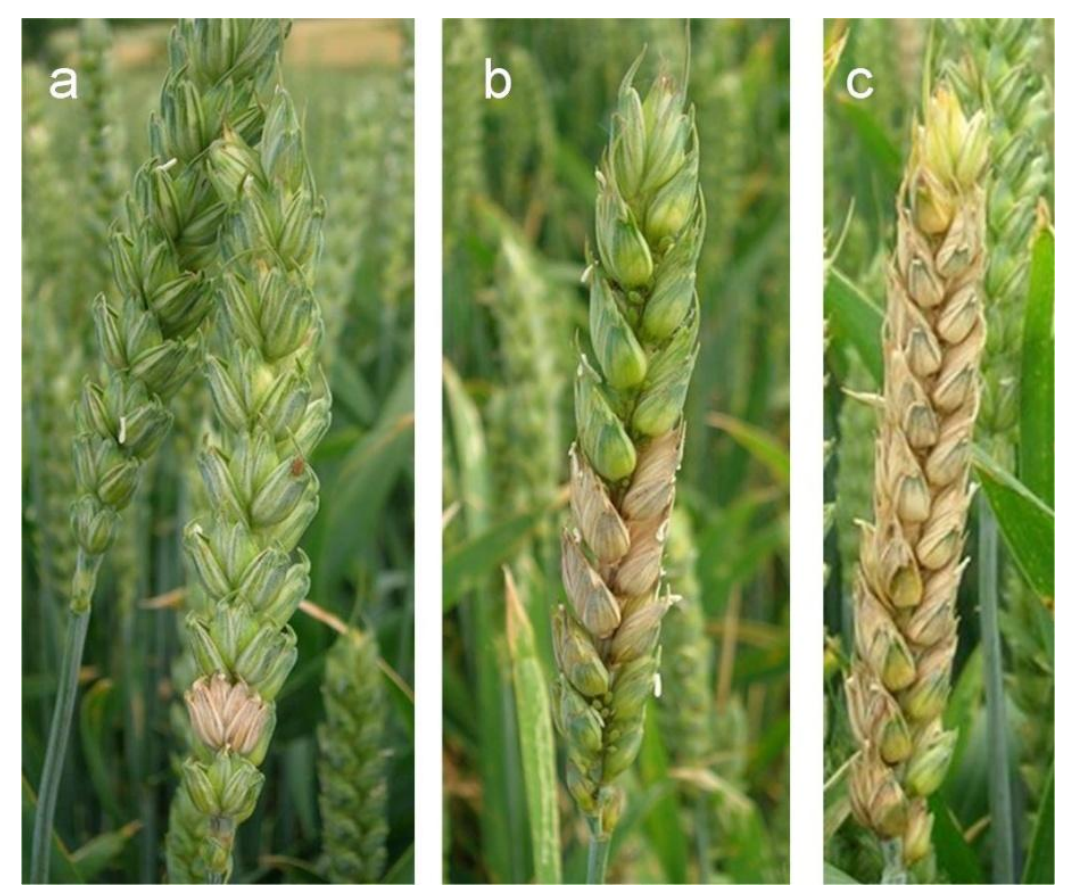

Abb. 3 Bilder verschiedener Befallsstärken im Feldversuch. a) Ein Ährchen der gesamten Ähre ist ausgeblichen, dies entspricht einer Befallstärke von 5\%; b) sechs Ährchen sind ausgeblichen, dies entspricht einer Befallsstärke von 30\%; c) achtzehn Ährchen zeigen Weißährigkeitssymptome, dies entspricht einer Befallsstärke von $90 \%$

\subsubsection{Visuelle Bonitur im Gewächshaus}

In Anlehnung an die visuelle Bonitur der Partiellen Weißährigkeit im Feldversuch wurde bei den Gewächshausversuchen als akkuratester Befallsparameter der FHB-Index als Produkt aus Befallshäufigkeit und Befallsstärke für jede vollständige Wiederholung berechnet. Die Befallsstärken der Einzelpflanzen und die Befallshäufigkeiten in vollständigen Versuchswiederholungen wurden dafür multipliziert. Die daraus resultierenden Einzelwerte für jede Pflanze wurden über die gesamte Wiederholung gemittelt, so dass die Ergebnisse der jeweiligen Wiederholungen auf bis zu 40 unabhängigen Einzelwerten beruhen und eine repräsentative Stichprobe darstellen.

FHB - Index $(\%)=\frac{\text { Befallshäufigkeit }(W d h)}{100} \times \frac{\text { Befallsstärke (Einzelpflanze })}{100} \times 100$ 
Bai \& Shaner (1996) postulierten, dass der Boniturtermin 21 dpi am besten zur Quantifizierung von Fusariumbefall in Gewächshausversuchen geeignet wäre. Um die Pathogenentwicklung optimal zu erfassen, wurden in den ersten Versuchen Bonituren an den Terminen 14dpi und 24dpi durchgeführt. Im Verlauf der Arbeit zeigte sich jedoch, dass sich das Pathogen in den verwendeten Sommerweizensorten schneller ausbreitete als erwartet, Dieser Entwicklung wurde mit einem weiteren Boniturtermin zu 7 dpi Rechnung getragen, so dass Boniturintervalle im Abstand von sieben Tagen bei 7 dpi, 14 dpi und 21 dpi stattfanden.

In den Versuchen zum Einfluss der Witterungsparameter auf die Mykotoxinbildung, die in Klimakammern durchgeführt wurden, konnte aufgrund des Versuchsdesigns (siehe Kapitel 2.16.3) die Bonitur am Termin 7 dpi nicht erhoben werden, hier wurden an den Versuch angepasste Boniturtermine bei 17 und 24 dpi durchgeführt.

Bei den Untersuchungen zur Pathogenität der Fusarium-Arten aus Zuckerrüben und dem Auftreten von „Black Point“ Symptomen im Getreide, traten untypische Symptome auf. Die Hüllund Deckspelzen einzelner Ährchen wiesen Verbräunungen und lokale Aufhellungen auf, es kam nicht zum typischen partiellen Ausbleichen der Weizenähre. Trotzdem wurden auch für diese Symptome die Befallshäufigkeit und die Befallsstärke bzw. der FHB-Index erfasst.

\subsection{Analysen der Proben aus Feld- und Gewächshausversuchen}

\subsubsection{Probennahme und Probenaufbereitung}

In den Feldversuchen wurden pro Parzelle ca. 10\% des gesamten Erntegutes für Analysen aufbewahrt. Das Getreide wurde durch einen Probenreiniger (MLN Rationel, Pfeuffer, Kitzingen) von Spelzen und Staub gereinigt und die Entgrannerzeiten bzw. das Windgebläse so eingestellt, dass keine Körner verloren gingen. Alle Rückstellproben wurden mittels einer Zentrifugalmühle (ZM 200, Retsch, Haan) mit einer Siebweite von 1mm vermahlen. Das gewonnene Vollkornmehl wurde gleichmäßig durchmischt, auf einen Trockenmassegehalt von 86\% zurückgetrocknet und eingelagert. Alle Ergebnisse der ELISA, qPCR und HPLCMS/MS Analysen in dieser Arbeit beziehen sich auf Mehle mit entsprechenden Trockenmassegehalten.

Für die Analysen der Gewächshausversuche wurde das gesamte Kornmaterial geerntet und entsprechend der Feldproben aufbereitet. 


\subsubsection{Mykotoxinanalytik}

\subsubsection{ELISA (Enzyme-linked-immunosorbent-assay)}

Zur Quantifizierung des Mykotoxins Deoxynivalenol in den Getreideproben der Feldversuche wurde der kommerzielle RIDASCREEN® DON ELISA (r-biopharm, Darmstadt) verwendet. Diese serologische Methode wurde ursprünglich für den Nachweis von Virosen in Pflanzengewebe entwickelt (Clark et al., 1977). Der RIDASCREEN® DON ist ein kompetitiver Enzymimmunoassay zur quantitativen Bestimmung von Deoxynivalenol in Getreide. Grundlage ist die Antigen-Antikörper-Reaktion. Die Vertiefungen der Mikrotiterstreifen sind mit Fänger-Antikörpern gegen Anti-Deoxynivalenol-Antikörper beschichtet. Zugegeben werden Standards bzw. Probelösung, enzymmarkiertes Deoxynivalenol (Enzymkonjugat) und AntiDeoxynivalenol-Antikörper. Freies und enzymmarkiertes Deoxynivalenol konkurrieren um die Deoxynivalenol-Antikörper-Bindungsstellen. Gleichzeitig werden auch die AntiDeoxynivalenol-Antikörper von den immobilisierten Fänger-Antikörpern gebunden. Nicht gebundes, enzymmarkiertes Deoxynivalenol wird anschließend in einem Waschschritt wieder entfernt. Der Nachweis erfolgt durch Zugabe von Substratlösung. Gebundenes Enzymkonjugat wandelt das Substrat in ein blaues Endprodukt um. Die Zugabe der StoppReagenz führt zu einem Farbumschlag von blau nach gelb. Die Messung erfolgt photometrisch; die Extinktion der Lösung (OD-Wert) ist umgekehrt proportional zur Deoxynivalenolkonzentration in der Probe, d.h. je geringer der OD-Wert desto höher ist die Mykotoxinbelastung.

\section{Durchführung des RIDASCREEN® DON ELISA}

Die Arbeitsschritte wurden nach Weinert (2007) an Getreideproben angepasst:

- $5 \mathrm{~g}$ Mehl wurden eine Stunde bei $8^{\circ} \mathrm{C}$ in $25 \mathrm{ml}$ Aqua bidest. schütteln gelassen

- Aliquots wurden in Eppendorfgefäße überführt und $10 \mathrm{~min}$ bei $13.000 \mathrm{rpm}$ zentrifugiert

Gewonnene Überstände wurden entsprechend verdünnt, so dass sich die ermittelten Deoxynivalenolgehalte im Detektionsbereich des ELISA zwischen 1 und $100 \mu \mathrm{g}$ DON kg-1 Mehl befanden

- $50 \mu \mathrm{l}$ Standard oder Probe wurden in die Vertiefungen pipettiert

- $50 \mu \mathrm{l}$ enzymmarkiertes Deoxynivalenol wurden in die Vertiefungen pipettiert

- $50 \mu \mathrm{l}$ Anti-Deoxynivalenol-Antikörper wurden in die Vertiefungen pipettiert

Die Mikrotiterplatte wurde leicht durchmischt und 30 min bei Raumtemperatur inkubiert 
Die inkubierte Mikrotiterplatte wurde ausgeschüttet und für 3 x 3 min mit Waschpuffer gespült. Im Anschluss erfolgte ein gründliches Trockenschlagen der Platte.

- $100 \mu \mathrm{l}$ Substratlösung wurden in die Vertiefung pipetiert

Die Mikrotiterplatte wurde 15min bei Raumtemperatur im Dunkeln stehen gelassen

- $100 \mu 1$ Stopp-Reagenz wurden in die Vertiefung pipetiert

Nach 2-10 Minuten wurde die Messung mit dem Photometer (Spectra SLT, TECAN, Crailsheim) bei einer Wellenlänge von $405 \mathrm{~nm}$ und einer Referenzwellenlänge von $595 \mathrm{~nm}$ durchgeführt. Aus acht separaten Standardverdünnungen wurde eine Standardkurve vierter Ordnung extrapoliert, mit der die Mykotoxingehalte der Proben verrechnet wurden.

\subsubsection{HPLC (High performance liquid chromagraphy)}

Die Mykotoxinbelastungen der einzelnen Proben aus den Gewächshausversuchen variierte sehr stark, daher wurde auf eine Mykotoxinanalytik mittels ELISA verzichtet.

Die Toxinanalytik wurde dankenswerterweise nach dem Protokoll von Hettwer et al. (2007) in der Abteilung Molekulare Phytopathologie und Mykotoxinforschung (Prof. Karlovsky) durch die zentrale Analytik des Forschungsverbundes durchgeführt.

Aufgrund des Bedarfs einer Multitoxinanalyse der Getreideproben aus den Kooperationsprojekten mit dem Institut für Zuckerrübenforschung, erfolgte die Toxinanalyse extern in Tulln/Österreich. Dort wurde die Multitoxinanalytik basierend auf einer HPLC-ESI-MS/MS nach Sulyok et al. (2007) durchgeführt.

\subsubsection{Quantitative PCR (Polymerase chain reaction)}

Alle Proben aus den Feld- und Gewächshausversuchen wurden einer quantitativen PCR Analyse unterzogen. Diese molekulare Methode ermöglicht, durch die Verwendung pathogenspezifischer Primerpaare und DNA-Standards, eine spezifische Quantifizierung der DNA von den Erregern Fusarium graminearum und Fusarium culmorum. Die Primerpaare Fg16N F und Fg16N R amplifizieren ein 280bp Fragment, das spezifisch für $F$. graminerum ist (Nicholson et al., 1998). Das für F. culmorum spezifische Fragment mit einer Größe von 472bp wurde mit dem Primerpaar OPT18 R und OPT18 F amplifiziert (Schilling et al., 1996). In der Abteilung Molekulare Phytopathologie und Mykotoxinforschung des Fachgebietes Pflanzenpathologie und Pflanzenschutz an der Universität Göttingen wurden diese Untersu- 
chungen dankenswerterweise im Rahmen der zentralen Analytik des Forschungsverbundes nach dem Protokoll von Brandfass et al. (2008) durchgeführt. Aus diesen Ergebnissen können

Rückschlüsse auf die Zusammenhänge zwischen der Pilzbiomasse und den Mykotoxingehalten und somit auf die spezifische Mykotoxinbildung gezogen werden.

\subsection{Isolierung und Identifikation von Fusarium-Arten aus dem Erntegut des FAEN Feldversuches}

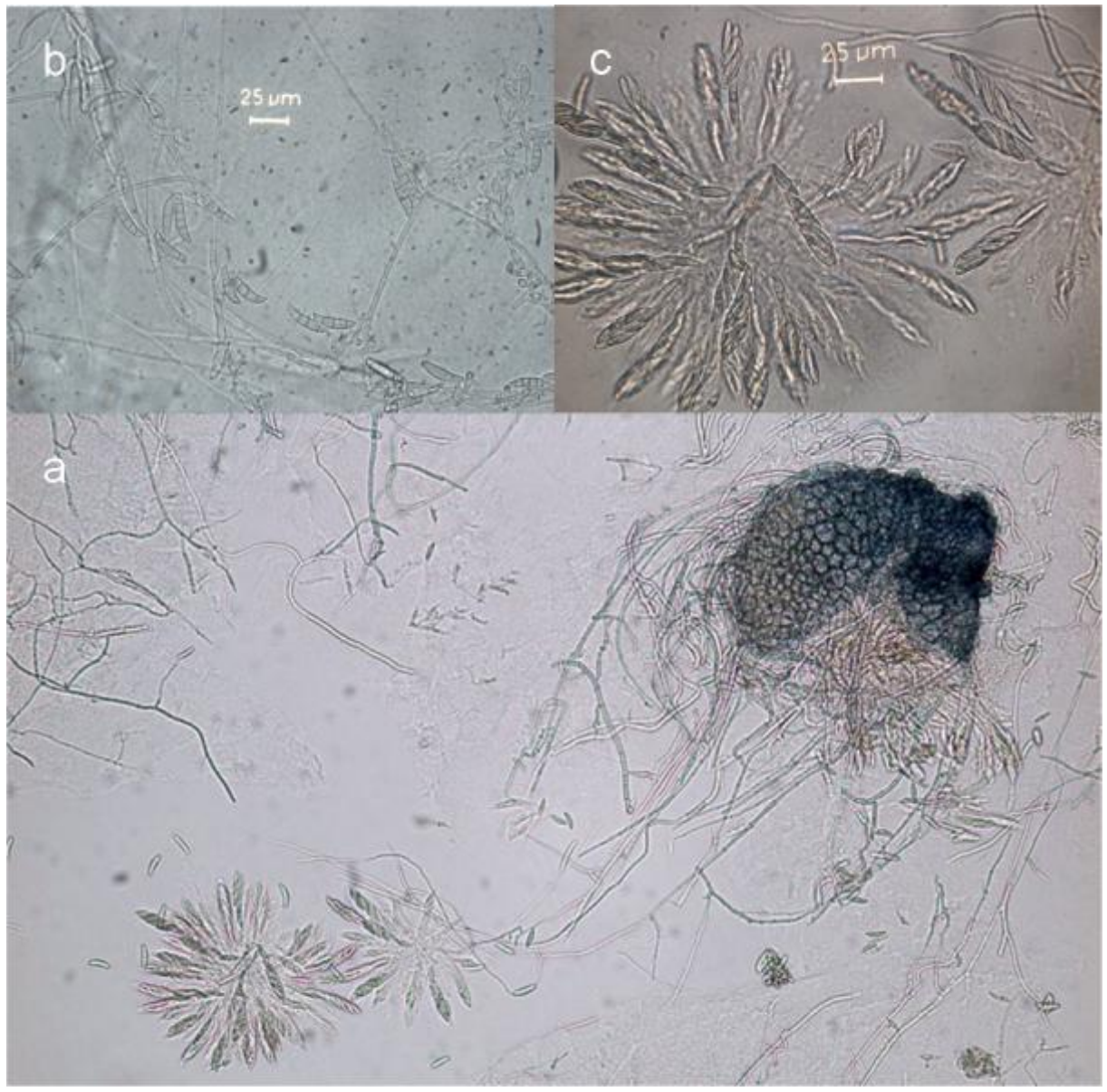

Abb. 4 Quetschpräparate verschiedener Fusarium-Arten, die mit dem Epifluoreszenzmikroskop Leica DMRB bei verschiedenen Vergrößerungen identifiziert wurden; a) Fusarium graminearum: Askosporen quellen aus einem aufgebrochenen Perithecium hervor (100x); b) Fusarium culmorum: Typische „raupenfürmige“ Konidien mit einer Länge von 25-30 $\mu \mathrm{m}$ (100x); c) Askosporen von Fusarium graminearum: In sich verdrehte Ascosporen sind deutlich zu erkennen und besitzen eine Länge von 30-40 $\mu \mathrm{m}$, im Vergleich zu den Konidien (50-60 $\mu \mathrm{m})(400 x)$.

Aus den Feldversuchen wurden pro Parzelle mehrere Körner zufällig ausgewählt, oberflächensterilisiert (10 min in $0,1 \% \mathrm{AgNO}_{3}+0,1 \%$ Tween 20 ), unter fließendem Wasser abgewaschen und auf sterilem Filterpapier zurückgetrocknet. Die Körner wurden auf KartoffelGlukose-Agar (PDA, Fluka Analytical, Buchs) ausgelegt (2007: 3 Körner pro PDA-Platte, 
2008 \& 2009: 5 Körner pro PDA-Platte) und täglich auf Myzelwachstum untersucht. Die Myzelspitzen der wachsenden Pilze wurden auf separate PDA Platten überimpft, bis kontaminationsfreie Isolate vorhanden waren. Diese Isolate wurden auf SEA $(0,2 \%)$ übertragen, 10 bis 15 Tagen unter Dauer-NUV-Licht (NUV = near UV mit $\lambda=400-440 \mathrm{~nm}$ ) bei $21^{\circ} \mathrm{C}$ inkubiert und anschließend morphologisch identifiziert (Abb. 4) (Leslie \& Summerell, 2006).

\subsection{Erfassung des Fusarium spp. Sporenfluges im FAEN Feldversuch}

In den Versuchsjahren 2008 und 2009 wurde zwischen den Entwicklungstadien BBCH 39-73 im Mai und Juni eine Burkard Saugfalle (Burkard 7 day volumetric spore sampler, Fa. Burkard Scientific, Uxbridge) in der Fahrgasse der Vorfruchtvariante Mais am Standort Torland aufgestellt. Die sich in Ährenhöhe von ca. $80 \mathrm{~cm}$ befindende Öffnung der Falle ist in der Lage 101 Luft $\min ^{-1}$ anzusaugen und in der Luft sich befindende Sporen auf einen Melinex® Kunststoffstreifen zu fixieren. Dieser wurde zuvor mit einem Gemisch aus $5 \mathrm{~g}$ Vaseline und 5 ml Hexan eingestrichen und an einem Drehteller in der Falle fixiert. Mit einer Geschwindigkeit von $2 \mathrm{~mm} \mathrm{~h}^{-1}$ bewegt sich dieser Aufsatz in der Sporenfalle, so dass ein Sporenflugintervall von 7 Tagen aufgezeichnet wird. Auf dem Kunststoffstreifen wurde unter einem Lichtmikroskop (400x) in 24 h-Segmenten die Menge an Fusariumsporen pro $\mathrm{m}^{3}$ Luft und Tag bestimmt. Eine Differenzierung zwischen den verschiedenen Arten war aufgrund der Fixierung der Sporen im Vaseline-Hexan-Gemisch morphologisch nicht möglich. Aufgrund der typischen Formengebung war davon auszugen, dass der überwiegende Teil der Fänge Askosporen von $F$. graminearum darstellte.

\subsection{Erfassung des Blühverlaufs in Gewächshaus- und Feldversuchen}

Mit einem Zählrahmen $\left(0,5 \mathrm{~m}\right.$ x 0,5 $\left.\mathrm{m}=0,25 \mathrm{~m}^{2}\right)$ wurde in den Parzellen des Feldversuches zufällig ein Bereich ausgewählt in dem nichtdestruktiv der Blühverlauf bestimmt wurde. Alle Ähren, die sich im Entwicklungsstadium BBCH 65 befanden wurden mit einem farbigen Etikett markiert und so lange täglich ausgezählt bis die Haupt- und die Nebentriebe erster und zweiter Ordnung abgeblüht waren.

Der Blühverlauf an der Sorte Centrum wurde im FAEN-Versuch in zweifacher Wiederholung in allen drei Fungizidvarianten (Strobilurin, Triazol und Neutral) ermittelt. Im Versuchsjahr 2008 wurden die Vorfruchtvarianten Winterweizen und Zuckerrübe und folgenden Jahr 2009 die Vorfruchtvarianten Ölrettich und Mais miteinander verglichen. Im Vordergrund dieser 
Untersuchungen stand dabei die Frage, ob und in welchem Umfang, physiologische Fungizideffekte den Blühverlauf des Winterweizens im Freiland beeinflussen können, bzw. ob klassische agronomische Faktoren wie die Vorfrucht nicht einen viel größeren Einfluss auf diesen Parameter haben.

In den Gewächshausversuchen wurde jede Ähre, die sich im Entwicklungsstadium BBCH 65 befand, mit einem Etikett markiert und für die Erfassung des Blühverlaufes ausgezählt.

\subsection{Bestimmung von fungiziden Restmengen in Pflanzenmaterial}

Zur Überprüfung der Hypothese, dass fungizide Restmengen Stressoren für Fusariosen und somit Auslöser für übermäßige Mykotoxinbildung seien, wurde im FAEN-Feldversuch eine gezielte Rückstandsanalyse des Ährengewebes zum Zeitpunkt der primären Infektion mit $F u$ sarium-Arten im Entwicklungsstadium $\mathrm{BBCH} 65$ durchgeführt. Dazu wurden $50 \mathrm{~g}$ Ährchenmaterial zufällig aus den vier Wiederholungen der Versuchsvarianten Centrum (Triazol und Strobilurin) und Ritmo (Triazol und Strobilurin) der Vorfruchtvariante Zuckerrübe geerntet und gepoolt. Die Probennahme erfolgte 200824 und 200927 Tage nach der letzten Fungizidapplikation. Die Analytik fungizider Restmengen der Wirkstoffe Azoxystrobin und Epoxiconazol wurde nach $§ 64$ des Lebensmittel und Futtermittelgesetzbuchs (LFGB) und der Methode 00.00.113-5: MULTIMETHODE ZUR BESTIMMUNG VON PFLANZENSCHUTZMITTELRÜCKSTÄNDEN IN PFLANZLICHEN LEBENSMITTELN mittels GC-MS(/MS) ODER LC-MS/MS nach Acetonitril-Extraktion/Verteilung und Aufreinigung durch das Institut für Boden und Umwelt der Landwirtschaftlichen Untersuchungs- und Forschungsanstalt Nord-West in Hameln im frischen Pflanzenmaterial durchgeführt. Für die Analyse wurde das Probenmaterial zerkleinert, ggf. auf einen einheitlichen Wassergehalt eingestellt und mit Acetonitril extrahiert. Nach Zugabe von Magnesiumsulfat und Natriumchlorid wurde die Lösung noch einmal kräftig geschüttelt und anschließend zentrifugiert. Ein Aliquot der Acetonitrilphase wurde mittels dispersiver SPE mit PSA und ggf. GCB gereinigt und mittels LC-MS/MS untersucht. Der Nachweis erfolgt durch ElektrosprayIonisierung (ESI) im Multi-Reaction-Monitoring (MRM bzw. SRM). Die Nachweisgrenze für beide Fungizide lag bei 0,01 $\mathrm{mg} \mathrm{kg}^{-1}$ FM (Appuhn, 2010). 


\subsection{Erfassung des Abreifeverlaufs von Weizenähren}

Als Parameter zur Quantifizierung des Abreifeverhaltens von Weizenpflanzen aus verschiedenen Fungizidvarianten, wurde der Wassergehalt in den entsprechenden Weizenähren bestimmt. Dazu wurden diese $19 \mathrm{~h}$ bei $130^{\circ} \mathrm{C}$ im Trockenschrank bis zur Massekonstanz getrocknet (ASAE S352.2, 1997) und der ursprüngliche Wassergehalt als Differenz aus der Frisch- und Trockenmasse berechnet.

\subsection{Messung der Gujakolperoxidaseaktivität im Spelzengewebe von Winter- weizen}

\section{Herstellung der Rohextrakte}

Zur Vorbereitung der Proben wurden 2 g PVPP in Zentrifugenröhrchen eingewogen, mit 10ml Extraktionspuffer (KPP-Puffer: 0,1 M K2 $\mathrm{HPO}_{4}, \mathrm{KH}_{2} \mathrm{PO}_{4}, \mathrm{pH} 7,8+1,5 \%$ Triton-X) versetzt und über Nacht bei $4^{\circ} \mathrm{C}$ vorgequollen. Am folgenden Tag wurde das zu untersuchende Pflanzenmaterial in einem vorgekühlten Mörser, durch Zugabe von flüssigem $\mathrm{N}_{2} \mathrm{zu}$ feinem Pulver zersprödet. Ungefähr $2 \mathrm{~g}$ des Materials und $5 \mathrm{ml}$ des Extraktionspuffers wurden in die vorbereiteten Zentrifugenröhrchen eingewogen, gevortext und 15 min auf Eis inkubiert. Die Proben wurden bei $40.000 \mathrm{rpm}$ und $4^{\circ} \mathrm{C}$ für $40 \mathrm{~min}$ zentrifugiert(Ultrazentrifuge, Sorvall Evolution RC, Fa. Kendro) und der Überstand anschließend dekantiert. Die gewonnenen Extrakte wurden durch eine Gelfiltrationssäule weiter aufgereinigt und von Molekülen mit geringerer Masse als 1000 Da getrennt (PD-10 Säulen, GE Healthcare, München). Die Kapazität der Säulen beträgt 2,5ml und zur Equilibrierung wurden diese dreimal mit je $5 \mathrm{ml}$ Elutionspuffer (50mM Kaliumphosphatpuffer, pH 7,8) gespült. Jeweils 2,5 ml der Extrakte wurden auf die Säule aufgetragen und das erste gewonnene Eluat verworfen (verdrängter Elutionspuffer). Anschließend wurden 3,5 ml Elutionspuffer aufgetragen und das austretende Filtrat aufgefangen. Dieses wurde bis zur enzymatischen Analyse der Gujakolperoxidase bei $-20^{\circ} \mathrm{C}$ eingefroren.

\section{Photometrische Bestimmung der Peroxidaseaktivität}

Die Gujakolperoxidaseaktivität in den Extrakten wurde photometrisch (Specord 40, Analytik Jena) über einen Zeitraum von 5 min bei einer Wellenlänge von $436 \mathrm{~nm}$ und $25^{\circ} \mathrm{C}$ bestimmt. Zur Gewährleistung der Linearität der Messung wurden die Extrakte mit dem Elutionspuffer (KPP, pH 7,8) entsprechend verdünnt und ein Volumen von $50 \mu 1$ in die Küvetten gegeben. Anschließend wurden $500 \mu \mathrm{l} \mathrm{KPP} \mathrm{Puffer} \mathrm{(50} \mathrm{mM,} \mathrm{pH} \mathrm{5,25),} \mathrm{400 \mu l} \mathrm{Gujakol} \mathrm{(100mM)} \mathrm{und} 50$ 
$\mu 1 \mathrm{H}_{2} \mathrm{O}_{2}$ (200mM) zugefügt. Mit einem Rührstäbchen wurden die Probenansätze gut durchmischt und unverzüglich gemessen (Polle et al., 1990). Die Aktivität der Gujakolperoxidase in den Extrakten bedurfte keiner Korrektur um die Ergebnisse einer Leerkontrolle. Die Peroxidaseaktivität wurde in nkat pro Gramm Frischmasse angegeben; 1 nkat entstpricht einem Substratumsatz von $1 \mathrm{mmol} / \mathrm{s}$ (Eisenthal et al., 1992).

Aktivität $($ nkat $)=[(\Delta \mathrm{E} / \mathrm{min}) / \varepsilon] * \mathrm{~V}_{\mathrm{f}} * 1000000 *\left(\mathrm{~V}_{\mathrm{t}} / \mathrm{V}_{\mathrm{s}}\right) * 16,7 * 1,4$

(Formel angepasst nach Riediger, 2008)

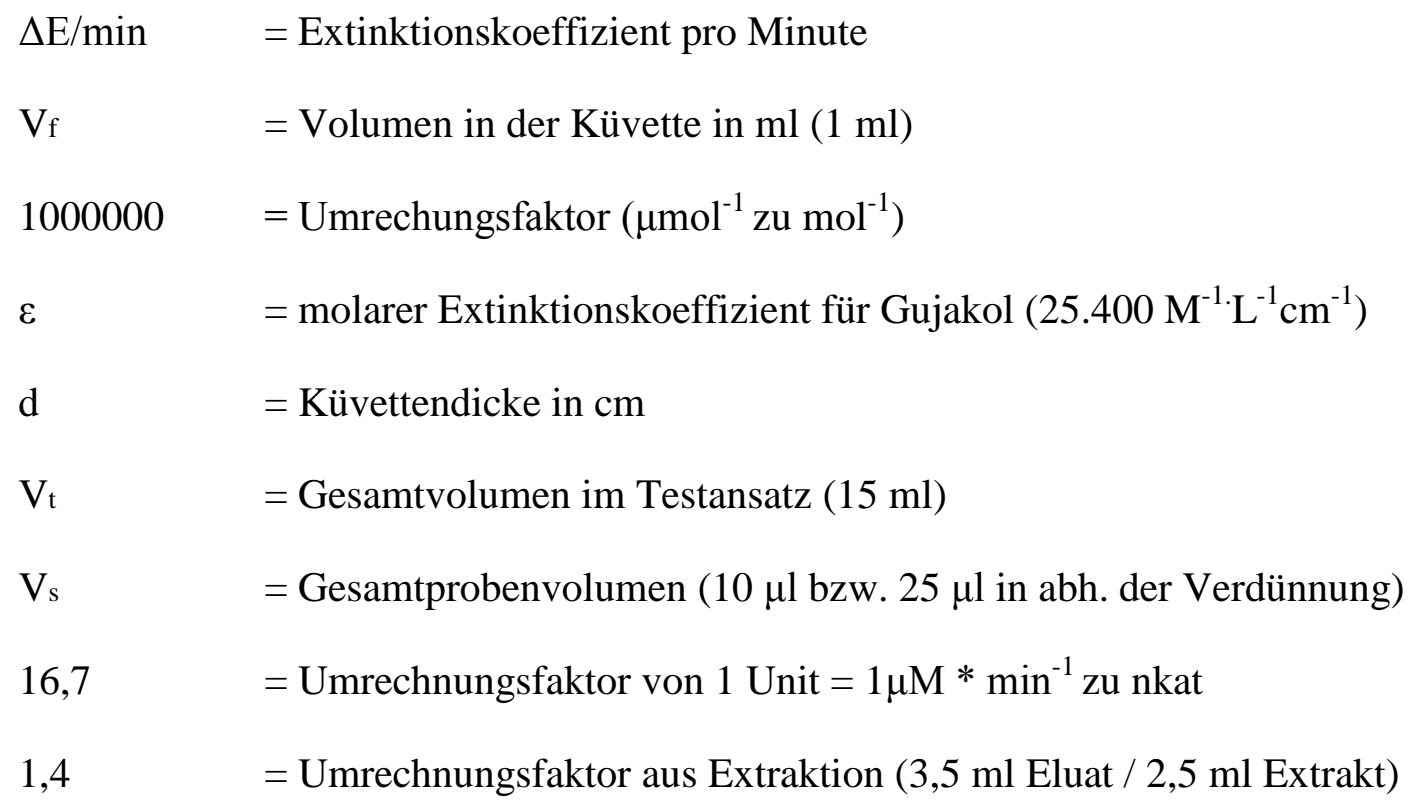

\subsection{Erfassung weiterer Parameter an Kornproben}

Neben der Erfassung des Befalls von Fusarium spp. und der Mykotoxinkontamination im Getreide wurde eine Reihe weiterer Parameter erhoben, die nicht zwingend für die Beurteilung der Schadwirkung von Fusariosen erforderlich sind, diese jedoch präzisieren können.

\section{Kornertrag und Tausendkorngewicht (TKG)}

In den Feldversuchen erfolgte die Ernte der Parzellen durch einen Mähdrescher (Farmliner, Deutz-Fahr, Köln). Das Erntegut wurde in Leinensäcken (40 x $50 \mathrm{~cm}$ ) aufgefangen und einzeln abgewogen. Im Anschluss fand eine Umrechnung der Parzellenerträge auf einen handelsüblichen Restfeuchtegehalt von 14\% statt. Das Tausendkorngewicht (TKG) der Versuchsproben wurde durch Auszählen von 1000 Körnern mit einem Saatgutzählgerät (Numigral, Sinar, Bracebridge/UK) und anschließendem Wiegen bestimmt. 


\section{Keimfähigkeit}

Die Bestimmung der Keimfähigkeit der Weizenkörner erfolgte in den Kooperationsversuchen mit dem Institut für Zuckerrübenforschung. Hierzu wurden Inkubationskästen mit ca. $1 \mathrm{~cm}$ Aqua bidest. befüllt, in die mittels eines Gitterrostes eine zweite Ebene eingesetzt wurde. Auf den Rost wurde ein Faltenfilter ausgelegt, der mit einer Wassersprühflasche befeuchtet wurde und in dessen Reihen die Weizenkörner im Abstand von mindestens $2 \mathrm{~cm}$ abgelegt wurden. Die Ermittlung der Keimfähigkeit fand, durch Auszählen der gekeimten Körner nach 7 Tagen bei Raumtemperatur statt. Während dieser Zeit wurden die Boxen verschlossen gelagert.

\section{Besatz mit „Black Point“" Körnern}

In dem Erntegut einiger Gewächshausversuche wurde ein unerwartetes, durch Fusarium spp. verursachtes, Symptom festgestellt. Es konnten so genannte „Black Point“ Körner (Bockus et al., 2010) gefunden werden. Diese weisen eine typische schwärzliche Verfärbung im Bereich des Keimlings auf, wodurch sie sich deutlich von den normalen Körnern unterscheiden. Für genauere Untersuchungen wurden diese Körner aus den Proben aussortiert, der prozentuale Anteil festgehalten und separat verarbeitet.

\subsection{Feldversuche}

\subsubsection{FAEN-Feldversuch}

Beide Standorte befinden sich in Südniedersachsen im Einzugsgebiet des oberen Leineberglandes, zwischen dem westlichen Harzvorland und dem Weserbergland auf ca. $170 \mathrm{~m}$ über n.N. Klimatisch betrachtet liegen sie im Übergangsbereich von maritimen zu kontinentalen Klima der gemäßigten Breiten, die Tagesdurchschnittstemperatur beträgt $8,7^{\circ} \mathrm{C}$ bei einer jährlichen Niederschlagssumme von $644,9 \mathrm{~mm}$ und einer mittleren Luftfeuchte von 77,3 \% (www.wetterstation-goettingen.de).

Torland: Die Fläche des Standortes Torland gehört zu den Versuchswirtschaften der Universität Göttingen und liegt am Ortsausgang von Bovenden (51³6' N, 955' O), zwischen dem Leinetal und dem Höhenzug des Göttinger Waldes. Im Göttinger Raum ist der Löß die vorherrschende Bodenart. Dieser ist an den Hängen oft von einer Frostschuttdecke aus tonigem Material, Röt oder wie am Versuchsstandort von Muschelkalk unterlegt (Ahl, 2002). Die standortspezifische Bodenart ist eine Braunerde-Terra Fusca (Kalkstein-Braunlehm), welche in Richtung des Göttinger Waldes bereits flachgründig von größeren Kalksteinen durchsetzt 
ist. An den tiefgründigeren Stellen erreicht dieser Standort eine Bodenpunktzahl von 78 (Reintke, 2010).

Gladebeck: Der Feldversuch am Standort Gladebeck (51 $37^{\prime}$ N, 9 ${ }^{\circ} 52^{\prime}$ O) liegt im Randbereich des Leinetals ca. 20 km entfernt von Göttingen. Das Mikroklima ist vom Hügelland des Sollings geprägt. Die vorherrschende Bodenart ist eine Parabraunerde mit einer Bodenpunktzahl von 77 (Reintke, 2010), die bei starken Regenereignissen zur Verschlämmung bzw. Überstauung neigt. Dies begründet eine schlechte Wärmeleitfähigkeit und führt dadurch zu einer verzögerten Erwärmung des Bodens.

\section{Versuchsaufbau und Fragestellung}

Im Rahmen des Forschungsverbundes Agrar- und Ernährungswissenschaften Niedersachsen (FAEN) wurden seit 2006 zwei Fruchtfolgeversuche in Südniedersachsen angelegt. Bei nichtwendender Bodenbearbeitung wurden auf den Standorten Gladebeck und Torland vier verschiedene Vorfruchtvarianten (Mais, Winterweizen, Zuckerrübe und ab 2008 Ölrettich) für die Folgefrucht Winterweizen etabliert, die aus je drei Blöcken $\left(900 \mathrm{~m}^{2}\right)$ bestehen und in der jeweils einer dieser Blöcke in 24 Parzellen $\left(25 \mathrm{~m}^{2}\right)$ eingeteilt wurde (Abb. 5).

Mehrfaktorielle Versuchsfragen erfordern aus technischen (Aussaattechnik) oder pflanzenbaulichen Gründen (limitierte Fläche) relativ große Teilstücke. Für diese Zwecke wurden in dem FAEN-Versuch, Anlagemethoden mit unterschiedlichen Teilstückgrößen geschaffen, die nach bestimmten Ordnungsprinzipien in Beziehung zueinander stehen (Munzert, 1992). In diesem Fall wurde eine Split-Split-Split-Plot Anlage gewählt, um die agronomischen Fragestellungen bearbeiten zu können. Die beiden Sorten wurden als fest definierte Spalten in die jeweiligen Versuchsblöcke integriert (Abb. 6), wohingegen die Randomisation der Fungizidvarianten zufällig innerhalb der Spalten erfolgte.

Die Vorfruchtvarianten wechselten aufgrund der limitierten Fläche auf vorher festgelegte Flächen und wurden daher nur als teilrandomisiert betrachtet. Die Anpassung der Saatstärke fand in Abhängigkeit vom Aussaatzeitpunkt statt und variierte daher in den drei Versuchsjahren zwischen 300-320 Körnern je $\mathrm{m}^{2}$. Die Düngung und Herbizidappliktionen erfolgten nach guter fachlicher Praxis. Fungizide wurden in drei Varianten eine strobilurinbetonte, eine triazolbetonte und eine physiologisch neutral wirkende Variante in den Entwicklungsstadien BBCH 31 und BBCH 39 appliziert (Abb. 7), wodurch eine direkte fungizide Wirkung auf den Befall mit Fusarium spp. in den Ähren ausgeschlossen wurde. 


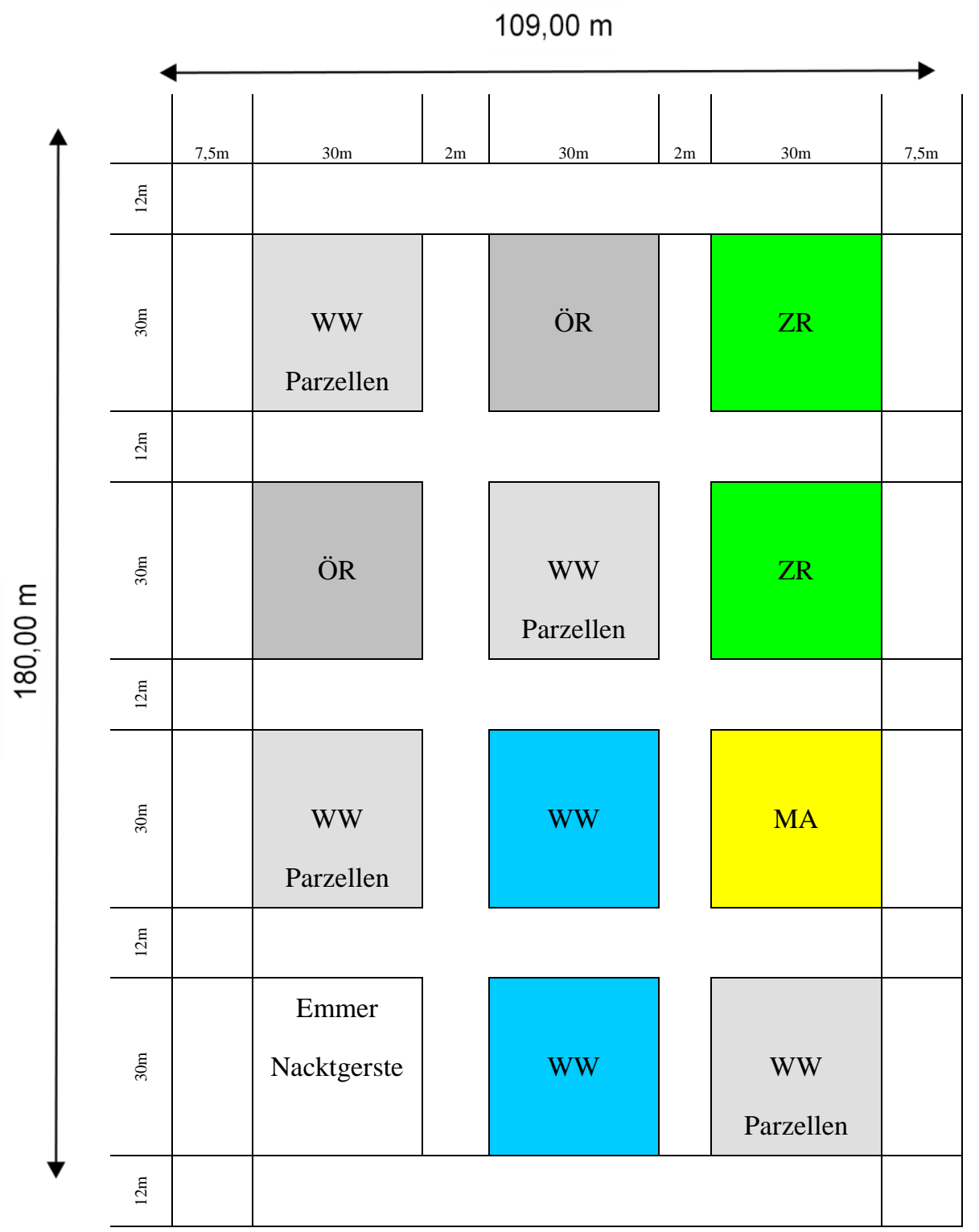

Abb. 5 Versuchsplan des FAEN Fruchtfolgeversuch auf den Standorten Gladebeck und Torland. Vier verschiedene Vorfruchtvarianten (Mais, Winterweizen, Zuckerrübe und ab 2008 Ölrettich) wurden bei nichwendender Bodenbearbeitung für die Folgefrucht Winterweizen angelegt. Jeder Vorfruchtspalte besteht aus je drei Blöcken $\left(900 \mathrm{~m}^{2}\right)$ in der jeweils einer dieser Blöcke in 24 Parzellen $\left(25 \mathrm{~m}^{2}\right)$ eingeteilt und für die Versuche genutzt wurde.

Hauptfragestellung des FEAN-Feldversuches war der Einfluss der verschiedenen agronomischen Versuchsfaktoren bzw. die Größe ihrer jeweiligen Varianzkomponenten auf die Mykotoxinbildung unter natürlichen Befallsbedingungen in den Versuchsjahren 2007-2009. In einem Starkbefallsjahr wie 2007 wurden darüber hinaus die Interaktionen der verschiedenen Versuchsparameter und ihre Wechselwirkungen zwischen der Pilzbiomasse von $F$. graminearum und den entsprechenden Mykotoxingehalten näher untersucht. Als neuer Parameter wurde hierfür die spezifische Mykotoxinbildung etabliert d.h. der Quotient aus der gebildeten DON-Menge ( $\mu \mathrm{g}$ DON kg ${ }^{-1}$ Mehl) pro Menge F.gramineraum DNA ( $\mu \mathrm{g}$ DNA kg ${ }^{-1}$ 
Mehl). Besonderes Augenmerk richtete sich in den Versuchen auf mögliche indirekte physiologische Effekte durch die Fungizide z.B. durch die Beeinflussung des Seneszenzverlaufes oder des Blühverlaufes bzw. durch eventuell vorhandene sublethale Fungizidrestmengen im Pflanzengewebe.

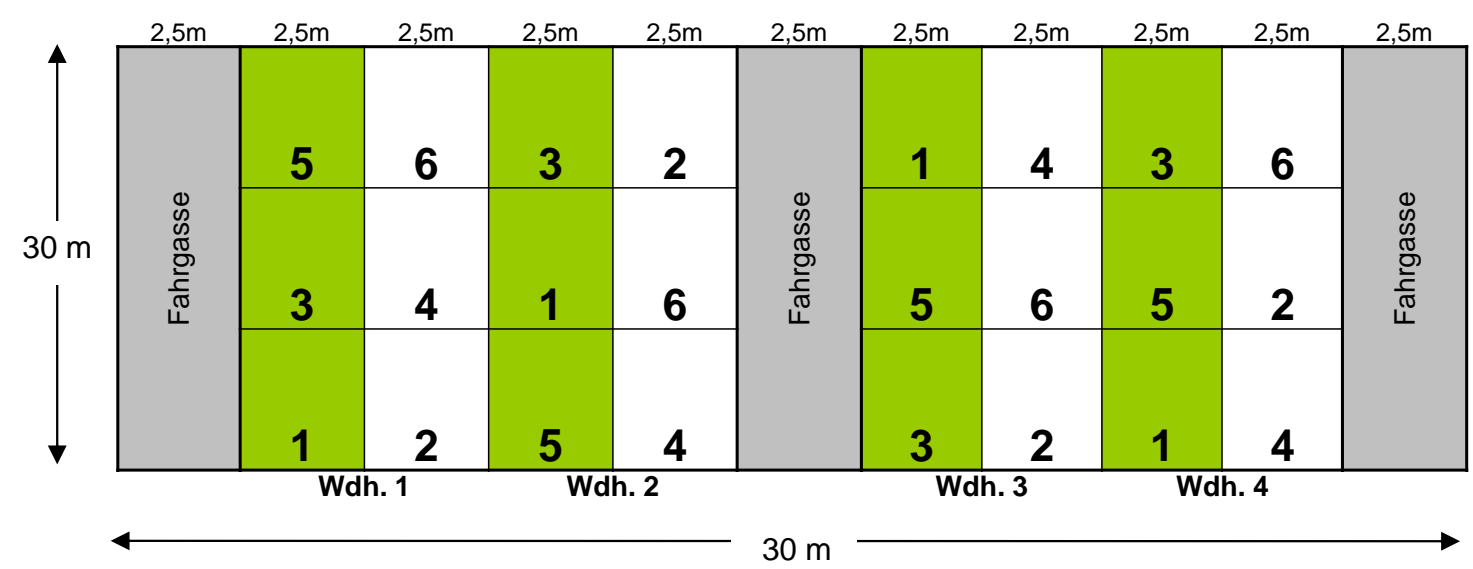

Abb. 6 Feldplan der Fungizidapplikationen im FAEN-Fruchtfolgeversuch: Varianten 1 (Centrum* Strobilurin), Variante 2 (Ritmo*Strobilurin), Variante 3 (Centrum*Triazol), Variante 4 (Ritmo*Triazol), Variante 5 (Centrum*Neutral) und Variante 6 (Ritmo*Neutral).

\begin{tabular}{|c|c|c|}
\hline & ВBCH 31 & ВBCH 39 \\
\hline Triazol & $\begin{array}{l}\text { CCC gesplittet } \\
0,81 \text { Proline (Prothioconazol) } \\
1,01 \text { Bravo (Chlorthalonil) }\end{array}$ & $\begin{array}{l}\text { 1,0 } 1 \text { Opus (Epoxiconazol) } \\
\text { 1,0 } 1 \text { Bravo (Chlorthalonil) }\end{array}$ \\
\hline Strobilurin & $\begin{array}{l}\text { CCC gesplittet } \\
\text { 1,0 1 Amistar (Azoxystrobin) } \\
\text { 1,0 1 Bravo (Chlorthalonil) } \\
\text { 0,4 1 Flexity (Metrafenone) }\end{array}$ & $\begin{array}{l}\text { 1,0 } 1 \text { Amistar (Azoxystrobin) } \\
\text { 1,0 1 Bravo (Chlorthalonil) }\end{array}$ \\
\hline Neutral & $\begin{array}{l}\text { CCC gesplittet } \\
\text { 1,0 1 Bravo (Chlorthalonil) } \\
\text { 1,0 1 Corbel (Fenpropimorph }\end{array}$ & $\begin{array}{l}\text { 1,0 1 Bravo (Chlorthalonil) } \\
1,01 \text { Corbel (Fenpropimorph) }\end{array}$ \\
\hline
\end{tabular}

Abb. 7 Zusammensetzung der Fungizidvarianten mit den verschiedenen Wirkstoffen im FAEN Feldversuch 2007-2009. Jede Literangabe in der Tabelle bezieht sich auf die ausgebrachte Menge pro Hektar.

\section{Meteorologische Daten der FAEN-Versuche}

Die für die Versuchsfragestellung wichtigen Witterungsparameter wie Niederschläge und Tagesdurchschnittstemperaturen wurden in den relevanten Monaten Mai und Juni, von Beginn des Schossens (BBCH 31), bis zur Milchreife (BBCH 73) ermittelt. Für den Standort 
Torland konnten die Daten der Messstation Göttingen des Deutschen Wetterdienstes (DWD) und für den Standort Gladebeck die Messdaten der privaten Wetterstation Göttingen in Hevensen genutzt werden (www.wetterstation-goettingen.de).

\subsubsection{Sortenversuch Wetze}

Am Standort Wetze/Northeim fand im Jahr 2009 mit den fünf Sorten: Centrum, Ritmo, KWS Erasmus, KWS Pius und Julius ein Versuch mit Unterstützung der KWS-Lochow GmbH statt. Es wurde eine Spaltanlage in vierfacher Wiederholung mit Doppelparzellen angelegt, wobei in diesem Versuch die Fungizidvarianten in den Spalten fixiert und die fünf Sorten in den Spalten randomisiert verteilt wurden. Im Gegensatz zum FAEN-Versuch fanden nur die Fungizidvarianten Triazol und Strobilurin (siehe Abb. 7) Verwendung. Dazu wurde jedoch eine neue Variante Null in den Versuch integriert. In dieser erfolgte nur im Entwicklungsstadium BBCH 31 eine Applikation der Fungizide Bravo ${ }^{\circledR}$ und Corbel ${ }^{\circledR}$ (vergl. Neutral-BBCH 31). Neben der klassischen Versuchsfrage, ob die spezifische Mykotoxinbildung in fusarienresistenten Sorten größer ist als in anfälligen Sorten und ob sich dies in den Sortenabstufungen des Bundessortenamtes widerspiegelt, sollte in diesem Versuch auch ein Vergleich zwischen einer nahezu unbehandelten Variante und den Blattapplikationen von Fungiziden erfolgen. Im Entwicklungsstadium BBCH 63-65 fand eine künstliche Inokulation mit dem Isolatgemisch des Pathogens F. culmorum (Fc 34/Fc35/Fc35) statt, deren Konidien von Haferinokulum abgespült wurden (siehe Kapitel 2.5.1). Bonituren, Probennahmen und die Analysen mittels ELISA und quantitativer PCR erfolgten analog und parallel zum FAENVersuch.

\subsubsection{Abreife- und Enzymaktivitätsversuch Weendelsbreite}

Der Versuchsstandort Weendelsbreite befindet sich nördlich von Göttingen am Grunde der Hänge des Göttinger Waldes. Wie am Standort Torland handelt es sich hier um eine Braunerde-Terra Fusca (Kalkstein-Braunlehm). Parallel zum FAEN-Versuch wurde hier die Wiederholung einer kompletten Vorfruchtvariante mit identischen Sorten und gleichen Fungizidapplikationen angebaut (Abb. 6). Die Befallsbonituren während der Milchreife und die Probennahmen zur Ernte erfolgten auch hier wie im FAEN-Versuch. Die Analysen der Mykotoxingehalte wurden mittels ELISA und der Gehalt an F. culmorum DNA mit Hilfe der 
qPCR gemessen. Vorfruchteffekte konnten durch eine Pflugfurche vor der Aussaat ausgeschlossen werden.

\subsubsection{Halbfreilandversuch zum Abreifeverlauf am Standort Weendelsbreite}

Nach der Applikation aller Fungizide wurden am Standort Weendelsbreite im Entwicklungsstadium BBCH 51, zu Beginn des Ährenschiebens d.h. nach Applikation der Fungizide, aus den Parzellen der Versuchsvarianten Centrum (Strobilurin und Triazol) und Ritmo (Strobilurin und Triazol) jeweils vier quadratische Pflanzenbüschel mit bis zu 40 ährentragenden Halmen ausgestochen und in 21 x $21 \mathrm{~cm}$ Töpfe umgepflanzt. Die Pflanzen wuchsen im Gewächshaus unter kontrollierten Bedingungen bis zum Beginn der Abreife weiter. Zu vier Terminen, mit jeweils drei Tagen Abstand, wurde der Abreifeverlauf der Ähren bestimmt. Aus den vier unabhängigen Wiederholungen jeder Versuchsvariante erfolgte zu jedem Termin eine zufällige Auswahl von 10 Ähren, in denen der Wassergehalt ermittelt wurde (siehe Kapitel 2.12). Unter kontrollierten Bedingungen sollte dabei der Einfluss von Fungizidapplikationen unter Feldbedingungen auf das Abreifeverhalten in Weizenähren untersucht und durch die Verwendung von mehr als einer Sorte auf mögliche Fungizid-Sorten Interaktionen hin geprüft werden.

\subsubsection{Feldversuch zur Enzymaktivität am Standort Weendelsbreite}

Im Entwicklungsstadium BBCH 63-65 erfolgte auf dem Standort Weendelsbreite eine künstliche Inokulation mit den Isolaten von F.culmorum $(\mathrm{Fc} 34 / \mathrm{Fc} 35 / \mathrm{Fc} 36)$ (siehe 2.5.2) um die Faktoreinflüsse der Versuchsvarianten Sortenresistenz und Fungizidapplikationen unter definierten künstlichen Befallsbedingungen auf die Mykotoxinbildung zu bewerten. Darüber hinaus wurde in den Entwicklungsstadien BBCH 75 am 06.07.2009, BBCH 85 am 14.07.2009 und BBCH 92 am 27.07.2009 Probennahmen von nichtinfizierten Pflanzen durchgeführt. Mit einem Spaten wurden quadratische Pflanzenbüschel (20 bis 30 ährentragende Halme) aus den Fungizidvarianten der Sorte Ritmo herausgestochen, diese wurden in vorbereitete Töpfe (21 x $21 \mathrm{~cm}$ ) umgepflanzt und unverzüglich für die Messung der Gujakolperoxidaseaktivität verwendet. Die Analyse fand im jüngsten Pflanzenmaterial, d.h. in Hüll- und Deckspelzen der Getreideähre statt. Dafür wurden aus jeder Wiederholung der Fungizidvarianten ca. $2 \mathrm{~g}$ der Spelzen mit Pinzetten von der Ähre abgetrennt und mit flüssigen $\mathrm{N}_{2}$ zermörsert. Die Gujakolperoxidasemessung erfolgte wie in Kapitel 2.13 beschrieben. Unter Freilandbedingungen 
wurde in diesem Versuch der Einfluss der drei verschiedenen Fungizidwirkstoffe auf den Seneszenzverlauf in der Winterweizensorte Ritmo ermittelt. Somit konnten die Ergebnisse der Peroxidaseaktivitätsmessung mit den Mykotoxingehalten der entsprechenden Fungizidvarianten verglichen werden. Die Bonitur und Probennahmen erfolgten auch hier wie im FAEN-Versuch.

\subsection{Gewächshausversuche}

Im Gewächshaus wurden Untersuchungen unter kontrollierten Bedingungen mit Winter- und Sommerweizen durchgeführt. Natürlich vernalisierte Pflanzen des Winterweizens wurde mit Beginn der Vegetation (BBCH 21-23) im März aus den Feldversuchen ins Gewächshaus umgepflanzt und bis zur Durchführung der Versuche angezogen. Der Sommerweizen wurde direkt in Töpfe (9 x 9 x 9cm) ausgesät, die mit einer Standardbodenmischung aus Sand (30\% v/w), gedämpfter Komposterde $(20 \% \mathrm{v} / \mathrm{w})$ und Blumentopferde $(50 \% \mathrm{v} / \mathrm{w})$ befüllt wurden (ca. 400 g). In allen Versuchen wurde mit zwei Pflanzen pro Topf gearbeitet, wobei immer nur der Haupttrieb erhalten wurde. Lampen oberhalb der Gewächshaustische gewährleisteten eine Beleuchtungsstärke von mindestens 10.000 Lux bei einer Photoperiode von 16 h. Die Pflanzen wurden während ihrer Entwicklung bedarfsgerecht mit dem Mehrnährstoffdünger Hakaphos $\left(15 \% \mathrm{~N}, 15 \% \mathrm{~K}_{2} \mathrm{O}, 11 \% \mathrm{P}_{2} \mathrm{O}, 1 \% \mathrm{MgO}\right)$ versorgt.

\subsubsection{Fungizidversuch im Gewächshaus}

Im Juni 2008 wurde in der Sommerweizensorte SW Kadrilj unter kontrollierten Gewächshausbedingungen der Einfluss verschiedener fungizider Blattbehandlungen auf den FHBIndex, die Mykotoxinmenge und die spezifische Mykotoxinbildung ermittelt. Die Versuchsanlage bestand aus einer Spaltanlage mit 24 Wiederholungen, mit jeweils 9 Töpfen (je 2 Haupttriebe) pro Wiederholung. Die drei Behandlungen Strobilurin, Triazol und Unbehandelt wurden als Untergruppen innerhalb der Wiederholungen randomisiert. Für die Befallserhebung und für weitere Analysen wurden die Ergebnisse von jeweils sechs Untergruppen gepoolt und verrechnet. Die Applikation der Fungizide erfolgte mit Hilfe einer Rückenspritze mit entsprechenden Mengen wie im Feldversuch und einem Spritzbalken, um eine vergleichbare Fungizidverteilung zu gewährleisten (Abb. 8). 


\begin{tabular}{|l|l|l|}
\cline { 2 - 3 } \multicolumn{1}{c|}{} & BBCH 31 & BBCH 39 \\
\hline Triazol & 1,01 Opus (Epoxiconazol & 1,01 Opus (Epoxiconazol) \\
\hline Strobilurin & 1,01 Amistar (Azoxystrobin) & 1,01 Amistar (Azoxystrobin) \\
\hline Unbehandelt & Wasserkontrolle & Wasserkontrolle \\
\hline
\end{tabular}

Abb. 8 Zusammensetzung der Fungizidvarianten mit den verschiedenen Wirkstoffen im Gewächshausversuch zu zwei Applikationsterminen. Jede Literangabe in der Tabelle bezieht sich auf die ausgebrachte Menge pro Hektar.

Mit Beginn der Vollblüte ab dem 15.06.2008 im Entwicklungsstadium BBCH 63-65 wurde eine Sprühinokulation mit einem Gemisch der Isolate von Fusarium graminearum (Fg142/Fg143/Fg144) durchgeführt (siehe Kapitel 2.5.2). Die Bonituren erfolgten zu den Terminen 14 und 24 dpi (siehe Kapitel 2.6.2). Nachweise mittels HPLC-MS/MS und quantitativer PCR fanden in den gewonnenen Mehlproben statt.

\subsubsection{Sortenversuch mit Einzelährchen- und Sprühinokulation}

Im Starkbefallsjahr 2007 zeigte die gegenüber Fusariosen resistentere Sorte Centrum eine signifikant geringere spezifische Mykotoxinbildung als die anfällige Sorte Ritmo, was im Widerspruch zu bisherigen Literaturergebnissen steht (Nicholson et al., 2003). In Gewächshausversuchen wurden die fünf Winterweizensorten Centrum, Ritmo, Julius, KWS Pius und KWS Erasmus aus dem Feldversuch der KWS-Lochow GmbH verwendet. Dabei wurde die eine Hälfte der Pflanzen mit einer Nadel und die andere Hälfte mit einem Handsprüher inokuliert (siehe Kapitel 2.5.2). Mit Hilfe dieser beiden Techniken konnten gezielt eine bzw. mehrere Primärinfektionen pro Weizenähre induziert werden. Die verwendeten Sorten decken das Resistenzspektrum gegenüber Fusarium spp. Ähreninfektionen laut Beschreibender Sortenliste $\mathrm{ab}$ und sind daher geeignet, um mögliche Interaktionen zwischen den Sorten und der Infektionsart (einzelne oder multiple Primärinfektion) bzw. des Infektionsgeschehens (Einzelährcheninfektionen oder multiple Primärinfektionen) im Feld auf die spezifische Mykotoxinbildung deutlich zu machen. Der Versuch wurde als teilrandomisierte Spaltanlage mit vier Wiederholungen im Gewächshaus angelegt. Jede Wiederholung bestand aus insgesamt 40 Töpfen mit je zwei Haupttrieben. Die Anlage der Sorten erfolgte als Spalten mit je acht Töpfen in den jeweiligen Wiederholungen. Zwischen den Wiederholungen wurden die 
Sortenspalten randomisiert, um mögliche Randeffekte in den Versuchen zu minimieren. Die Durchführung beider Inokulationsvarianten fand parallel unter identischen Bedingungen statt. Die Inokulation erfolgte im Entwicklungsstadium BBCH 63-65 zwischen dem 12-25.05.2010. Die Bonituren wurden nach 7, 14 und 21 dpi durchgeführt (siehe Kapitel 2.6.2). Der Nachweis der Toxinkontamination und der DNA-Mengen in den Mehlproben erfolgte mittels HPLC-MS/MS und quantitativer PCR (siehe Kapitel 2.7.2 + 2.7.3).

\subsubsection{Klimakammerversuche zum Einfluss von Witterungsparametern}

Ziel dieser Versuche war es, den Einfluss verschiedener Witterungsparameter, wie die Temperatur und die Intervalllänge von Feuchteperioden auf die Mykotoxinbildung und die spezifische Mykotoxinbildung zu messen. Durch Veränderungen der Temperatur sollte dabei auf mögliche Interaktionen zwischen diesen beiden Parameter hin geprüft und ihr jeweiliger Einfluss bestimmt werden. Die Pflanzen der Sommerweizensorte Tybalt wurden im Gewächshaus bis zum Entwicklungsstadium BBCH 39 angezogen und danach in den begehbaren Klimakammern (Kälte-Klima Mattern, Northeim) an die verschiedenen Witterungszenarien adaptiert. Neonlampen oberhalb der Klimakammertische gewährleisteten eine Beleuchtungsstärke von mindestens 10.000 Lux bei einer Photoperiode von $16 \mathrm{~h}$ (Tag) und $8 \mathrm{~h}$ (Nacht). Mit Beginn der Vollblüte (BBCH 63-65) wurde gezielt eine Punktinokulation pro Ähre durchgeführt (siehe Kapitel 2.5.2) und die Ähren für zwei Tage in verschließbaren Klemmbeuteln inkubiert. Der Inkubationsintervalltest begann 10 d nach dem Setzen der Primärinfektion, wobei jedes Intervall in Abschnitte von $10 \mathrm{~d}$ Schritten eingeteilt wurde. In Abhängigkeit von der Variante wurden die Ähren innerhalb dieser Intervalle entweder 2 d, 5 d, 8 d, oder über den gesamten Zeitraum mit Klemmbeuteln feucht inkubiert (Abb. 9). In der unbehandelten Kontrollvariante wurden Ähren mit Wasser inokuliert, danach $2 \mathrm{~d}$ inkubiert und während des Intervalltests normal wachsen gelassen, so dass der Einfluss der Witterungsparameter auf unbehandelte Pflanzen erfasst werden konnte.

Für 30 d wurden die Pflanzen in den Klimakammern dem Test unterzogen, so dass drei komplette Intervalldurchläufe möglich waren und danach die vorhandenen Körner gererntet werden konnten. Der Versuch wurde als randomisierte Blockanlage mit vier Wiederholungen in der Klimakammer angelegt. Jede Wiederholung bestand aus 10 Töpfen mit insgesamt 20 ährentragenden Halmen, die 7 und 14 Tage nach Beginn des Intervalltests (entspricht 17 und 24 dpi) bonitiert (siehe Kapitel 2.6.2) und zur Totreife geerntet wurden. Die geernteten Körner wurden aufbereitet (siehe Kapitel 2.7.1) und mittels HPLC-MS/MS und quantitativer PCR 
(siehe Kapitel 2.7.2) analysiert. Pro Versuchsdurchgang waren bis zu vier verschiedene Inkubationsintervalle möglich, die aufgrund der limitierten Fläche nicht immer genutzt werden konnten, als wichtigste Inkubationsintervalle wurden die Varianten $2 \mathrm{~d}, 5 \mathrm{~d}$ und $8 \mathrm{~d}$ in jedem der fünf Durchläufe getestet (Abb.9).

\begin{tabular}{|l|c|c|c|c|c|c|}
\hline \multirow{2}{*}{ Inokulationszeitraum } & \multicolumn{2}{|c|}{ Temperatur } & \multicolumn{4}{|c|}{ Feuchtinkubationszeitraum } \\
\cline { 2 - 7 } & Tag & Nacht & Unbehandelt & 2 Tage & 5 Tage & 8 Tage \\
\hline $25.5-8.6 .2009$ & $20^{\circ} \mathrm{C}$ & $16^{\circ} \mathrm{C}$ & & $\mathrm{x}$ & $\mathrm{x}$ & $\mathrm{x}$ \\
\hline $9.7-16.7 .2009$ & $25^{\circ} \mathrm{C}$ & $16^{\circ} \mathrm{C}$ & & $\mathrm{x}$ & $\mathrm{x}$ & $\mathrm{x}$ \\
\hline $31.8-16.9 .2009$ & $16^{\circ} \mathrm{C}$ & $12^{\circ} \mathrm{C}$ & & $\mathrm{x}$ & $\mathrm{x}$ & $\mathrm{x}$ \\
\hline $3.11-18.11 .2009$ & $12^{\circ} \mathrm{C}$ & $12^{\circ} \mathrm{C}$ & $\mathrm{x}$ & $\mathrm{x}$ & $\mathrm{x}$ & $\mathrm{x}$ \\
\hline $5.1 .-14.1 .2010$ & $28^{\circ} \mathrm{C}$ & $8^{\circ} \mathrm{C}$ & & $\mathrm{x}$ & $\mathrm{x}$ & $\mathrm{x}$ \\
\hline
\end{tabular}

Abb. 9 Temperatur- und Inkubationszeiträume der Versuche zum Einfluss verschiedener Witterungsparameter unter kontrollierten Bedingungen in Klimakammern.

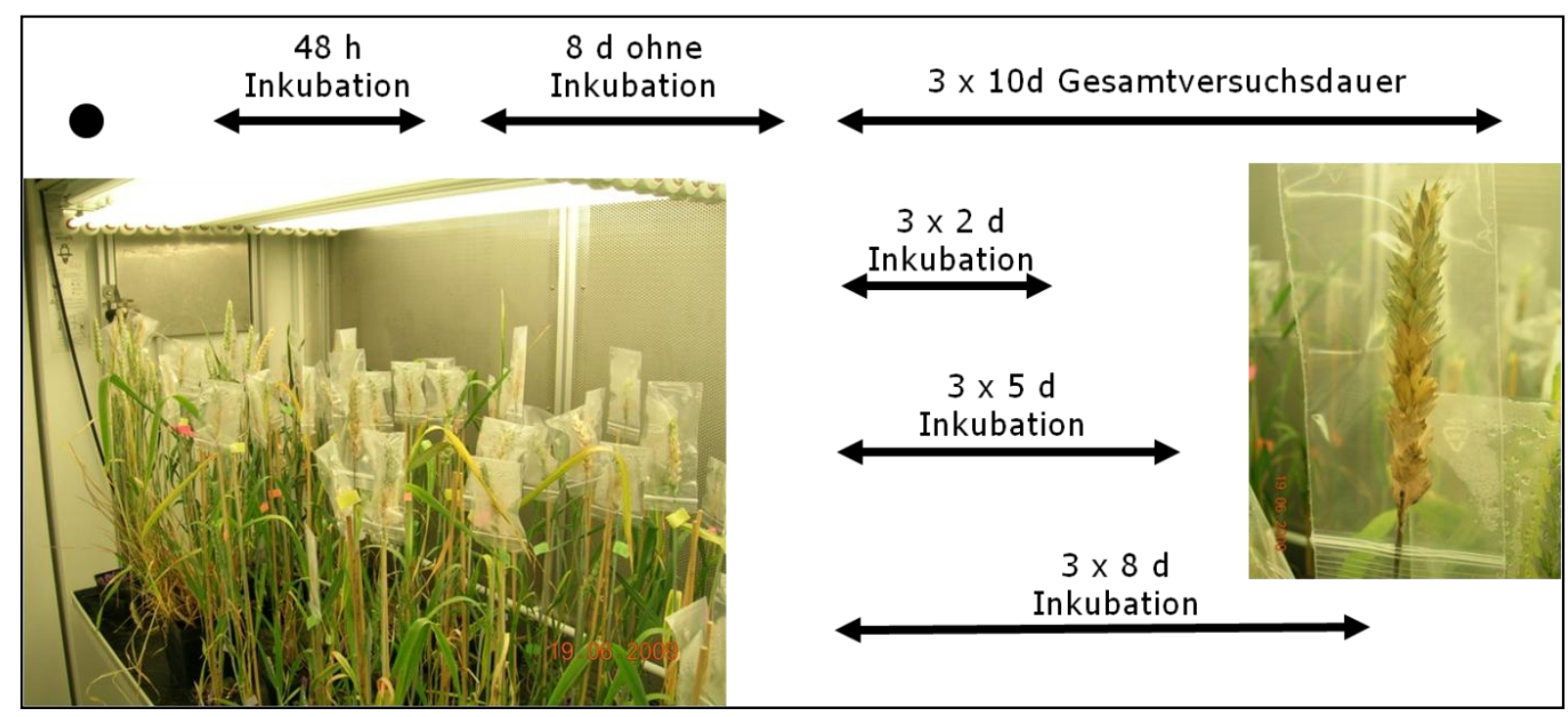

Abb. 10 Versuchsaufbau der Inokulationsexperimente unter kontrollierten Bedingungen in Klimakammern und Ablauf der Feuchtinkubationsperioden. 


\subsubsection{Pathogenitätstest an Weizen mit Fusarium-Isolaten aus Zuckerrüben und deren Mykotoxinprofile}

Im Rahmen einer Kooperation innerhalb von FAEN mit Frau Daniela Christ vom IFZ wurde die Pathogenität von verschiedenen Fusarium-Arten in Gewächshausversuchen an der Sommerweizensorte Kadrilj getestet. Ziel war es, einen Vergleich zwischen einem Referenzisolat aus Winterweizen und Isolaten verschiedener Fusarium-Arten aus Zuckerrüben durchzuführen. In einem vollständig randomisierten Versuchsdesign wurden die Isolate $F$. graminearum Fg142, F. graminearum O14, F. culmorum O29, F. cerealis O45, F. oxysporum O38, F. redolens $\mathrm{O} 1, F$. equiseti $\mathrm{O} 19$ und $F$, tricinctum $\mathrm{O} 63$ zum Zeitpunkt der Vollblüte (BBCH 65) per Handsprüher mit entsprechenden Inokulumdichten inokuliert (siehe Kapitel 2.5.2). Als Negativkontrolle dienten Pflanzen, die mit Aqua bidest. besprüht wurden. Jede der 80 Ähren, wurden 7, 14 und 21 Tage nach der Inokulation bonitiert und mittels HPLC-MS/MS in Tulln, Österreich, zur Bestimmung des jeweiligen Mykotoxinprofils, analysiert. Der Versuch wurde bei einer durchschnittlichen Luftfeuchtigkeit von 50\% pro Tag durchgeführt. Zur Bestätigung der Kochschen Postulate wurden zusätzlich Reisolationen der einzelnen Isolate aus dem Erntegut vorgenommen. Auf Grund der in einigen Getreideproben entdeckten „Black Point“ Symptome an Weizenkörnern wurde außerdem eine visuelle Differenzierung durchgeführt und eine Häufigkeitsverteilung der verschiedenen Kornfraktionen (FHB-Körner und „Black Point“" Körner) in Abhängigkeit von den verschiedenen Fusarium-Arten erstellt.

\subsubsection{Untersuchungen zum „Black Point" Symptom an Weizen}

Als Konsequenz aus den Ergebnissen des Pathogenitätsversuchs der aus Zuckerrüben isolierten Fusarium-Arten wurden weitere Versuche durchgeführt, um das „Black Point“ Symptom an Getreidekörnern besser analysieren und bewerten zu können. Ziel dieser Versuche war eine separate Analysen der Qualitätsparameter wie das TKG und die Keimfähigkeit bei BlackPoint Körnern und symptomlosen Körnern. Überdies sollten Mykotoxinprofile der beiden Korntypen ermittelt werden, um zu überprüfen ob das „Black Point“ Symptom als Indikator für eine erhöhte Mykotoxinbelastung herangezogen werden kann.

Die Sprühinokulation erfolgte im Entwicklungsstadium BBCH 65 mit den Isolatgemischen $F$. graminearum $\mathrm{Fg} 142 / \mathrm{Fg} 143 / \mathrm{Fg} 144$, F . tricinctum O63/O35/O32, F. equiseti O19/O20/O90, F. oxysporum O38/O39/O40, F. redolen O1/O4/O7. Zusätzlich wurde eine Wasserkontrolle in den Versuchsaufbau integriert. Da von einem Zusammenhang zwischen der Luftfeuchte und 
den BP-Mengen ausgegangen wird (Williamson, 1997), wurde vom Zeitpunkt der Inokulation bis zum Abschluss der Bonitur die relative Luftfeuchtigkeit auf durchschnittlich 60\% pro Tag erhöht. Der Versuch mit der Sommerweizensorte Tybalt wurde vollständig randomisiert aufgebaut. Um eine ausreichende Menge an Körnen mit „Black Point“ Symptomen zu produzieren wurden in der Variane $F$. tricinctum und $F$. equiseti 7 Wiederholungen, in der Variante $F$. redolens und $F$. oxysporum 6 Wiederholungen und in denVarianten $F$. graminearum und Unbehandelt 4 Wiederholungen durchgeführt. Jede Wiederholung bestand aus 18 ährentragenden Halmen, die 7, 14 und 21 Tage nach der Inokulation bonitiert und mittels HPLCMS/MS in Tulln, Österreich, zur Bestimmung des jeweiligen Mykotoxinprofils analysiert wurden.

\subsection{Statistische Auswertung}

Die statistische Analyse des FAEN Feldversuches erfolgte aufgrund des komplexen Aufbaus und multipler Interaktionen in enger Kooperation mit Dr. Christian Kluth (Applied Biostatistics and Consulting). Die Daten wurden dabei untransformiert als Mixed Model mit dem Statistikprogramm SAS (Cary/NC, USA) ausgewertet. Im Rahmen dieser Berechnungen wurde auch eine Varianzkomponentenanalysen zur Bewertung des Einflusses der fünf Hauptversuchsfaktoren (Jahr, Standort, Vorfrucht, Sorte und Fungizidapplikation) durchgeführt. Auf das Fruchtfolgeglied Ölrettich wurde bei diesen Berechnunge jedoch verzichtet, da es nur in den Versuchsjahren 2008 und 2009 stand. Auf Grund der komplexen Interaktionen des Feldversuches, war daher eine Integration dieses Parameters in die Varianzkomponentenanalyse nicht möglich.

Um einen einfacheren Überblick über mögliche Interaktionen zwischen den Versuchsfaktoren zu erlangen, wurde darüber hinaus eine Gewichtung der Faktoreffekte nach Koch et al. (2006) vorgenommen. Für jeden einzelnen Versuchsfaktor wurden dabei die Mittelwerte der zu vergleichenden Versuchsparameter dividiert, der so erhaltene dimensionslose Wert spiegelt die Bedeutung des jeweiligen Versuchsfaktors auf den Mykotoxingehalt im Winterweizen wider.

Alle anderen Versuche in dieser Arbeit wurden mit dem Statistikprogramm STATISTICA (StatSoft, Tulsa, USA) varianzanalytisch verrechnet und unter Annahme der Normalverteilung der Residuen, multiplen Mittelwertvergleichen mit dem Fisher Least Significant Difference Test (LSD-Test) bzw. dem Tukey Test unterzogen. Unterschiedliche Buchstaben kennzeichnen signifikante Unterschiede bei einer Irrtumswahrscheinlichkeit von 5\% ( $\mathrm{p} \leq$ 
0,05). Die in dieser Arbeit dargestellten Versuche wurden, wenn nicht anders beschrieben nicht wiederholt. In jedem Versuch wurden mindestens vier Wiederholungen integriert, die in den Versuchen unter kontrollierten Umwelten mit vielfach gepoolten Einzelwerten berechnet wurden. 


\section{Ergebnisse}

\subsection{Ergebnisse des FAEN-Feldversuches}

Bei der Analyse der Daten des FAEN-Versuches wurde auf die Werte der Vorfruchtvariante Ölrettich aus statistischen Erwägungen verzichtet. Daten für diese Variante waren erst ab demVersuchsjahr 2008 verfügbar, eine Verrechnung im Mixed Model für die DON-Gehalt im Winterweizen über alle Versuchsjahre war nicht möglich, daher beschränken sich die Analysen auf die Vorfruchtvarianten Mais, Winterweizen und Zuckerrübe.

\subsubsection{Meteorologische Daten und Sporenmessungen}

In Abb. 11 sind die Witterungsverläufe der Monate Mai und Juni für die Versuchsjahre 20072009 und der Sporenflug 2008 und 2009 dargestellt. Im Versuchsjahr 2007 kam es zu einer Koinzidenz zwischen dem Entwicklungsstadium BBCH 65 (Vollblüte) und starken Regenereignissen vom 26. bis 30.05.2007. Bis zum Zeitpunkt der Ernte führten regelmäßige Niederschläge zu einer permanenten Durchfeuchtung des Bestandes und der Weizenähren. Eine Erfassung des Sporenfluges konnte in diesem Jahr nicht durchgeführt werden. Das Versuchsjahr 2008 war durch eine anhaltende Vorsommertrockenheit von Anfang Mai bis Mitte Juni geprägt, ein Aufbau des Inokulums auf den Ernterückständen der Vorfrüchte war nicht möglich. Bei sehr hohen Tagesdurchschnittstemperaturen traten die ersten Niederschläge erst 7 Tage nach dem Entwicklungsstadium BBCH 65 auf, eine Koinzidenz war somit nicht gegeben. Die maximale Menge der gefangenen Askosporen war mit ca. 80 Sporen $\mathrm{d}^{-1} \mathrm{~m}^{-3}$ auf einem sehr geringen Niveau. Einen Temperatursturz zum Zeitpunkt des Entwicklungsstadiums BBCH 65 (6-10.06.2009) führte im Versuchsjahr 2009 dazu, dass die Tagesdurchschnittstemperatur auf ca. $6^{\circ} \mathrm{C}$ fiel mit schwachem Bodenfrost in den frühen Morgenstunden. Aufgrund der gleichmäßigen Verteilung der Niederschläge konnte sich aber ein Inokulumpotential von Perithezien auf den Ernteresten aufbauen, was die große Anzahl gefangener Sporen von bis zu 1000 Sporen $\mathrm{d}^{-1} \mathrm{~m}^{-3}$ zeigte.

Das Versuchsjahr 2007 wies im Mai und Juni neben relativ hohen Temperatursummen an beiden Standorten die höchsten Niederschlagsmengen der drei Versuchsjahre auf, die auf mehrere Starkregenereignisse zurückzuführen waren und in der Summe um den Faktor 2,5 -3 höher lagen als in den Versuchsjahren 2008 und 2009 (Tab. 3). Besonders am Standort Gladebeck führte eine ausgeprägte Vorsommertrockenheit im Jahr $2008 \mathrm{zu}$ den höchsten Temperatursummen bei gleichzeitig sehr geringen Niederschlagsmengen während des gesam- 
ten Versuchszeitraums, was ebenfalls am Standort Torland bestätigt werden konnte. Das Versuchsjahr 2009 war in den Monaten Mai und Juni im Vergleich zu den Vorjahren etwas kühler. An beiden Standorten wurden die niedrigsten Temperatursummen gemessen, jedoch waren die Niederschläge gleichmäßiger verteilt, aber in der Summe auf einem ähnlich niedrigen Niveau wie 2008.

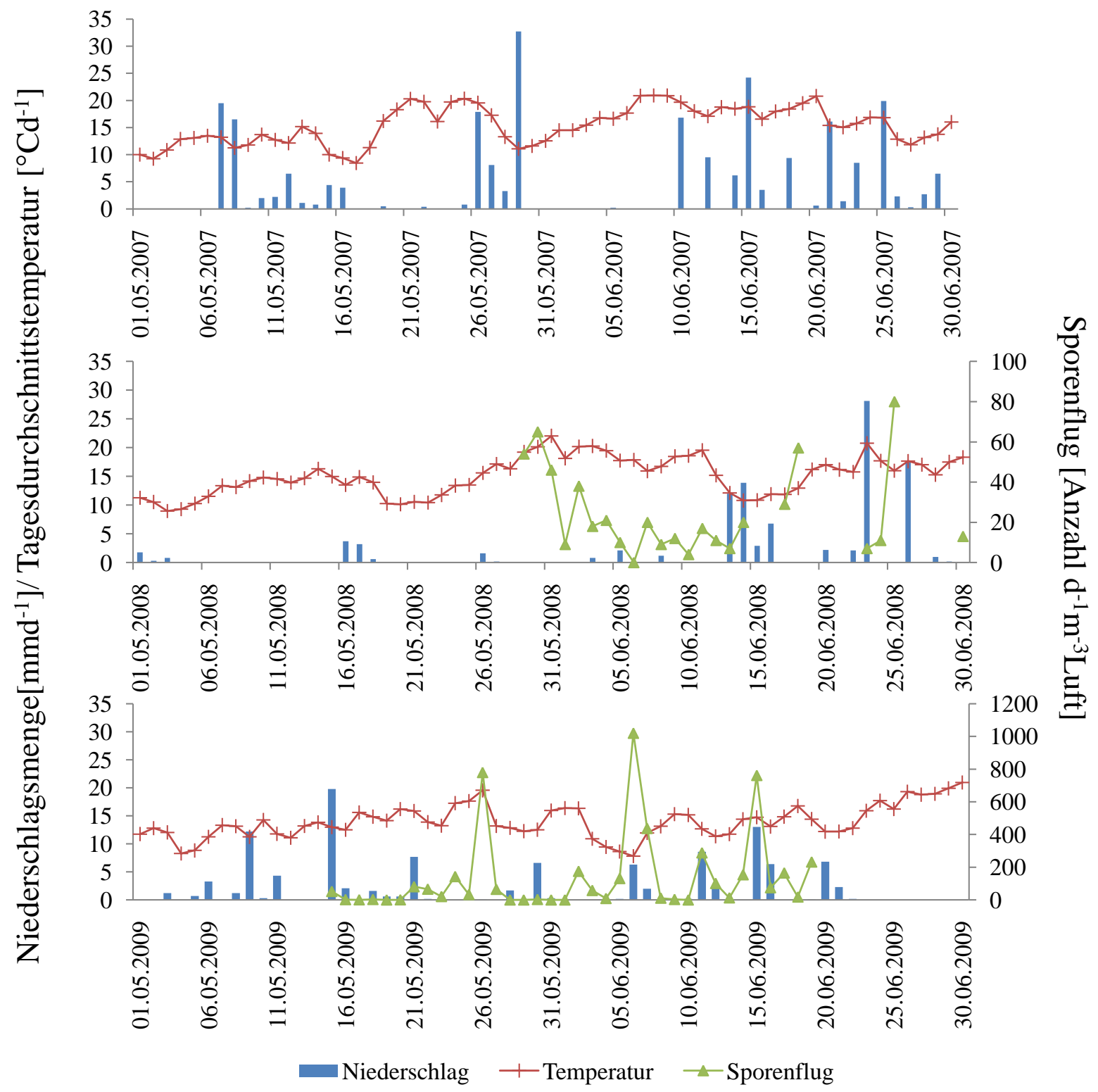

\begin{abstract}
Abb. 11 Witterungs- und Sporenflugdiagramm für den Standort Torland in den Monaten Mai und Juni ( $x$-Achse) der Versuchsjahren 2007-2009. Dargestellt sind auf der $y$-Achse die durchschnittlichen Tagesniederschläge $\left[\mathrm{mm} \mathrm{d}^{-1}\right]$ und die Tagesdurchschnitttemperaturen $\left[{ }^{\circ} \mathrm{C} \mathrm{d}^{-1}\right]$. Auf der $\mathrm{z}-$ Achse ist für die Jahre die 2008 und 2009 die Höhe des Sporenfluges [Anzahl d ${ }^{-1} \mathrm{~m}^{-3}$ ] verschiedener Fusarium spp. während der Entwicklungsstadien BBCH 51-71 aufgetragen. Die Daten der Wetterstation des Deutschen Wetterdienstes (DWD) in Göttingen wurden für den Standort Torland verwendet.
\end{abstract}


Tab. 3 Temperatursummen $\left[{ }^{\circ} \mathrm{C}\right]$ und Niederschlagssummen [mm] der Monate Mai und Juni an den Standorten Torland und Gladebeck in den Versuchsjahren 2007 - 2009. Für den Standort Torland wurden die Daten der Wetterstation des DWD in Göttingen und für den Standort Gladebeck die Daten der Wetterstation-Göttingen in Hevensen genutzt.

\begin{tabular}{llcc} 
Versuchsjahr & Standort & Temperatursumme & Niederschlagssumme \\
\hline \multirow{2}{*}{2007} & Torland & 938 & 249 \\
& Gladebeck & 957 & 295 \\
\multirow{2}{*}{2008} & Torland & 918 & 103 \\
& Gladebeck & 965 & 65 \\
2009 & Torland & 851 & 113 \\
& Gladebeck & 870 & 102 \\
\hline
\end{tabular}

\subsubsection{Blühverlauf}
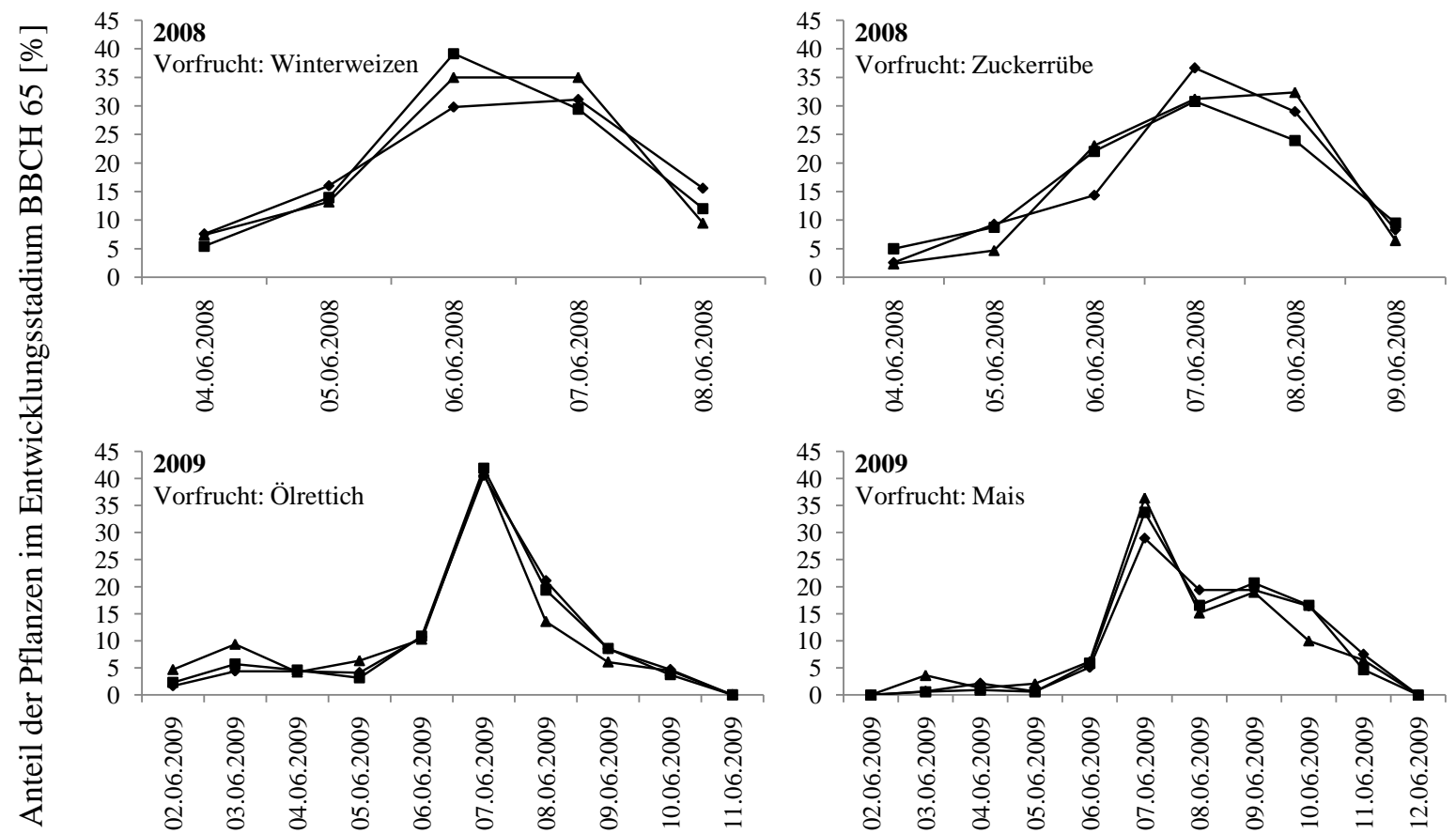

$\rightarrow$ Strobilurin $\rightarrow$-Triazol $₫$ Neutral

Abb. 12 Blühverlauf der Sorte Centrum in den Versuchsjahren 2008 und 2009 in Abhängigkeit von der Vorfrucht und der Fungizidapplikation. Dargestellt sind im Versuchsjahr 2008 die Ergebnisse aus den Vorfruchtvarianten Winterweizen bzw. Zuckerrübe; im Versuchsjahr 2009 wurden die Vorfruchtvarianten Ölrettich und Mais untersucht und der Anteil Pflanzen im Entwicklungsstadium BBCH 65 [\%] bestimmt.

Die unterschiedlichen Längen der Blühzeiträume spiegelten das klimatische Geschehen in den Versuchsjahren 2008 und 2009 wieder. Bei hohen Tagesdurchschnittstemperaturen von bis zu 
$20^{\circ} \mathrm{C}$ blühten die Getreidebestände 2008 innerhalb von 5-6 Tagen ab (Abb.12). In beiden Vorfruchtvarianten (Winterweizen und Zuckerrübe) waren keine Unterschiede im Blühverlauf zwischen den drei Fungizidvarianten Strobilurin, Neutral und Triazol erkennbar. Es konnte im Versuchsjahr 2008 aber eine Verschiebung der Vollblüte um zwei Tage in der Vorfruchtvariante Zuckerrübe im Vergleich zur Vorfruchtvariante Winterweizen festgestellt werden. Aufgrund des Temperatursturzes im Jahr 2009 verlängerte sich die Blüte der Weizenbestände auf bis zu 12 Tage. Dessen ungeachtet hatten die Fungizidapplikationen selbst in diesen Vorfruchtvarianten (Ölrettich und Mais) keinen Einfluss auf das Blühverhalten. Ähnlich wie im Versuchsjahr 2008 trat auch 2009 ein Effekt der Vorfrucht auf. In der Variante Mais verschob sich auch hier der Zeitpunkt der Vollblüte um ein bis zwei Tage im Vergleich zur Vorfrucht Ölrettich.

\subsubsection{Befallshäufigkeit der partiellen Weißährigkeit}

Unter natürlichen Befallsbedingungen konnten im Starkbefallsjahr 2007 in den Getreideproben bei Befallshäufigkeiten von $70 \%$ bis zu $80.000 \mu \mathrm{g}^{\mathrm{DON} \mathrm{kg}}{ }^{-1} \mathrm{Mehl}$ gemessen werden. Das Bestimmtheitsmaß $\left(\mathrm{r}^{2}\right)$ lag mit einem Wert von 0,40 jedoch nur auf einem relativ niedrigen Niveau. An Hand der Lage der Punkte rund um die Regressionsgerade ist erkennbar, das vor allem die hohen Mykotoxingehalte und Befallshäufigkeiten, weit abweichen, d.h. sie wurden beim Bonitieren über- bzw. unterschätzt. Im Versuchsjahr 2008 kam es witterungsbedingt nur zu einem minimalen Auftreten der partiellen Weißährigkeit im FAEN Feldversuch. Es konnte kein Zusammenhang zwischen der Befallshäufigkeit und den DON-Gehalten festgestellt werden, das Bestimmtheitsmaß mit $\mathrm{r}^{2}=0,08$ war minimal. Bei Befallshäufigkeiten von weniger als $0,05 \%$ wurden einzelne Mykotoxinkontaminationen von maximal $1000 \mu \mathrm{g}$ DON kg-1 Mehl gemessen. Bei einem mittleren Befallsdruck, wie im Versuchsjahr 2009, wurde über beide Standorte der engste Zusammenhang zwischen der Befallshäufigkeit und den Mykotoxingehalten in den Getreideproben festgestellt. Die Regressionsgerade schmiegte sich an die linear aufgereihten Punkte an, so dass das Bestimmtheitsmaß mit $r^{2}=0,81$ den höchsten Wert aller drei Versuchsjahre annahm. Mykotoxinkontaminationen von maximal $5.000 \mu \mathrm{g}$ DON kg ${ }^{-1}$ Mehl konnten bei Befallshäufigkeiten von bis zu 5\% ermittelt werden (Abb.13).

Für die Darstellung des Zusammenhangs zwischen der Befallshäufigkeit der partiellen WeiBährigkeit und dem DON-Gehalt im Vollkornmehl, mussten aufgrund des sehr stark unterschiedlichen starken Auftretens von Fusarium spp., für jedes Versuchsjahr unterschiedliche Achsenskalierungen verwendet werden (Abb.13). 


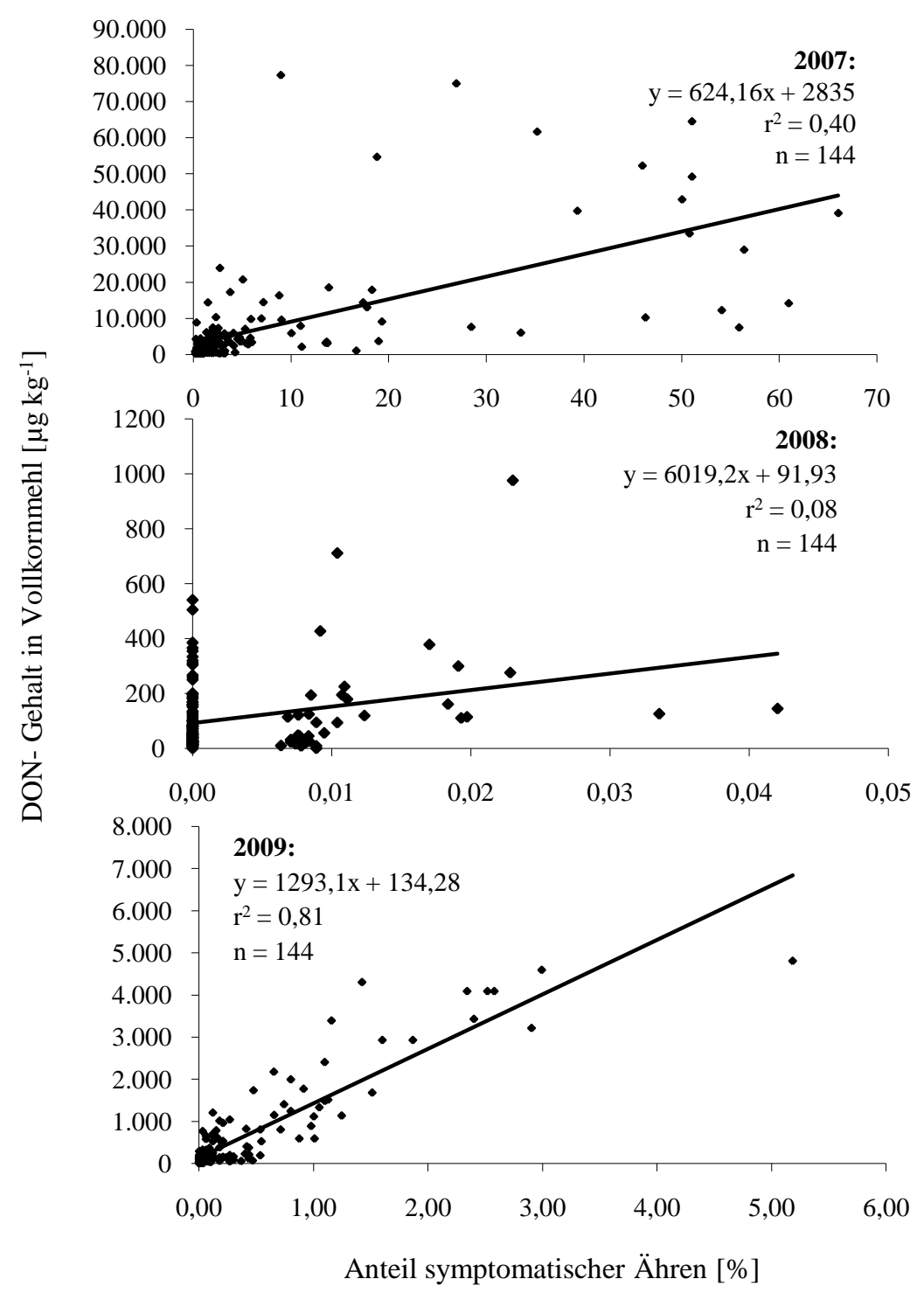

Abb. 13 Vergleich der Beziehung zwischen der Befallshäufigkeit [\% symptomatischer Ährchen pro $\mathrm{m}^{2}$ ] mit Fusariosen infizierter Ähren und den Deoxynivalenolgehalten der entsprechenden Getreideproben der Standorte Torland und Gladebeck $(n=144)$ in Südniedersachsen in den Versuchsjahren 2007-2009. Für die Regressionsgerade wurde ein lineares Modell angenommen.

\subsubsection{Deoxynivalenolgehalte}

Die Varianzanalyse aller fünf Versuchsfaktoren und ihrer Interaktionen im FAEN Versuch (Tab. 4) zeigte, dass jeder einzelne Faktor (Jahr, Ort, Vorfrucht, Sorte und Fungizid) über den gesamten Versuchszeitraum einen höchst signifikanten Einfluss $(\mathrm{p} \leq 0,001)$ auf den DONGehalt des Ernteguts hatte. Auf Grund dieser starken Einflüsse der Versuchsfaktoren, wurden auch signifikante Effekte von einem Großteil der daraus resultierenden Interaktionen berechnet. Da die Ursachen mehrfaktorieller Interaktionseffekte nur schwer darstellbar sind, werden im Rahmen dieser Arbeit nur einige dieser Effekte aufgegriffen und erklärt. 


\section{Gesamtvarianzanalyse über alle drei Versuchsjahre}

Tab. 4 Varianzanalyse des FAEN-Versuches für die Mykotoxingehalt über die Versuchsjahre 2007-2009. Die Daten wurden untransformiert als Mixed Model verrechnet. Dargestellt sind die fünf Versuchsfaktoren und die daraus resultierenden Interaktionskomponenten. Effekte sind signifikant bei einem Wert $\mathbf{p} \leq$ 0,05 (hoch signifikant bei $p \leq 0,01$, höchst signifikant bei $p \leq 0,001$ ).

\begin{tabular}{|c|c|c|c|}
\hline Effekt & Freiheitsgrad & F-Wert & $\mathrm{p}$-Wert \\
\hline $\operatorname{Ort}(\mathrm{O})$ & 1 & 87,81 & $<0,0001$ \\
\hline $\operatorname{Jahr}(\mathrm{J})$ & 2 & 419,84 & $<0,0001$ \\
\hline Ort*Jahr & 2 & 107,51 & $<0,0001$ \\
\hline Vorfrucht (Vf) & 2 & 163,81 & $<0,0001$ \\
\hline Ort*Vorfrucht & 2 & 74,13 & $<0,0001$ \\
\hline Jahr*Vorfrucht & 4 & 210,69 & $<0,0001$ \\
\hline $\mathrm{O} * \mathrm{~J} * \mathrm{Vf}$ & 4 & 98,78 & $<0,0001$ \\
\hline Sorte $(\mathrm{S})$ & 1 & 242,47 & $<0,0001$ \\
\hline Ort*Sorte & 1 & 50,29 & $<0,0001$ \\
\hline Jahr*Sorte & 2 & 183,20 & $<0,0001$ \\
\hline $\mathrm{O} * \mathrm{~J} * \mathrm{~S}$ & 2 & 39,94 & $<0,0001$ \\
\hline Sorte*Vorfrucht & 2 & 104,19 & $<0,0001$ \\
\hline $\mathrm{O} * \mathrm{~S} * \mathrm{Vf}$ & 2 & 47,03 & $<0,0001$ \\
\hline$J * S * V f$ & 4 & 87,24 & $<0,0001$ \\
\hline $\mathrm{O} * \mathrm{~J} * \mathrm{~S} * \mathrm{Vf}$ & 4 & 42,44 & $<0,0001$ \\
\hline Fungizid (F) & 2 & 8,65 & 0,0002 \\
\hline Ort*Fungizid & 2 & 1,75 & 0,1751 \\
\hline Jahr*Fungizid & 4 & 6,09 & $<0,0001$ \\
\hline $\mathrm{O} * \mathrm{~J} * \mathrm{~F}$ & 4 & 1,46 & 0,2157 \\
\hline $\mathrm{Vf} * \mathrm{~F}$ & 4 & 4,37 & 0,0019 \\
\hline $\mathrm{O} * \mathrm{Vf} * \mathrm{~F}$ & 4 & 1,11 & 0,3522 \\
\hline $\mathrm{J} * \mathrm{Vf} * \mathrm{~F}$ & 8 & 3,67 & 0,0004 \\
\hline $\mathrm{O} * \mathrm{~J} * \mathrm{Vf} * \mathrm{~F}$ & 8 & 1,21 & 0,2924 \\
\hline Sorte*Fungizid & 2 & 4,98 & 0,0075 \\
\hline $\mathrm{O} * \mathrm{~S} * \mathrm{~F}$ & 2 & 1,44 & 0,2386 \\
\hline $\mathrm{J} * \mathrm{~S} * \mathrm{~F}$ & 4 & 3,36 & 0,0103 \\
\hline $\mathrm{O} * \mathrm{~J} * \mathrm{~S} * \mathrm{~F}$ & 4 & 1,11 & 0,3536 \\
\hline$S * V f * F$ & 4 & 2,86 & 0,0236 \\
\hline $\mathrm{O} * \mathrm{~S} * \mathrm{Vf} * \mathrm{~F}$ & 4 & 1,07 & 0,3705 \\
\hline $\mathrm{J} * \mathrm{~S} * \mathrm{Vf} * \mathrm{~F}$ & 8 & 2,40 & 0,0158 \\
\hline $\mathrm{O} * \mathrm{~J} * \mathrm{~S} * \mathrm{Vf} * * \mathrm{~F}$ & 8 & 1,12 & 0,3463 \\
\hline
\end{tabular}




\section{Varianzkomponentenanalyse aller Versuchsfaktoren über alle Versuchsjahre ohne Interakionen}

Tab. 5 Varianzkomponentenanalyse der Mykotoxingehalte im FAEN Feldversuch 2007-2009, geschätzt nach dem „Restricted Maximum-Likelihood“ (REML) Modell. Dargestellt sind die einzelnen Versuchsfaktoren mit ihren jeweiligen Anteilen an der Gesamtvarianz der Mykotoxingehalte im Erntegut.

\begin{tabular}{lcc} 
Varianzkomponente & Geschätzte Varianz & Anteil an der Gesamtvarianz [\%] \\
\hline Jahr (J) & 19,79 & 19,71 \\
Vorfrucht (Vf) & 11,72 & 11,67 \\
Sorte (S) & 7,51 & 7,48 \\
Ort (O) & 4,07 & 4,05 \\
Fungizid (F) & 0,02 & 0,02 \\
Fehler & 57,35 & 57,08 \\
\hline Gesamt & 100,47 & 100
\end{tabular}

Über die Größe des F-Wertes (Tab. 4), kann der Einfluss des Versuchsfaktors auf die Gesamtvariation nur grob abgeleitet werden. Eine genauere Bewertung der einzelnen Faktoren bietet jedoch eine Varianzkomponentenanalyse. Trotz eines höheren F-Wertes des Faktors Sorte im Vergleich zur Vorfrucht ist der prozentuale Anteil der Vorfrucht an der Gesamtvarianz deutlich größer, was aufgrund verschiedener mathematischer Berechnungen nicht ungewöhnlich ist (Kluth, 2010).

Der Anteil jedes einzelnen Faktors wurde in Tab. 5 hierarchisch nach seinem Komponentenanteil dargestellt. Es zeigte sich, dass z.B. ein Versuchsfaktor wie das Fungizid, trotz seines signifikanten Effekts bei der Varianzanalyse, nur einen äußerst geringen Anteil an der Gesamtvarianz des DON-Gehaltes besaß. Im Gegensatz dazu waren im Feldversuch das Jahr, die Vorfrucht, die Sorte und der Ort bedeutende Varianzkomponenten. Mit Hilfe dieser vier Faktoren war es möglich ca. 40\% der Gesamtvariation des DON-Gehaltes zu erklären.

Varianzkomponentenanalyse der Versuchsfaktoren innerhalb jedes Versuchsjahres ohne Interaktionen

Parallelen in der Bedeutung und der Größe der einzelnen Varianzkomponenten konnten in den Versuchsjahren 2007 und 2009 festgestellt werden. In beiden Fällen hatte jeweils die Vorfrucht mit ca. 30\% den größten Anteil an der Gesamtvarianz, gefolgt von den Sorteneffekten (ca. 20\%) und den Standorteffekten mit ca. 10\%. Diese Komponentengrößen verringerten sich im Versuchsjahr 2008 für die Vorfrucht auf nur noch ca. 8\% und für den Standort auf ca. 
1\%. Im Gegensatz dazu, stieg der Anteil des Sorteneffektes in diesem Jahr auf bis zu 50\% an. Den geringsten Anteil an der Gesamtvarianz hatte in jedem einzelnen Versuchsjahr der Versuchsfaktor Fungizid, einzig im Versuchsjahr 2009 konnte dieser Effekt auf mehr als 1\% ansteigen.

Tab. 6 Varianzkomponentenanalyse der Mykotoxingehalte im FAEN Feldversuch für jedes einzelne Versuchsjahr (2007, 2008 und 2009), geschätzt nach dem „Restricted Maximum-Likelihood“ (REML) Modell. Dargestellt sind die einzelnen Versuchsfaktoren mit ihren jeweiligen Anteilen an der Gesamtvarianz der Mykotoxingehalte im Erntegut.

\begin{tabular}{lccc}
\multirow{2}{*}{ Varianzkomponente } & \multicolumn{3}{c}{ Anteil an der Gesamtvarianz [\%] } \\
& 2007 & 2008 & 2009 \\
\hline Vorfrucht (Vf) & 32,91 & 7,69 & 26,65 \\
Sorte (S) & 19,74 & 46,77 & 24,86 \\
Ort (O) & 11,14 & 1,04 & 14,51 \\
Fungizid (F) & 0,28 & 0,15 & 2,11 \\
Fehler & 35,94 & 44,35 & 31,87 \\
\hline Gesamt & 100 & 100 & 100
\end{tabular}

Der Vergleich der DON-Mittelwerte der verschiedenen Versuchsfaktoren (Tab. 7) bestätigte die in der Varianzkomponentenanalyse berechneten Effekte. Signifikante Unterschiede traten z.B. zwischen den Versuchsjahren 2007 und 2008 bzw. 2009 auf. In Folge der hohen durchschnittlichen Mykotoxingehalte im Versuchsjahr 2007 waren hier die Differenzierungen zwischen den einzelnen Versuchsparametern sehr klar zu sehen. Signifikante Effekte der Standorte, der Vorfruchtvarianten, der Fungizidapplikationen und der Sorten konnten hier festgestellt werden. Diese Unterschiede traten in den Jahren 2008 und 2009 mit minimalen und mittleren Mykotoxinkontaminationen nicht auf, nur tendenzielle Effekte der einzelnen Versuchsfaktoren konnten ermittelt werden.

Zur Verdeutlichung des Einflusses einzelner Effekte auf den Mykotoxingehalt wurden in Tabelle 8 die Faktoreffekte nach der Methode von Koch et al. (2002) für einige Versuchsfaktoren und deren Interaktionen berechnet. Dabei wiesen erwartungsgemäß die Vergleiche der drei Versuchsjahre die höchsten Faktoreffekte des gesamten Feldversuches auf, was somit die Ergebnisse der Varianzkomponentenanalyse bestätigte. 
Tab. 7 Varianzanalytische Untersuchung der Einflussfaktoren der Mykotoxingehalte [ $\mu \mathrm{g}$ DON kg ${ }^{-1}$ Mehl] in den Jahren 2007-2009 im FAEN-Versuch. Aufgeführt sind die Mittelwerte der DON-Gehalte, in Abhängigkeit von der Vorfrucht (n = 48), des Standortes(T: Torland, G: Gladebeck) (n = 72), der Sorte(C: Centrum, R: Ritmo) (n $=72$ ), der Fungizide $(n=48)$ und der Jahre $(n=144)$. Unterschiedliche Buchstaben desselben Typs kennzeichnen signifikante Unterschiede der jeweiligen Versuchsfaktoren zwischen den drei Versuchsjahren (Tukey Test mit $\mathbf{p} \leq \mathbf{0 , 0 5}$ ).

\begin{tabular}{|c|c|c|c|c|c|c|c|c|c|c|c|}
\hline \multirow{2}{*}{ Jahr } & \multirow{2}{*}{ Standort } & \multicolumn{3}{|c|}{ Vorfrucht } & \multirow{2}{*}{$\begin{array}{c}\text { Mittelwert des } \\
\text { Standortes }\end{array}$} & \multirow{2}{*}{ Sorte } & \multicolumn{3}{|c|}{ Fungizid } & \multirow{2}{*}{$\begin{array}{l}\text { Mittelwert } \\
\text { der Sorte }\end{array}$} & \multirow{2}{*}{$\begin{array}{l}\text { Mittelwert } \\
\text { des Jahres }\end{array}$} \\
\hline & & $\mathrm{ZR}$ & WW & M & & & Strobilurin & Triazol & Neutral & & \\
\hline \multirow{3}{*}{2007} & $\mathrm{~T}$ & 2485 & 2892 & 31325 & $12234 \mathbf{Z}$ & $\mathrm{C}$ & 3115 & 2265 & 2873 & $2751 \mathbf{y}$ & \multirow{2}{*}{$8144 \boldsymbol{\alpha}$} \\
\hline & G & 2145 & 2339 & 7678 & $4054 \mathbf{Y}$ & $\mathrm{R}$ & 16338 & 10357 & 13919 & $13538 \mathbf{z}$ & \\
\hline & $\begin{array}{l}\text { Vorfrucht- } \\
\text { mittelwert }\end{array}$ & $2315 \mathbf{B}$ & $2616 \mathbf{B}$ & $19501 \mathbf{A}$ & & $\begin{array}{l}\text { Fungizid- } \\
\text { mittelwert }\end{array}$ & $9726 \mathbf{a}$ & $6311 \mathbf{b}$ & $8396 \mathbf{a}$ & & \\
\hline \multirow{3}{*}{2008} & $\mathrm{~T}$ & 73 & 106 & 111 & $97 \mathbf{X}$ & $\mathrm{C}$ & 32 & 27 & 32 & $31 \mathbf{x}$ & \multirow{2}{*}{$110 \boldsymbol{\beta}$} \\
\hline & G & 80 & 221 & 70 & $123 X$ & $\mathrm{R}$ & 187 & 158 & 219 & $188 \mathbf{x}$ & \\
\hline & $\begin{array}{l}\text { Vorfrucht- } \\
\text { mittelwert }\end{array}$ & $77 \mathrm{C}$ & $164 \mathrm{C}$ & $89 \mathrm{C}$ & & $\begin{array}{l}\text { Fungizid- } \\
\text { mittelwert }\end{array}$ & $111 \mathrm{c}$ & $94 \mathrm{c}$ & $126 \mathrm{c}$ & & \multirow{4}{*}{$638 \boldsymbol{\beta}$} \\
\hline \multirow{3}{*}{2009} & $\mathrm{~T}$ & 104 & 785 & 2045 & $978 \mathbf{X}$ & $\mathrm{C}$ & 211 & 157 & 217 & $195 \mathbf{x}$ & \\
\hline & G & 79 & 143 & 669 & $297 \mathbf{X}$ & $\mathrm{R}$ & 1378 & 648 & 1215 & $1080 \mathbf{x}$ & \\
\hline & $\begin{array}{l}\text { Vorfrucht- } \\
\text { mittelwert }\end{array}$ & $91 \mathrm{C}$ & $464 \mathrm{C}$ & $1357 \mathbf{B C}$ & & $\begin{array}{l}\text { Fungizid- } \\
\text { mittelwert }\end{array}$ & 795 c & $403 \mathrm{c}$ & $716 \mathrm{c}$ & & \\
\hline
\end{tabular}


Tab. 8 Einfluss der Versuchsparameter Jahr (2007 -2009), Standort (Torland, Gladebeck), Vorfrucht (Mais: M, Winterweizen: WW, Zuckerrübe:ZR), Sorte (Ritmo, Centrum) und Fungizid (Triazol, Strobilurin, Neutral) und deren Interaktionen auf den Mykotoxingehalt in den Versuchsjahren 2007 2009. Die dimensionslosen Faktoreffekte ergeben sich aus der Divison der Mittelwerte der Mykotoxingehalte der miteinander verglichenen Versuchsvarianten.

\begin{tabular}{|c|c|c|c|c|}
\hline \multirow{2}{*}{ Faktoren } & & \multicolumn{2}{|c|}{ Mittelwerte } & \multirow{2}{*}{ Faktoreffekt } \\
\hline & & Zähler & Nenner & \\
\hline \multirow{3}{*}{ Jahr } & & 2007 & 2008 & 74,0 \\
\hline & & 2007 & 2009 & 12,8 \\
\hline & & 2009 & 2008 & 5,8 \\
\hline \multirow{3}{*}{$\begin{array}{l}\text { Jahr* } \\
\text { Standort }\end{array}$} & 2007 & Torland & Gladebeck & 3,0 \\
\hline & 2008 & Torland & Gladebeck & 0,8 \\
\hline & 2009 & Torland & Gladebeck & 3,3 \\
\hline \multirow{6}{*}{$\begin{array}{l}\text { Jahr* } \\
\text { Vorfrucht }\end{array}$} & \multirow{2}{*}{2007} & $\mathrm{M}$ & ZR & 8,4 \\
\hline & & WW & ZR & 1,1 \\
\hline & \multirow{2}{*}{2008} & M & ZR & 1,1 \\
\hline & & WW & $\mathrm{ZR}$ & 2,1 \\
\hline & \multirow{2}{*}{2009} & M & ZR & 14,9 \\
\hline & & WW & $\mathrm{ZR}$ & 5,1 \\
\hline \multirow{6}{*}{$\begin{array}{l}\text { Jahr* } \\
\text { Fungizid }\end{array}$} & \multirow{2}{*}{2007} & Strobilurin & Triazol & 1,5 \\
\hline & & Neutral & Triazol & 1,3 \\
\hline & \multirow{2}{*}{2008} & Strobilurin & Triazol & 1,2 \\
\hline & & Neutral & Triazol & 1,3 \\
\hline & \multirow{2}{*}{2009} & Strobilurin & Triazol & 1,9 \\
\hline & & Neutral & Triazol & 1,8 \\
\hline \multirow{4}{*}{$\begin{array}{l}\text { Sorte* } \\
\text { Fungizid }\end{array}$} & \multirow{2}{*}{ Ritmo } & Strobilurin & Triazol & 1,6 \\
\hline & & Neutral & Triazol & 1,4 \\
\hline & \multirow{2}{*}{ Centrum } & Strobilurin & Triazol & 1,4 \\
\hline & & Neutral & Triazol & 1,3 \\
\hline
\end{tabular}

Die Versuchsfaktoren mit den nächstgrößten Effekten auf den mittleren DON-Gehalt im FAEN-Versuch waren die Vorfrucht und der Standort (Tab. 8). Unter natürlichen Befallsbe- 
dingungen wies dabei der Standort Torland in den Jahren 2007 und 2009 jeweils einen ca. dreimal höheren Mykotoxingehalt als der Standort Gladebeck auf. Im Gegensatz dazu traten in den drei Vorfruchtvarianten Interaktionen mit den jeweiligen Jahren auf. In einem Starkbefallsjahr wie 2007 wurden keine Unterschiede zwischen den Vorfruchtvarianten Zuckerrübe und Winterweizen hinsichtlich der Mykotoxinbelastungen im Getreide festgestellt, was im Jahr 2009 deutlich sichtbar wurde. Darüber hinaus war der Unterschied der Mykotoxingehalten zwischen den Vorfruchtvarianten Zuckerrübe und Mais mit 8,4 in einem Starkbefallsjahr nur etwa halb so groß wie in einem Jahr mit mittlerem Befall wie 2009. In diesem Fall lag der Faktoreffekt bei 15,4. Unabhängig von den jeweiligen Jahreseffekten wurden in den Fugizidvarianten Strobilurin und Neutral ca. 1,3-1,9-fach höhere Mykotoxingehalte als in den Triazolvarianten gemessen. Die Kombination aus der anfälligen Sorte Ritmo und einer Fungizidapplikation mit Strobilurinen neigte $\mathrm{zu}$ tendenziell höheren Mykotoxingehalten, als alle anderen Sorten x Fungizid Kombinationen.

\subsubsection{Spezifische Mykotoxinbildung}

Das Versuchsjahr 2007 bot günstige Witterungsbedingungen für einen Starkbefall mit $F$. graminearum im FAEN-Versuch. In den Proben aller Versuchsvarianten waren detektierbare Mengen von Mykotoxinen und pilzlicher DNA messbar, so dass die spezifische Mykotoxinbildung unter Annahme der Normalverteilung der Residuen mit einem MixedModell für den vierfaktoriellen FAEN-Versuch bestimmt werden konnte. Dies war in den Versuchsjahren 2008 und 2009 in den Vorfruchtvarianten Winterweizen, Ölrettich und Zuckerrübe auf Grund eines zu geringen natürlichen Befalls nicht möglich.

Die vollständige Varianzanalyse der vier Versuchsfakoren und deren Interaktionen zeigte einen signifikanten Einfluss des Ortes, der Vorfrucht und der Sorte auf die spezifische Mykotoxinbildung im Erntegut. Für die Fungizidapplikation konnte kein signifikanter Einfluss ermittelt werden (Tab. 9). Zur Bewertung der einzelnen Versuchsfaktoren und ihrer jeweiligen Anteile an der Gesamtvarianz der spezifischen Mykotoxinbildung wurde ebenfalls eine Komponentenanalyse durchgeführt. Bedeutendster Faktor im Versuchsjahr 2007 war der Ort, mit ca. 30\% Anteil an der Gesamtvariation auf die Vorfrucht und die Sorte entfielen zusammen weitere $10 \%$, so dass ca. $40 \%$ der Gesamtvariation der spezifischen Mykotoxinbildung von diesen drei Faktoren bestimmt wurden. Erwartungsgemäß konnten für die Fungizidapplikation keine messbaren Einflüsse ermittelt werden (Tab.10). 
Tab. 9 VollständigeVarianzanalyse der spezifischen Mykotoxinbildung im FAEN-Versuch 2007. Die Daten wurden untransformiert als Mixed Model verrechnet. Dargestellt sind die vier Versuchsfaktoren (Ort, Vorfrucht, Sorte und Fungizid) und die daraus resultierenden Interaktionskomponenten. Effekte sind signifikant bei einem Wert $p \leq 0,05$ (hoch signifikant bei $p \leq 0,01$, höchst signifikant bei $p \leq 0,001$ ).

\begin{tabular}{cccc} 
Effekt & Freiheitsgrad & F-Wert & p-Wert \\
\hline Ort $(\mathrm{O})$ & 1 & 16,43 & 0,0066 \\
Vorfrucht $(\mathrm{Vf})$ & 2 & 5,60 & 0,0190 \\
Ort*Vorfrucht & 2 & 2,67 & 0,1094 \\
Sorte $(\mathrm{S})$ & 1 & 4,85 & 0,0408 \\
Ort*Sorte & 1 & 1,78 & 0,1989 \\
Sorte*Vorfrucht & 2 & 2,43 & 0,1159 \\
$\mathrm{O} * \mathrm{~S} * \mathrm{Vf}$ & 2 & 3,05 & 0,0718 \\
Fungizid $(\mathrm{F})$ & 2 & 0,65 & 0,5244 \\
Ort*Fungizid & 2 & 2,99 & 0,0567 \\
Vorfrucht*Fungizid & 4 & 0,74 & 0,5648 \\
$\mathrm{O} * \mathrm{Vf} * \mathrm{~F}$ & 4 & 0,17 & 0,9534 \\
Sorte*Fungizid & 2 & 0,02 & 0,9779 \\
$\mathrm{O} * \mathrm{~S} * \mathrm{~F}$ & 2 & 0,02 & 0,9841 \\
$\mathrm{~S} * \mathrm{Vf} * \mathrm{~F}$ & 4 & 0,84 & 0,5047 \\
$\mathrm{O} * \mathrm{~S} * \mathrm{Vf} * \mathrm{~F}$ & 4 & 0,36 & 0,8330 \\
\hline
\end{tabular}

Tab. 10 Varianzkomponentenanalyse der spezifische Mykotoxinbildung im Versuchsjahr 2007 im FAEN Feldversuch, geschätzt nach dem Restringierten Maximum-Likelihood (REML) Modell. Dargestellt sind die einzelnen Versuchsfaktoren mit ihren jeweiligen Anteilen an der Gesamtvarianz der Mykotoxingehalte im Erntegut

\begin{tabular}{lcc} 
Varianzkomponente & GeschätzteVarianz & Anteil an der Gesamtvarianz [\%] \\
\hline Ort & 13,15 & 28,69 \\
Vorfrucht & 3,94 & 8,60 \\
Sorte & 1,49 & 3,27 \\
Fungizid & 0 & 0 \\
Fehler & 27,26 & 59,44 \\
\hline Gesamtvarianz & 45,85 & 100
\end{tabular}

Der varianzanalytische Vergleich der Mittelwerte der spezifischen Mykotoxinbildung bestätigt diese Ergebnisse. Signifikante Unterschiede waren zwischen den Standorten messbar, wobei der Standort Torland eine nahezu doppelt so hohe spezifische Mykotoxinbildung auf- 
wies wie der Standort Gladebeck (Tab. 11). Ähnlich hohe Differenzen wurden zwischen den Vorfruchtvarianten festgestellt, die Mykotoxinbildung in den Vorfrüchten Mais und Zuckerrübe war signifikant höher als in der Variante Winterweizen. Die gegenüber Ährenfusariosen weniger anfällige Sorte Centrum verringerte überdies signifikant die spezifische Mykotoxinbildung im Vergleich zur anfälligeren Sorte Ritmo.

Tab. 11 Varianzanalytische Untersuchung der spezifischen Mykotoxinbildung [ $\mu$ g DON pro $\mu$ g $F$. graminearum DNA] im FAEN-Versuch 2007. Aufgeführt sind die Mittelwerte der spezifischen Mykotoxinbildung, in Abhängigkeit von der Vorfrucht $(n=48)$, des Standortes: (T: Torland, G: Gladebeck) $(n=72)$, der Sorte $(C$ : Centrum, R: Ritmo) $(n=72)$ und der Fungizide $(n=48)$ Unterschiedliche Buchstaben desselben Typs kennzeichnen signifikante Unterschiede zwischen den jeweiligen Versuchsfaktoren und deren Interaktionen (Tukey Test mit $\mathbf{p} \leq \mathbf{0 , 0 5}$ ).

\begin{tabular}{|c|c|c|c|c|c|c|}
\hline \multirow{2}{*}{ Jahr } & \multirow{2}{*}{ Standort } & \multicolumn{3}{|c|}{ Vorfrucht } & \multirow{2}{*}{$\begin{array}{c}\text { Mittelwert des } \\
\text { Standortes }\end{array}$} & \multirow{2}{*}{$\begin{array}{l}\text { Mittelwert } \\
\text { des Jahres }\end{array}$} \\
\hline & & $\mathrm{ZR}$ & WW & $\mathrm{M}$ & & \\
\hline & $\mathrm{T}$ & $11,83 \mathbf{g}$ & $5,61 \mathrm{~h}$ & $11,81 \mathbf{g}$ & $9,75 \mathbf{x}$ & \\
\hline & $\mathrm{G}$ & $4,68 \mathbf{h}$ & $3,82 \mathbf{h}$ & $5,17 \mathbf{h}$ & $4,57 \mathbf{y}$ & \\
\hline & $\begin{array}{l}\text { Vorfrucht- } \\
\text { mittelwert }\end{array}$ & $8,25 \mathbf{a}$ & $4,74 \mathbf{b}$ & $8,49 \mathbf{a}$ & & \\
\hline
\end{tabular}

2007

\begin{tabular}{|c|c|c|c|c|}
\hline \multirow{2}{*}{ Sorte } & \multicolumn{3}{|c|}{ Fungizid } & \multirow{2}{*}{$\begin{array}{c}\text { Mittelwert der } \\
\text { Sorten }\end{array}$} \\
\hline & Strobilurin & Triazol & Neutral & \\
\hline $\mathrm{C}$ & $5,94 \mathbf{G}$ & $6,80 \mathbf{G}$ & $5,81 \mathbf{G}$ & $6,18 \mathbf{X}$ \\
\hline $\mathrm{R}$ & $8,31 \mathbf{G}$ & $8,70 \mathbf{G}$ & $7,57 \mathbf{G}$ & $8,19 \mathbf{Y}$ \\
\hline $\begin{array}{l}\text { Fungizid- } \\
\text { nittelwert }\end{array}$ & $7,09 \mathbf{A}$ & 7,75 A & $6,69 \mathbf{A}$ & \\
\hline
\end{tabular}

Im Versuchsjahr 2009 lagen nur in der Vorfruchtvariante Mais am Standort Torland für alle Versuchsfaktoren detektierbe Mykotoxin- und F. graminearum-DNA Werte unter natürlichen Befallsbedingungen oberhalb der Nachweisgrenze vor. Somit war ein Vergleich der Zusammenhänge zwischen der Pilzbiomase von F. graminearum und den entsprechenden DONGehalten für einen Versuchsfaktor des FAEN-Versuches zwischen dem Starkbefallsjahr 2007 und einem weiteren Jahr möglich. Unterschiedliche Achsenskalierungen waren notwendig um das Befallsgeschehen der beiden Jahre abzubilden. Trotzdem zeigten die ermittelten Bestimmtheitsmaße beider Jahre $\left(\mathrm{r}^{2}>0,80\right)$ unabhängig von den Jahreseffekten einen für Feldversuche sehr engen Zusammenhang zwischen dem DNA- und dem DON-Gehalt (Abb.14). Beim Vergleich der Steigungen der Regressionsgeraden zeigten sich jedoch deutliche Unterschiede. In Jahren mit geringem Fusariumbefall scheint die spezifische Mykotoxinbildung 
höher zu liegen als in Jahren mit einem Starkbefall. Hierbei muss aber berücksichtigt werden, dass die DNA-Mengen deutlich geringer waren, d.h. die DON-Produktion pro Einheit Pilzbiomasse war im Jahr 2009 nahezu doppelt so hoch wie im Jahr 2007, bei einer absoluten Mykotoxinkontamination die etwa 90\% geringer war.
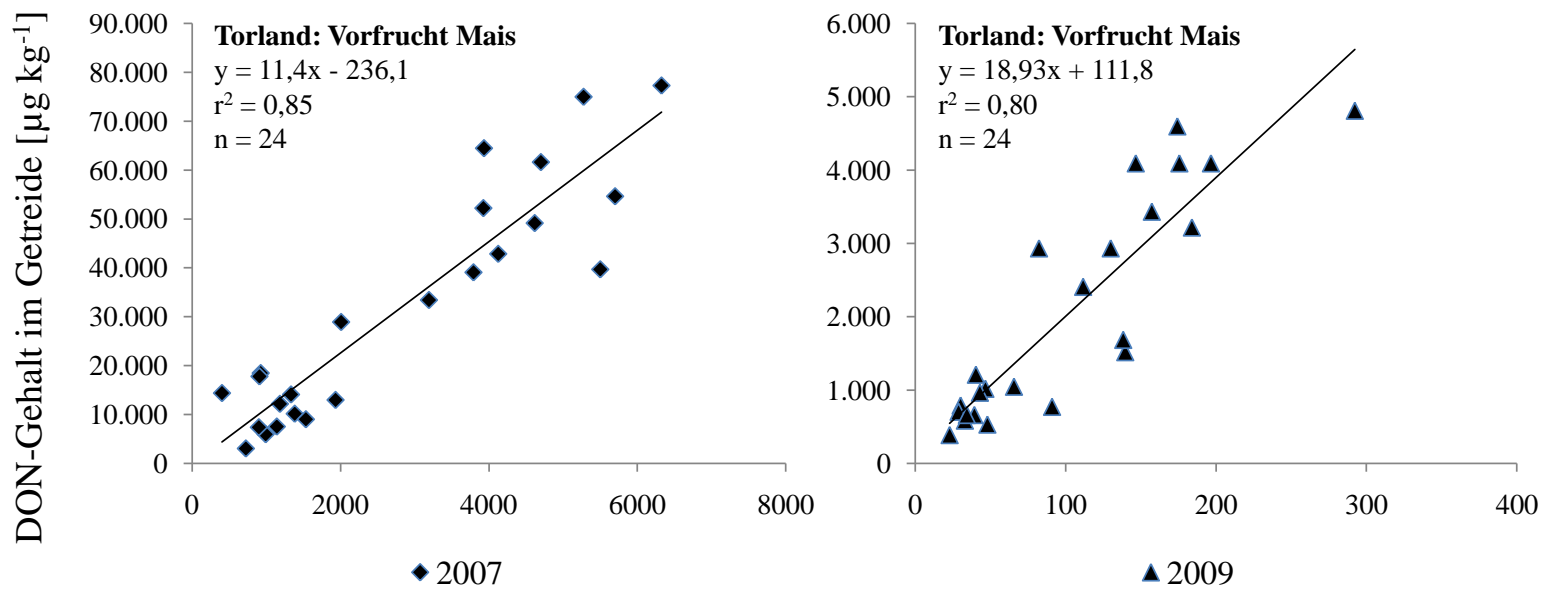

F. graminearum Pilzbiomasse [ $\mu \mathrm{g}$ DNA kg-1]

Abb. 14 Vergleich der Beziehung zwischen der Pilzbiomasse von $F$. graminearum $\left[\mu \mathrm{kg}^{-1}\right.$ ] mit den DONGehalten in den entsprechenden Getreideproben $\left[\mu \mathrm{g} \mathrm{kg}^{-1}\right]$ am Standort Torland in der Vorfruchtvariante Mais $(n=24)$ in den Versuchsjahren 2007 und 2009. Die Fusariumfektionen traten unter natürlichen Befallsbedingungen auf. Für die Regressionsgerade wurde ein lineares Modell angenommen.

\subsubsection{Artenspektrum von Fusarium spp.}

Im Starkbefallsjahr 2007 gehörten über 70\% aller von Getreidekörnern isolierten Pilze der Gattung Fusarium spp. an (Tab. 12). Zwischen den einzelnen Vorfruchtvarianten konnte in 2007 und 2009 eine klare Differenzierung zwischen den Getreideproben der Vorfrucht Mais mit einem Anteil von 90\% (2007) und 50\% (2009) an F. graminearum und den beiden übrigen Vorfruchtvarianten festgestellt werden, wo dieser Anteil geringer war. Die Pilzpopulationen der Varianten Winterweizen und Zuckerrübe ähnelten sich im Versuchsjahr 2007 (ca. 50\% F. graminearum in 2007) und zeigten beide eine größere Vielfalt an Fusarium spp. im Vergleich zur Variante Mais. Beide Varianten unterschieden sich jedoch im Versuchsjahr 2009 sehr stark voneinander, wo ein Anstieg des Anteils saprophytischer Schwärzepilze (Alternaria spp., Epicoccum spp., Cladosporium spp.) besonders in den Proben der Vorfrucht Zuckerrübe auf über 70\% beobachtet wurde. Im Jahr 2008 konnten aufgrund des geringen Befalls mit Fusarium spp. fast ausschließlich Schwärzepilze identifiziert werden, eine Differenzierung zwischen den Vorfruchtvarianten war nicht möglich. 
Tab. 12 Besiedlung von Weizenkörnern mit Fusarium spp. und anderen saprophytischen Pilzen in Abhängigkeit von den Vorfrüchten Zuckerrübe, Winterweizen und Mais in den Versuchsjahren 2007-2009, Versuchsstandort Torland bei Göttingen. Die Anzahl isolierter Pilzstämme in jeder Variante wurde unabhängig von der Befallshäufigkeit gleich $100 \%$ gesetzt, die prozentualen Anteile der jeweiligen Spezies beziehen sich auf diese Bezugsgröße.

\begin{tabular}{l|ccc|ccc|ccc} 
& \multicolumn{3}{|c|}{ Torland 2007 } & \multicolumn{3}{c|}{ Torland 2008 } & \multicolumn{3}{c}{ Torland 2009 } \\
& M & WW & ZR & M & WW & ZR & M & WW & ZR \\
\hline F. graminearum & 90,6 & 48,0 & 57,9 & & 2,9 & 4,8 & 51,4 & 33,9 & 11,3 \\
F. culmorum & 1,9 & 10,0 & 7,9 & & & & & & \\
F. tricinctum & & 6,0 & 5,3 & & 5,9 & 3,2 & 2,9 & 4,8 & 3,2 \\
F. compactum & & & 2,6 & & & & & & \\
F. poae & & 2,0 & & 5,0 & 2,9 & & 1,4 & & \\
F. avenacaeum & & 6,0 & 2,6 & & & & & & 3,2 \\
Fusarium spp. & & 2,0 & 2,6 & & 1,5 & & & & 3,2 \\
M. nivale & & 2,0 & & & & & & 1,6 & 1,6 \\
Unbekannt & 1,9 & & & 10,0 & 11,8 & 7,9 & 2,9 & 6,5 & 4,8 \\
$\begin{array}{l}\text { Alternaria spp./ } \\
\text { Epicoccum spp./ }\end{array}$ & 5,7 & 24,0 & 21,1 & 85,0 & 75,0 & 84,1 & 41,4 & 53,2 & 72,6 \\
Cladosporium spp. & & & & & & & & & \\
\hline Anzahl Körner (n) & 72 & 72 & 72 & 120 & 120 & 120 & 120 & 120 & 120 \\
Befallshäufigkeit (\%) & 73 & 69 & 53 & 33 & 56 & 52 & 58 & 52 & 52
\end{tabular}

\subsubsection{Fungizidrestmengen in Weizenährchen}

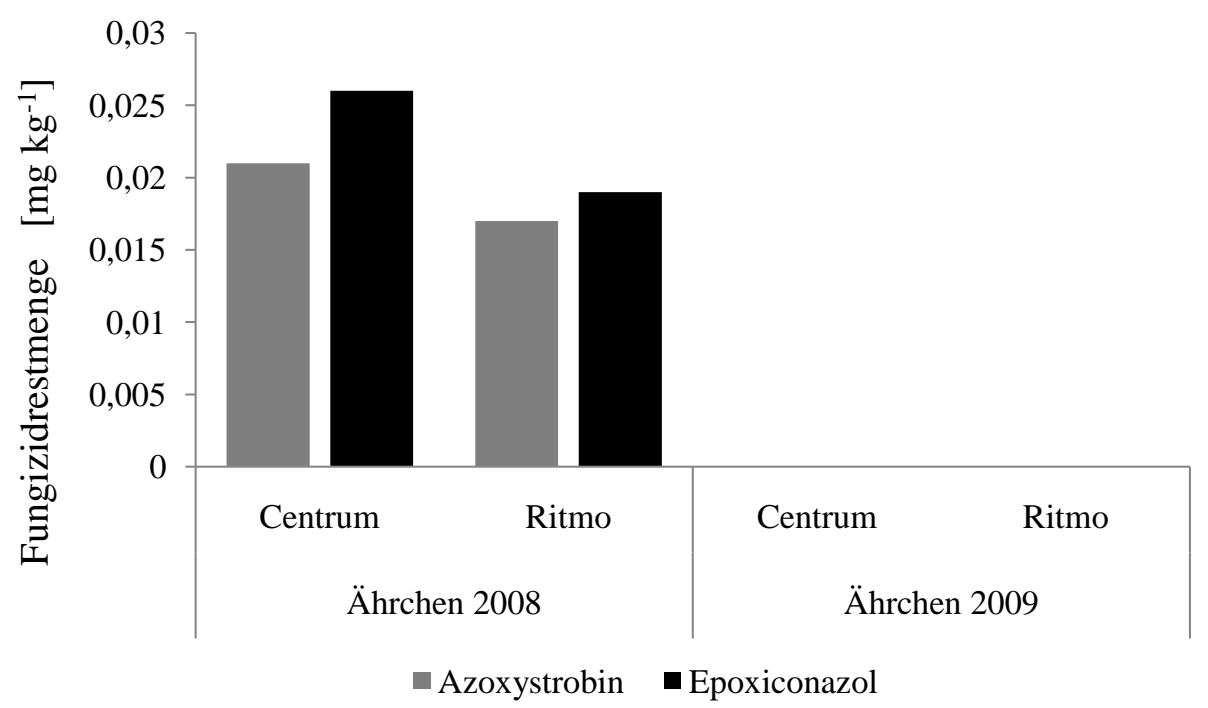

Abb. 15 Fungizide Restmengen [mg kg-1] von Azoxystrobin und Epoxiconazol im Gewebe der geernteten Ährchen aus der Vorfruchtvariante Zuckerrübe des FAEN-Versuchs. Die Probennahme erfolgte 200824 Tage und 200927 Tage nach der letzten Fungizidapplikation zum Zeitpunkt der Vollblüte BBCH 65 (n = 1; gepoolt aus je $50 \mathrm{~g}$ Ährchenmaterial aller vier Wiederholungen) 
Bei der Analyse der fungiziden Restmengen zum Zeitpunkt der Vollblüte in den Ährchen der beiden Winterweizensorten Centrum und Ritmo der Vorfruchtvariante Zuckerrübe im FAENVersuch konnten nur im Probennahmejahr 2008 detektierbare Mengen durch die LUFA NordWest nachgewiesen werden. Die Konzentration des Wirkstoffs Epoxiconazol lag mit 0,020$0,025 \mathrm{mg} \mathrm{kg}^{-1} \mathrm{FM}$ in beiden Sorten tendenziell etwas höher als der Wirkstoff Azoxystrobin. Überdies wurden in der Sorte Centrum höhere Rückstandsmengen gemessen als in der Sorte Ritmo. Im Versuchsjahr 2009 konnten in keiner der Proben fungizide Restmengen ermittelt werden (Abb. 15).

\subsection{Sortenversuch Wetze}

Unter künstlichen Infektionsbedingungen wurden im Versuch Wetze fünf Sorten und ihre Interaktionen mit drei verschiedenen Fungizidapplikationen untersucht. In Übereinstimmung mit den Resistenzeinstufungen des Bundessortenamtes konnte bei der Betrachtung der Beziehung zwischen der Feldbefallsstärke und dem DON-Gehalt eine klare Differenzierung zwischen den fünf angebauten Sorten beobachtet werden (Abb. 16). Das Bestimmtheitsmaß für eine mögliche Regressionsgrade $(y=1234 x+1825)$ über alle fünf Sorten war mit $r^{2}=0,70$ für einen Feldversuch sehr hoch.

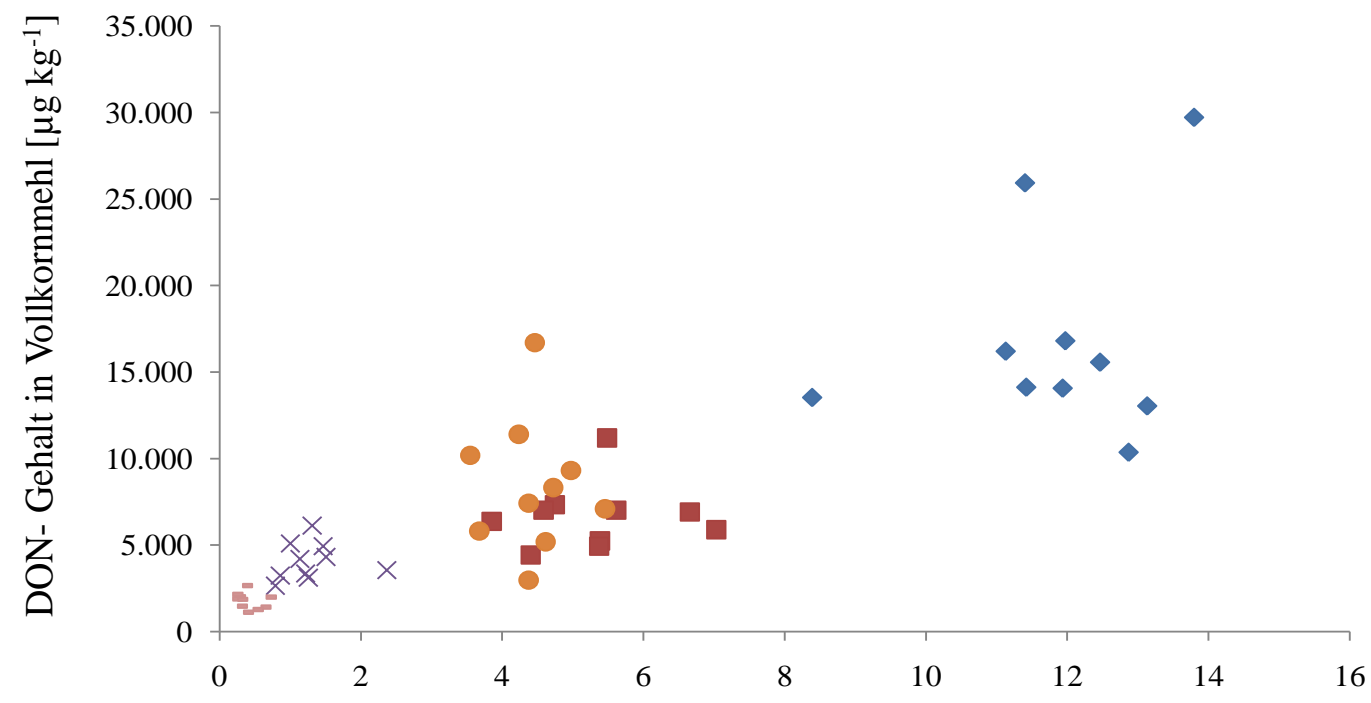

Feldbefallsstärke [FHB-Index in \%]

$\bullet$ Ritmo (7) Julius (5) $\quad \times$ KWS Erasmus (4) $\quad$ KWS Pius (5) - Centrum (2)

Abb. 16 Mykotoxinbelastung und Feldbefallsstärke im Feldversuch der KWS-Lochow GmbH in Abhängigkeit der fünf getesteten Sorten Ritmo, Julius, KWS Erasmus, KWS Pius und Centrum. Die Resistenzeinstufungen des Bundessortenamtes (BSA) gegenüber Ährenfusariosen stehen hinter den jeweiligen Sortennamen. Dargestellt ist auf der $x$-Achse die Feldbefallsstärke, der FHB-Index [\%] und auf der $y$-Achse der DON Gehalt $\left[\mu \mathrm{g} \mathrm{kg}^{-1}\right]$ 
Tab. 13 Analysen im Sortenversuch Wetze 2009. Aufgeführt ist der mittlere FHB Index der fünf Sorten (n $=20$ je Sorte) bei drei verschiedenen Fungizidapplikationen (Unbehandelt $\mathbf{n}=\mathbf{2 0}$, Triazol und Strobilurin $n=40$ ). Die Resistenzeinstufungen des Bundessortenamtes (BSA) gegenüber Ährenfusariosen stehen hinter den jeweiligen Sortennamen. Unterschiedliche Buchstaben desselben Typs kennzeichnen signifikante Unterschiede zwischen der jeweiligen Feldbefallsstärke der Sorten- bzw. der Fungizidmittelwerte (LSD Test mit $\mathbf{p} \leq \mathbf{0 , 0 5}$ ). Identische Varianzanalysen wurden für den Versuchsfaktor DON-Gehalt, DNA-Gehalt von $F$. culmorum und der spezifischen Mykotoxinbildung jeweils separat durchgeführt. Signifikante Unterschiede der jeweiligen Versuchsparameter wurden ebenfalls mit verschiedenen Buchstaben kenntlich gemacht.

\begin{tabular}{|c|c|c|c|c|c|}
\hline \multirow{2}{*}{ Parameter } & \multirow{2}{*}{ Sorte } & \multicolumn{3}{|c|}{ Fungizid } & \multirow{2}{*}{$\begin{array}{c}\text { Mittelwert der } \\
\text { Sorte }\end{array}$} \\
\hline & & Strobilurin & Triazol & Unbehandelt & \\
\hline \multirow{6}{*}{ 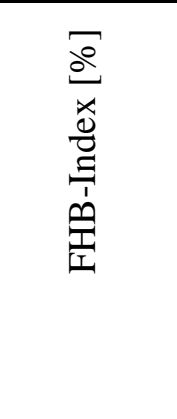 } & Ritmo (7) & 11,51 & 11,98 & 12,28 & $11,85 \mathbf{z}$ \\
\hline & KWS Pius (5) & 4,5 & 4,14 & 4,91 & $4,44 \mathbf{x}$ \\
\hline & Julius (5) & 5,44 & 5,36 & 4,99 & $5,31 \mathbf{y}$ \\
\hline & KWS Erasmus (4) & 1,23 & 1,57 & 0,82 & $1,29 \mathbf{w}$ \\
\hline & Centrum (2) & 0,3 & 0,46 & 0,25 & $0,35 \mathbf{v}$ \\
\hline & $\begin{array}{l}\text { Fungizid- } \\
\text { mittelwert }\end{array}$ & $4,60 \mathbf{a}$ & $4,70 \mathbf{a}$ & $4,65 \mathbf{a}$ & \\
\hline \multirow{6}{*}{$\begin{array}{l}7 \\
b 00 \\
y \\
000 \\
3 \\
z \\
0 \\
0 \\
0\end{array}$} & Ritmo (7) & 17155 & 16539 & 13738 & $16226 \mathrm{Z}$ \\
\hline & KWS Pius (5) & 8895 & 7082 & 7118 & $7814 \mathbf{Z Y}$ \\
\hline & Julius (5) & 6271 & 5322 & 5852 & $5807 \mathbf{Y X}$ \\
\hline & KWS Erasmus (4) & 4576 & 3759 & 3122 & $3958 \mathbf{X}$ \\
\hline & Centrum (2) & 2340 & 1878 & 1788 & 2045 W \\
\hline & $\begin{array}{l}\text { Fungizid- } \\
\text { mittelwert }\end{array}$ & $7847 \mathbf{A}$ & $6916 \mathrm{~A}$ & $6324 \mathrm{~A}$ & \\
\hline \multirow{6}{*}{ 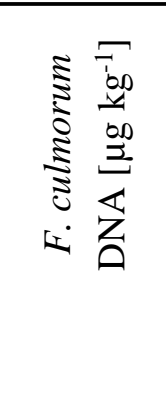 } & Ritmo (7) & 3477 & 2566 & 3294 & $3076 \mathbf{z}$ \\
\hline & KWS Pius (5) & 1832 & 1413 & 1972 & $1692 \mathbf{y}$ \\
\hline & Julius (5) & 1029 & 900 & 1554 & $1083 \mathbf{x}$ \\
\hline & KWS Erasmus (4) & 2214 & 1538 & 1853 & $1871 \mathbf{y}$ \\
\hline & Centrum (2) & 674 & 749 & 941 & $757 \mathbf{x}$ \\
\hline & $\begin{array}{l}\text { Fungizid- } \\
\text { mittelwert }\end{array}$ & $1845 \mathbf{b}$ & $1433 \mathbf{a}$ & $1923 \mathbf{b}$ & \\
\hline \multirow{6}{*}{ 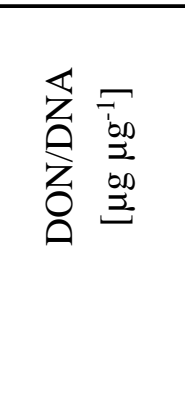 } & Ritmo (7) & 5,41 & 6,89 & 4,36 & $5,80 \mathbf{Z}$ \\
\hline & KWS Pius (5) & 5,08 & 5,25 & 3,57 & $4,85 \mathbf{Z}$ \\
\hline & Julius (5) & 6,78 & 6,32 & 4,05 & $6,05 \mathbf{Z}$ \\
\hline & KWS Erasmus (4) & 2,3 & 2,82 & 1,81 & $2,41 \mathbf{Y}$ \\
\hline & Centrum (2) & 4,23 & 2,63 & 1,94 & $3,14 \mathbf{Y}$ \\
\hline & $\begin{array}{l}\text { Fungizid- } \\
\text { mittelwert }\end{array}$ & $4,76 \mathbf{B}$ & $4,79 \mathbf{B}$ & $3,15 \mathbf{A}$ & \\
\hline
\end{tabular}


In der Tabelle 13 sind die Mittelwerte der vier untersuchten Parameter dargestellt und nach den Versuchsfaktoren Sorte und Fungizidapplikation varianzanalytisch verrechnet. Für den FHB-Index zeigten alle fünf Sorten dezidiert signifikante Unterschiede, entsprechend ihren Resistenzeigenschaften, was durch den Vergleich der DON-Mittelwerte bestätigt wurde. Im Gegensatz dazu ließen sich keine signifikanten Unterschiede beim FHB-Index bzw. dem DON- Gehalt zwischen den Fungizidvarianten ermitteln. Es konnte aber auch hier, ähnlich wie im FAEN-Versuch, in jeder der fünf getesteten Sorten festgestellt werden, dass eine Strobilurinapplikation tendenziell $\mathrm{zu}$ den höchsten Mykotoxinkontaminationen führte. Die Abstufungen zwischen den Sorten bei der DNA-Menge von F. culmorum zeigten für die beiden Standardvarianten Centrum und Ritmo die erwarteten signifikanten Differenzen. In der anfälligen Sorte wurden die höchsten DNA-Mengen gefunden, in der resistenteren Sorte hingegen, ließen sich die geringsten Mengen nachweisen. Die Fungizidapplikation mit Triazolen wies in dem Feldversuch signifikant geringere DNA-Mengen auf als die beiden Varianten Strobilurin und Unbehandelt. Bei der spezifischen Mykotoxinbildung wurde, ähnlich zum FAEN-Versuch eine signifikante Reduktion in den resistenteren Sorten festgestellt. Die Sorten Centrum und KWS Erasmus besaßen unter Freilandbedingungen eine durchschnittlich halb so hohe spezifische Mykotoxinbildung wie die übrigen anfälligeren Sorten. Auch die Fungizidapplikation zeigte einen deutlichen Einfluss. In allen fünf Sorten war die spezifische Mykotoxinbildung in der unbehandelten Variante geringer als in den Triazol- und Strobilurinvarianten, so dass eine interaktionsunabhängige signifikante Reduktion berechnet wurde.

\subsection{Abreife- und Enzymaktivitätsversuche Weendelsbreite}

\subsubsection{Halbfreilandversuch zum Abreifeverlauf am Standort Weendelsbreite}

Die varianzanalytische Verrechnung der aus dem Feldversuch ins Gewächshaus geholten Pflanzen zeigte unter kontrollierten Umweltbedingungen für die Faktorkombination Sorte (Ritmo) und Fungizidapplikation (Strobilurin) zu allen vier Probenahmeterminen einen signifikant höheren Wassergehalt in den Ähren und somit ein deutlich verzögerten Abreifeverlauf (Tab. 14). Für die Sorte Centrum war der Effekt des Strobilurins nur tendenziell in den ersten beiden Probennahmeterminen zu beobachten, in den späteren Terminen traten keine signifikanten Differenzen mehr auf. Im Vergleich zu den Pflanzen im parallel verlaufenden Feldversuch reiften die Weizenähren im Gewächshaus ca. drei Wochen früher ab. 
Tab. 14 Varianzanalyse der Wassergehalte [\%] in den Ähren der Winterweizensorten aus dem Halbfreilandversuch Weendelsbreite. Aufgeführt sind die mittleren Wassergehalte der Sorten Ritmo und Centrum $(n=10)$ als Maß der Abreife zu vier verschiedenen Ernteterminen nach zwei verschiedenen Fungizidapplikationen (Triazol und Strobilurin). Unterschiedliche Buchstaben desselben Typs kennzeichnen signifikante Unterschiede zwischen dem Abreifeverlauf der beiden Sorten in Abhängigkeit von der Fungizidapplikation zu jedem Erntetermin (LSD Test mit $\mathbf{p} \leq \mathbf{0 , 0 5}$ ).

\begin{tabular}{cccccc} 
& & \multicolumn{4}{c}{ Wassergehalt } \\
\cline { 3 - 6 } Sorte & Fungizid & 30.06 .2009 & 03.07 .2009 & 06.07 .2009 & 09.07 .2009 \\
& & BBCH 75 & BBCH 80 - 85 & BBCH 85 - 89 & BBCH 92 \\
\hline \multirow{2}{*}{ Ritmo } & Triazol & $32,57 \mathbf{y}$ & $18,04 \mathbf{a}$ & $15,99 \mathbf{Z}$ & $11,30 \mathbf{A}$ \\
& Strobilurin & $44,54 \mathbf{z}$ & $31,91 \mathbf{~ b}$ & $31,79 \mathbf{Y}$ & $12,70 \mathbf{~ B}$ \\
& Triazol & $34,55 \mathbf{y}$ & $17,49 \mathbf{a}$ & $10,58 \mathbf{Z}$ & $10,84 \mathbf{~ A}$ \\
\multirow{2}{*}{ Centrum } & Strobilurin & $38,90 \mathbf{z y}$ & $26,23 \mathbf{~ a b}$ & $13,12 \mathbf{Z}$ & $11,05 \mathbf{A}$ \\
\hline
\end{tabular}

\subsubsection{Feldversuch zur Enzymaktivität am Standort Weendelsbreite}

Tab. 15 Enzymaktivität der Gujakolperoxidase im Gewebe der Hüll- und Deckspelzen von Winterweizen (Sorte: Ritmo) im Feldversuch Weendelsbreite. Dargestellt ist die mittlere Aktivität der Gujakolperoxidase in nkat $\mathrm{g}^{-1}$ FM ( \pm Standardabweichungen) zu drei Terminen $(\mathrm{BBCH} 75,85$ und 92) in den drei Fungizidvarianten der Sorte Ritmo $(n=4)$. Unterschiedliche Buchstaben desselben Typs kennzeichnen signifikante Unterschiede zwischen der jeweiligen Höhe der Enzymaktivität (LSD Test mit p $\leq$ 0,05)

BBCH Entwicklungsstadium

\begin{tabular}{lccc}
\cline { 2 - 4 } Fungizid & 06.07 .2009 & 14.07 .2009 & 27.07 .2009 \\
& BBCH 75 & BBCH 85 & BBCH 92 \\
\hline Neutral & $456 \pm 33 \mathbf{A}$ & $270 \pm 45 \mathbf{a}$ & $9 \pm 11 \mathbf{y}$ \\
Triazol & $489 \pm 42 \mathbf{A}$ & $318 \pm 27 \mathbf{a}$ & $33 \pm 45 \mathbf{y}$ \\
Strobilurin & $281 \pm 7 \mathbf{B}$ & $326 \pm 53 \mathbf{a}$ & $237 \pm 118 \mathbf{z}$ \\
\hline
\end{tabular}

Als weiterer Parameter für die Quantifizierung des Abreifeverlaufs von Weizenpflanzen wurde die Gujakolperoxidaseaktivität in den Deck- und Hüllspelzen direkt aus dem Feldversuch in der Ähre ermittelt. Bereits im Entwicklungsstadium BBCH 75 wurde in den Fungizidvarianten Triazol und Neutral die maximale Peroxidaseaktivität gemessen. Zum Zeitpunkt BBCH 85 war bereits eine Abnahme und während der Abreife (BBCH 92) nur noch 
eine schwache Aktivität messbar (Tab. 15). In der Fungizidvariante Strobilurin stieg die enzymatische Aktivität hingegen im untersuchten Gewebe bis zum Entwicklungsstadium BBCH 85 an und verringerte sich nur leicht mit Beginn der Abreife, so dass kurz vor der Ernte, zum Probenahmezeitpunkt BBCH 92, eine signifikant höhere Enzymaktivität festgestellt werden konnte.

Tab. 16 Befallsanalyse des Versuches Weendelsbreite 2009. Aufgeführt ist der mittlere FHB-Index der Sorten Centrurm (C) und Ritmo (R) nach Inokulation mit $F$. culmorum $(n=12$ je Sorte) bei drei verschiedenen Fungizidapplikationen (Unbehandelt, Triazol und Strobilurin $n=8$ ). Unterschiedliche Buchstaben desselben Typs kennzeichnen signifikante Unterschiede zwischen den jeweiligen Feldbefallsstärken der Sorten- bzw. der Fungizidmittelwerte (LSD Test mit $\mathbf{p} \leq \mathbf{0 , 0 5}$ ). Identische Varianzanalysen wurden für den Versuchsfaktor DON-Gehalt, $F$. culmorum-DNA und der spezifischen Mykotoxinbildung jeweils separat durchgeführt. Analysen der Interaktionen von Sorte*Fungizid wurden mit den Buchstaben g-i beschriftet.

\begin{tabular}{|c|c|c|c|c|c|}
\hline \multirow{2}{*}{ Parameter } & \multirow{2}{*}{ Sorte } & \multicolumn{3}{|c|}{ Fungizid } & \multirow{2}{*}{$\begin{array}{c}\text { Mittelwert de } \\
\text { Sorte }\end{array}$} \\
\hline & & Strobilurin & Triazol & Neutral & \\
\hline \multirow{3}{*}{ FHB-Index [\%] } & $\mathrm{C}$ & $0,54 \mathbf{G}$ & $0,45 \mathbf{G}$ & $0,46 \mathbf{G}$ & $0,48 \mathbf{Z}$ \\
\hline & $\mathrm{R}$ & $10,05 \mathbf{H}$ & $9,57 \mathbf{H}$ & $10,15 \mathbf{H}$ & $9,93 \mathbf{Y}$ \\
\hline & $\begin{array}{l}\text { Fungizid- } \\
\text { mittelwert }\end{array}$ & $5,30 \mathbf{A}$ & $5,01 \mathbf{A}$ & $5,30 \mathrm{~A}$ & \\
\hline \multirow{3}{*}{$\mathrm{DON}\left[\mu \mathrm{g} \mathrm{kg}^{-1}\right]$} & $\mathrm{C}$ & $644 \mathrm{~g}$ & $692 \mathbf{g}$ & $677 \mathbf{g}$ & $671 \mathbf{z}$ \\
\hline & $\mathrm{R}$ & $3389 \mathbf{i}$ & $2360 \mathbf{h}$ & $2573 \mathbf{h}$ & $2774 \mathbf{y}$ \\
\hline & $\begin{array}{l}\text { Fungizid- } \\
\text { mittelwert }\end{array}$ & $2016 \mathbf{a}$ & $1527 \mathbf{a}$ & $1625 \mathbf{a}$ & \\
\hline \multirow{3}{*}{$\begin{array}{c}\text { F.culmorum } \\
\text { DNA }\left[\mu \mathrm{g} \mathrm{kg}^{-1}\right]\end{array}$} & $\mathrm{C}$ & $233 \mathbf{G}$ & $282 \mathbf{G}$ & $242 \mathbf{G}$ & $253 \mathbf{Z}$ \\
\hline & $\mathrm{R}$ & 369 GH & $503 \mathrm{HI}$ & $621 \mathrm{I}$ & $497 \mathbf{Y}$ \\
\hline & $\begin{array}{l}\text { Fungizid- } \\
\text { mittelwert }\end{array}$ & $301 \mathbf{B}$ & $392 \mathbf{A B}$ & $432 \mathrm{~A}$ & \\
\hline \multirow{3}{*}{$\begin{array}{c}\text { DON/DNA } \\
{\left[\mu \mathrm{g} \mu \mathrm{g}^{-1}\right]}\end{array}$} & $\mathrm{C}$ & $2,94 \mathbf{g}$ & $2,81 \mathbf{g}$ & $3,14 \mathbf{g}$ & $2,96 \mathbf{z}$ \\
\hline & $\mathrm{R}$ & $10,47 \mathbf{h}$ & $4,76 \mathbf{g}$ & $4,34 \mathbf{g}$ & $6,52 \mathbf{y}$ \\
\hline & $\begin{array}{l}\text { Fungizid- } \\
\text { mittelwert }\end{array}$ & $6,71 \mathbf{b}$ & $3,79 \mathbf{a}$ & $3,74 \mathbf{a}$ & \\
\hline
\end{tabular}


Als Konsequenz aus diesen Untersuchungen, wurden in Tabelle 16 Mittelwertvergleiche aller vier untersuchten Parameter der Ernteproben aus dem Feldversuch durchgeführt und mögliche Interaktionen berechnet. Beim FHB-Index wurde ein signifikanter Unterschied zwischen der anfälligen und der resistenteren Sorte festgestellt, jedoch traten keine absicherbaren Unterschiede zwischen den Fungizidvarianten auf. Diese Sortenunterschiede waren ebenfalls beim DON-Gehalt zu beobachten. Darüber hinaus war eine tendenzielle Erhöhung der Mykotoxingehalte in der Kombination Ritmo x Strobilurin festzustellen, die in vorherigen Versuchen bereits beobachtet wurde. Die DNA-Menge von F. culmorum war in der resistenteren Sorte Centrum signifikant geringer als in der anfälligen Sorte Ritmo, gleiches wurde auch für die spezifischen Mykotoxinbildung ermittelt. Eine Strobilurinapplikation hingegen erhöhte die spezifische Mykotoxinbildung in diesem Feldversuch signifikant (Tab. 16). Wie bereits bei den zuvor vorgestellten Parametern hob sich besonders die signifikant unterschiedliche Variante Ritmo x Strobilurin mit einem mehr als zweimal so hohen Wert von den anderen Fungizidpplikationen ab.Dieses lässt auf einen spezifischen Interaktionseffekt schließen.

\subsection{Fungizidversuch im Gewächshaus}

Unter kontrollierten Bedingungen wurde im Gewächshaus der Einfluss fungizider Blattapplikationen untersucht. In Tabelle 17 wurden varianzanalytische Mittelwertvergleiche der vier Untersuchungsparameter durchgeführt. Beim FHB-Index konnten weder bei der Variante 14dpi noch in der Variante 24 dpi signifikante Differenzen zwischen den Fungizidbehandlungen festgestellt werden. Gleiches galt für den DON-Gehalt, jedoch war auch hier wie bereits in den Versuchen zuvor eine tendenzielle Erhöhung in der Variante Strobilurin feststellbar. Beim Vergleich der DNA-Mengen von F. graminearum und der spezifischen Mykotoxinbildung wurden ebenfalls keine signifikanten Differenzen zwischen den Fungizidapplikationen und der unbehandelten Variante ermittelt (Tab. 17). 
Tab. 17 Varianzanalytische Untersuchung des Fungizidversuches mit Sommerweizen im Gewächshaus. Aufgeführt ist der mittlere FHB-Index [\%] zu zwei Terminen (14 und 24 dpi) der Sorte Kadrilj nach Fungizidbehandlungen (BBCH 31 und 39) mit drei verschiedenen Fungizidwirkstoffen nach künstlicher Inokulation mit $F$. graminearum (Fg 142/143/144) (n = 4 mit jeweils 36 Pflanzen). Unterschiedliche Buchstaben desselben Typs kennzeichnen signifikante Unterschiede zwischen der jeweiligen Befallsstärke (LSD Test mit $p \leq 0,05)$. Identische Varianzanalysen $(n=4)$ wurden für die Faktoren DON-Gehalt, $F$. graminearum-DNA und der spezifischen Mykotoxinbildung jeweils separat durchgeführt. Signifikante Unterschiede der Effekte wurden ebenfalls mit verschiedenen Buchstaben kenntlich gemacht.

\begin{tabular}{|c|c|c|c|c|}
\hline \multirow{2}{*}{\multicolumn{2}{|c|}{ Parameter }} & \multicolumn{3}{|c|}{ Fungizid } \\
\hline & & Strobilurin & Triazol & Unbehandelt \\
\hline \multirow{2}{*}{ 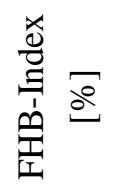 } & 14 dpi & $30,83 \mathbf{a}$ & $25,22 \mathbf{a}$ & $25,39 \mathbf{a}$ \\
\hline & 24 dpi & $79,72 \mathbf{z}$ & $66,14 \mathbf{z}$ & $79,82 \mathbf{z}$ \\
\hline \multicolumn{2}{|c|}{$\mathrm{DON}\left[\mu \mathrm{g} \mathrm{kg}^{-1}\right]$} & 26692 A & $12928 \mathbf{A}$ & $17986 \mathbf{A}$ \\
\hline \multicolumn{2}{|c|}{$\begin{array}{c}\text { F.graminearum DNA } \\
{\left[\mu \mathrm{g} \mathrm{kg}^{-1}\right]}\end{array}$} & $471 \mathrm{Z}$ & $274 \mathbf{Z}$ & $178 \mathbf{Z}$ \\
\hline \multicolumn{2}{|c|}{ DON/DNA $\left[\mu \mathrm{g} \mu \mathrm{g}^{-1}\right]$} & 220 G & $67 \mathrm{G}$ & $134 \mathbf{G}$ \\
\hline
\end{tabular}

\subsection{Sortenversuch mit Einzelährchen- und Sprühinokulation}

Zur Überprüfung des Einflusses unterschiedlicher Infektionsverläufe auf die verschiedenen Untersuchungsparameter wurden unter kontrollierten Bedingungen die fünf Sorten des Versuches in Wetze mit zwei verschiedenen Methoden inokuliert. Beim FHB-Index zum Termin 7 dpi waren signifikante Unterschiede zwischen den Inokulationsmethoden innerhalb der fünf Sorten auszumachen. Die Mittlere Befallsstärke lag in der multiplen Inokulationsvariante ca. dreimal höher als in der Variante mit einer einzigen Primärinfektion (Tab. 18). Die Resistenzabstufungen zwischen den fünf Sorten traten im Gewächshaus nicht so deutlich hervor wie in den Feldversuchen. Dennoch waren die Unterschiede teilweise signifikant absicherbar und deutlich zu sehen. Zu den Boniturterminen 14 dpi und 21 dpi lagen die mittleren FHB-Indexe der Sprühinokulationen weiterhin signifikant höher als bei der Punktinokulationen. 
Tab. 18 Befallsanalysen im Sortenversuch 2009 mit Winterweizen im Gewächshaus. Aufgeführt ist der mittlere FHB-Index (7,14 und $21 \mathrm{dpi)}$ der fünf Sorten bei zwei verschiedenen Inokulationstechniken(Einzel: Punktinokulation, Multiple: Sprühinokulation mit $F$. graminearum Fg 142/143/144) $(n=4$, mit je 18 gepoolten Pflanzen).Die Resistenzeinstufungen des BSA gegenüber Ährenfusariosen stehen hinter den jeweiligen Sortennamen. Unterschiedliche Buchstaben desselben Typs kennzeichnen signifikante Unterschiede zwischen der jeweiligen Befallsstärke der Variante Sorte*Innokulationstechnik (LSD Test mit $\mathbf{p} \leq \mathbf{0 , 0 5})$. Identische Varianzanalysen $(n=4)$ wurden für den Versuchsfaktor DON-Gehalt, $F$. graminearum-DNA und der spezifischen Mykotoxinbildung jeweils separat durchgeführt. Signifikante Unterschiede der jeweiligen Interaktionen der Sorten wurden ebenfalls mit verschiedenen Buchstaben kenntlich gemacht.

\begin{tabular}{|c|c|c|c|c|c|c|c|}
\hline \multicolumn{2}{|c|}{ Parameter } & $\begin{array}{l}\text { Inokulations- } \\
\text { technik }\end{array}$ & Ritmo (7) & $\begin{array}{l}\text { KWS } \\
\text { Pius (5) }\end{array}$ & Julius (5) & $\begin{array}{c}\text { KWS } \\
\text { Erasmus (4) }\end{array}$ & Centrum (2) \\
\hline \multirow{6}{*}{ 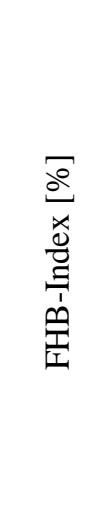 } & \multirow{2}{*}{7 dpi } & Einzel & $21,48 \mathbf{e}$ & $12,39 \mathbf{f}$ & $14,57 \mathbf{f}$ & $21,15 \mathbf{e}$ & $12,2 \mathbf{f}$ \\
\hline & & Multiple & $59,11 \mathbf{a}$ & $29,72 \mathbf{d}$ & $44,03 \mathbf{b}$ & $35,56 \mathrm{c}$ & $33,64 \mathbf{c d}$ \\
\hline & \multirow{2}{*}{14 dpi } & Einzel & $72,90 \mathbf{B}$ & $28,31 \mathbf{F}$ & $49,74 \mathbf{E}$ & $46,84 \mathbf{E}$ & $30,43 \mathbf{F}$ \\
\hline & & Multiple & $92,20 \mathbf{A}$ & $67,54 \mathbf{B C}$ & $73,31 \mathbf{B}$ & 58,42 D & 64,72 CD \\
\hline & \multirow[b]{2}{*}{$21 \mathrm{dpi}$} & Einzel & $99,17 \mathbf{z}$ & $68,66 \mathbf{v u}$ & $76,09 \mathbf{w v}$ & $60,39 \mathbf{u}$ & $60,82 \mathbf{u}$ \\
\hline & & Multiple & $100 \mathrm{z}$ & $84,02 \mathbf{y x w}$ & $89,64 \mathbf{y}$ & $80,18 \mathbf{x w}$ & $85,79 \mathbf{y x}$ \\
\hline \multirow{2}{*}{\multicolumn{2}{|c|}{$\mathrm{DON}\left[\mu \mathrm{g} \mathrm{kg}^{-1}\right]$}} & Einzel & $145727 \mathbf{a b}$ & $50034 \mathbf{g}$ & 83989 def & 59165 fg & 77542 ef \\
\hline & & Multiple & $174319 \mathbf{a}$ & 112996 bed & 134807 abc & 105040 cde & 124209 bc \\
\hline \multirow{2}{*}{\multicolumn{2}{|c|}{$\begin{array}{l}\text { F.graminearum } \\
\text { DNA }\left[\mu \mathrm{g} \mathrm{kg}^{-1}\right]\end{array}$}} & Einzel & $1267 \mathbf{b}$ & $326 \mathrm{e}$ & 570 cde & 533 de & 397 de \\
\hline & & Multiple & $3226 \mathbf{a}$ & 895 bcd & 1053 bc & $1159 \mathbf{b}$ & 644 cde \\
\hline \multirow{2}{*}{\multicolumn{2}{|c|}{$\begin{array}{c}\text { DON/DNA } \\
{\left[\mu g^{-1}\right]}\end{array}$}} & Einzel & 90 de & $155 \mathrm{c}$ & $148 \mathrm{c}$ & $111 \mathrm{~d}$ & $198 \mathbf{b}$ \\
\hline & & Multiple & $54 \mathbf{e}$ & 145 bcd & $253 \mathbf{a}$ & 102 de & $173 \mathbf{b c}$ \\
\hline
\end{tabular}

Einzig in der Sorte Ritmo war beim letzten Boniturtermin kein Unterschied der Befallsstärke zwischen den Inokulationsvarianten feststellbar. Ein vergleichbares Muster trat auch bei den Analysen der DON-Gehalte auf, die innerhalb der Sorten mit Punktinokulationen um den Faktor 1,5 bis 2 signifikant geringer waren, als nach einer Sprühinokulation. Die Sorten KWS Erasmus und KWS Pius wiesen in beiden Inokulationsvarianten die geringsten DON-Gehalte auf. Interessanterweise wurde der niedrigste Wert nicht für die resistenteste Sorte aus den 
Feldversuchen, Centrum, ermittelt. Signifikante Differenzen konnten ebenfalls beim Vergleich der DNA-Mengen von $F$. graminearum zwischen den Inokulationsmethoden nachgewiesen werden, innerhalb der Sorten lag der Faktor zwischen 2,5 und 3. Die mittleren DNAMengen entsprachen dabei den Ergebnissen aus dem Feldversuch in Wetze, jedoch waren die Ergebnisse der spezifischen Mykotoxinbildung aufgrund der hohen Mykotoxinkontaminationen vollständig invers. Der in Feldversuchen beobachtete Effekt einer Verringerung der spezifischen Mykotoxinbildung in resistenten Sorten war nicht mehr zu sehen. Vielmehr war die spezifische Mykotoxinproduktion in der anfälligen Sorte Ritmo die geringste in beiden Inokulationsvarianten im Gesamtversuch. Bemerkenswert war, dass die spezifische Mykotoxinbildung nur von den Sorten und deren Interaktionen abhängig war und nicht von der Inokulationstechnik bzw. dem Infektionsmodus (Tab. 19). So wurden innerhalb der jeweiligen Sorten bis auf Julius keine signifikanten Unterschiede zwischen einer Primärinfektion und multiplen Primärinfektionen festgestellt. Ein Starkbefall mit Ährenfusariosen im Freiland mit möglicherweise multiplen Primärinfektionen kann somit zu einer nahezu identischen spezifischen Mykotoxinbildung führen wie ein schwacher bis mittlerer Befall mit einzelnen Primärinfektionen.

Tab. 19 Varianzanalyse der spezifischen Mykotoxinbildung im Sortenversuch 2009 im Gewächshaus. Dargestellt sind die drei Versuchsfaktoren Sorte $(n=5)$, Inokulationstechnik mit $(n=2)$ und die sich daraus ergebende Interaktionskomponente. Effekte sind signifikant bei einem Wert von $\mathbf{p} \leq \mathbf{0 , 0 5}$ (hoch signifikant bei $p \leq 0,01$, höchst signifikant bei $p \leq 0,001$ )

\begin{tabular}{lccc} 
Effekt & Freiheitsgrad & F-Wert & p-Wert \\
\hline Sorte & 4 & 22,13 & $<0,0001$ \\
Inokulationstechnik & 1 & 116,6 & 0,643 \\
Sorte*Inokulationstechnik & 4 & 7,47 & 0,0013 \\
\hline
\end{tabular}

\subsection{Klimakammerversuche}

In Klimakammern wurden in kontrollierten Umwelten der Einfluss der Tages- bzw. Nachttemperatur und der Intervalllänge von Feuchteperioden auf die Mykotoxinbildung und die spezifische Mykotoxinbildung untersucht. Hohe Tagestemperaturen führten zu einer stärkeren Symptomausprägung der partiellen Weißährigkeit und somit zu einem signifikant höheren FHB-Index über alle drei Inkubationsvarianten (Tab. 20). Im Gegensatz dazu, wurde bei dem Temperaturregime $12^{\circ} \mathrm{C} / 12^{\circ} \mathrm{C}$ selbst in der Inkubationsvariante von 8 Tagen keine Erhöhung 
der Befallstärke gemessen. Eine Kombination aus hoher Tagestemperatur $\left(25^{\circ} \mathrm{C} / 16^{\circ} \mathrm{C}\right.$ und $20^{\circ} \mathrm{C} / 16^{\circ} \mathrm{C}$ ) und relativ hoher Nachttemperatur ließ dagegen teilweise die kompletten Ähren ausbleichen. Zwischen diesen beiden Extremszenarien lagen die FHB-Indices einer unteren Temperaturvariante mit $16^{\circ} \mathrm{C} / 12^{\circ} \mathrm{C}$ und einer Variante mit hohen Tag und Nachtdifferenzen $\left(28^{\circ} \mathrm{C} / 8^{\circ} \mathrm{C}\right)$. Trotz der aufgrund des Versuchsdesigns relativ spät gewählten Boniturtermine, war es möglich die Symptome der partiellen Weißährigkeit klar zu erfassen. Bis auf die Variante mit den niedrigsten Temperaturkombinationen, war durchschnittlich eine Verdopplung der Feldbefallsstärke in den Klimakammerexperimenten zwischen den Terminen 17 und 24 dpi zu beobachten.

Tab. 20 Befallsanalyse an Sommerweizen (Sorte: Tybalt) nach Inokulation mit $F$. graminearum (Fg 142/143/144) unter verschiedenen Temperaturregimen in der Klimakammer. Aufgeführt ist der mittlere FHB-Index (17 und 24 dpi) der fünf Temperaturkombinationen bei vier verschiedenen Inkubationszeiträumen (Unbehandelt, 2 Tage, 5 Tage und 8 Tage) $(n=4$, mit bis zu 20 gepoolten Pflanzen). Unterschiedliche Buchstaben desselben Typs kennzeichnen signifikante Unterschiede zwischen der jeweiligen Feldbefallsstärke der Temperaturregime innerhalb eines Inkubationszeitraums (LSD Test mit p $\leq \mathbf{0 , 0 5}$ ). Mit „-” gekennzeichnete Versuchskombinationen wurden nicht durchgeführt. ${ }^{\text {a) }}$ Der Wert wurde nur in der Temperaturvariane $12^{\circ} \mathrm{C} / 12^{\circ} \mathrm{C}$ ermittelt und nicht für eine varianzanalytische Verrechnung herangezogen.

\begin{tabular}{|c|c|c|c|c|c|c|}
\hline \multirow{2}{*}{\multicolumn{2}{|c|}{ Parameter }} & \multirow{2}{*}{$\begin{array}{l}\text { Temperatur- } \\
\text { regime }\end{array}$} & \multicolumn{4}{|c|}{ Feuchtinkubationszeitraum } \\
\hline & & & Unbehandelt ${ }^{\mathrm{a}}$ & 2 Tage & 5 Tage & 8 Tage \\
\hline \multirow{10}{*}{ 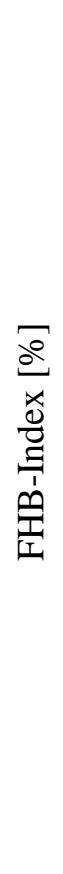 } & \multirow{5}{*}{$\begin{array}{l}\bar{a} \\
\text { 금 }\end{array}$} & $12^{\circ} \mathrm{C} / 12^{\circ} \mathrm{C}$ & $0^{\mathrm{a}}$ & $11,74 \mathbf{E}$ & $11,37 \mathbf{W}$ & $11,32 \mathbf{I}$ \\
\hline & & $16^{\circ} \mathrm{C} / 12^{\circ} \mathrm{C}$ & - & $17,41 \mathbf{D}$ & $28,03 \mathbf{X}$ & $36,38 \mathbf{H}$ \\
\hline & & $20^{\circ} \mathrm{C} / 16^{\circ} \mathrm{C}$ & - & $38,33 \mathbf{A}$ & $45,56 \mathbf{Y}$ & $63,18 \mathbf{G}$ \\
\hline & & $25^{\circ} \mathrm{C} / 16^{\circ} \mathrm{C}$ & - & $33,25 \mathbf{B}$ & $59,36 \mathbf{Z}$ & $68,83 \mathbf{G}$ \\
\hline & & $28^{\circ} \mathrm{C} / 8^{\circ} \mathrm{C}$ & - & $26,71 \mathrm{C}$ & $39,81 \mathbf{Y}$ & $44,00 \mathbf{H}$ \\
\hline & \multirow{5}{*}{$\begin{array}{l}\bar{z} \\
\stackrel{7}{7}\end{array}$} & $12^{\circ} \mathrm{C} / 12^{\circ} \mathrm{C}$ & $0^{\mathrm{a}}$ & $15,42 \mathbf{e}$ & $16,79 \mathbf{w}$ & $15,88 \mathbf{i}$ \\
\hline & & $16^{\circ} \mathrm{C} / 12^{\circ} \mathrm{C}$ & - & $35,38 \mathbf{d}$ & $55,19 \mathbf{x}$ & $70,07 \mathbf{h}$ \\
\hline & & $20^{\circ} \mathrm{C} / 16^{\circ} \mathrm{C}$ & - & 70,15 b & $82,16 \mathbf{y}$ & $96,75 \mathbf{g}$ \\
\hline & & $25^{\circ} \mathrm{C} / 16^{\circ} \mathrm{C}$ & - & $86,80 \mathbf{a}$ & $95,22 \mathbf{z}$ & $100 \mathrm{~g}$ \\
\hline & & $28^{\circ} \mathrm{C} / 8^{\circ} \mathrm{C}$ & - & $53,79 \mathbf{c}$ & $62,88 \mathbf{x}$ & $63,63 \mathbf{h}$ \\
\hline
\end{tabular}

In der Feuchtinkubationsvariante $3 \times 2$ Tage zeigte die Temperaturkombination $28^{\circ} \mathrm{C} / 8^{\circ} \mathrm{C}$ einen signifikant höheren Mykotoxingehalt als alle anderen Witterungszenarien. Dies setzte sich auch in den Varianten $3 \times 5 \mathrm{~d}$ und $3 \times 8 \mathrm{~d}$ fort, jedoch erreichten hier auch die Tempera- 
turkombinationen $20^{\circ} \mathrm{C} / 16^{\circ} \mathrm{C}$ und vor allem $16^{\circ} / 12^{\circ} \mathrm{C}$ vergleichbar hohe Werte. Die Varianten $12^{\circ} \mathrm{C} / 12^{\circ} \mathrm{C}$ und $25^{\circ} \mathrm{C} / 16^{\circ} \mathrm{C}$ führten auf einem vergleichbaren Niveau in allen drei Feuchtinkubationsperioden zu den geringsten Mykotoxinkontaminationen (Abb. 17).

Die $F$. graminearum DNA-Mengen der Temperaturkombinationen $12^{\circ} \mathrm{C} / 12^{\circ} \mathrm{C}, 20^{\circ} \mathrm{C} / 16^{\circ}$ und $28^{\circ} \mathrm{C} / 8^{\circ} \mathrm{C}$ waren in der $3 \times 2 \mathrm{~d}$ Feuchteperioden signifikant erhöht. Dies setzte sich jedoch bei der Kombination $12^{\circ} \mathrm{C} / 12^{\circ} \mathrm{C}$ in den beiden weiteren Inkubationsvarianten nicht fort, wohingegen die beiden anderen Kombinationen weiterhin die höchsten DNA-Mengen aufwiesen. Vergleichbar zu den DON-Messungen, wies auch in dieser Analyse die Temperaturkombination $25^{\circ} \mathrm{C} / 16^{\circ} \mathrm{C}$ die signifikant geringsten Werte in allen drei Varianten auf (Abb. 18).

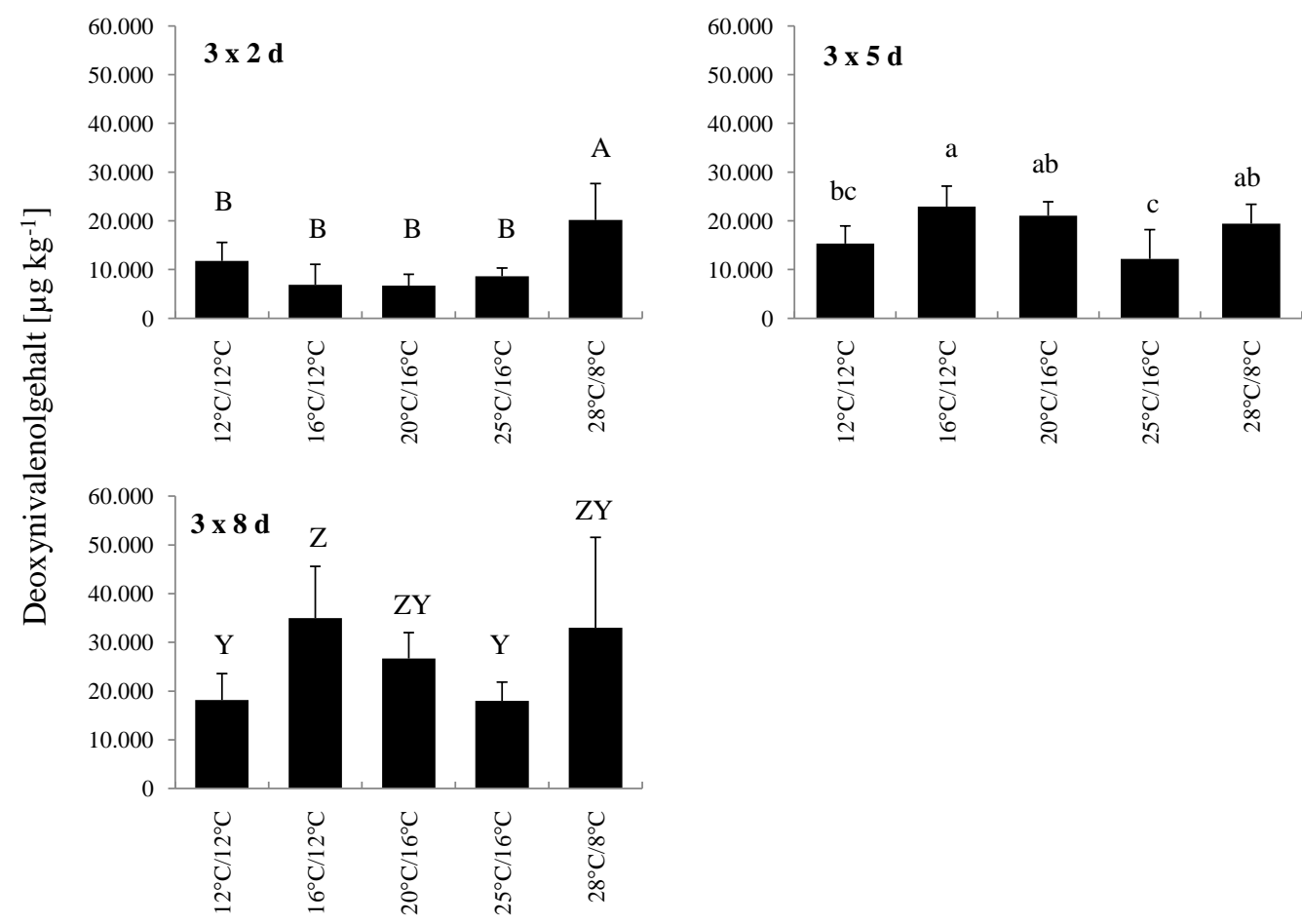

Abb. 17 Analyse der DON Gehalte $\left[\mu \mathrm{g} \mathrm{kg}^{-1}\right]$ in Körnern von Sommerweizen (Sorte: Tybalt) nach Inokulation mit F. graminearum (Fg 142/143/144) im Klimakammerversuch. Varianzanalytische Verrechnungen wurden innerhalb der drei Inkubationszeiträume (2d: zwei Tage, 5d: fünf Tage und 8d: acht Tage) für jede der fünf Temperturkombiantionen durchgeführt ( $n=4$ mit je 20 gepoolten Pflanzen). Unterschiedliche Buchstaben desselben Typs kennzeichnen signifikante Unterschiede zwischen den DON-Gehalten der Temperaturregime (LSD Test mit $p \leq 0,05)$.

Im Gegensatz zu den Analysen der DON- und DNA-Gehalte führte die Temperaturkombination $25^{\circ} \mathrm{C} / 16^{\circ} \mathrm{C}$ bei der spezifischen Mykotoxinbildung in den Inkubationsvarianten $3 \times 2 \mathrm{~d}$ und 3 x 5d zu den signifikant höchsten Werten. In der Inkubationsvariante 3 x 8d erreichte nur das Temperaturszenario $12^{\circ} \mathrm{C} / 12^{\circ} \mathrm{C}$ vergleichbar hohe Mengen DON pro Einheit $F$. 
graminearum DNA. Die geringste spezifische Mykotoxinbildung im gesamten Versuch wurde in der Inkubationsvariante $3 \times 8 \mathrm{~d}$ bei der Temperaturkombination $16^{\circ} \mathrm{C} / 12^{\circ} \mathrm{C}$ ermittelt (Abb. 19).

Die varianzanalytische Verrechnung der DON-Gehalte der Klimakammerversuche mit den Werten der gepoolten Temperaturszenarien zeigte eindeutige Unterschiede zwischen den Inkubationsvarianten. Eine Inkubation von 3 x 8 Tagen führte $\mathrm{zu}$ signifikant höheren Mykotoxinmengen im Getreide als eine Inkubation von 3 x 5 Tagen, die sich auch signifikant von der Variante 3 x 2 Tage unterschied (Tab. 21). Gleiches war bei den DNA-Mengen von F. graminearum zu beobachten, nur war hier der Unterschied zwischen den Inkubationsvarianten noch deutlicher ausgeprägt. Als Konsequenz aus diesem starken Anstieg der DNAGehalte kam es bei der berechneten spezifischen Mykotoxinbildung dazu, dass die Feuchtinkubationsperiode 3 × 2 d die höchsten DON-Gehalte pro DNA-Menge aufwies und sich signifikant von den länger inkubierten Varianten unterschied.

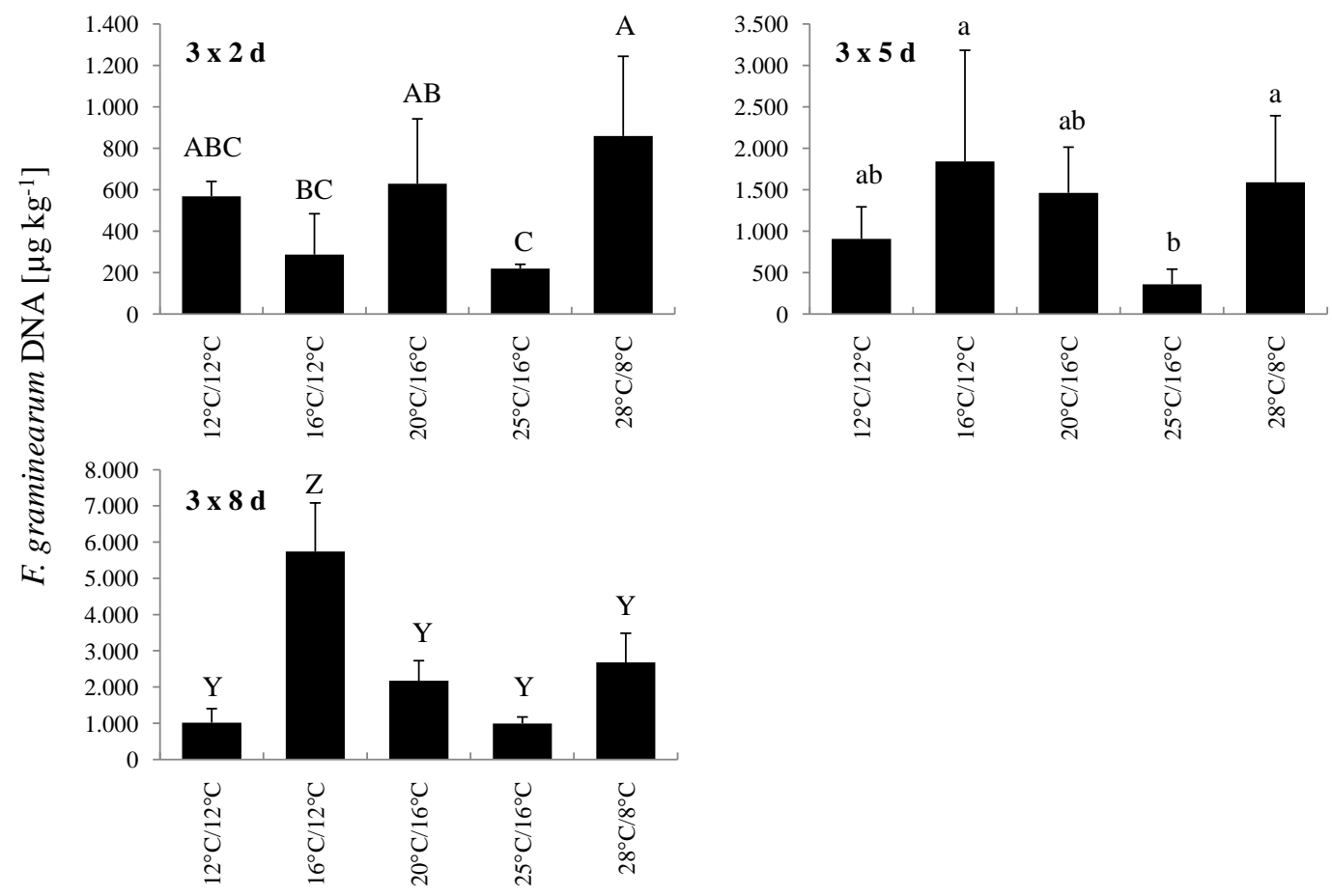

Abb. 18 Analyse der $F$. graminearum DNA Gehalte $\left[\mu \mathrm{g} \mathrm{kg}^{-1}\right]$ in Körnern von Sommerweizen (Sorte: Tybalt) nach Inokulation mit $F$. graminearum (Fg 142/143/144) im Klimakammerversuch. Varianzanalytische Verrechnungen wurden innerhalb der drei Inkubationszeiträume (2d: zwei Tage, 5d: fünf Tage und 8d: acht Tage) für jede der fünf Temperturkombiantionen durchgeführt ( $n=4$ mit je 20 gepoolten Pflanzen). Unterschiedliche Buchstaben desselben Typs kennzeichnen signifikante Unterschiede zwischen den DNA-Gehalten der Temperaturregime (LSD Test mit $\mathbf{p} \leq \mathbf{0 , 0 5}$ ). 


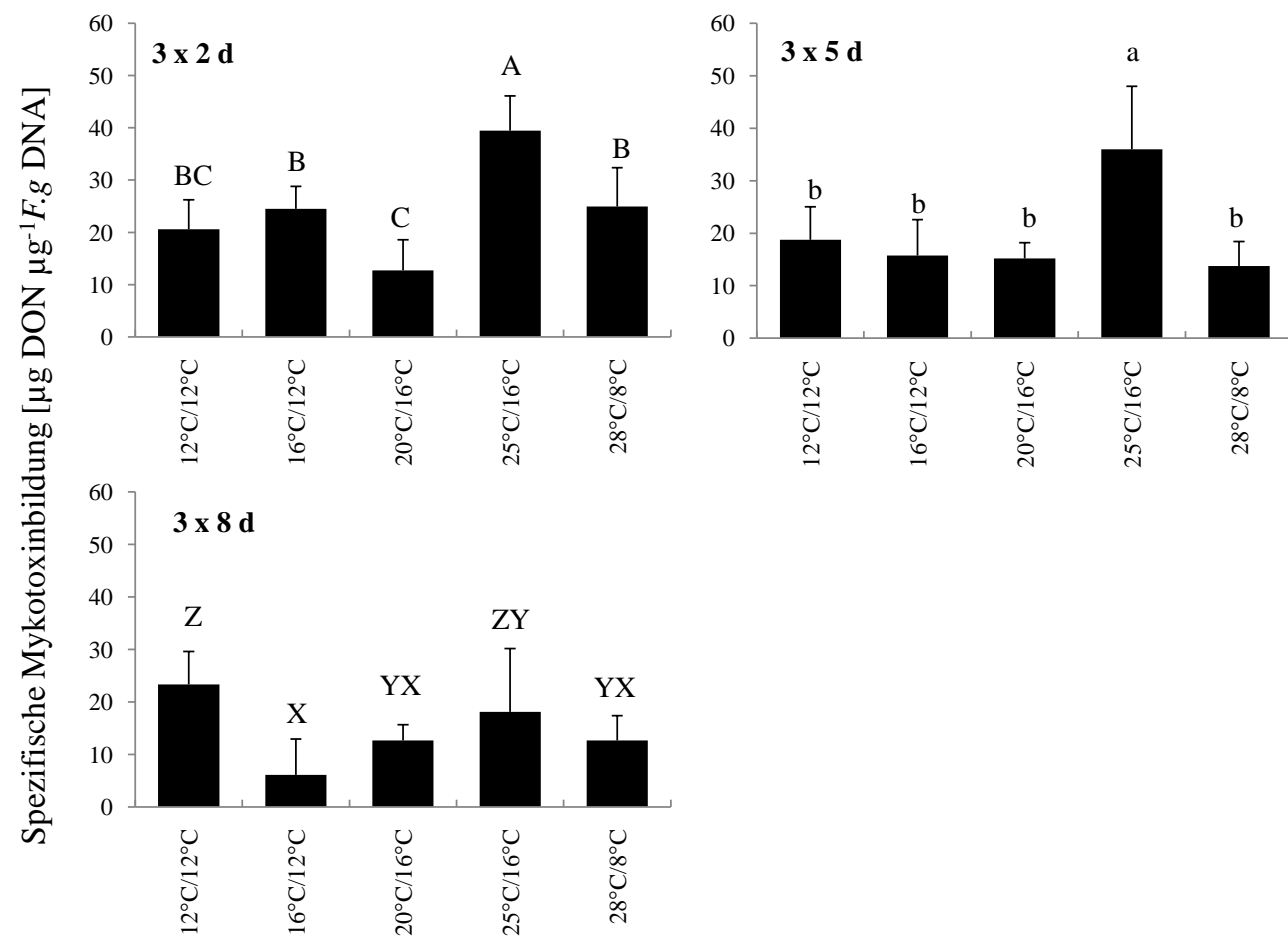

Abb. 19 Analyse der spezifischen Mykotoxinbildung [ $\mu \mathrm{g}$ DON $\mu \mathrm{g}^{-1} F$. g DNA] in Körnern von Sommerweizen (Sorte: Tybalt) nach Inokulation mit F. graminearum (Fg 142/143/144) im Klimakammerversuch. Varianzanalytische Verrechnungen wurden innerhalb der drei Inkubationszeiträume (2d: zwei Tage, 5d: fünf Tage und 8d: acht Tage) für jede der fünf Temperturkombiantionen durchgeführt $(\mathrm{n}=4$ mit je 20 Pflanzen). Unterschiedliche Buchstaben desselben Typs kennzeichnen signifikante Unterschiede zwischen der spezifischen Mykotoxinbildung der Temperaturregime (LSD Test mit $\mathbf{p} \leq \mathbf{0 , 0 5}$ ).

Tab. 21 Varianzanalytische Untersuchung der Versuche unter kontrollierten Umweltbedingungen in Klimakammern. Aufgeführt ist, nach künstliche Inokulation, der DON-Gehalt $\left[\mu \mathrm{g} \mathrm{kg}^{-1}\right]$ in Körnern von Sommerweizen (Sorte: Tybalt) nach künstlicher Inokulation mit F. graminearum (Fg 142/143/144) nach verschiedenen Inkubationszeiträumen (Unbehandelt, $3 \times 2$ Tage, 3 x 5 Tage und 3 x 8 Tage), gepoolt über alle fünf getesteten Temperaturkombinationen ( $n=20$ mit jeweils 20 Pflanzen). Unterschiedliche Buchstaben desselben Typs kennzeichnen signifikante Unterschiede zwischen den jeweiligen Versuchsvarianten (LSD Test mit $p \leq \mathbf{0 , 0 5})$. Identische Varianzanalysen $(n=20)$ wurden für den Versuchsfaktor $F$. graminearum DNA und die spezifische Mykotoxinbildung jeweils separat durchgeführt. ${ }^{\text {a) }}$ Die Werte der Variante „Unbehandelt" wurden nur in der Versuchsserie $12^{\circ} \mathrm{C} / 12^{\circ} \mathrm{C}$ erhoben, und nicht für die Varianzanalyse verwendet.

\begin{tabular}{ccccc}
\multirow{2}{*}{ Parameter } & \multicolumn{4}{c}{ Inkubationszeitraum } \\
\cline { 2 - 5 } & Unbehandelt $^{\mathrm{a}}$ & $3 \times 2$ Tage & $3 \times 5$ Tage & $3 \times 8$ Tage \\
\hline DON $\left[\mu \mathrm{g} \mathrm{kg}^{-1}\right]$ & $10825 \mathbf{X}$ & $18184 \mathbf{Y}$ & $26167 \mathbf{Z}$ \\
\hline $\begin{array}{c}\text { a graminearum DNA } \\
{\left[\mu \mathrm{g} \mathrm{kg}^{-1}\right]}\end{array}$ & $0^{\mathrm{a}}$ & $512 \mathbf{x}$ & $1231 \mathbf{~}$ & $2520 \mathbf{z}$ \\
\hline & & & & \\
\hline DON/DNA $\left[\mu \mathrm{g}^{-1}\right]$ & $0^{\mathrm{a}}$ & $24,44 \mathbf{A}$ & $19,88 \mathbf{~ B}$ & $14,58 \mathbf{~ C}$ \\
\hline
\end{tabular}




\subsection{Pathogenitätsversuch an Weizen mit aus Zuckerrüben isolierten Fusa- rium-Isolaten und deren Mykotoxinprofile}

Die Untersuchungen zur Pathogenität verschiedener Fusarium-Arten in diesem Kapitel erfolgten in Kooperation mit Frau Daniela Christ (IFZ), alle erhobenen Daten die hier in Tabellen und Abbildungen zu sehen sind, sind ein Produkt dieser Zusammenarbeit.

Klassische FHB-Symptome (Ausbleichen weiter Teile der Ähre, Ausbildung von Schrumpfkörnern) wurden in diesem Versuch nur bei den mit $F$. graminearum, $F$. culmorum und $F$. cerealis inokulierten Ähren beobachtet. Alle anderen Varianten, abgesehen von der Wasserkontrolle und den mit $F$. oxysporum inokulierten Ähren, zeigten nur Verbräunungen bzw. Aufhellungen einiger Hüll-, Deck- und Vorspelzen (Abb. 20). Da in der Literatur aber alle bisher an Weizen beschriebenen Fusarien zum FHB-Komplex gerechnet werden, wurden hier auch alle Symptome mit dem FHB-Index bewertet.

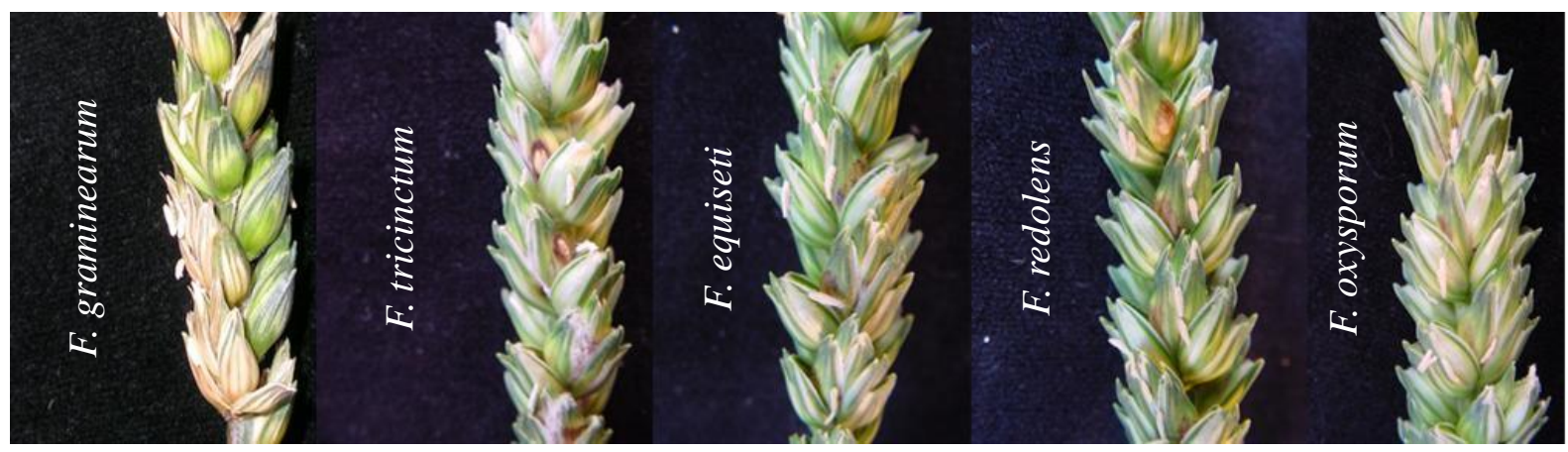

Abb. 20 Symptomausprägungen von Ähreninfektionen mit verschiedenen Fusarium-Arten im Sommerweizen Tybalt nach 14 dpi. $F$. graminearum verursacht eine typische partielle Weißährigkeit an der gesamten Ähre, die übrigen Fusarium-Arten führen zu Verbräunungen und Aufhellungen der Vor-, Deckund Hüllspelzen.

Der FHB-Index zum Boniturtermin 7 dpi zeigte signifikante Differenzen zwischen den klassischen FHB-Bildnern und den Isolaten aus der Zuckerrübe (Tab. 22). Im Vergleich zum Referenzisolat aus dem Winterweizen führte das $F$. graminearum Isolat der Zuckerrübe tendenziell zu einer erhöhten Befallsstärke, was mit den späteren Boniturterminen noch zunahm. Die Symptomausprägung zum Boniturtermin 21 dpi hervorgerufen durch die beiden Isolate von $F$. graminearum lag signifikant höher als bei allen anderen getesteten Isolaten. Von den Fusarium-Arten die keine klassischen FHB-Symptome induzierten, wurden vor allem in den Infektionsvarianten mit $F$. equiseti und $F$. tricinctum signifikant erhöhte Befallsstärken festgestellt. 
Tab. 22 Analyse des FHB-Indexes [\%] im Pathogenitätsversuch in der Sommerweizensorte Kadrilj. Aufgeführt ist der mittlere FHB-Index zu drei verschiedenen Terminen (7,14 und 21dpi) hervorgerufen durch verschiedene Fusarium-Arten. Unterschiedliche Buchstaben desselben Typs kennzeichnen signifikante Unterschiede zwischen der Befallsstärke der künstlichen Inokulationen mit den verschiedenen Arten (Tukey Test mit $p \leq 0,05)$. Die Reisolationen aus dem Erntegut wurden bis auf die Variante $F$. graminearum Fg142/Fg143/Fg144) mit $n=25$ Körnern durchgeführt. ). Die vorliegenden Daten und Tabellen sind ein Produkt der Kooperation mit Frau Daniela Christ (IFZ).

\begin{tabular}{|c|c|c|c|c|c|c|}
\hline \multirow[b]{2}{*}{ Isolat } & \multirow[b]{2}{*}{$\mathrm{n}$} & \multicolumn{3}{|c|}{ FHB Index $(\%)$} & \multicolumn{2}{|c|}{ Reisolation } \\
\hline & & 7 dpi & $14 \mathrm{dpi}$ & $21 \mathrm{dpi}$ & $\mathrm{n}$ & Rate $(\%)$ \\
\hline F. graminearum $\mathrm{Fg} 142$ & 79 & $28,76 \mathbf{a b}$ & $47,35 \mathbf{A}$ & $55,53 \mathbf{v w}$ & & n.d. \\
\hline F. graminearum $\mathrm{O} 14$ & 78 & $30,76 \mathbf{a}$ & $50,96 \mathbf{A}$ & $61,08 \mathbf{v}$ & 25 & 84 \\
\hline F. culmorum $\mathrm{O} 29$ & 77 & $31,94 \mathbf{a}$ & $43,38 \mathbf{A B}$ & $47,23 \mathbf{w x}$ & 25 & 96 \\
\hline F. cerealis $\mathrm{O} 45$ & 77 & $23,23 \mathbf{b}$ & $38,12 \mathbf{B}$ & $43,18 \mathbf{x}$ & 25 & 100 \\
\hline F. oxysporum $\mathrm{O} 38$ & 78 & $0 \mathbf{d}$ & $0 \mathbf{D}$ & $0 \mathbf{z}$ & 25 & 100 \\
\hline F. redolens $\mathrm{O} 1$ & 79 & $0 \mathbf{d}$ & $0,05 \mathbf{D}$ & $0,06 \mathbf{z}$ & 25 & 100 \\
\hline F. equiseti $\mathrm{O} 19$ & 79 & $8,97 \mathbf{c}$ & $15,71 \mathbf{C}$ & $17,11 \mathbf{y}$ & 25 & 89 \\
\hline F. tricinctum $\mathrm{O} 63$ & 80 & $1,13 \mathbf{d}$ & $9,69 \mathbf{C}$ & $12,16 \mathbf{y}$ & 25 & 100 \\
\hline Wasserkontrolle & 80 & $0 \mathbf{d}$ & $0 \mathbf{D}$ & $0 \mathbf{z}$ & 25 & 0 \\
\hline
\end{tabular}

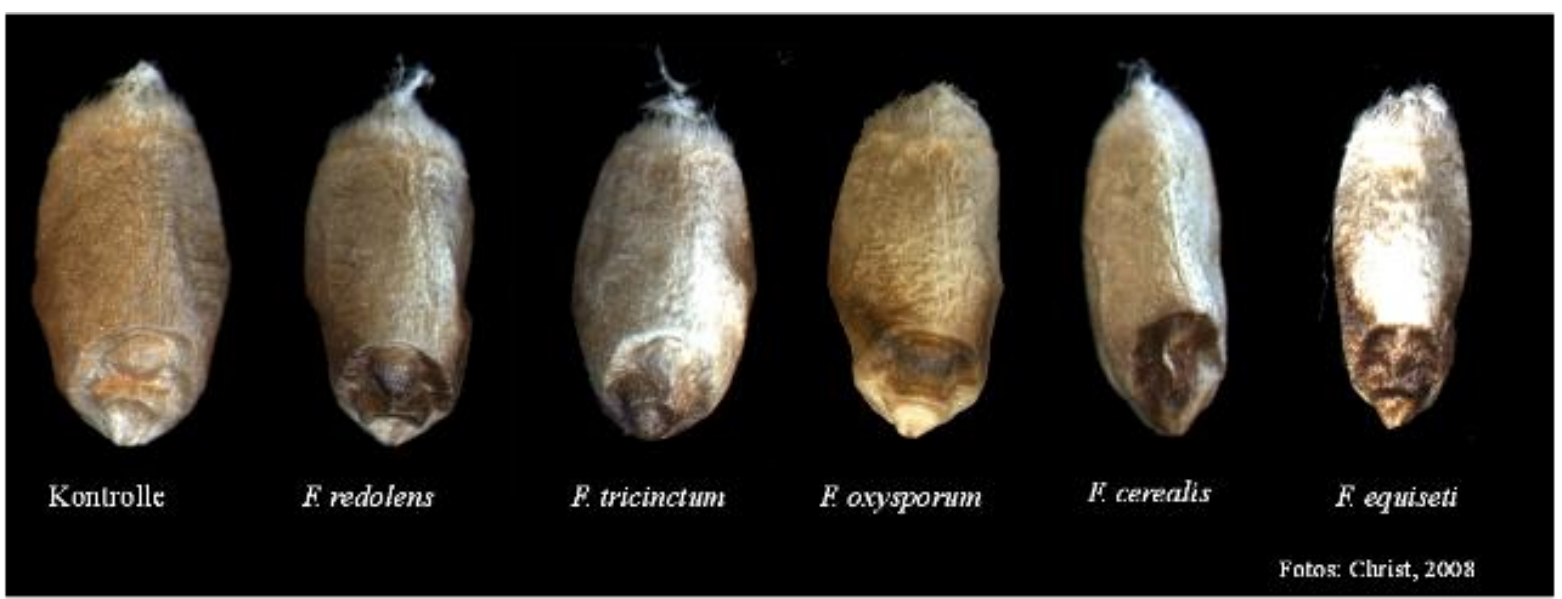

Abb. 21 „Black Point“" Symptome an der Sommerweizensorte Kadrilj, hervorgerufen durch verschiedene Fusarium-Arten 
Zur Überprüfung, ob die zur Inokulation verwendeten Isolate tatsächlich die erhobenen Symptome hervorriefen, wurden Reisolationen aus dem Erntegut durchgeführt. In mehr als 85\% aller Fälle konnte das entsprechende Isolat in den Kornproben identifiziert werden, so dass eine eindeutige Zuordnung der Symptome zu dem dazugehörenden Pilz vorgenommen werden konnte (Tab. 22). Zudem wurden keine Kontaminationen zwischen den Varianten gefunden.
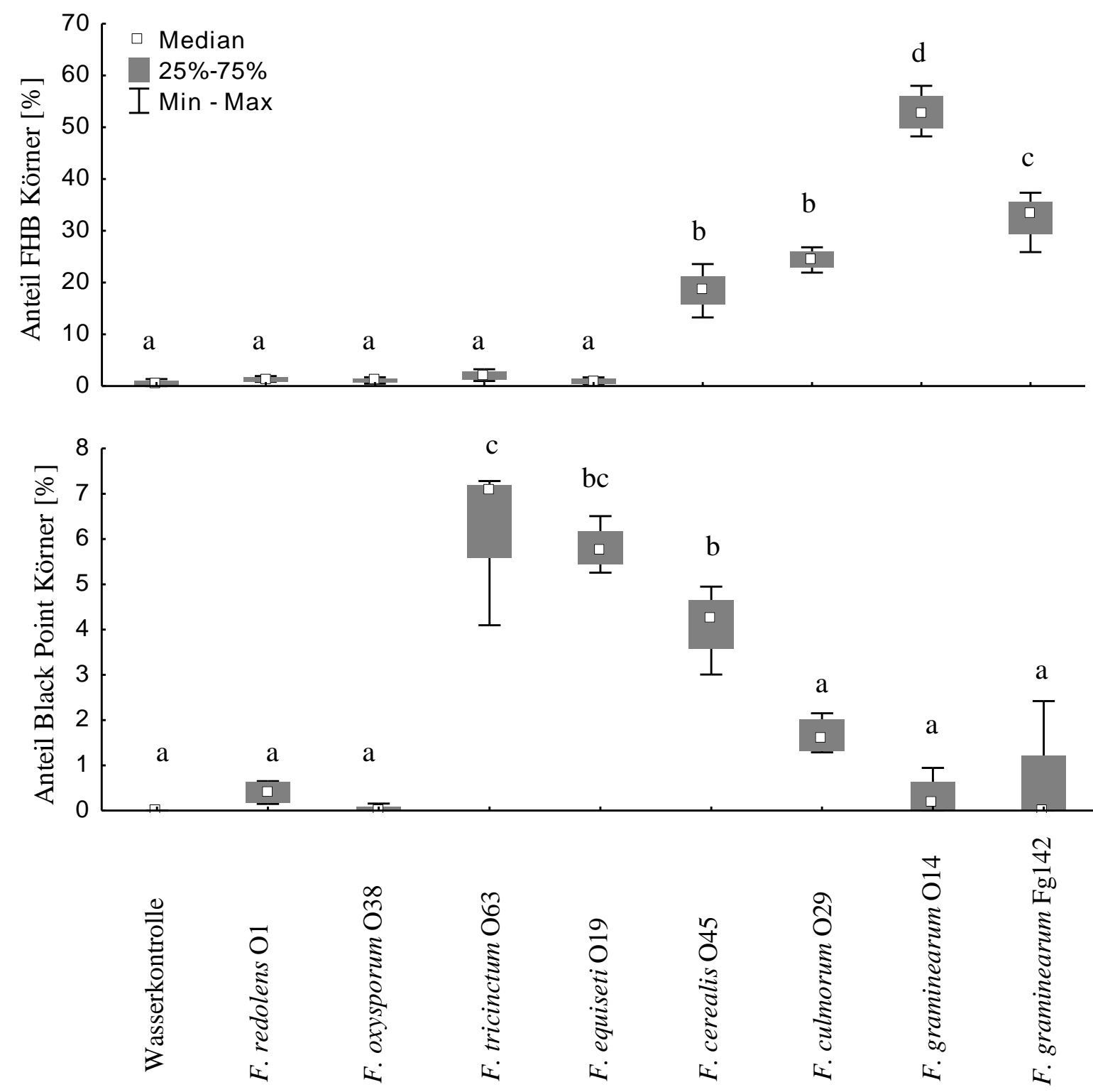

Abb. 22 Häufigkeitsverteilung von „Black Point““ Körnern im Vergleich zu klassischen FHB Körnern im Pathogenitätsversuch. Dargestellt sind für die jeweilige Inokulationsvariante Box-Whisker-Plots mit dem Median. Unterschiedliche Buchstaben kennzeichnen signifikante Unterschiede zwischen dem Anteil der Kornfraktionen in Abhängigkeit von der Inokulation mit den verschiedenen Fusarium-Arten (n $=4$ mit je 20 Einzelpflanzen, Tukey Test mit $p \leq 0,05$ ). Die vorliegenden Daten und Tabellen sind ein Produkt der Kooperation mit Frau Daniela Christ (IFZ). 
Tab. 23 Mykotoxinprofile und -mengen $(\mu \mathrm{g} / \mathrm{kg})$ in Weizenmehl. Weizenähren der Sorte Kadrilj wurden mit versch. Fusarium-Arten aus Zuckerrüben inokuliert. ${ }^{\text {a) }}$ DON: Deoxynivalenol, 3-ADON: 3Acetyldeoxynivalenol, 15-ADON: 15-Acetyldeoxynivalenol, DON-3-G: Deoxynivalenol-3-glucoside, NIV: Nivalenol, FUS X: Fusarenon X, DAS: Diacetoxyscirpenol, MAS: Monoacetoxyscirpenol, ZEA: Zearalenon, BEAU: Beauvericin, ENNI: Enniatin, MON: Moniliformin, AURO: Aureofusarin. Mykotoxinmengen unterhalb der Nachweisgrenze (LOD) sind mit „-" gekennzeichnet; ${ }^{\text {b) }}$ REC: Wiederfindungsrate; ${ }^{c)}$ Ergebnisse wurden um die Wiederfindungsrate korrigiert. Die vorliegenden Daten und Tabellen sind ein Produkt der Kooperation mit Frau Daniela Christ (IFZ).

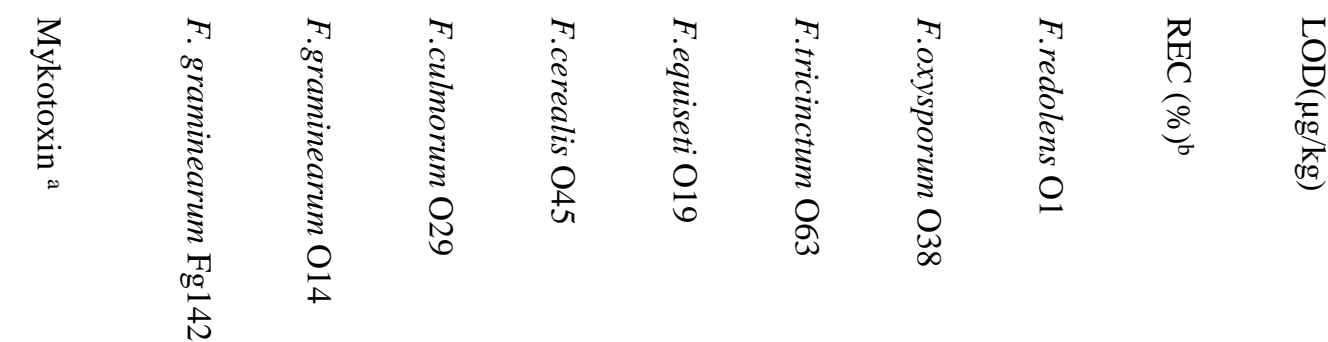

\begin{tabular}{lcccccccccc}
\hline DON & 10520 & 22200 & 89 & 28 & - & - & - & - & 98,00 & 5,00 \\
3-ADON & 70 & 115 & - & - & - & - & - & - & 90,00 & 2,00 \\
15-ADON & 116 & 161 & - & - & - & - & - & - & 105,00 & 30,00 \\
DON-3-G & 1571 & 2240 & 17 & 15 & - & - & - & - & $57^{c}$ & 0.5 \\
NIV & - & 11 & 8239 & 5670 & 634 & - & - & - & $77^{c}$ & 5,00 \\
FUS X & - & - & 755 & 1024 & 370 & - & - & - & 102,00 & 5,00 \\
MAS & - & - & - & - & 78 & - & - & - & 110,00 & 4,00 \\
DAS & - & - & - & - & 3 & - & - & - & 99,00 & 0.7 \\
ZEA & 2 & 1 & - & 5 & - & - & - & - & 90,00 & 0.5 \\
AURO & 487 & 49 & 1403 & 450 & - & 748 & - & - & n.d. & 40,00 \\
BEAU & - & 0,05 & 0,40 & 0,20 & - & 1 & 9 & 40 & 94 & 0,05 \\
ENNI A & - & - & - & - & - & 302 & 49 & 30 & n.d. & 0,10 \\
ENNI A1 & - & - & - & - & - & 2576 & 26 & 24 & n.d. & 0,10 \\
ENNI B & - & - & - & - & - & 3264 & 1 & 3 & n.d. & 0,01 \\
ENNI B1 & - & - & - & - & - & 4820 & 7 & 13 & n.d. & 0,20 \\
ENNI B2 & - & - & - & - & - & 80 & - & - & n.d. & 0,10 \\
MON & - & - & - & - & - & 1650 & - & - & $68^{c}$ & 20,00 \\
\hline
\end{tabular}

Darüber hinaus wurde im Erntegut ein unerwartetes Symptom entdeckt. Der Bereich rund um den Keimling einiger Körner wies eine starke schwärzliche Verfärbung auf, die bis auf den Mehlkörper ausstrahlte und eine Art „Sattelstruktur“ bildete (Abb. 21). Dieses Erscheinungsbild wird in der Literatur als „Black Point“ Symptom bezeichnet. In der Abbildung 22 sind 
die Häufigkeitsverteilungen von klassichen FHB-Körnern (weißliche Kümmerkörner) und Körnern mit dem „Black Point“ Symptom dargestellt. Erwartungsgemäß wurden in den Inokulationsvarianten mit klassischen FHB-Bildnern wie $F$. graminearum, $F$. culmorum und $F$. cerealis hauptsächlich FHB-Körner gefunden und kaum Körner mit „Black Point“ Symptomen. Im Gegensatz dazu bildeten überraschenderweise die Isiolate $F$. equiseti und $F$. tricinctum die signifikant höchsten Mengen an „Black Point“ Körnern. Bei den Isolaten $F$. redolens und F. oxysporum wurden weder distinkt Symptome an den Ähren (Tab. 22) noch schwärzliche Verfärbungen an den Körner identifiziert (Abb. 22).

Der Versuch wurde insgesamt dreimal wiederholt, wobei die Ergebnisse reproduzierbar waren. Zwischen den verschiedenen Fusarium-Arten zeigten sich deutliche Unterschiede in den Mykotoxinprofilen. Das Isolat von F. graminearum O14 aus der Zuckerrübe produzierte ca. zweimal mehr DON als das Referenzisolat aus Winterweizen. Bei beiden handelt es sich um reine DON-Bildner, eine Produktion von Nivalenol konnte nicht beobachtet werden. Im Gegensatz dazu waren die Isolate $F$. culmorum $\mathrm{O} 29$ und $F$. cerealis $\mathrm{O} 45$ typische Nivalenolbildner, wobei die Menge an Nivalenol in der mit $F$. culmorum infizierten Variante deutlich höher war. Das Isolat F. tricinctum O63 zeichnete sich durch die Bildung großer Mengen Moniliformin und verschiedener Enniatine im Erntegut aus. Die Isolate $F$. redolens $\mathrm{O} 1$ und $F$. oxysporum $\mathrm{O} 38$ produzierten ein ähnliches Mykotoxinspektrum, jedoch auf einem erheblich geringeren Niveau (Tab. 23).

\subsection{Untersuchungen zum „Black Point“ Symptom}

Zur besseren Interpretation der Bedeutung von „Black Point“ Symptomen wurden in separaten Inokulationsversuchen der Abteilung Allgemeine Phytopathologie und Pflanzenschutz zusätzlich zur Bestimmung des FHB-Index unterschiedliche Qualitätsparameter geprüft. Dabei wurde der Einfluss von „Black Point“ Symptomen auf die Keimfähigkeit, das TKG und den Mykotoxingehalt untersucht. Die Mykotoxinanalytik beschränkte sich auf die FusariumArten $F$. tricinctum, F. equiseti und $F$. oxysporum. Auf eine Reisolation musste ebenfalls verzichtet werden, da die geernteten Probenmengen zu gering waren und primär für die Analytik genutzt wurden. Der „Black Point““ Innokulationsversuch wurde im April 2009 durchgeführt und im Januar 2010 wiederholt, wobei die Ergebnisse reproduzierbar waren und im folgenden Kapitel wenn nicht anders beschrieben, einzeln dargestellt werden. 
Die varianzanalytische Verrechnung des FHB-Index zum Boniturtermin 7 dpi machte wie in den vorherigen Versuchen die unterschiedlichen Infektionsverläufe zwischen den klassischen FHB-Bildnern und den Fusarium-Arten deutlich, die nur Verbräunungen an den Spelzen hervorrufen. $\mathrm{Zu}$ allen drei Boniturterminen war das Referenzgemisch von F. graminearum aus Weizen das aggressivste. Hier ließ sich die signifikant höchste Befallsstärke im Vergleich zu allen anderen Isolaten (Tab. 24) feststellen. Bei der Betrachtung der Fusarium-Arten aus Zuckerrüben hob sich das Isolatgemisch von $F$. tricinctum signifikant ab. $\mathrm{Zu}$ allen Boniturterminen wurden signifikant höhere Befallsstärken gemessen, die drei bis viermal höher lagen, als in den übrigen Varianten.

Tab. 24 Varianzanalyse des FHB-Index im „Black Point“" Inokulationsversuch vom Januar 2010. Aufgeführt ist der mittlere FHB-Index zu drei verschiedenen Terminen (7,14 und 21 dpi) hervorgerufen durch künstliche Inokulation mit verschiedenen Fusarium-Artengemischen $(F$. graminearum, $F$. tricinctum, $F$. equiseti, $F$. oxysporum und $F$. redolens) an der Sommerweizensorte Tybalt. Unterschiedliche Buchstaben desselben Typs kennzeichnen signifikante Unterschiede zwischen der Befallsstärke der künstlichen Inokulationen mit den verschiedenen Arten (LSD Test mit $\mathbf{p} \leq \mathbf{0 , 0 5}$ ). Die vorliegenden Daten und Tabellen sind ein Produkt der Kooperation mit Frau Daniela Christ (IFZ).

\begin{tabular}{lcccc} 
& \multicolumn{3}{c}{ FHB-Index (\%) } \\
Isolat & $\mathrm{n}$ & $7 \mathrm{dpi}$ & $14 \mathrm{dpi}$ & $21 \mathrm{dpi}$ \\
\hline $\begin{array}{l}\text { F. graminearum } \\
\text { Fg142/Fg143/Fg144 }\end{array}$ & 64 & $19,06 \mathbf{a}$ & $38,11 \mathbf{A}$ & $57,04 \mathbf{z}$ \\
$\begin{array}{l}\text { F. tricinctum } \\
\text { O63/O35/O32 }\end{array}$ & 126 & $7,75 \mathbf{b}$ & $28,90 \mathbf{B}$ & $47,34 \mathbf{y}$ \\
$\begin{array}{l}\text { F. equiseti } \\
\text { O19/O20/O90 }\end{array}$ & 126 & $1,51 \mathbf{c}$ & $8,85 \mathbf{C}$ & $17,46 \mathbf{x}$ \\
$\begin{array}{l}\text { F. oxysporum } \\
\text { O38/O39/O40 }\end{array}$ & 108 & $0,13 \mathbf{c}$ & $1,25 \mathbf{D}$ & $6,40 \mathbf{w v}$ \\
$\begin{array}{l}\text { F. redolens } \\
\text { O1/O4/O7 }\end{array}$ & 108 & $0,26 \mathbf{c}$ & $1,93 \mathbf{D}$ & $13,48 \mathbf{x w}$ \\
Unbehandelt & 64 & $0 \mathbf{c}$ & $0 \mathbf{D}$ & $0 \mathbf{v}$ \\
\hline
\end{tabular}

Im Vergleich zu den Befallsstärken des Pathogenitätsversuches waren in diesem Versuchsaufbau jedoch auch in den Varianten der Isolatgemische $F$. oxysporum und $F$. redolens deutliche Symptomausprägungen im Verlauf der Bonitur an den Ähren zu finden. Die in Tabelle 25 aufgeführten Qualitätsparameter Anteil Körner (\%) und TKG (g) wurden mit Körnern aus dem Versuch im Januar 2010 ermittelt, der Parameter Keimfähigkeit (\%) mit Material aus der Wiederholung des Versuchs im April 2009. Das Referenzisolatgemisch F. graminearum pro- 
duzierte, wie bereits zuvor beobachtet, die geringste Anzahl von Körnern mit „Black Point“ Symptomen. Die höchsten Mengen wurden von den Isolatgemischen $F$. tricinctum und von $F$. oxysporum gebildet. In der Inokulationsvariante der Fusarium spp. aus Zuckerrüben wurden im Erntegut die geringsten Mengen an Körnern mit „Black Point“ Symptomen gefunden, welche mit einem Isolatgemisch von $F$. redolens infiziert wurde. Das deutet auf eine geringe Aggressivität hin, jedoch war auch das TKG der „Black Point“ Körner dieser Variante signifikant geringer als das der entsprechenden symptomlosen Körner. Die größte, signifikante Reduktion des TKGs der „Black Point“ Körner wurde in der Inokulationsvariante mit $F$. tricinctum festgestellt, wo sich die durchschnittliche Masse der symptomatischen Körner nahezu halbierte. Eine deutliche signifikante Reduktion des TKGs wurde ebenfalls beim Isolatgemisch von $F$. equiseti festgestellt, wohingegen eine Inokulation mit dem Isolatgemisch von $F$. oxysporum keine Veränderungen der Korngewichte hervorrief.

Tab. 25 Anteile normaler Körner und Körner mit „Black Point“ Symptom, sowie deren Qualitätseigenschaften nach Inokulation der Ähren der Sorte Tybalt mit versch. Fusarium-Artengemischen. Der Anteil der beiden Kornfraktionen und deren Tausendkorngewicht (TKG) wurden mit den Daten des Pathognitätsversuches vom Januar 2010 berechnet $(F$. tricinctum \& $F$. equiseti $n=7$ mit je 18 Einzelwerten, $F$. oxysporum \& $F$. redolens $n=6$ mit je 18 Einzelwerten, $F$. graminearum \& Unbehandelt $n=4$ mit je 16 Einzelwerten). ${ }^{\text {a) }}$ Die durchschnittliche Keimfähigkeit wurde mit den Daten des Pathogenitätsversuches vom April 2009 erhoben, der Keimtest wurde in der Variante $F$. graminearum mit $\mathbf{n}=20$ Körnern, in den übrigen Varianten mit $\mathbf{n}=\mathbf{4 0}$ Körner durchgeführt. Unterschiedliche Buchstaben zeigen signifikante Unterschiede zwischen den Inokulationsvarianten hinsichtlich des TKG Werts an (LSD Test mit $p \leq 0,05$ ), diese Signifikanzanalyse beschränkte sich auf die Isolatgemische von $F$. tricinctum, $F$. equiseti, $F$. oxysporum, $F$. redolens und die unbehandelte Variante. Die vorliegenden Daten und Tabellen sind ein Produkt der Kooperation mit Frau Daniela Christ (IFZ).

\begin{tabular}{|c|c|c|c|c|c|c|}
\hline \multirow[b]{2}{*}{ Isolat } & \multicolumn{2}{|c|}{ Anteil Körner (\%) } & \multicolumn{2}{|c|}{ TKG $(\mathrm{g})$} & \multicolumn{2}{|c|}{ Keimfähigkeit ${ }^{\mathrm{a}}(\%)$} \\
\hline & Normal & $\begin{array}{l}\text { Black } \\
\text { Point }\end{array}$ & Normal & $\begin{array}{l}\text { Black } \\
\text { Point }\end{array}$ & Normal & $\begin{array}{l}\text { Black } \\
\text { Point }\end{array}$ \\
\hline $\begin{array}{l}\text { F. graminearum } \\
\text { Fg142/Fg143/Fg144 }\end{array}$ & 95,72 & 4,28 & 23,31 & 18,68 & 74,68 & 35,00 \\
\hline $\begin{array}{l}\text { F.tricinctum } \\
\text { O63/O35/O32 }\end{array}$ & 71,51 & 28,49 & $44,46 \mathbf{b}$ & $25,13 \mathbf{d}$ & 95,00 & 77,50 \\
\hline $\begin{array}{l}\text { F.equiseti } \\
\text { O19/O20/O90 }\end{array}$ & 85,61 & 14,39 & $48,91 \mathbf{a}$ & $39,67 \mathrm{c}$ & 92,50 & 65,00 \\
\hline $\begin{array}{l}\text { F.oxysporum } \\
\text { O38/O39/O40 }\end{array}$ & 75,42 & 24,58 & 45,09 b & 44,49 b & 97,50 & 90,00 \\
\hline $\begin{array}{l}\text { F.redolens } \\
\text { O1/O4/O7 }\end{array}$ & 92,05 & 7,95 & $49,88 \mathbf{a}$ & $38,77 \mathbf{c}$ & 96,25 & 87,50 \\
\hline Unbehandelt & 100 & - & $46,95 \mathbf{a b}$ & - & 96,25 & - \\
\hline
\end{tabular}


Auf eine varianzanalytische Verrechnung zusammen mit dem $F$. graminearum Isolatgemisch wurde verzichtet, da eine Unterscheidung zwischen der pathogenbedingten und einer „Black Point" bedingten Reduktion des TKG in dieser Variante nicht möglich erschien. Diese Analyse wurde nur für die Isolatgemische $F$. tricinctum, F. equiseti, F. redolens, F. oxysporum und die unbehandelten Varianten durchgeführt (Tab. 25).

Von Körnern aus Beständen mit starken Fusariuminfektionen ist bekannt, dass sie eine verminderte Keimfähigkeit besitzen. In der Variante mit dem Isolatgemisch von $F$. graminearum war dies deutlich erkennbar, in der symptomlosen Kornfraktion verringerte sich die Keimfähigkeit auf ca. 75\% und in der „Black Point“ Fraktion sogar auf 35\% (Tab. 25). Bei den Verbräunungen induzierenden Fusarium-Arten reduzierten nur die Isolatgemische von $F$. tricinctum und F. equiseti die Keimfähigkeit in der Fraktion der „Black Point“ Körner in einem ähnlichen Maße. In der Gruppe der symptomlosen Körner wurden Reduktionen um maximal $8 \%$ beobachtet.

Der Vergleich der Mykotoxinprofile der beiden Kornfraktionen zeigte deutliche Unterschiede in der Quantität der einzelnen Sekundärmetaboliten. Das Isolatgemisch von F. tricinctum produzierte, wie im Pathogenitätsversuch bereits beobachtet, große Mengen an verschiedenen Enniatin-Gruppen, wobei die Gehalte in der Fraktion der „Black Point“ Körner um den Faktor 3 bis 8 höher war als bei den symptomlosen Körnern. Vom Sekundärmetabolit Enniatin B1 wurden mit $37.500 \mu \mathrm{g} / \mathrm{kg}$ die höchsten Mengen in dieser Kornfraktion festgestellt (Tab. 26), die darüber hinaus auch beachtenswerte Mengen von weniger bekannten Mykotoxinen wie Aurofusarin und Aminodimethyloctodecanol aufwies. In den Kornproben, welche durch ein Isolatgemisch von $F$. equiseti infiziert wurden, konnten vor allem die Mykotoxine Nivalenol, Monoacetoxyscirpenol und Equisetin analysiert werden. Auch hier wurden in der „Black Point" Kornfraktion 3-7 mal höhere Mengen gemessen als in der symptomlosen Kornfraktion. Trotz eines relativ hohen Anteils von „Black Point“ Körnern in der Inokulationsvariante mit dem F. oxysporum-Isolatgemisch (Tab. 25) wurden hier die geringsten Mengen an Mykotoxinen ermittelt. Einzig Beauvericin zeigte in der Kornfraktion der „Black Point“ Körner einen leicht erhöhten Wert an, ansonsten waren hier keine Unterschiede in den Mykotoxinbelastungen feststellbar. 
Tab. 26 Mykotoxinprofil und -mengen $[\mu \mathrm{g} / \mathrm{kg}]$ in Weizenmehl des „Black Point" Inokulationsversuches. Weizenähren der Sommerweizensorte Tybalt wurden mit Fusarium-Arten inokuliert $(F$. tricinctum, $F$. equiseti und $F$. oxysporum), die aus Zuckerrüben isoliert wurden. Die Kornfraktionen wurden visuell getrennt in Normale Körner (N) und Körner mit „Black Point" Symptom (BP) und analysiert. Ein Multiplikatorfaktor (F) wurde aus der Division der Mykotoxingehalte der beiden Kornfraktionen berechnet und grau hinterlegt. a) NIV: Nivalenol, DAS: Diacetoxyscirpenol, MAS: Monoacetoxyscirpenol, BEAU: Beauvericin, ENNI: Enniatin, MON: Moniliformin, AURO: Aurofusarin, EQUI: Equisetin, CHLAM: Chlamydosporol, AVE Y: Avenacein Y, FUS A: Fusarinsäure, 2-AOD-3-ol: Aminodimethyloctodecanol, s: Mykotoxinmengen, die geringfügig oberhalb der Nachweisgrenze liegen; ${ }^{\text {b) }}$ Für die Inokulationsvarianten $F$. tricinctum und $F$. equiseti wurden jeweils die Wiederholungen 1-3 und 47 gepoolt, analysiert und die Mittelwerte der zwei Analysen berechnet ${ }^{\text {c) }}$ für die Variante F. oxysporum wurden die Wiederholungen 1-7 gepoolt und nur eine Analyse durchgeführt. Mykotoxinmengen unterhalb der Nachweisgrenze (LOD) sind mit ,-" gekennzeichnet ${ }^{\text {d) }}$ REC: Wiederfindungsrate ${ }^{\text {e) }}$ Ergebnisse wurden um die Wiederfindungsrate korrigiert. Die vorliegenden Daten und Tabellen sind ein Produkt der Kooperation mit Frau Daniela Christ (IFZ).

\begin{tabular}{|c|c|c|c|c|c|c|c|c|c|c|c|}
\hline \multirow[t]{2}{*}{ 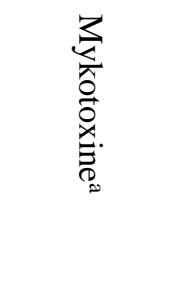 } & \multicolumn{3}{|c|}{$\begin{array}{l}\text { F.tricinctum }{ }^{\mathrm{b}} \\
\text { O63/O35/O32 }\end{array}$} & \multicolumn{3}{|c|}{$\begin{array}{c}\text { F.equiseti }{ }^{\mathrm{b}} \\
\text { O19/O20/O90 }\end{array}$} & \multicolumn{3}{|c|}{$\begin{array}{l}\text { F.oxysporum } \\
\text { O38/O39/O40 }\end{array}$} & \multirow[t]{2}{*}{ 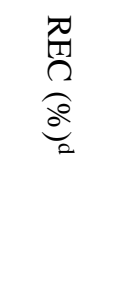 } & \multirow[t]{2}{*}{ 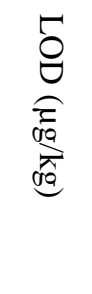 } \\
\hline & $\mathrm{N}$ & $\mathrm{BP}$ & $\mathrm{F}$ & $\mathrm{N}$ & $\mathrm{BP}$ & $\mathrm{F}$ & $\mathrm{N}$ & $\mathrm{BP}$ & F & & \\
\hline NIV & - & - & & 555 & 3750 & 6,8 & - & - & & $77,00^{\mathrm{e}}$ & 5,00 \\
\hline MAS & - & - & & 600 & 2400 & 4,0 & - & - & & 110,00 & 4,00 \\
\hline DAS & - & - & & 7,9 & 33 & 4,2 & - & - & & 99,00 & 0.7 \\
\hline BEAU & $\mathrm{s}$ & $\mathrm{s}$ & & 7,5 & 6,7 & 0,9 & 290 & 380 & 1,3 & 94,00 & 0,05 \\
\hline ENNI A & 1005 & 5850 & 5,8 & $\mathrm{~s}$ & $\mathrm{~s}$ & & 0,5 & 0,2 & 0,4 & n.d. & 0,10 \\
\hline ENNI A1 & 4850 & 19500 & 4,0 & $\mathrm{~s}$ & $\mathrm{~s}$ & & 150 & 160 & 0,9 & n.d. & 0,10 \\
\hline ENNI B & 3200 & 9000 & 2,8 & $\mathrm{~s}$ & $\mathrm{~s}$ & & 5,1 & 6,5 & 0,8 & n.d. & 0,01 \\
\hline ENNI B1 & 8000 & 37500 & 4,7 & $\mathrm{~s}$ & $\mathrm{~s}$ & & 46 & 49 & 0,9 & n.d. & 0,20 \\
\hline ENNI B2 & 200 & 1650 & 8,3 & $\mathrm{~s}$ & $\mathrm{~s}$ & & - & - & & n.d. & 0,10 \\
\hline MON & 715 & 4150 & 5,8 & - & - & & 27 & 27 & 1 & $68,00^{\mathrm{e}}$ & 20,00 \\
\hline AUREO & 1025 & 7200 & 7,0 & - & - & & - & - & & $114,80^{\mathrm{e}}$ & 12,00 \\
\hline EQUI & - & - & & 185 & 555 & 3,0 & - & - & & $211,60^{\mathrm{e}}$ & 6 \\
\hline CHLAM & 104 & 575 & 5,5 & - & - & & - & - & & $58,90^{\mathrm{e}}$ & 8 \\
\hline AVE Y & - & 120 & & - & - & & - & - & & $83,10^{\mathrm{e}}$ & 10 \\
\hline FUS A & 100 & 525 & 5,3 & - & - & & - & - & & $85,50^{\mathrm{e}}$ & 30 \\
\hline 2-AOD-3-ol & 555 & 4800 & 8,6 & - & - & & - & - & & $5,70^{\mathrm{e}}$ & 160,00 \\
\hline
\end{tabular}




\section{$4 \quad$ Diskussion}

Vom Zeitpunkt der Identifizierung der chemischen Struktur des Mykotoxins Deoxynivalenol durch Yoshizawa \& Morooka (1973) aus kontaminierten Gerstenkörnern an stellte sich unverzüglich die Frage in wie weit verschiedene agronomische Faktoren die Belastungen des Erntegutes mit diesen Sekundärmetaboliten beeinflussen bzw. verringern können. Im Rahmen der vorliegenden Arbeit wurden Versuche unter kontrollierten und Freilandbedingungen durchgeführt, in denen der bis heute unklare Einfluss der verschiedenen Faktoren auf die Mykotoxinbildung, die Pilzbiomasse bzw. die spezifische Mykotoxinbildung typischer Ährenfusariosen wie $F$. graminearum und $F$. culmorum untersucht wurde. Die Diskussion setzt sich zunächst mit grundsätzlichen Fragestellungen der Versuche auseinander, bevor jeweils auf die einzelnen Versuchsfakoren und deren Interaktionen eingegangen wird. Den Abschluss der Diskussion bilden die Kapitel zur Pathogenität verschiedener Fusarium-Arten aus Zuckerrüben und die mögliche Nutzung des „Black Point“ Symptoms als Indikator für Mykotoxinkontaminationen.

\subsection{Methodische Fragestestellungen zu Versuchen mit FHB im Feld und Ge- wächshaus}

\subsubsection{Boniturparameter}

Bei vielen Feldversuchen tritt das Problem auf, dass nur ein schwacher Zusammenhang zwischen der visuellen Befallsbonitur und den späteren mikrobiologischen und biochemischen Analysen im Labor besteht. Gleiches ist häufiger bei der partiellen Weißährigkeit und den Mykotoxingehalten der aufgearbeiteten Getreideproben festzustellen. Mehrere visuelle Boniturschlüssel stehen hier zur Verfügung, welche verschiedene Vorzüge und Nachteile haben. Bai \& Shaner (1994) postulierten eine bessere Eignung der Befallsstärke zur Bewertung der Resistenzeigenschaften verschiedener Weizensorten gegenüber Fusarium spp. in großen Screeningprogrammen bei künstlicher Infektion und entsprechend hohem Befallsdruck. Jedoch ist die Erfassung der reinen Befallshäufigkeit das am häufigsten genutzte Boniturverfahren, da die Erhebung der Werte unter allen Befallsbedingungen, schnell und relativ einfach möglich ist und zuverlässige Ergebnisse liefert.

Im FAEN-Feldversuch wurde ebenfalls der Zusammenhang zwischen den Mykotoxingehalten und der Befallshäufigkeit partiell ausgeblichener Ähren hergestellt (Abb. 13). Es zeigte sich das in einem mittleren bis schwachen Befallsjahr wie 2009, eine sehr enge Korrelation zwi- 
schen diesen beiden Parametern mit einem Bestimmtheitsmaß von $r^{2}=0,81$ bestand. Dies konnte erwartungsgemäß im Versuchsjahr 2008 bei minimalem Befall mit Ährenfusariosen nicht bestätigt werden. Bereits Koch et al. (2006) stellten geringe bis keine aussagekräftigen Korrelationen bei geringem Befallsdruck fest. Überraschenderweise war aber auch die Korrelation zwischen der Befallshäufigkeit und den Mykotoxingehalten in einem Starkbefallsjahr wie 2007 trotz stärkerer Symptomausprägung deutlich geringer $\left(r^{2}=0,40\right)$. Vor allem bei hohen Befallshäufigkeiten wichen die Werte weit von der Regressionsgeraden ab, d.h. ihre wahren Werte wurden beim Bonitieren unter- bzw. überschätzt so dass zu überlegen ist, ob die Befallshäufigkeit das tatsächliche Befallsgeschehen unter allen Infektionsbedingungen realistisch wiederspiegelt. Wilcoxson et al. (1992) entwickelten einen neuen Parameter, den sogenannten Fusarium Head Blight Index (FHB-Index) der diesen Problemen in der Praxis Rechnung trägt. Hierbei handelt es sich um ein Produkt aus der Befallshäufigkeit und der Befallsstärke. Für 2007 war das Bestimmtheitsmaß des FHB-Index mit $r^{2}=0,82$, im Vergleich zur Befallshäufigkeit $\left(r^{2}=0,40\right)$ deutlich enger korreliert und vergleichbar mit den Ergebnissen des Versuchsjahres 2009. Singuläre ausgeblichene Ährchen pro Ähre wurden hierbei nicht überschätzt und komplett ausgeblichene Ähren nicht unterschätzt, so dass dieser Parameter verlässlichere Daten liefern kann (Groth et al., 1999). Dieser Index ist jedoch nur für mittlere bis stärkere Befallsszenarien, bzw. für Gewächshausversuche zu verwenden, da zur Bestimmung der Befallsstärke eine ausreichende Menge an symptomatischen Ähren vorhanden sein muss. Bei Befallssituationen wie in den Versuchsjahren 2008 und 2009 kann nur die Befallshäufigkeit erfasst werden.

\subsubsection{Probennahme}

In Feldversuchen außerhalb des Gewächshauses in denen in der Regel mehr Material anfällt als für Analysen benötigt wird, ist eine repräsentative Probennahme zur Messung der Mykotoxine und DNA-Mengen ein wichtiger Einflussfaktor für valide Ergebnisse. Die Verteilungen von Mykotoxinbelastungen innerhalb einzelner Parzellen zeigen bereits auf kurzen Distanzen hohe Variabilitäten (Hart \& Schabenberger, 2001), was eine gleichmäßige Belastung des Erntegutes nahezu ausschließt. Es ist daher zu prüfen, wie viele Beprobungen pro Parzelle (Wiederholung) notwendig sind, um eventuelle Variationen der Mykotoxinverteilung innerhalb einer Parzelle auszugleichen, um reproduzierbare und belastbare Werte zu erhalten. In Untersuchungen zum optimalen Probennahmedesign kamen Hart \& Schabenberger (2004) zu dem Ergebnis, das zu einer substanziellen Verringerung der Variation des DON-Gehalts min- 
destens vier Wiederholungen pro Untersuchungseinheit notwendig waren, wobei jede Wiederholung zusätzlich noch mit bis zu vier technischen Wiederholungen überprüft wurde. Die GIPSA (Grain Inspection, Packers and Stockyards Administration) der USA führte seit 1995 als Konsequenz für jeden Transportertypus von Getreideprodukten ein Handbuch ein, nach dessen Vorgaben entweder nach einem sieben bzw. neun Punktesystem Proben gleichmäßig genommen werden müssen, um repräsentative Werte zu erhalten (USDA-GIPSA, 1995). Darüber hinaus müssen alle gewonnenen Proben nach einem Standardprotokoll gereinigt werden, so dass alle Analysen mit vergleichbarem Material durchgeführt werden. In einem Verbundprojekt wie FAEN, wo mehrere Arbeitsgruppen mit dem identischen Material arbeiten, kann genau dies problematisch werden. In den ersten Versuchsjahren standen nicht allen Institutionen die gleichen Reinigungsmaschinen zur Verfügung, so dass sich die Aufbereitungsschritte der Proben unterschieden. Infolgedessen traten teilweise trotz Parallelproben aus gleichen Parzellen, bei den DNA-Analysen und den Mykotoxinnachweisen zwischen den Teilprojekten innerhalb FAEN, erhebliche Unterschiede auf. Durch eine engere Zusammenarbeit wurden diese Probleme durch Festlegung einer einheitlichen Probenaufbereitung gelöst. Generell ist aber zu überlegen, ob eine einzige Analyse mit $5 \mathrm{~g}$ Mehl für das Mykotoxin DON einen repräsentativen Wert für das gesamte Erntegut einer Parzelle (15-25 kg) darstellt bzw. wie hoch eine akzeptable Varianz wäre. Durch das in diesen Versuchen durchgeführte Vermahlen von ca. $500 \mathrm{~g}$ des Gesamterntegutes, erhöht sich zwar die Uniformität des Produktes und es kommt zu einer gleichmäßigeren Verteilung der Mykotoxine (Champeil et al., 2004), dieser Prozess hat aber nicht den varianzreduziernden Effekt möglicher technischer Wiederholungen pro Parzelle. Für eine Analysenoptimierung ist natürlich der Kostenfaktor entscheidend, der bei Mykotoxinanalysen zwischen $6 €$ (DON-ELISA) und 20-180€ (Multitoxin HPLC-MS/MS) liegen kann. In einem so komplexen Versuch wie dem FAENVerbundprojekt mit bis zu fünf verschiedenen Versuchsfaktoren, würden sich durch eine reine Erhöhung der Wiederholungen, die Analysekosten unverhältnismäßig steigern lassen, ohne daß ein Mehrwert an wahren Ergebnissen zu erwarten ist. Eine an die Versuche adaptierte Analyse wäre daher sinnvoll. So wäre in Versuchsjahren wie 2008 in denen kein Befall mit Fusarium spp. in den Feldversuchen festzustellen war, eine Fokussierung auf das Leittoxin DON mittels ELISA-Untersuchung ausreichend, die schnell und relativ kostengünstig durchzuführen wäre. Teure und arbeitsaufwändigere HPLC-MS/MS-Nachweise sollten auf Analysen in Starkbefallsjahren, bei künstlichen Inokulationen im Feld oder für Gewächshausversuche verwendet werden. Noch schwieriger als die exakte Erfassung der Mykotoxingehalte in Erntepartien ist die Messung des DNA-Gehaltes der FHB-Bildner F. culmorum und $F$. 
graminearum, da sich die untersuchte Menge noch einmal um den Faktor 50 von 5 g Probenmaterial auf $0,1 \mathrm{~g}$ verringert. Trotz der anscheinend hohen Korrelation zwischen diesen beiden Parametern unter starken und mittleren Befallsbedingungen (Abb. 14) sind keine Untersuchungen bekannt, die die Variation dieses Parameters in größeren Partien im Erntegut überprüft haben. Es wäre somit sinnvoll die Streuung des DNA-Gehaltes in Abhängigkeit von der Wiederholungsanzahl in Parzellen unter verschiedenen Befallsszenarien zu messen, um über eine Anpassung des Analysenumfanges sicherere Ergebnisse zu erhalten.

\subsection{Einflussfaktoren der Mykotoxinbildung}

\subsubsection{Jahres- bzw. Witterungseffekt}

Typischerweise kann die durch $F$. graminearum verursachte partielle Weißährigkeit in Abständen von bis zu mehreren Jahren sporadisch und zufällig in Weizenbeständen auftreten $(\mathrm{Xu}, 2003)$. In Kanada kam es in den letzten 60 Jahren theoretisch nur alle 9 Jahre zu einem verstärkten Befall mit Ährenfusariosen (Sutton, 1982), was die enge Kopplung des Pathogens mit einer notwendigen infektionsfördernden Witterung deutlich aufzeigt (Hooker et al., 2002). Die Anfälligkeit der Weizenähre für Ähreninfektionen ist zum Zeitpunkt der beginnenden Vollblüte (BBCH 63) am Höchsten (Pugh et al., 1933), so dass Infektionen hauptsächlich über frisch aufgeblühte Ährchen erfolgen können. Vom Zeitpunkt des Ährenschiebens (BBCH 55) bis zum Ende der Blüte (BBCH 69) besitzen Fusariensporen zwar ebenfalls die Fähigkeit die Ährchen zu besiedeln, die Effektivität der Infektionen fällt jedoch außerhalb des Maximums der Optimumskurve stark ab (Brandfaß \& Weinert, 2009). Als Inokulum können Makrokonidien, Chlamydosporen und Hyphenreste von F. graminearum dienen. Die wichtigste Quelle stellen jedoch die Perithezien dar, die auf organischen Resten am Boden unter feucht-warmen Witterungsbedingungen $\left(16^{\circ} \mathrm{C}\right.$ bis $\left.31^{\circ} \mathrm{C}\right)$ wachsen (Tschanz et al., 1976) und in den Temperaturbereichen zwischen $13^{\circ} \mathrm{C}$ und $33^{\circ} \mathrm{C}$ flugfähige Askosporen produzieren können (Abb. 4). Der Wind ist der Vektor zur Ähre und somit zur primären Infektionsstelle (Atanasoff, 1920), jedoch ist der Mechanismus der Ausschüttung der Askosporen immer noch umstritten. Tschanz et al. (1975) stellten ein Austrocknen der Perithezien fest, dass zu einer Ausschüttung der Sporen führte. Dies steht jedoch im Widerspruch mit den Beobachtungen im Feld, wo Askosporenausschüttungen hauptsächlich unmittelbar nach Regenereignissen gemessen wurde (Paulitz, 1996) und Trail et al. (2002), wobei ein Herausschleudern der Askosporen auch unter hohen Luftfeuchten $(\varphi>92 \%)$ nachwiesen werden konnte. Zusammen- 
fassend bedeutet dies, dass eine Koinzidenz von Weizenpflanzen, die sich im Entwicklungsstadium der Vollblüte befinden und eine lang anhaltende, feucht warme Witterung mit Niederschlagsereignissen notwendig für ein großflächiges Auftreten der partiellen Weißährigkeit ist. Zusätzlich muss eine ausreichende Inokulumproduktion vor dem eigentlichen Infektionszeitpunkt gewährleistet sein und überdies ist es zwingend notwendig, dass die gebildeten Askosporen bzw. Makrokonidien zum Zeitpunkt der Vollblüte durch Regen und Wind in die Ährchen gelangen (Obst, 2000). Aufgrund dieser Kausalzusammenhänge wurden Prognosemodellen wie expert.classic von proPlant entwickelt um Wahrscheinlichkeiten für das Auftreten von Fusarienähreninfektionen anhand meteorologischer bzw. klimatischer Parameter, zu bestimmen (www.proplant.de, 2010). Daneben wurden bereits auch wegen der häufig hohen Korrelationen zwischen der Feldbefallsstärke und den DON-Kontaminationen (siehe Sortenversuch Wetze, Abb. 16), mit nahezu identischen Parametern Modelle entwickelt, die in der Lage sind approximativ die DON-Kontamination im Erntegut zu prognostizieren (Hooker et al., 2002). Die Temperatur- und Feuchtebedingungen, insbesondere ihre Interaktionen, sind dabei Schlüsselfaktoren für einen Ährenbefall mit F. graminearum und somit auch für die spätere Kontamination des Ernteguts mit Mykotoxinen. Sie sind daher zentrale Bestandteile dieser Modelle. Im FAEN-Versuch bot das Versuchsjahr 2007 vom Zeitpunkt des Ährenschiebens bis zur Ernte günstige Infektionsbedingungen mit einer relativ hohen Temperatursumme im Mai und Juni und häufigen Niederschlagsereignissen von mehr als $5 \mathrm{~mm}$ pro Tag. Im Gegensatz dazu verhinderten eine Frühsommertrockenheit im Mai 2008 und ungünstige, hohe Temperaturen zur Blüte mit extrem geringen Niederschlägen eine natürliche Infektion mit F. graminearum in den Ähren und somit eine Mykotoxinakkumulation im Erntegut. Eine kühle Witterung mit Tagesdurchschnittstemperaturen von $<6^{\circ} \mathrm{C}$ und Bodenfrost zum Zeitpunkt der Weizenblüte (Abb. 11 \&Tab. 3) verhinderten auch im Jahr 2009 trotz gleichmäßigerer Niederschläge als 2008 einen Starkbefall mit Fusariosen und führten zu signifikant geringeren Mykotoxinbelastungen des Weizens. Der Vergleich dieser Temperaturund Niederschlagsdaten der drei Versuchsjahre im FAEN-Feldversuch zeigte drei distinkte Witterungs- und somit Infektionsszenarien, was zu signifikant unterschiedlichen DONKontaminationen im Weizen zwischen den Jahren 2007 und 2008/2009 führte (Tab. 7). Mykotoxinkontaminationen von bis zu $80.000 \mu \mathrm{g}$ DON kg${ }^{-1}$ Mehl wurden im Versuchsjahr 2007 gemessen, 2009 bis $\mathrm{zu} 4.000 \mu \mathrm{g}$ DON kg${ }^{-1}$ Mehl und im Jahr 2008, bei sehr geringem Fusarienbefall, nur bis zu $600 \mu \mathrm{g}$ DON kg${ }^{-1}$ Mehl (Abb. 11). Gleiches wurde auch bei der Gesamtvarianzanalyse der DON-Gehalte aller Versuchsfaktoren und ihrer Interaktionen deutlich. Der Versuchsfaktor Jahr und somit die Witterung wies den höchsten F-Wert aller Fakto- 
ren auf und besaß somit einen höchst signifikanten Einfluss ( $\mathrm{p}<0,0001)$ auf den Mykotoxingehalt. Dieser Effekt war so hoch, dass sogar die unmittelbaren Interaktionen des Jahres wie z.B. Jahr*Vorfrucht und Jahr*Fungizid selbst noch signifikant waren (Tab. 4). Auch die Varianzkomponentenanalyse bestätigte diese Resultate, ca. 20\% der Gesamtvariation des DONGehaltes im gesamten Versuchszeitraum 2007-2009 konnte mit Hilfe des Faktors Jahr bzw. der Jahreswitterung bestimmt werden (Tab. 5). Dieser Wert ist zwar deutlich geringer als der von Schaafsma et al. (2001) bestimmte Jahreseffekt von 48\%, da sich die Feldversuche des FAEN Verbundprojektes jedoch auf die Landkreise Göttingen und Northeim beschränkten und in einem von drei Versuchsjahren so gut wie kein Ährenfusarienbefall auftrat, besitzt er dennoch für den Raum Südniedersachsen eine hohe Aussagekraft. Die realen Größen einzelner Versuchsfaktoren auf den DON-Gehalt wurden beim Vergleich der Faktoreffekte deutlich (Tab. 8). Zwischen den Jahren 2007 und 2008 ergab sich ein Wert von 74, der sich auf 12,8 zwischen den Jahren 2007 und 2009 verringert (Tab. 8). Dies bedeutet, dass die Mykotoxingehalte im Erntegut des Jahres 2007, unter sonst gleichen Bedingungen, nur aufgrund der unterschiedlichen Witterung 74-mal höher waren als im Jahr 2008. Der Vergleich eines durchschnittlichen Befallsjahres wie 2009 mit den Werten aus 2007 machte auch die Ausnahmestellung dieses Starkbefallsjahres deutlich. Befallshäufigkeiten von bis zu 70\% (Abb. 13) unter natürlichen Infektionsbedingungen sind ungewöhnlich (Pomeranz et al., 1990) und Mykotoxinkontaminationen in Weizenproben von bis zu $80.000 \mu \mathrm{gDON} \mathrm{kg}^{-1}$ Mehl nur aus künstlichen Inokulationsversuchen bekannt (eigene Daten, unveröffentlicht). Anhand der vorliegenden Daten ist deutlich zu erkennen, dass durch ein optimales Zusammenwirken mehrerer Witterungsparameter zu einem infektionsgünstigen Zeitpunkt auch unter natürlichen Feldbedingungen ein Starkbefall mit $F$. graminearum in Kombination mit unerwartet hohen Mykotoxinbelastungen hervorgerufen werden kann.

Ein weiterer Effekt, welcher in den drei Versuchsjahren des FAEN-Versuches durch das Jahr bzw. die Witterung beeinflusst wurde, war der Standort. Signifikante Differenzen der DONGehalte konnten 2007 zwischen den Standorten Torland und Gladebeck festgestellt werden (Tab. 7). Die Gesamtvarianzanalyse über alle drei Versuchsjahre wies einen höchst signifikanten Effekt für den Standort auf ( $\mathrm{p}<0,0001$ ) (Tab. 4). Insgesamt konnten ca. 4\% der Gesamtvariation des Mykotoxingehaltes diesem Versuchsfaktor im Versuchszeitraum von 20072009 zugeordnet werden (Tab. 5). Wurden diese Komponentenanalysen für jedes Jahr einzeln durchgeführt und der Jahreseffekt außen vor gelassen, stiegen für den Versuchsfaktor Standort die Anteile an der Gesamtvarianz auf bis zu 15\% an, unabhängig von der Stärke des Auftretens von Ährenfusariosen in den Jahren 2007 und 2009 (Tab.6). Kam es jedoch nur zu ei- 
nem minimalen Infektionsereigniss wie im Versuchsjahr 2008, verringerten sich die Standorteffekte auf ca. 1\%. Der relative Einfluss der beiden Standorte war unter den bereits beschriebenen, verschiedenen Infektionsbedingungen in den Befallsjahren 2007 und 2009 nahezu identisch (2007: 3,0 und 2009: 3,3) (Tab. 8), was darauf hindeutet, dass es sich hierbei unter Befallsbedingungen um einen relativ konstanten und möglicherweise berechenbaren Faktor handelt. Die Getreideproben vom Standort Torland, im Windschatten eines Höhenzuges und relativ nah an einem Fluss gelegen, wiesen bei erhöhtem Befallsdruck in der Regel einen dreimal höheren durchschnittlichen Mykotoxingehalt auf als Proben vom Standort Gladebeck (Tab. 8). Die Lage dieses Standortes in einer weiträumigen Ebene scheint einen Befall mit Fusarium spp. aufgrund vermutlich höherer Windgeschwindigkeiten und einer schnelleren Abtrocknung der Ähren nicht zu begünstigen. Dies sollte in den folgenden Jahren jedoch erst durch Messungen der relevanten Witterungsparameter, direkt an den Standorten überprüft und mit den Befalls- und Mykotoxinwerten der Versuche abgeglichen werden, bevor eine abschließende Bewertung dieses Faktors vorgenommen werden kann.

Für eine exaktere Bewertung der klimatischen Faktoren wie die Temperatur und die Dauer von Feuchteperioden, ihrer Interaktionen und deren Einfluss auf DON-Bildung in planta, wurden fünf Versuchsserien mit verschiedenen Tag-Nacht-Temperaturregimen in Klimakammern durchgeführt. F. graminearum besitzt in vitro einen breiten Temperaturtoleranzbereich zwischen $10^{\circ} \mathrm{C}$ und $25^{\circ} \mathrm{C}$ in dem das Myzelwachstum ansteigend ist, das Optimum wurde bei $25^{\circ} \mathrm{C}$ festgestellt (Brennan et al., 2003). Je geringer die Temperaturen, desto geringer war auch das Wachstum des Pilzes nach künstlicher Inokulation an Weizen in der Klimakammer. Bei einer Tag-Nacht-Temperatur von $12^{\circ} \mathrm{C}$ wurden nur wenige Symptome und zum Zeitpunkt 24 dpi mit 15,88\% der signifikant geringste FHB-Index aller Temperaturvarianten festgestellt (Tab. 20). Für F. culmorum wurde in vitro bei $15^{\circ} \mathrm{C}$ eine Wuchsreduktion, im Vergleich zum Optimum um 40-50\% beobachtet (Magan et al., 2002), diese aktuellen Studien zu F. graminerarum zeigten sogar eine Symptomreduktion von über $80 \%$ im Vergleich zu den günstigeren Temperaturkombinationen (Tab. 20). Tag-Nacht-Kombinationen wie z.B. $20^{\circ} \mathrm{C} / 16^{\circ} \mathrm{C}$ oder vor allem $25^{\circ} \mathrm{C} / 16^{\circ} \mathrm{C}$ führten bei den Inkubationsvarianten von 8 Tagen beide zum vollständigen Ausbleichen aller Ähren und somit zu einer Befallsstärke von nahezu $100 \%$. Die Kombination aus einer Tagestemperatur mit $28^{\circ} \mathrm{C}$ mit einer Nachttemperatur von $8^{\circ} \mathrm{C}$ führte zu einer gedämpften Symptomausprägung an den Ähren, die vergleichbare Werte hervorrief wie die Temperaturkombination $16^{\circ} \mathrm{C} / 12^{\circ} \mathrm{C}$. Die sehr niedrige Nachttemperatur scheint somit einen stärkeren Einfluss auf die Symptomausbildung der partiellen Weißährigkeit zu besitzen als eine hohe, sich im Temperaturoptimum befindende Tagestemperatur. 
Nach einer Fusariumähreninfektion hat neben der Temperatur, auch die Dauer von Feuchteperioden einen Einfluss auf den DON-Gehalt. In vitro Versuche zeigten, das sowohl $F$. graminearum als auch $F$. culmorum nur bei $\mathrm{a}_{\mathrm{w}}$-Werten (Wasseraktivität) $>0,90$, d.h. bei hohen Luftfeuchtigkeiten zu wachsen in der Lage sind (Hope et al., 2005). In typischen Versuchen die diesen Effekt an Pflanzen untersuchten, wurde dabei unter kontrollierten Bedingungen die Inkubationszeit nach der künstlichen Inokulation verlängert, was einen Anstieg der DON-Gehalte mit steigender Inkubationszeit zur Folge hatte (Hart et al., 1984, Xu et al., 2007). Im Gegensatz zu diesen relativ artifiziellen Ansätzen wiesen Cowger et al. (2009) auch in Feldversuchen nach, dass z.B. eine verlängerte Feuchteperiode zu erhöhten Mykotoxinkontaminationen führt, wobei aber auch hier die Beregnung nach der künstlichen Inokulation verlängert wurde. In den vorliegenden Versuchen in Klimakammern wurden dagegen die drei verschiedenen Inkubationszeiträume erst 10 Tage nach der Inokulation (2 Tage Inkubation mit $100 \%$ Luftfeuchtigkeit und 8 Tage Umgebungsluftfeuchte von 70\%) gestartet und drei Inkubationsintervalle mit je 10 Tagen durchgeführt, was einer periodischen Durchfeuchtung und Abtrocknung, wie sie auch im Feld vorkommt, am ehesten entspricht. Auch bei diesem Szenario konnte neben deutlich stärker ausgeprägten Symptomen ein signifikanter Anstieg des DONs in allen drei Inkubationsvarianten gemessen werden. Auch kam es trotz des relativen langen Inkubationszeitraumes nicht zu Auswaschungseffekten des DON, wie sie von Culler et al. (2007) aufgrund des engen Kontaktes der Ähren mit teilweise flüssigem Wasser beschrieben wurden. Im Vergleich zur $2 \mathrm{~d}$ Inkubationsvariante mit $10.825 \mu \mathrm{g} \mathrm{DON} \mathrm{kg}^{-1} \mathrm{Mehl}$, stieg der Mykotoxingehalt bei einer Inkubationszeit von $8 \mathrm{~d}$ auf $26.167 \mu \mathrm{g}$ DON kg ${ }^{-1}$ Mehl an (Tab. 21). Dieser klare Zusammenhang zwischen der Dauer von Feuchteperioden und den Mykotoxinkonzentrationen konnte erwartungsgemäß beim Vergleich der Temperaturregime nicht beobachtet werden. Im Gegensatz zu den Ergebnissen aus der Literatur, wo die günstigsten Umweltbedingungen für die Bildung von DON mit $\mathrm{a}_{\mathrm{w}}$-Werten > 0,97 (Doohan et al., 2003) und Temperaturen von $25^{\circ} \mathrm{C}$ (Hope et al., 2005) angegeben werden, führte genau die Tag-Nacht-Kombination mit den höchsten Durchschnittstemperaturen $\left(25^{\circ} \mathrm{C} / 16^{\circ} \mathrm{C}\right) \mathrm{zu}$ den geringsten Mykotoxingehalten im Versuch und lag auf einem vergleichbaren Niveau wie die DON-Gehalte der Variante mit den niedrigsten Temperaturen $\left(12^{\circ} \mathrm{C} / 12^{\circ} \mathrm{C}\right)$ (Abb. 17). Nach künstlicher Inokulation wuchs das Pathogen unter optimalen Umweltbedingungen wahrscheinlich unverzüglich vom Kelchgrund des inokulierten Ährchens in das Gewebe der Spindelstufe und von dort basipetal in die Spindel, wo es systemisch über Phloem und Xylem andere Ährchen besiedeln und absterben lassen konnte (Tu, 1950; Kang et al., 2008). Hohe Temperaturen und Luftfeuchtigkeiten können somit zwar in einem artifiziellen System, z.B. 
auf Weizenkörnermedium (Hope et al., 2005) zu den höchsten Mengen an Mykotoxinen führen. Diese Bedingungen führen jedoch im System Pflanze zu einer massiven Ausbreitung des Pathogens in der Ähre. Die Körner in denen Mykotoxine im Laufe der Abreife gebildet werden sollten, konnten sich in diesen Versuchen nicht mehr entwickeln, weil höchstwahrscheinlich der Kelchgrund der meisten Ährenanlagen bereits systemisch mit F. graminearum besiedelt war. Dies führte zum Absterben und Ausbleichen der Ährchen, was durch die signifikant höchsten FHB-Indices in diesen Versuchsserien deutlich gezeigt wurde. Einzig die über der Infektionsstelle liegenden Kornanlagen, die aufgrund des Pathogenwachstums vom Assimilatstrom abgeschlossen waren, konnten geerntet werden und wiesen geringere Mykotoxingehalte auf, als theoretisch für die gesamte Ähre zu erwarten war. Die Ergebnisse und ihre Schlussfolgerungen aus diesen Temperaturregimen müssen daher besonders kritisch betrachtet werden, da sie wahrscheinlich größtenteils mit Körnern ermittelt wurden, deren Einfluss auf die Mykotoxinbildung unter normalen Umweltbedingungen als gering einzustufen ist. In wie weit solche Situationen auch auf Infektionsverläufe im Freiland übertragbar sind oder ob es sich bei diesen Ergebnissen sogar um Artefakte handelt, ist noch ungeklärt und bedarf weiterer Untersuchungen. Ein möglicher Lösungsansatz für kommende Versuche wäre z.B. die Ernte nur auf die Körner der Ähren zu beschränken, die unterhalb der Inokulationsstelle gebildet werden. Das basipethal vordringende Pathogen produziert hauptsächlich in diesen Kornfraktionen Mykotoxine und Biomasse, eine Vermischung mit den Kümmerkörnern oberhalb der Infektionsstelle wäre somit vermieden, und eine mögliche Fehlerquelle ausgeschaltet.

Im Gegensatz zu den günstigen Umweltszenarien kam es in der Tag-Nacht-Kombination $12^{\circ} \mathrm{C} / 12^{\circ} \mathrm{C}$ aufgrund der niedrigen Temperatur zu einer geringen Ausbreitung des Pathogens und somit auch zu einer verringerten Mykotoxinbildung in den Körnern, die sich aber in dieser Variante in nahezu allen Ährenanlagen bilden konnten. Die höchsten Mykotoxingehalte in diesen Versuchen konnten in den Temperaturregimen $16^{\circ} \mathrm{C} / 12^{\circ} \mathrm{C}$ und $28^{\circ} \mathrm{C} / 8^{\circ} \mathrm{C}$ gemessen werden, die bereits ähnliche FHB-Indexe aufwiesen. Die niedrige Nachttemperatur vor allem in der $28^{\circ} \mathrm{C}$-Variante schien das Wachstum von $F$. graminearum so weit zu drosseln, so dass sich das Pathogen zwar über die Spindel in der Ähre ausbreiteten konnte, aber es nicht zum sofortigen Absterben der Kornanlagen kam. Diese Tag-Nacht-Temperaturkombination kommt in Südniedersachsen zum Zeitpunkt der Weizenblüte im Mai-Juni durchaus vor und stellt somit ein realistischeres Modell, als die bisherigen in vitro Ansätze dar. Als weiterer Parameter wurde in diesen Versuchen die DNA-Menge von $F$. graminearum gemessen, die erwartungsgemäß eng mit den Ergebnissen der Mykotoxinmessungen korrelierte (Schnerr et al., 2002;). 
Aufgrund der geringen Temperatur kam es in der Tag-Nacht-Variante $12^{\circ} \mathrm{C} / 12^{\circ} \mathrm{C}$ zu einem geringen Pathogenwachstum, und somit zu geringeren DNA-Mengen. Die Zerstörung der Kornanlagen bei optimalen Wachstumstemperaturen $\left(25^{\circ} \mathrm{C} / 16^{\circ} \mathrm{C}\right)$ führte hier ebenfalls $\mathrm{zu}$ signifikant geringeren DNA-Gehalten, wohingegen die höchsten Mengen abermals in den Varianten $16^{\circ} \mathrm{C} / 12^{\circ} \mathrm{C}$ und $28^{\circ} \mathrm{C} / 8^{\circ} \mathrm{C}$ gemessen wurden (Abb. 18). Auch die drei verschiedenen Inkubationszeiten hatten einen signifikanten Einfluss auf die DNA-Mengen. Im Gegensatz zu den Mykotoxinen, wo die Mengen um den Faktor 2,5 anstiegen, wurde hier sogar ein Anstieg um den Faktor 5 ermittelt, so dass sich die Abstufungen der Quotienten aus der Mykotoxin- und der DNA-Menge umkehrten. Die höchste spezifische Mykotoxinbildung wurde somit bei der kürzesten Feuchteperiode von zwei Tagen gemessen, die signifikant gröBer war als in den beiden anderen Varianten (Tab. 21). Parallel dazu wurde ein ähnlich starker Anstieg der DNA-Mengen in den Temperaturszenarien $16^{\circ} \mathrm{C} / 12^{\circ} \mathrm{C}$ und $28^{\circ} \mathrm{C} / 8^{\circ} \mathrm{C}$ gemessen, der ebenfalls dazu führte, dass in den Varianten mit den geringsten Mykotoxinmengen, die signifikant höchste spezifische Mykotoxinbildung $\left(12^{\circ} \mathrm{C} / 12^{\circ} \mathrm{C}\right) \mathrm{zu}$ finden war (Abb. 19). Cumagun et al. (2004) konnten keine Unterschiede in der spezifischen Mykotoxinbildung zwischen verschiedenen Umwelten feststellen. Im Gegensatz dazu zeigen diese Ergebnisse deutlich, dass günstige Umweltbedingungen in planta, im Vergleich zu den DON-Gehalten, zu einem verhältnismäßig stärkeren vegetativen Wachstum und somit zu einem Anstieg der DNA von $F$. graminearum führen können, so dass die spezifische Mykotoxinbildung bei diesen Umweltbedingungen geringer ist. Brandfass (2006) ging aufgrund der hohen Korrelation zwischen der F. graminearum DNA und den Mykotoxingehalten von einer konstanten spezifischen DON-Bildung unabhängig von den Versuchsjahren aus, was jedoch nicht bestätigt werden konnte. Vielmehr stellte er die höchste spezifische Mykotoxinbildung im Versuchsjahr 2003 mit den ungünstigsten Witterungsbedingungen für einen Befall mit $F$. graminearum fest, was die aktuellen Ergebnisse der Klimakammerversuche bestätigt. Auch im FAENFeldversuch konnte eine gesteigerte spezifische Mykotoxinbildung aufgrund ungünstigerer Witterungsbedingungen festgestellt werden. Der Vergleich der Vorfruchtvarianten Mais der Jahre 2007 und 2009 am Standort Torland zeigte im Starkbefallsjahr eine Regressionsgerade mit deutlich geringerer Steigung als in einem Jahr mit ungünstigeren Befallsbedingungen, d.h. 2007 wurde trotz einer deutlich höheren Gesamtmykotoxinbelastung im Erntegut pro Einheit F. graminearum DNA weniger DON produziert als 2009 (Abb. 14). Signifikante Unterschiede in der spezifischen Mykotoxinbildung waren auch zwischen beiden FAEN-Standorten im Starkbefallsjahr $2007 \mathrm{zu}$ beobachten. Vergleichbar zu den erhöhten Mykotoxinbelastungen am Standort Torland, wurde hier auch eine erhöhte Mykotoxinbildung pro Einheit $F$. 
graminearum-DNA gemessen, die ebenfalls nur mit der spezifischen lokalen Witterung zu erklären ist (Tab. 11). Hierfür konnte ein Anteil an der Gesamtvariation von ca. 30\% (Tab. 10) dieses Untersuchungsparameters im Jahr 2007 ermittelt werden. Umfangreichere Auswertungen zur spezifischen Mykotoxinbildung im FAEN-Feldversuch waren nicht möglich, da der Pathogenbefall nur im Jahr 2007 über beide Standorte und alle Versuchsfaktoren mittels qPCR quantifizierbar war. Im Versuchsjahr 2008 lagen alle Analysen unterhalb der Nachweisgrenze. Auch 2009 konnten nur aufgrund eines mittelstarken natürlichen Befalls am Standort Torland Werte oberhalb der quantifizierbaren Nachweisgrenze in der Vorfruchtvariante Mais ermittelt werden, so dass ein Vergleich der spezifischen Mykotoxinbildung nur für die Vorfruchtvariante Mais in den Jahren 2007 und 2009 vorgenommen werden konnte.

Neben dem Mykotoxingehalt scheint somit vor allem dieDNA-Menge von $F$. graminearum bzw. die Pilzbiomasse hochgradig von der Witterung während des Infektions- und Abreifprozesses abhängig zu sein. Die in diesen Versuchen untersuchten Parameter der Temperatur und die Dauer von Feuchteperioden scheinen dabei von besonderer Bedeutung zu sein. Jedoch machen diese auch nur einen geringen Teil der komplexen Witterungsinteraktionen aus, die unter natürlichen Befallsbedingungen auftreten und die Mykotoxinbildung beeinflussen können (Xu, 2003). Weitere Untersuchungen sind erforderlich um realitätsnahe Modelle zu entwickeln, die die Mykotoxinbildung im Feld sicherer prognostizieren können. In wie weit für solche Prozesse die Verwendung der in dieser Arbeit umfangreich untersuchten spezifischen Mykotoxinbildung sinnvoll ist, muss sich erst in weiteren Untersuchungen zeigen. Aufgrund der schwer prognostizierbaren starken Wechselwirkungen dieses Faktors mit den Umweltbedingungen, erscheint es jedoch sinnvoll, sich bei weiteren Versuchen zunächst auf die Parameter Mykotoxinmenge und DNA-Gehalt von F. graminearum zu beschränken.

\subsubsection{Vorfruchteffekt}

Zweitgrößter Faktor in der Gesamtvarianz- und Komponentenanalyse des FAEN-Versuchs war die Vorfrucht, die für ca. 12\% der Variation des DON-Gehaltes in dem gesamten dreijährigen Untersuchungszeitraum verantwortlich war (Tab. 4 \& 5). Dieser Wert war vergleichbar mit Ergebnissen aus Kanada, wo Vorfruchteffekte zwischen 14-28\% gemessen wurden (Schaafsma et al., 2001). Diese realtiv hohen Werte wurden dann erreicht, wenn die Komponentenanalysen für jedes Jahr einzeln durchgeführt und der Jahreseffekt außen vor gelassen wurde. In diesem Fall stiegen für den Versuchsfaktor Vorfrucht die Anteile an der Gesamtvarianz auf bis zu 32\% an, unabhängig von der Stärke des Auftretens von Ährenfusariosen in 
den Befallsjahren 2007 und 2009 (Tab.6). Kam es jedoch nur zu einem minimalen Infektionsereigniss wie im Versuchsjahr 2008, verringerten sich die Vorfruchteffekte auf nur noch ca.7\%. Die Vorfrucht und ihre möglichen Interaktionen mit der Jahreswitterung (Tab. 4) können somit für einen Großteil der Kontaminationen des Erntegutes mit pilzlichen Sekundärmetaboliten verantwortlich sein. Bereits 1920 zeigte Atanasoff den Zusammenhang zwischen dem gehäuften Auftreten der partiellen Weißährigkeit in der Folgefrucht Weizen nach dem Anbau von Mais. Dieser stellt eine nahezu optimale Ressource zur Besiedelung und Überdauerung von F. graminearum dar (Sutton, 1982). Mit Beginn der Abreife dringen Fusarien in den unteren Stängelteil der Maispflanzen ein, so dass nach der Ernte bereits die meisten Stoppelreste besiedelt sind. Die auf dem Boden verbliebenden Maisstoppeln scheinen mit ihrem hohen Stickstoffanteil (C:N-Verhältnis im Maisstroh 25:1; in Getreidestroh 80100:1) eine günstige Ressource für die spätere Inokulumentwicklung darzustellen. Darüber hinaus kann das Pathogen auf den schwerer verrottbaren Maisstoppeln länger überdauern (Beck \& Lepschy, 2000). Im FAEN-Versuch war genau dies in den Jahren 2009 und vor allem $2007 \mathrm{zu}$ beobachten. Kam es witterungsbedingt zu einem natürlichen Befall mit $F$. graminearum konnten, wie im Jahr 2007, signifikante Differenzen zwischen der Vorfrucht Mais und den beiden anderen Vorfrüchten Winterweizen und Zuckerrübe festgestellt werden (Tab. 7). Untersuchungen von Krauthausen et al. (2003) und Dill-Macky \& Jones (2000) bestätigen die Vorzüglichkeit von Mais im Vergleich zu Weizen als Wirt für Fusarium spp.. In Kombination mit einer nichtwendenden Bodenbearbeitung könnte es ihrer Meinung nach zu einer kontinuierlichen Anreicherung von potentiellem Inokulum auf der Bodenoberfläche und somit zu einem erhöhten Risiko des Auftretens der partiellen Weißährigkeit im Weizen kommen. Dieser Effekt war bislang in den Untersuchungsjahren des FAEN-Versuchs noch nicht festzustellen. Die höchsten Mykotoxinkontaminationen wurden im ersten Versuchsjahr 2007 gemessen, unabhängig von der Dauer der jeweiligen Vorfruchtvarianten. Jedoch sollte die Möglichkeit eines kontinuierlichen „Aufschaukelns“ der Inokulummengen in den Vorfruchtversuchen über die nächsten Jahre weiterhin überprüft werden, besonders falls die Witterungsbedingungen für natürliche Fusarieninfektionen günstiger sein sollten, als in den beiden letzten Versuchsjahren 2008 und 2009.

Der Einfluss der Vorfrüchte Winterweizen und Zuckerrüben auf einen Befall mit FHB in der Folgefrucht Winterweizen wird in der Literatur teilweise sehr widersprüchlich beschrieben. Beck \& Lepschy (2000) konnten in einem Monitoring von 1989-1999 in Bayern deutlich höhere DON-Gehalte nach Zuckerrüben im Vergleich zu einer Vorfrucht Winterweizen feststellen. Weinert et al. (2007) fanden dagegen in den Vorfruchtvarianten Zuckerrübe und Winter- 
weizen 2003-2005 vergleichbar hohe Deoxynivalenolgehalte, wohingegen Koch et al. (2006) und Champeil et al. (2004) von Reduktionen der DON-Gehalte nach der Vorfrucht Zuckerrübe um den Faktor 4,3 bzw. 2 berichteten. Im Jahr 2009 konnten bei mittlerem Infektionsdruck im FAEN-Versuch keine signifikanten Differenzen zwischen den Mykotoxinmittelwerten der verschiedenen Vorfruchtvarianten festgestellt werden. Der Vergleich der gewichteten Faktoreffekte zeigte aber den in der Literatur bereits beschriebenen günstigen Effekt der Vorfrucht Zuckerrübe (Tab. 8). Die Mykotoxingehalte nach Zuckerrübe lagen im Jahr 2009 im Vergleich zur Vorfrucht Winterweizen um den Faktor 5,1 niedriger, was dem Literaturwert (Koch et al., 2006) sehr nahe kommt. Eine mögliche Erklärung der beobachteten Vorfruchteffekte wäre die unterschiedliche Eignung der Rückstände für eine Pathogenbesiedlung. Nach Domsch et al. (1968) sind Fusarien typische „Weizenpilze“, die ein hohes saprophytisches Konkurrenzvermögen im Boden besitzen und sich vor allem im Dauerweizenanbau anreichern. Dies kann sogar dazu führen, dass häufiger $F$. graminearum von Weizen- als von Maisstoppeln isoliert wird (Dill-Macky \& Jones, 2000). Bei nichtwendender Bodenbearbeitung können Fusarium spp. das auf dem Boden verbliebene Stroh bis zu drei Jahre besiedeln (Pereyra et al., 2004), was eine dauerhafte und relativ gleichmäßig verteilte Inokulumquelle für mögliche Infektionen in der Folgefrucht Winterweizen darstellt. Im Gegensatz dazu ist über die pilzliche Besiedlung und Zersetzung von Zuckerrübenresten wenig bekannt. Neben diesem qualitativen Unterschied besteht aber auch ein bedeutender quantitativer Unterschied zwischen den beiden Vorfruchtvarianten. Bei Getreiden wird von einem Harvest-Index von 50\% ausgegangen (Geissler, 1983), dies bedeutet das neben der abgefahrenen Erntemengen noch einmal gut die gleiche Masse an Stroh und Spreu auf den Flächen zurückbleibt, so dass ca.70-80 dt ha ${ }^{-1}$ Material nach der Vorfrucht Weizen für eine mögliche Besiedlung durch $\mathrm{Fu}$ sarium spp. zur Verfügung stehen. Aktuelle Untersuchungen zur Zuckerrübe gehen von Ernterückständen von ca. 30dt ha ${ }^{-1}$ aus (Hanse \& Tijink, 2010), was knapp die Hälfte im Vergleich zu einer Vorfrucht Winterweizen ausmacht, so dass eine maßgebliche Übertragung von Inokulum durch Reste der Zuckerrübenvorfrucht schwer vorstellbar erscheint. Auch scheinen Vorfruchteffekte nicht kontinuierlich aufzutreten, sondern hochgradig von den jeweiligen Jahreseffekten abhängig zu sein, was das Starkbefallsjahr 2007 deutlich aufzeigte. Zwar waren auch hier die durchschnittlichen Mykotoxingehalte in den Weizenproben nach der Vorfrucht Mais erwartungsgemäß die höchsten (Tab. 7), jedoch halbierte sich der Faktoreffekt zwischen den Vorfruchtvarianten Mais und Zuckerrübe von 14,9 im Jahr 2009 auf 8,4 im Jahr 2007 (Tab. 8). Noch erstaunlicher ist die Veränderung der Faktoreffekte in den beiden Befallsjahren beim Vergleich der Vorfruchtvarianten Winterweizen und Zuckerrübe. Hier 
kam es nicht wie beim Mais zu einer Halbierung der Werte, sondern sogar zu einer Verringerung auf ein Fünftel von 5,1 (2009) auf 1,1 (2007), d.h. die Mykotoxingehalte in der Vorfruchtvariante Zuckerrübe stiegen im Jahr 2007 im Vergleich zum Winterweizen überproportional stark an, so dass die Mykotoxingehalte der Getreideproben beider Vorfruchtvarianten auf nahezu identischem Niveau lagen (Tab. 7). Somit war 2007 die Vorfruchtwirkung von Zuckerrübe und Winterweizen auf die Mykotoxinbelastung im nachfolgenden Weizen nicht voneinander unterscheidbar. In den USA wurden in den letzten Jahren bereits häufiger ähnliche Befallssituationen festgestellt. Diese führten dazu, dass selbst nach einer Blattvorfrucht die Mykotoxingehalte im Erntegut nicht signifikant von denen nach der Vorfrucht Mais abwichen (Bergstrom et al., 2009). Als mögliche Inokulumquellen wurden bereits in früheren Untersuchungen Sporen von verschiedenen Fusarium-Arten in der Atmosphäre identifiziert (Schmalle III et al., 2006). Diese Sporenwolken können sich in den Weizenanbauregionen der USA so stark ausbreiten, dass sie als luftbürtige Infektionen flächenspezifische Vorfruchteffekte überlagern. Es ist anzunehmen, dass solche Situationen auch auf die kleinräumigeren Strukturen und Anbaubedingungen in Deutschland übertragbar sind, da es auch hier in Starkbefallsjahren zu einer relativen Abschwächung des flächenbezogenen Vorfruchteffektes kommt, obwohl der Anteil der von der Vorfrucht verbleibenden Zuckerrübenreste über die Jahre vermutlich gleich ist. Für die Rolle der Zuckerrübe als Vorfrucht hinsichtlich der Toxinproblematik im Weizen ergibt sich daraus, dass die in Starkbefallsjahren festgestellte Förderung möglicherweise weitgehend auf luftbürtigen regionalen Infektionen und nicht aus unmittelbarer Übertragung von Ernteresten aus der Fläche beruht. Aus den vorliegenden Untersuchungen kann gefolgert werden, dass bei nichtwendender Bodenbearbeitung unter normalen Befallsbedingungen die Mykotoxinbelastung in Winterweizen absteigend nach den Vorfrüchten Mais > Winterweizen > Zuckerrübe erfolgt, während sie unter Starkbefallsbedingungen der Abstufung Mais > Winterweizen = Zuckerrübe folgt. Die diesen Effekten zugrunde liegenden Kausalbeziehungen müssen im Einzelnen noch aufgeklärt werden.

Erstaunlicherweise wurde im Versuchsjahr 2007 am Standort Torland auch ein signifikanter Effekt der Vorfrucht auf die spezifische Mykotoxinbildung festgestellt. Die Werte in den Vorfruchtvarianten Zuckerrübe und Mais lagen fast doppelt so hoch wie in der Vorfruchtvariante Winterweizen (Tab. 11) und machten im Rahmen einer Komponentenanalyse ca. 10\% der Gesamtvariation des Parameters im Versuchsjahr 2007 aus. Die Hypothese, daß ungünstige Wachstumsbedingungen die spezifische Mykotoxinbildung fördern können (siehe 4.2.1), kann auf diesen Fall wahrscheinlich nicht angewendet werden, da sich die Parzellen der Versuche in ihrer Bestandesdichte und Nährstoffversorgung nicht unterschieden. In wie weit 
toxigenere Fusarium-Arten wie sie z.B. von Bulakoti et al. (2007) an Zuckerrüben auf dem amerikanischen Kontinent isoliert werden konnten einen möglichen Erklärungsansatz für diese ungewöhnlichen Ergebnisse bieten, ist ebenfalls unklar. Somit sind alle Hypothesen spekulativ und es bedarf weiterer Untersuchungen ob es sich bei diesen Ergebnissen um reale Effekte oder nicht um eventuelle Artefakte des Jahres handelt.

\subsubsection{Resistenz- bzw. Sorteneffekt}

Nach dem Jahr und der Vorfrucht hatte der Faktor Sorte mit ca. 8\% an der Gesamtvariation des DON-Gehaltes den drittgrößten Anteil im FAEN-Versuch über die drei Versuchsjahre (Tab. 5). Dieser Wert ist deutlich geringer als die 27\% Gesamtvariation die Schaafsma et al. (2001) in Kanada ermittelten. Dennoch ist er hoch genug, so dass in der Gesamtvariationsanalyse über die drei Versuchsjahre ein höchst signifikanter Effekt mit $p<0,0001$ berechnet wurde (Tab. 4). Dieser realtiv hohe Anteil der Sortenresistenz an der Gesamtvarianz wurde nur dann erreicht, wenn die Komponentenanalysen für jedes Jahr einzeln durchgeführt und der Jahreseffekt außen vor gelassen wurde. In diesem Fall stieg für den Sortenfaktor der Anteil an der Gesamtvarianz auf bis zu 46\% an (Tab. 6). Dieser extrem hohe Wert wurde überraschenderweise nur im Versuchsjahr 2008 ermittelt, in dem nahezu keine natürlichen Infektionen mit F. graminearum auftraten. Die Sortenresistenz ist als einziger der Versuchsfaktoren unabhängig von der Jahreswitterung und ist selbst bei sehr geringen Mykotoxinkontaminationen im Getreide, weit unterhalb der entsprechenden Grenzwerte messbar (Tab. 7). Im Gegensatz dazu stiegen in Befallsjahren mit infekionsgünstigeren Umweltbedingungen wie 2007 und 2009 die Bedeutung der witterungsabhängigen Parameter wie z.B. dem Standort und vor allem der Vorfrucht zu Lasten des Sorteneffektes an. Dies führte zu einer Verschiebung der Anteile an der Gesamtvarianz von 30\% für dieVorfrucht, 10\% für den Standort und nur noch ca. $20 \%$ für die Sortenresistenz (Tab. 6).

In Jahren mit natürlichem Befallsdruck konnten deutliche Differenzen zwischen den Sorten festgestellt werden, jedoch unterschieden sich nur im Starkbefallsjahr 2007 die Toxingehalte der anfälligen Sorte Ritmo und der resistenteren Sorte Centrum signifikant. Mesterhazy (2003) beschrieb die Resistenz gegenüber der partiellen Weißährigkeit als ein „kompliziertes Phänomen“, deren Einzelkomponenten unabhängig wären, wobei Interaktionen innerhalb verschiedener Genotypen aber durchaus vorkämen. Aktuell unterscheidet man fünf verschiedene aktive Resistenzmechanismen: 
I. Resistenz gegenüber einer Primärinfektion (Schroeder \& Christensen, 1963): Dieser Resistenzmechanismus wurde mit der Sprühinokulationstechnik (2.5.2) getestet.

II. Ausbreitungsresistenz gegenüber dem Pathogen (Schroeder \& Christensen, 1963): Nach einer Punktinokulation wird die Ausbreitung des Pathogens in benachbartes Gewebe gemessen.

III. Resistenz gegenüber Körnerinfektionen (Mesterhazy, 1995)

IV. Toleranz (Mesterhazy, 1995): Tolerante Sorten zeigen keine Ertragsreduktion trotz vorhandenem Pathogen.

V. Toxinresistenz: Die Pflanze besitzt die Fähigkeit Mykotoxine z.B. durch Glukosylierung (Gareis, 1994) zu inaktivieren oder abzubauen.

Darüber hinaus gibt es noch weitere passive Resistenzmechanismen wie z.B. die Pflanzenlänge, die Begrannung der Ähre, die Ährchendichte oder das Blühverhalten, die ebenfalls ihren Beitrag zur Gesamtresistenz der Pflanzen leisten können (Mesterhazy, 1995). Von den in diesen Versuchen verwendeten Sorten ist nicht bekannt, ob sie über eine der aktiven Resistenzmechanismen verfügen, die Einstufungen erfolgten durch das Bundessortenamt (Anonymus, 2006 \& 2009). Aufgrund der ungewöhnlich hohen Mykotoxingehalte im Versuchsjahr 2007 stellte sich die Frage ob dies das Ergebnis eines besonders stark ausgeprägten Infektionsprozesses während der Vollblüte war und welchen Einfluss dies auf die spezifische Mykotoxinbildung haben könnte. Diese Hypothese wurde in einem Versuch mit verschiedenen Inokulationstechniken überprüft, in denen multiple Infektionen mit einzelnen Primärinfektionen und somit die Resistenzmechanismen I und II der fünf Sorten verglichen wurden (siehe Kapitel 3.5). Der Vergleich der FHB-Indices zeigte signifikante Differenzen zwischen den beiden Inokulationstechniken zu jedem Bonitutermin auf, jedoch waren die zu erwartenden Resistenzunterschiede in diesen Gewächshausversuchen nicht so deutlich ausgeprägt wie es aufgrund der Einstufung des Bundessortenamtes zu erwarten gewesen wäre (Tab. 18). Beide Inokulationstechniken schienen zu starke Symptome hervorzurufen, was zu einer Verwischung der Resistenzeinstufungen führte und typisch für Sorten ist, die nur über mittlere quantitavie Resistenzen gegenüber FHB verfügen (Bai \&Shaner, 1996). Eine weitere mögliche Erklärung wäre, dass die Inokulationsmethoden nicht für die kontrollierten Bedingungen im Gewächshaus geeignet waren, somit gegebenenfalls für weitere Versuche abgeändert und vielleicht abgeschwächt werden müssen. Ähnliche Effekte wurde bei der Messung der DONGehalte festgestellt, wo sogar in der als relativ resistent eingestuften Sorte Centrum hohe Belastungen gemessen wurden. Diese waren zwar immer noch signifikant geringer als die Mykotoxinmengen in der Sorte Ritmo, jedoch nicht die geringsten Werte in den Versuchen. 
Die Sprühinokulationstechnik verursachte unabhängig von der Sorte eine doppelt so hohe Mykotoxinkonzentration in den Weizenähren wie die Punktinokulation und führte ebenfalls zu einem vergleichbaren Anstieg der Menge an DNA von F. graminearum. Die Hypothese, dass die Inokulationstechnik bzw. die höhere Befallsstärke die spezifische Mykotoxinbildung fördert, konnte somit wiederlegt werden (Tab. 19). Im Gegensatz dazu, war der Anstieg der DNA von $F$. graminearum zwischen den Sorten deutlich ausgeprägter. Signifikant höhere DNA-Gehalte des Pathogens wurden in der anfälligeren Sorte Ritmo im Vergleich zu den resistenteren Sorten gemessen. Als Konsequenz daraus wies die spezifische Mykotoxinbildung in der Sorte Ritmo in beiden Inokulationsvarianten die geringsten Werte des gesamten Versuches auf und war signifikant geringer als in der Sorte Centrum (Tab. 18). Der Faktor Sorte besaß somit einen signifikanten Einfluss auf die spezifische Mykotoxinbildung. Dies entsprach der Hypothese von Nicholson et al. (2003), die ähnliche Effekte feststellten und daraus schlossen „das resistente Sorten eine unfreundlichere Umgebung für Pathogene darstellen“ und diese als eine mögliche Stressreaktion daraufhin mit der Bildung von unverhältnismäßig mehr Mykotoxinen reagieren (Abb. 23: Gewächshaus). Dies stand jedoch im Widerspruch zu den Ergebnissen des FAEN-Versuchs im Jahr 2007, wo die anfällige Sorte Ritmo eine signifikant höhere spezifische Mykotoxinbildung als die resistentere Sorte Centrum aufwies (Tab. 11) und woraufhin in einem weiteren Feldversuch in Wetze mit fünf Winterweizensorten diese Hypothese unter Feldbedingungen überprüft wurde. Nach künstlicher Inokulation zeigten die Sorten Centrum, KWS Erasmus, Julius, KWS Pius und Ritmo in diesem Versuch jeweils signifikante Unterschiede in der Anfälligkeit gegenüber Ährenfusariosen (Tab. 13). Dies war in den Gewächshausversuchen zuvor nicht so klar zu erkennen gewesen. Diese signifikanten Differenzen spiegelten sich ebenfalls in den Mykotoxinkontaminationen wider, die von Centrum $\left(2.045 \mu \mathrm{g}\right.$ DON kg$\left.{ }^{-1}\right)$ hin zur anfälligen Sorte Ritmo (16.226 $\mu \mathrm{g}$ DON kg$\left.{ }^{-1}\right)$ um den 8-fachen Wert anstiegen. Im Gegensatz dazu wurde bei der DNA-Menge von F. culmorum nur ein Anstieg um den Faktor 4 festgestellt, was dazu führte, dass im Feldversuch die spezifische Mykotoxinbildung der beiden resistenteren Sorten Centrum bzw. KWS Erasmus signifikant geringer war, als die der anfälligeren Sorten KWS Pius, Julius und Ritmo. Der künstlich inokulierte Sortenversuch bestätigte somit die Ergebnisse des natürlichen Ährenbefalls im FAEN-Versuch im Jahr 2007 (Tab. 11), so dass auch nicht von einem möglichen Effekt der Inokulationsmethodik bzw. der verwendeten Fusarium spp. ausgegangen werden kann. Vielmehr scheint die künstliche Inokulation im Feldversuch, die Konsequenzen eines natürlich auftretenden Befalls realitätsnah darzustellen. 


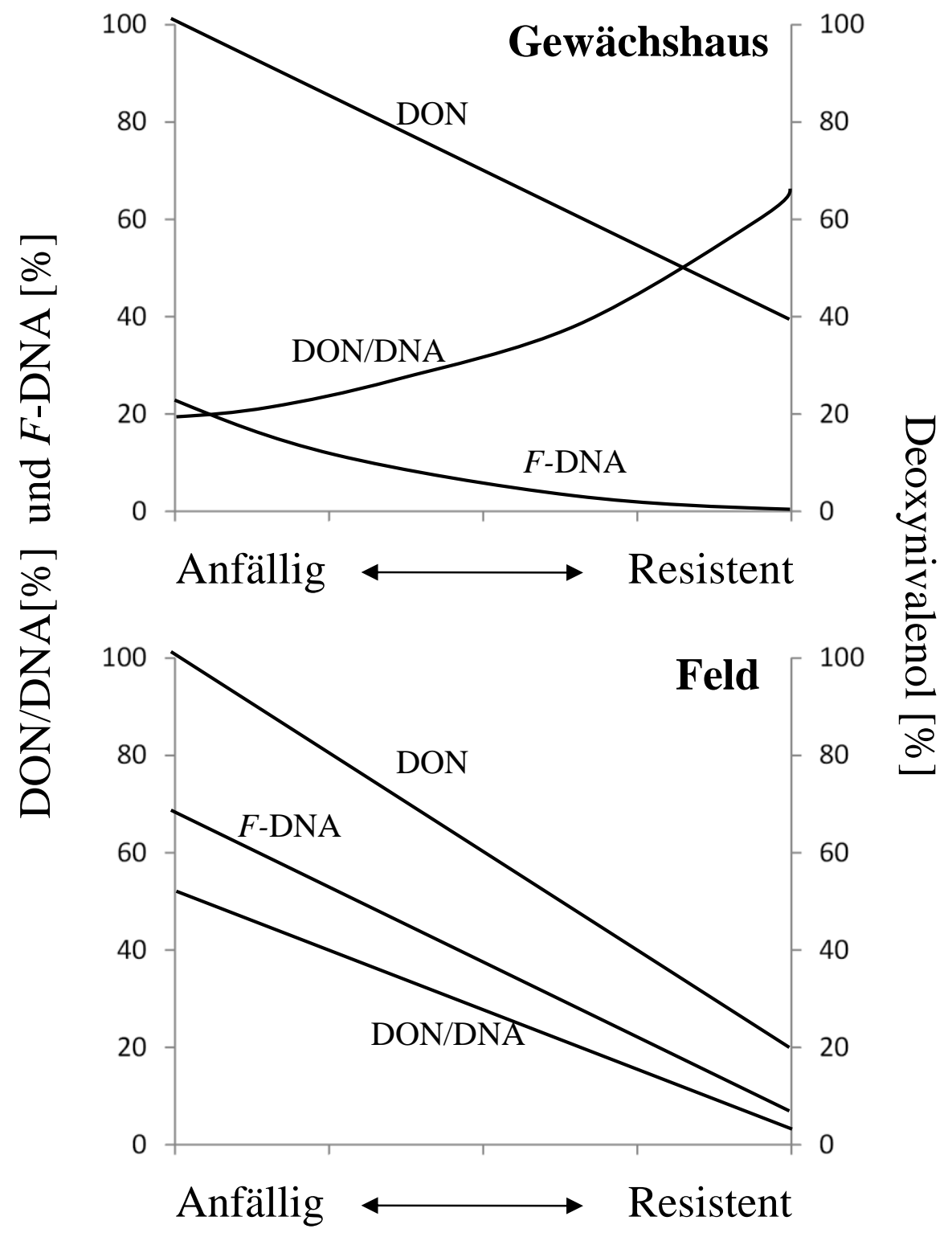

Abb. 23: Trend der Mykotoxingehalte (DON: Deoxynivalenol in \%), der Fusarium DNA-Mengen (F-DNA in \%) und der spezifischen Mykotoxinbildung (DON/DNA in \%) unterschiedlich resistenter Weizensorten (x-Achse) in Abhängigkeit vom Ort der Versuchsdurchführung; im Feld unter natürlichen Umweltbedingungen oder im Gewächshaus unter kontrollierten Bedingungen. Die Darstellung der Verläufe in der Abbildung „Gewächshaus“ orientiert sich an Nicholson et al. (2003), jedoch stellen die Geraden nur Trendlinien dar.

Dies bedeutet, dass die Hypothese von Nicholson et al. (2003) für Feldversuche mit den derzeitigen Winterweizenlinien angepasst werden muss. Resistentere Weizensorten besitzten eine geringere spezifische Mykotoxinbildung als anfälligere Sorten (Abb. 23: Feld). Unter natürlichen Umweltbedingungen schienen in diesem Fall die passiven Resistenzmechanismen der Sorten, falls sie vorhanden waren, deutlich besser zu wirken. Der Befallsdruck war geringer und eine Ausbreitung des Pathogens in der Ähre wurde durch wechselnde Tag-NachtTemperaturen gedämpft. Im Gegensatz dazu wurden in den Gewächshausversuchen wahr- 
scheinlich zu starke Inokulationsmethoden verwendet, die die Resistenzmechnismen überwanden. Das Pathogen konnte sich bei günstigen, konstanten Temperaturen ungehindert in der Ähre ausbreiten, Mykotoxine- und vor allem sehr viel Pilzbiomasse bilden, was zur Verschiebung der spezifischen Mykotoxinbildung führte.

Diese Effekte zeigen die hohe Bedeutung der Witterung als integraler Bestandteil des Infektionsprozesses, der Pathogenentwicklung und der Mykotoxinproduktion in Weizenähren. All diese Prozesse interagieren miteinander, so dass einzelne Änderungen in diesem System zur totalen Umkehr von Resultaten führen, was anhand der spezifischen Mykotoxinbildung bewiesen werden konnte. Die Aussage, daß resistentere Sorten eine ungünstigere Umgebung für Ährenfusariosen darstellen und somit die spezifische Mykotoxinbildung fördern, sollte daher kritisch hinterfragt werden, unter besonderer Berücksichtigung der möglichen Umweltinteraktionen.

\subsubsection{Fungizideffekt}

Wie bereits unter Kapitel 4.2.1 beschrieben ist eine Koinzidenz aus dem entsprechenden Entwicklungsstadium (Vollblüte des Weizens), ausreichendem Inokulumquellen und feuchtwarmer Witterung für eine erfolgreiche Ähreninfektion durch F. graminearum notwendig. Dieser Vorgang läuft in einem relativ kurzen Zeitkorridor ab, so dass dieses Pathogen als monozyklisch angesehen wird (Sutton, 1982). Um eine optimale Wirkung zu erhalten, beschränkt sich ein möglicher Fungizideinsatz zur direkten Bekämpfung von Ährenfusariosen und den damit einhergehenden Mykotoxinen somit ebenfalls auf diesen Zeitraum, (Obst \& Gammel, 2000). Fungizide aus der Wirkstoffklasse der Triazole, die die pilzliche Ergosterolbiosynthese hemmen (Lyr, 1995), werden weltweit gegen Ährenpathogene eingesetzt. Ihre direkte Wirkung gegenüber $F$. graminearum ist unstrittig. Jedoch besitzen die verschiedenen Triazolfungizide unterschiedliche Wirkungsgrade gegenüber der Feldbefallsstärke der partiellen Weißährigkeit, wie auch gegenüber der Mykotoxinakkumulation. Bei Applikation zum Zeitpunkt der Vollblüte erbringt der aktuell effektivste am Markt verfügbare Triazolwirkstoff Prothioconazol eine durchschnittliche Reduktion der Symptome und der Mykotoxingehalte um ca. 40\%, wohingegen der Einsatz von Tebuconazol eine Symptomreduktion um ca. 30\% und eine Mykotoxinreduktion von nur ca. $16 \%$ bewirkt (Hershman, 2008). Für die Wirkstoffgruppe der Strobilurine, die die Atmungskette pilzlicher Pathogene inhibieren (Lyr, 1995), ist trotz ihrer Indikation gegen Ährenfusariosen die Wirkung bei der Symptomreduktion und vor allem bei der Reduktion von Mykotoxinen umstrit- 
ten. Mit Beginn des Einsatzes dieser neuen Wirkstoffgruppe in den neunziger Jahren wurden nach Ährenbehandlungen mit Strobilurinpräparaten immer wieder erhöhte Mykotoxingehalte im Erntegut im Vergleich zu unbehandelten Varianten festgestellt (Obst \& Gammel, 2000), wobei gleichzeitig auch andere Studien symptom- und toxinreduzierende Effekte, ähnlich der Azole, feststellten (Matthies et al., 2000). Neben diesen direkten Fungizideffekten der verschiedenen Wirkstoffe können Fungizidapplikationen auch indirekte Effekte auf das Pathogen haben. Von den Azol- und vor allem von den Strobilurinwirkstoffen ist bekannt, dass sie die Seneszenz von pflanzlichen Gewebe verzögern können (Grossmann \& Retzlaff, 1997; Wu \& von Tiedemann, 2001), was als sogenannter „Greening-Effekt“ bezeichnet wird. Die Interaktion dieser indirekten Fungizideffekte mit Fusarienähreninfektionen bzw. der Mykotoxinbildung und die möglichen Ursachen dieses Phänomens waren eine zentrale Fragestellung dieser Arbeit. Um die direkten Fungizideffekte auszuschalten wurden Applikationen von Fungiziden bis spätestens zum Ende des Schossens (BBCH 39-41) durchgeführt. Im Vergleich zu den Fungiziden der Triazol- und Strobiluringruppe wurde das Chlorthalonil als Referenzfungizid in der Behandlungsstufe Neutral eingesetzt. Dieses Kontaktfungizid reagiert in vitro z.B. mit Glutathion und dem Coenzym A, es kann dabei mit anderen Verbindungen vor allem Disulfidbrückenbindungen bilden, die dann zur Inaktivierung von Enzymen führen können (Lyr, 1995). Von diesem Fungizid ist nicht bekannt, dass es physiologische Effekte auf Pflanzen besitzt (von Tiedemann, 2009)

In der Gesamtvarianzanalyse der DON-Gehalte des FAEN-Versuches über die drei Versuchsjahre hatte die Fungizidvariante einen signifikanten Einfluss auf die Mykotoxinkontaminationen (Tab. 4). Im Vergleich zum Jahr oder der Sorte konnte aber anhand des relativ geringen F-Wertes bereits abgeschätzt werden, dass der Varianzkomponenteneffekt äußerst gering war, was mit einem Wert von $0,02 \%$ bestätigt wurde (Tab. 5). Die Fungizidapplikationen bis zum Ende des Schossens hatten somit keinen Anteil an der Gesamtvarianz der DON-Gehalte. Auch in der für jedes Versuchsjahr einzeln durchgeführten Varianzkomponetenanalyse stieg der Anteil der Fungizide auf nur 0,2\% (2007, 2008) - 2\% (2009) unabhängig vom jeweiligen Infektionsgeschehen an und lag somit deutlich unterhalb der Varianzanteile der anderen Versuchsfaktoren wie der Vorfrucht (30\%), der Sortenresistenz (20\%) und des Standortes (10\%) (Tab. 6). Signifikante Differenzen zwischen den Mykotoxinkontaminationen der Fungizidvarianten Strobilurin und Triazol konnten im Starkbefallsjahr 2007 festgestellt werden, was die Ergebnisse von Ellner (2005) bestätigte, der vor allem dann eine deutliche Toxinsteigerung in den Strobilurinvarianten nachweisen konnte, wenn eine frühe Fungizidapplikation, vergleichbar zum FAEN-Versuch erfolgte. Selbst in Jahren mit mittleren 
bis gar keinem Befall war diese Tendenz trotz nicht signifikanter Unterschiede deutlich zu sehen. Die Variante mit Strobilurinapplikation wies durchgängig mehr DON auf als die Variante mit Triazolapplikation. Überraschenderweise führte aber auch der Fungizidwirkstoff Chlorthalonil zu ähnlich hohen Mykotoxinkontaminationen wie die Strobilurinvariante und dies auch über alle drei Versuchsjahre. Mehrere Hypothesen die diese Effekte erklären könnten werden in der Literatur diskutiert und wurden im Rahmen dieser Arbeit gezielt überprüft.

\section{Blühverhalten}

Untersuchungen unter kontrollierten Bedingungen im Gewächshaus zeigten das zum Zeitpunkt BBCH 31/32 die Applikation von Fungiziden aus der Wirkstoffgruppe der Strobilurine das Blühverhalten von Weizenpflanzen im Vergleich zu Triazolen beeinflussen kann. Tendenziell führten Wirkstoffe wie Azoxystrobin und Kresoxim-methyl zu einer Vorverlegung des Blühbeginns, wobei sich jedoch die Gesamtblühdauer nicht veränderte (Ellner, 2006). Aufgrund der notwendigen Koinzidenz des Blühzeitraums mit einer Askosporenausschüttung von $F$. graminearum könnte eine Verlängerung dieses infektionssensitiven Zeitraums auch die Wahrscheinlichkeit für Ähreninfektionen und somit für Mykotoxinkontaminationen erhöhen. Die Ergebnisse unter Freilandbedingungen im FAEN-Versuch zeigten für die Versuchsjahre 2008 und 2009 jedoch keinen Einfluss der Fungizide auf das Blühverhalten im Winterweizenbestand, es konnte auch keine Vorverlegung der Blüte in den Strobilurinvarianten bobachtet werden (Abb. 10). Als Ursache für die unterschiedlichen Mykotoxinbelastungen in den Fungizidvarianten kann diese Hypothese mit an Sicherheit grenzender Wahrscheinlichkeit verworfen werden. Im Gegensatz zu den Fungiziden, hatten aber die Vorfruchtvarianten in beiden Jahren einen deutlichen Einfluss auf das Blühverhalten im Bestand, was in 2008 zwischen der Vorfruchtvariante Winterweizen und Zuckerrübe zu einer Verschiebung der Vollblüte um einen Tag und 2009 in der Variante Mais zu einer Verlängerung der Blüte um zwei Tage führte (Abb. 12). Eine mögliche Erklärung hierfür könnte in der unterschiedlichen Umsetzung der organischen Bodensubstanz in den verschiedenen Vorfruchtvarianten zu finden sein, welche zu unterschiedlichen Nährstoffnachlieferungen geführt haben könnte. Dies sind jedoch nur Hypothesen und die beobachteten Effekte scheinen zu gering zu sein um einen Einfluss auf den Ährenbefall mit F. graminearum zu haben.

\section{Physiologische bzw. Seneszenzeffekte der Fungizide}

Im pflanzlichen System gilt es als gesichert, dass die antioxidative Kapazität in direktem $\mathrm{Zu}$ sammenhang mit der Lebensdauer des pflanzlichen Gewebes steht (Zimmermann \& Zentgraf, 2004). So konnten Maislinien identifiziert werden, deren verfrühten Seneszenzsymptome 
durch eine erhöhte $\mathrm{H}_{2} \mathrm{O}_{2}$-Produktion und Lipidperoxidation, sowie durch eine verringerte Aktivität verschiedener antioxidativer Enzyme zum Zeitpunkt der Reife ausgelöst wurden (Prochazkova et al., 2001). Eine dieser Enzymgruppen sind Peroxidasen, die vor allem zur Reduktion des Wasserstoffperoxids im pflanzlichen Gewebe benötigt werden. Wu \& von Tiedemann (2001) konnten nach einer Epoxiconazol- bzw. einer Azoxystrobinapplikation eine erhöhte Aktivität der Peroxidasen und darüber hinaus einen verzögerten Abfall von deren Aktivität, im Vergleich zu unbehandelten Varianten, feststellen, was auf eine verzögerte Seneszenz des Gewebes nach Fungizidapplikationen hindeutete. Bisherige Untersuchungen zu Enzymaktivitäten in Pflanzen wurden zumeist an Blattgewebe durchgeführt, was zur Konsequenz hatte, dass z.B. der Rückgang der Aktivität bei Weizen bereits zum Entwicklungsstadium BBCH 75/77 (Wu \& von Tiedemann, 2001) gemessen wurde, so dass der eigentliche Abreifeprozess nicht mehr erfasst werden konnte. Als Konsequenz daraus wurden in den Feldversuchen auf der Weendelsbreite (siehe Kapitel 3.3) erstmals die Hüll- und Deckspelzen von Pflanzen aus Feldversuchen untersucht, da es sich hierbei um das jüngste zugewachsene Gewebe und gleichzeitig das mögliche Substrat für Ährenpathogene wie F. graminearum handelt. Für die Fungizidvarianten Triazol und Neutral bestätigten sich hier die Ergebnisse, dass bereits zum Entwicklungsstadium BBCH 75 die höchste Enzymaktivität vorliegt, und danach die Seneszenz auch in der Ähre beginnt. Signifikante Differenzen konnten aber in der Fungizidvariante Strobilurin gemessen werden, deren maximale Enzymaktivität in der Milchreife (BBCH 85) lag und die selbst zum Zeitpunkt der beginnenden Totreife (BBCH 92) noch eine relativ hohe Enzymaktivität aufwies. Diese verzögerte Seneszenz bzw. der GreeningEffekt wurde vor allem zu Beginn des Einsatzes der Strobilurine in den neunziger Jahren an der Gesamtpflanze beobachtet, da das Stroh länger grün blieb (Jorgensen \& Olesen, 2002). Dies konnte zu Ernterschwernissen beim Mähdrusch (Wacker, 2000) und teilweise zu Ernteverzögerungen führen. Jedoch wurden nur geringe bis gar keine Effekte der Fungizide auf das Abreifeverhalten der Ähren festgestellt. Um Wechselwirkungen mit der Umwelt auszuschlieBen wurde daher ein Halbfreilandversuch mit fungizidbehandelten Pflanzen aus dem Feldversuch an der Weendelsbreite durchgeführt und die Wassergehalte gesunder Ähren in verschiedenen Reifestadien gemessen. Signifikante Differenzen zwischen der Strobilurin- und Triazolvariante traten vor allem in den ersten beiden Ernteterminen bei noch relativ hohen Wassergehalten auf, was die Ergebnisse der Enzymaktivitätsmessung bestätigte, in welcher ein früherer Beginn der Seneszenz in der Triazolvariante festgestellt wurde (Tab. 14). Je trockener die Körner wurden desto geringer wurden die Differenzen zwischen den Varianten, was ebenfalls positiv mit den bisherigen Ergebnissen aus der Literatur übereinstimmt 
(Jorgensen \& Olesen, 2002; Wacker, 2000). Folgende zwei Hypothesen erscheinen somit realistisch:

I. Pathogene die auf weniger seneszentem Gewebe wachsen, könnten bei günstigeren Wassergehalten einen längeren Zeitraum für die Mykotoxinakkumulation zur Verfügung haben. Darüber hinaus ist dieses Gewebe aufgrund der höheren enzymatischen Aktivität möglicherweise unempfindlicher gegenüber abiotischen Stressfaktoren und könnte somit eine günstigere Gewebegrundlage für Ährenpathogene bilden, was eine der möglichen Ursachen für die erhöhte Mykotoxinakkumulation in den Strobilurinvarianten sein könnte.

II. Im Zuge der erhöhten Resistenz gegenüber abiotischen Stress besitzt das juvenilere Ährengewebe der Strobilurinvarianten möglicherweise eine partielle Resistenz gegen nekrotrophe Pathogene wie Fusarium-Arten.und setzt diese ebenfalls unter Stress, so daß diese mit einer erhöhten Mykotoxinbildung reagieren könnten.

Die abschließenden Ernteergebnisse des Standortes Weendelsgraben bestätigten die bereits beschriebenen Effekte. Trotz nahezu identischen Feldbefallsstärken konnten in den Körnern der Variante Strobilurin zwar keine signifikante, aber dennoch deutliche höhere Mykotoxingehalte als in der Variante Azol festgestellt werden (Tab. 16).

\section{Sublethale Fungizidmengen}

Eine weitere Hypothese die häufig für die Erklärung der erhöhten Mykotoxingehalte nach einer Strobilurinapplikation in frühen Entwicklungsstadien herangezogen wird, stellt das mögliche Vorhandensein sublethaler Fungizidmengen im Pflanzengewebe dar. Diese könnten demnach Stressoren für das Pathogen $F$. graminearum sein und führen somit zu einer unverhältnismäßigen Steigerung der spezifischen Mykotoxinbildung (D`Mello et al., 1998; Prigozliev et al., 2003). Verschiedene in vitro-Untersuchungen zeigten eine Erhöhung der Mykotoxinproduktion bei F. graminearum (Matthies et al., 1999) bzw. F. sporotrichioides (D`Mello et al., 2001) wenn die Wirkung fungizider Mindermengen, sogenannter sublethaler Dosen, von Tebuconazol und Azoxystrobin getestet wurden. Diese Effekte konnten für Triazole im Feldversuch nicht bestätigt werden (Matthies \& Buchenauer, 2000) und auch bei Versuchen mit Strobilurinen traten nur Effekte auf, die nicht statistisch signifikant abzusichern waren (Simpson et al., 2001). Es muss somit die Frage gestellt werden ob es sich bei den zuvor beobachteten Effekten, nicht vielleicht um Artefakte gehandelt hat, die auf der Interaktion der spezifischen Medien mit dem Pathogen beruhen. Covarelli et al. (2004) konnten bei vergleichbaren in vitro-Experimenten in einem einheitlichen Medium keine gesteigerte 
Mykotoxinbildung von F. culmorum bei verschiedensten Konzentrationen der beiden fungiziden Wirkstoffe feststellen, so dass an der Wirkung sublethaler Fungizidmengen im pflanzlichen Gewebe gezweifelt werden muss. Die Bestimmung, wann eine Fungizidmenge gegenüber einem Pathogen im Pflanzengewebe nur noch sublethal wirkt, ist nahezu unmöglich. Daher wurde in dieser Arbeit angenommen, dass per Definition die Fungizide, die zum Zeitpunkt BBCH 39 in den Feldversuchen appliziert wurden, maximal in sublethalen Dosen zum Zeitpunkt einer möglichen Ähreninfektion (BBCH 65) zum ersten Mal mit F. graminearum in Kontakt kommen. Restmengenuntersuchungen der Fungizidwirkstoffe im Gewebe der Weizenähren der beiden Sorten Ritmo und Centrum konnten detektierbare Mengen nur im Versuchsjahr 2008 feststellen. Im Versuchsjahr 2009 waren diese Mengen unterhalb der Nachweisgrenze der HPLC-MS/MS-Analytik und können höchstwahrscheinlich als nicht mehr wirksam zum Zeitpunkt des Pathogenkontakts eingestuft werden. Aufgrund der bereits zuvor beschriebenen ausgeprägten Frühsommertrockenheit 2008 waren die umweltbedingten physiko-chemischen Abbauprozesse der Pflanzen wahrscheinlich nicht in der Lage, die Fungizide vollständig umzusetzen, so dass selbst ein loco-systemischer Wirkstoff wie ein Azoxystrobin noch in neu zugewachsenem Pflanzengewebe nachweisbar war. Unter relativ normalen Umweltbedingungen wie 2009 mit gleichmäßig verteilten Niederschlägen und durchschnittlichen Tagestemperaturen waren weder Azoxystrobin noch Epoxiconazol nachweisbar. Trotzdem konnte der Effekt der erhöhten Mykotoxingehalte in den Strobilurinvarianten, auch wenn er nicht immer signifikant war, in nahezu allen Feldversuchen, festgestellt werden (Tab. 7; Tab. 13; Tab. 16). Im FAEN-Versuch wurden unabhängig von der Befallssituation über alle drei Versuchsjahre kaum Unterschiede zwischen den Faktoreffekten der verschiedenen Fungizidvarianten festgestellt. Die Strobilurinvariante führte immer zu einem 1,2- bis 1,9-fach höheren Mykotoxingehalt als die Triazolvariante (Tab. 8). Der Fungizidversuch im Gewächshaus (siehe Kapitel 3.4) unter kontrollierten Bedingungen wies ebenfalls keine signifikanten Differenzen zwischen den Fungizidvarianten auf, weder bei der Befallsstärke noch bei den Mykotoxingehalten. Trotzdem konnten deutlich erhöhte DON-Gehalte in der Strobilurinvariante gemessen werden (Tab. 17), was die Vermutung verstärkt, dass es sich bei dem beobachteten fungiziden Effekt höchstwahrscheinlich um einen physiologischen Prozess handelt, der unabhängig von den Umweltfaktoren auftreten kann. Demzufolge kann die sogenannte „Stress-Theorie“, die besagt das F. graminearum durch sublethale Fungizidmengen mehr Mykotoxine pro Pilzbiomasse produziert (Schmidt-Heydt et al., 2008) nicht bestätigt werden. Zwar konnten in einigen Versuchen eine erhöhte spezifische Mykotoxinbildung festgestellt werden, diese waren jedoch zumeist nicht signifikant und es 
wurden auch keine sich wiederholenden Tendenzen festgestellt. Vielmehr muss die Frage gestellt werden, ob diese physiologischen Fungizideffekte, nicht eher das Gegenteil von Stress im Pathogen auslösen. Laut Definition von Hans Selye (1936) ist Stress die „unspezifische Reaktion eines Körpers auf jegliche Anforderung“. Physiologische Fungizdeffekte wie sie hier beschrieben wurden, scheinen demgegenüber die Anforderungen an das Pathogen eher zu minimieren so dass sie sich in einer ,angenehmeren“ Umgebung etablieren können, und demzufolge weniger Stress ausgesetzt sind, was zu den Ergebnissen führen kann, die im Abschnitt „Physiologische Fungizideffekte“ bereits beschrieben wurden.

\section{Selektive Pathogenwirkung von Fungiziden}

Neben der bereits beschriebenen monozyklischen Ausbreitung von F. graminearum über die Perithezien auf den Stoppelresten der Vorfrucht wird von Adolf (1998) im Weizenbestand auch ein zeitlich versetztes stufenweises Aufsteigen von Konidien über die Blattetagen beschrieben. Ähreninfektionen können ebenfalls von Konidien ausgelöst werden (Sutton, 1982), so dass auch diese eine potentielle Inokulumquelle darstellen. Fungizidapplikationen wie sie im FAEN-Versuch bis zum Zeitpunkt des Entwicklungsstadiums BBCH 39 durchgeführt wurden, haben die Aufgabe den gesamten Blattapparat der Pflanzen für einen gewissen Zeitraum gesund zu erhalten. Von Strobilurinen ist aus in vitro und Gewächshausversuchen bekannt, dass sie Vertreter der saproyhytischen Mikroflora wie Alternaria alternata und Cladosporium herbarum zurückdrängen, und somit die natürliche Pufferkapazität auf der Pflanzenoberfläche zu Gunsten der Fusarium spp. verschieben (Liggitt et al., 1997). Die Möglichkeit polyzyklischer Infektionszyklen durch Konidien und das Befallsrisiko für Blattund Ähreninfektionen könnte somit steigen, was ebenfalls die erhöhte Myktoxinkonzentration besonders beiden frühen Strobilurinapplikationen erklären würde. Es ist jedoch ebenfalls zu überlegen, welchen Anteil eine Konidieninfektion an der Gesamtinfektion eines Weizenbestandes überhaupt besitzt. Fernando et al. (2000) konnten nur geringe Mengen von Makrokonidien trotz künstlicher Inokulation in einem Maisbestand feststellen und folgerten daraus, dass Perithezien bzw. Askosporen die Hauptquelle für spätere Infektionen darstellen. Im Gegensatz zu den Perithezien zeigte sich bei den Konidien auch kein deutlicher Zusammenhang zwischen der Inokulummenge in der Luft und Regenereignissen, was diametral zu den bisherigen Annahmen steht, dass Konidien durch Einschläge von Regentropfen in die Sporodochienlager herausgeschleudert werden (Sutton, 1982). Es scheint somit zweifelhaft ob Konidienähreninfektionen einen signifikanten Einfluss auf den Gesamtinfektionsprozess besitzen und ob die Hypothese von der selektiven Pathogenwirkung der Strobilurine weiteren 
Überprüfungen standhält. Trotz allem sollten die Strobilurinnebenwirkungen und ihre Interaktionen mit den Saprophyten und möglichen Applikationsterminen weiter überprüft werden.

\subsection{Artenspektrum von Fusarium spp. am Erntegut des FAEN-Versuches}

Die am häufigsten in Südniedersachsen auftretenden Fusarium-Arten waren unter natürlichen Befallsbedingungen in den Jahren 2007-2009 F. graminearum (bis zu 90\%), F. culmorum (bis zu $10 \%$ ) und $F$. tricinctum (bis zu 7\%). Es wurden des weiteren $F$. avenaceum, $F$. poae, $F$. compactum, M. nivale und nicht näher identifizierte Fusarien von dem Erntegut des FAENVersuches isoliert. Dies unterstützt die Ergebnisse von Krauthausen et al. (2003) dass es in den letzten Jahrzehnten im Winterweizenanbau in Deutschland zu einer Verschiebung von $F$. culmorum selbst im kühleren norddeutschen Bereich hin zu F. graminearum als Hauptverursacher der partiellen Weißährigkeit gekommen ist. Noch 1932 schrieb Wollenweber: „Wohl ist er [F. graminearum] in Europa fast überall vorhanden. Von einer starken Besiedlung der Länder ist jedoch wenig zu merken“. Es handelt sich hierbei auch nicht um eine auf Deutschland lokal beschränkt Erscheinung, vielmehr um ein europäisches Phänomen. Denn auch in den Niederlanden wurde innerhalb eines Jahrzehnts das Arten-Shifting von F. culmorum hin zu F. graminearum dokumentiert (Waalwijk et al., 2003). Hauptursache für diese komplette Artenverschiebung ist wahrscheinlich die stetige Ausweitung des Maisanbaus (Rintelen, 2000). F. graminearum besitzt eine besondere Affinität zu Mais bzw. zu dessen Stoppelresten, die eine vorzügliche Inokulumquelle für Infektionen in einer Weizenfolgefrucht darstellen. Der Pilz kann in seiner teleomorphen Form an den auf dem Acker verbleibenden Maisstoppelresten überwintern und breitet sich dann in der folgenden Vegetationsperiode nach Bildung von Perithezien und entsprechender Askosporen erneut im Bestand aus (Obst, 1994). Diese Zusammenhänge zwischen Perithezienbildung und Auftreten der partiellen Weißährigkeit in einer Weizenfolgefrucht wurden in den ersten großflächigen Maisanbauregionen in den USA bereits in den zwanziger Jahren des vorigen Jahrhunderts beschrieben (Atanasoff, 1920). In einem Starkbefallsjahr wie 2007 wurden im FAEN-Versuch an den Körnern der Vorfruchtvariante Mais $90 \%$ aller Pilze als F. graminearum identifiziert und selbst in einem schwachen Befallsjahr wie 2009 war dies noch bei ca. 50\% aller Isolate möglich (Tab. 12). In den Vorfruchtvarianten Winterweizen und Zuckerrübe erschienen die Fusariumpopulationen etwas diverser, jedoch war auch hier das Leitpathogen $F$. graminearum. Untersuchungen aus dem Rheinland zeigten, dass dort hauptsächlich $F$. avenaceum von Weizenkörnern isoliert werden konnte (Birzele et al., 2002), was damit erklärt wurde, dass dieses Pathogen besonders 
gut an die dortige langjährige Fruchtfolge Winterweizen-Winterweizen-Zuckerrüben angepasst sei (Lieneman et al., 2003). In Südniedersachsen war dies in der Zuckerrübenfruchtfolge bisher nicht $\mathrm{zu}$ beobachten, jedoch besteht die Möglichkeit, dass sich eine spezifische Pathogenflora erst nach mehrmaliger Fruchtfolgerotation aufbauen kann. Unabhängig von der Vorfrucht war bis jetzt im FAEN-Versuch eine Kontamination der Körner mit 3\%-6\% F. avenaceum zu beobachten. Zahlreicher jedoch wurde in den drei Versuchsjahren $F$. tricinctum vom Erntegut isoliert. Diese Art tritt besonders häufig in den skandinavischen Ländern neben $F$. avenaceum, $F$. poae und $F$. culmorum auf (Kosiak et al., 1997). Über die notwendigen Infektionsbedingungen ist noch relativ wenig bekannt, sie scheinen jedoch unabhängig von der Witterung zu sein, da diese Art selbst in einem Jahr wie 2008, als nahezu einzige Fusarium spp. mit bis zu $6 \%$ auf den Körnern anzufinden war. Ob es sich hierbei um eine rein saprophytische Art handelt wird im Laufe der weitern Diskussion noch genauer erläutert.

\subsection{Pathogenität der aus Zuckerrüben isolierten Fusarium-Isolaten und das „Black Point“" Symptom}

Für die Erreger der partiellen Weißährigkeit wie $F$. graminearum und $F$. culmorum herrscht die Annahme vor, das Weizen nur horizontale Resistenzen gegenüber diesen Pathogenen besitzt, so dass nicht von rassenspezifischen sondern von artspezifischen Resistenzen ausgegangen werden kann, die höchstwahrscheinlich polygen determiniert sind (van Euwijk et al., 1995). Außer für F. oxysporum (Houterman et al., 2009) sind für die anderen verwendeten Fusarium spp. in diesen Versuchen ebenfalls keine Avirulenzgene bekannt, so dass per Definition unter Beachtung des Gen-für-Gen Konzepts (Flor, 1971) bei der Quantifizierung der Symptome in dieser Arbeit der Terminus Aggressivität im Gegensatz zur Virulenz verwendet wird (Shaner et al., 1992). Die Ergebnisse zeigten, dass alle Fusarium-Arten aus Zuckerrüben pathogen gegenüber den beiden Weizensorten SW Kadrilj bzw. Tybalt waren und Symptome an den Deck- und Hüllspelzen auslösen konnten (Abb. 20). Die Symptomausprägung und die Agressivität waren dabei abhängig von den verschiedenen Arten, der getesteten Weizensorte und der Zusammenstellung des Inokulationsgemisches. Von den sieben getesteten Isolaten waren fünf pathogen an der Sorte SW Kadrilj. Das Isolat $F$. redolens, für das bislang keine Untersuchungen an Weizen vorlagen und $F$. oxysporum, welches bisher als apathogen an Weizen eingestuft wurde (Wilcoxson et al., 1988) lösten nach einer Sprühinokulation in dieser Variante keine Symptome aus. Die Versuche mit der Sorte Tybalt zeigten deutlich stärkere Symptomausprägungen, was mit einer erhöhten Sensitivität der Sorte gegenüber Ährenpatho- 
genen, aber auch mit dem Einsatz von Isolatgemischen und einer veränderten Inkubation erklärt werden könnte. In dieser Variante wiesen die Isolate $F$. oxysporum und $F$. redolens zwar immer noch die signifikant geringsten Befallsstärken auf (Tab. 24), aber es waren deutliche Symptome an den Hüll- und Deckspelzen erkennbar (Abb. 20), so dass zwar von einer geringen aber doch vorhandenen Pathogenität ausgegangen werden kann. Bei allen FusariumArten konnte ein stetiger Anstieg der FHB-Indices von 7 bis 21 dpi beobachtet werden. Typische FHB-Bildner wie F. graminearum und F. culmorum wiesen die signifikant höchste Aggressivität auf, gefolgt von $F$. equiseti und $F$. tricinctum. Von diesen Spezies war bisher nur bekannt, dass sich ihr Wachstum bei einer Punktinokulation auf das inokulierte Ährchen beschränkt (Stack \& McMullen, 1985; Wilcoxson et al. 1988). Da in den vorliegenden Versuchen aber eine Sprühinokulation vorgenommen wurde, scheint dies die Symptomausbreitung zumindest in den inokulierten Ährchen unterstützt zu haben. Dies bestätigte sich auch in dem zweiten Versuch, wo vor allem bei F. tricinctum ein erheblicher Anstieg der Aggressivität beobachtet werden konnte, was auf eine mögliche Interaktion der Inokulationstechnik und der anfälligen Sorte schließen lässt (Tab. 24). Nahezu alle Ährchen die mit dem Inokulum in Kontakt kamen schienen zu 21 dpi Symptome aufzuweisen, wobei jedoch keine bräunlich, gelbe Verfärbung der Spindelachse auftrat, was ein typisches Symptom der systemischen Pilzausbreitung in der Ähre ist (Pugh, 1933) und in allen mit F. graminearum und $F$. culmorum infizierten Varianten deutlich sichtbar auftrat. Trotz der geringeren Ausbreitungsfähigkeit in den Ähren werden F. equiseti, F. tricinctum und F. oxysporum, wenn auch zu einem geringen Anteil, als Mitverursacher des FHB Komplexes in Europa angesehen (Bottalico, 1998).

F. graminearum wird, wie bereits zuvor beschrieben, in Deutschland als Hauptverursacher der partiellen Weißährigkeit angesehen (Krauthausen et al., 2003) und wies erwartungsgemäß in den Versuchen die signifikant höchste Menge symptomatischer weißlicher Körner auf (Abb. 20). Überraschenderweise unterschieden sich jedoch die Mengen und die Mykotoxingehalte, der beiden Isolate von $F$. graminearum. Das Isolat aus der Zuckerrübe verursachte einen signifikant höheren Gehalt an FHB-Körnern und einen nahezu doppelt so hohen Gehalt an DON auf (Tab. 23), im Vergleich zum Referenzisolat aus dem Weizen. Dieses wird in der Literatur fälschlicherweise häufig als Indikator für eine höhere Aggressivität fehlinterpretiert, da höhere DON-Gehalte zumeist mit höheren Befallsstärken korreliert sind (Wanyoike et al., 2002). Genetisch modifizierte Stämme von F. graminearum deren Fähigkeit zur DONProduktion ausgeschaltet wurde, wiesen eine geringere Aggressivität auf, im Vergleich zu unveränderten Wildstämmen (Desjardins et al., 1996). Dies zeigt zwar das Deoxynivalenol an 
der Besiedlung von Gewebe beteiligt ist, die zumeist vorgenommene Einstufung als Pathogenitätsfaktor erscheint jedoch zweifelhaft, da in diesem Fall Ursache und Wirkung durcheinandergebracht werden. Die Symptomausprägung der partiellen Weißährigkeit ist, wie der DON Gehalt, ein Produkt der Pilzbiomasse in der infizierten Ähre, so dass hier zwei Wirkungen miteinander verglichen werden. Selbst wenn DON keinen Einfluss auf die Ausbreitung des Pathogens in der Ähre besitzt, würde wahrscheinlich auf Grund derselben Ursache,nämlich der Pilzbiomasse, eine enge Korrelation der beiden Effekte auftreten (Brandfass, 2006). Andere Ursachen der Aggressivität wie z.B. die Zusammensetzung zellwandabbauender Enzyme des Pathogens werden in solchen Fällen vernachlässigt, obwohl relativ wenig über die unterschiedliche Zusammensetzung zwischen den Arten bekannt ist (Wanyoike et al., 2002; Vincent et al., 2009). Neben den hohen Mengen an DON wurde in den beiden Proben von $F$. graminearum auch glukosiliertes DON, sogenannte maskierte Mykotoxine gefunden (Gareis, 1994). Metabolite wie DON-3-G, die eine Konjugatbildung mit Glukose eingegangen sind, können durch Routinemethoden wie z.B. ELISA nicht nachgewiesen werden. Beim Verdauungsprozesses kann das Glucosid während der Darmpassage durch die Aktivität der dortigen Flora wieder aufgespalten werden und es besteht die Möglichkeit, dass die Mykotoxine wieder aktiv werden (Gareis, 1994). Die in diesen Versuchen gemessenen Bestandteile von 10-15\% DON-Glucosiden an der gesamten DON-Menge (Tab. 23) spiegeln die Erfahrungswerte aus der Literatur bei künstlich inokulierten Weizen wieder (Berthiller et al., 2005). Die Isolate von $F$. culmorum und $F$. cerealis waren in diesem Versuch Nivalenol (NIV) Produzenten, von denen angenommen wird, das sie weniger aggressiv als DON Chemotypen sind (Miedaner \& Reinbrecht, 2001). Der Vergleich der FHB-Indices zeigte jedoch keine signifikanten Unterschiede zwischen dem Referenzisolat von $F$. graminearum aus Weizen und den beiden NIV-Produzenten, so dass dies nicht bestätigt werden konnte.

Auf Grund der nichtsystemischen Ausbreitung von F. equiseti und F. tricinctum, bzw. der Beschränkung der Pathogenbesiedlung auf die inokulierten Ährchen war auch deren Ertragsreduktion geringer als bei den typischen FHB-Bildnern. Diese Isolate waren nicht in der Lage signifikante Mengen von FHB-Körnern zu bilden (Abb. 20). Im zweiten Versuch konnte jedoch eine signifikante Reduktion des TKG durch Infektion mit $F$. tricinctum gemessen werden, die bei $F$. equiseti und $F$. redolens deutlich geringer ausgeprägt war (Tab. 25). Im Gegensatz dazu verursacht $F$. oxysporum keine signifikante Veränderung des TKG, was eng mit den geringen Befallstärken in dieser Inokulationsvariante korrelierte (Tab. 24). Trotz dieses geringeren Ertragseffekts beeinflussten all diese Fusarium-Arten die Getreidequalität negativ. Neben B-Trichothecenen wie Nivalenol und deren acetylierter Derivatform Fusarenon X, die 
in der Inokulationsvariante von $F$. equiseti identifiziert werden konnten, wurden hohe Mengen von Moniliformin und verschiedener Enniatine in den mit $F$. tricintum infizierten Varianten gefunden. Der zweite Versuch mit mehreren Isolaten als Inokulumgemisch zeigte neben einer deutlich stärkeren Mykotoxinbelastung eine größere Vielfalt an identifizierten Mykotoxinen (Tab. 26), was darauf hindeutet, dass sich die Chemotypen der Isolate voneinander unterscheiden. Daneben wurde an den inokulierten Körnern am Bereich des Keimlings häufig das sogenannte „Black Point“ Symptom (BP) gefunden, eine schwärzliche Verfärbung der Samenschale in Form eines Sattels (Abb. 19). Die signifikant höchste Menge an BP-Körner bildeten in den Versuchen mit der Sorte Kadrilj die Isolate von F. tricinctum und F. equiseti (Abb. 20), was bei der Sorte Tybalt für F. tricinctum ebenfalls zutraf, wobei hier jedoch auch große Mengen bei F. oxysporum festgestellt werden konnten (Tab. 25). „Black Point“ ist weder ein typisches Symptom für eine Infektion mit Ährenfusarien, noch ist es besonders typisch für Weizen. In Roggen und Gerste ist es ebenfalls anzufinden (Machacek \& Greaney, 1938). Es wird derzeit davon ausgegangen, dass Peroxidasen der Aleuronschicht im Bereich des Embryos mit Phenolen aufgrund bestimmter biotischer bzw. abiotischer Impulse reagieren und somit eine deutliche Melanisierung des Korns verursachen. Unter normalen Bedingungen sollte dieser Prozess erst bei der Keimung ausgelöst werden, so dass die Körner keine Verfärbungen aufweisen würden (Cochrane, 1994). Welche Faktoren diesen Prozess genau und wann überhaupt auslösen ist noch umstritten. In Feldversuchen zeigte sich jedoch ein enger Zusammenhang zwischen dem Auftreten von Alternaria spp. und Cochliobolus sativus und der Menge an „Black Point“ Körnern (Hanson \& Christensen, 1953). Wobei aber auch bereits verschiedene andere „Black Point“-induzierende Ährenpathogene wie z.B. F. proliferatum (Conner et al., 1996) und F. avenaceum (Golinski et al., 1996) identifiziert wurden.

Bisher wurde „Black Point“ eher als ein ästhetisches Problem des getreideverarbeitenden Gewerbes angesehen, da die Qualtiätseigenschaften des Getreides durch dieses Symptom nicht negativ beeinträchtigt wurden (Lorenz, 1986). Jedoch zeigten sich in den aktuellen Versuchen ein hoher Zusammenhang zwischen der Mykotoxinbelastung und der jeweiligen Kornfraktion. In BP-Körnern in der mit $F$. tricinctum infizierten Variante konnten zwischen 4 bis 8,6 mal höhere Mykotoxinwerte als in symptomlosen Körnern gemessen werden, ähnliches wurde in der Infektionsvariante mit $F$. equiseti festgestellt (Tab. 26). Vergleichbare Ergebnisse wurden bereits für $F$. proliferatum bei Fumonisin (Desjardins et al., 2007) und $F$. avenaceum bei Moniliformin (Golinski et al., 1996) festgestellt. Gleichwohl zeigte aber die Inokulation mit dem Isolatgemisch von $F$. oxysporum, dass auch relativ große Mengen von BP-Körnern nicht zwangsweise eine höhere Mykotoxinbelastung bedeuten müssen. Zwischen 
beiden Kornfraktionen konnten in diesem Fall keine deutlichen Unterschiede im Mykotoxingehalt gemessen werden. Trotz allem erscheint, solange die Ursache von BP während der Ernte nicht bekannt ist, eine Separierung des Getreides und somit eine Entfernung von BPKörnern aus dem Erntegut notwendig, um mögliche Mykotoxinkontaminationen frühzeitig auszuschließen. 


\section{$5 \quad$ Zusammenfassung}

Im Rahmen der vorliegenden Arbeit wurde unter Klimakammer- und Freilandbedingungen der Einfluß von Witterung, Standort, Sorte, Vorfrucht und Blattapplikation mit verschiedenen Fungizidklassen auf die Mykotoxinbildung von Fusarium spp. für den Klimaraum Niedersachsen überprüft. Erstmalig wurde dabei die spezifische Mykotoxinbildung, d.h. die Menge Mykotoxin die pro Einheit $F$. graminearum DNA gebildet wird im Feld und im Gewächshaus ermittelt. Vorherige Untersuchungen stellten für die spezifische Mykotoxinbildung große Schwankungsbreiten in verschiedenen Versuchsjahren fest, die bisher nur unzureichend mit Witterungseinflüssen erklärt wurden. Im Verlauf dieser Arbeit wurden verschiedene Umweltfaktoren in Versuchen unter kontrollierten Umweltbedingungen identifiziert, die diese komplexen Interaktionen zwischen Mykotoxinmenge und Pilzbiomasse teilweise erklärten.

Haupteinflussfaktor auf die Mykotoxinbildung im FAEN-Feldversuch war erwartungsgemäß der Jahres- bzw. Witterungseffekt mit einem Anteil von ca. 20\% an der Gesamtvariation. Dies beruhte auf der notwendigen Koinzidenz von Weizenpflanzen, die sich im Entwicklungsstadium der Vollblüte befanden mit einer relativ lang anhaltenden, feucht warmen Witterung mit Niederschlagsereignissen.

Mit 12\% Anteil an der Gesamtvariation des DON-Gehaltes stellte die Vorfrucht den zweitbedeutendsten Versuchsfaktor dar. Neben der Förderung des Ährenbefalls durch $F$. graminearum führten die Vorfruchtvarianten Mais in allen drei Versuchsjahren zu den höchsten Mykotoxinkontaminationen im Ernteprodukt. Für die Vorfruchtvarianten Winterweizen und Zuckerrübe waren die Effekte nicht eindeutig, sie waren von der Befallsstärke des jeweiligen Jahres abhängig. Unter schwachen bis mittleren Befallsbedingungen galt für die drei Versuchsjahre die Abstufung: Mais > Winterweizen > Zuckerrübe; hingegen bei Starkbefall: Mais $>$ Winterweizen $=$ Zuckerrübe. Ursache dieser Verschiebungen sind wahrscheinlich luftbürtige Infektionen durch Askosporenwolken, die in Starkbefallsjahren flächenbezogene Vorfruchteffekte überlagern.

Die Mykotoxingehalte der Sorte Centrum unterschieden sich bei Ährenbefall signifikant von der Sorte Ritmo. Der ermittelte Anteil der Sortenresistenz an der Gesamtvarianz aller drei Versuchsjahre war mit einem Anteil von 8\% im Vergleich zu den Erfahrungswerten aus der Literatur von bis zu $40 \%$ überraschend gering. Wurden diese Analysen nur auf Ebene der einzelnen Versuchsjahre durchgeführt, stieg der Anteil der Sortenresistenz an der Jahresvarianz jedoch deutlich an. Der Einfluß der Sortenresistenz war als einziger der Versuchsfaktoren im Feldversuch unabhängig vom spezifischen Befallsniveau des Versuchsjahrs. Im Gegensatz 
dazu war der Einfluß von Standort und Vorfrucht auf den Mykotoxingehalt nur in Jahren mit hohem Befallsniveau wie 2007 und 2009 signifikant. Bis zu 70\% der Varianz des Deoxynivalenolgehaltes im jeweiligen Versuchsjahr ließ sich mittels der vier Versuchsfaktoren Vorfrucht, Sorte, Standort und Fungizidapplikation erklären.

Der Anteil der Fungizidapplikationen an der Gesamtvariation des DON-Gehaltes war nur gering, jedoch war dieser Effekt über die drei Versuchsjahre signifikant. Eine Blattapplikation von Fungiziden wie Strobilurinen, die die Pflanzenphysiologie beeinflussen, führte zwar nicht zu einer signifikanten Erhöhung der Mykotoxinkonzentration im Korn, jedoch konnte in jedem Versuch dieser Arbeit eine solche Tendenz festgestellt werden. Unter Freilandbedingungen wiesen mit Strobilurinen behandelte Weizenpflanzen eine später einsetzende Seneszenz auf. Möglicherweise stand auf solchen Pflanzen dem Pathogen bei günstigeren Wassergehalten ein längerer Zeitraum für die Mykotoxinproduktion zur Verfügung, was eine der Ursachen für die erhöhten DON-Mengen in den Strobilurinvarianten sein könnte. Andererseits könnte juvenileres Gewebe auch eine partielle Resistenz gegen nekrotrophe Pathogene besitzen, so dass der erhöhte Stress des Pathogens bei der Gewebebesiedlung zu einer Erhöhung der Mykotoxinbildung beitrug.

Die spezifische Mykotoxinbildung war im Feld hochgradig abhängig von den Jahres- bzw. Witterungseffekten. Es bestätigte sich, dass hohe Mykotoxingehalte im Erntegut, aufgrund günstiger Infektions- und feuchter Abreifebedingungen, i.d.R. mit geringeren spezifischen Mykotoxinbildungen assoziiert sind. Das Pilzwachstum reagierte sensitiver auf veränderte Umweltbedingungen als die Mykotoxinproduktion, was in Klimakammerexperimenten bestätigt wurde. Günstige Umweltbedingungen mit hohen Tagesdurchschnittstemperaturen und Luftfeuchten führten in planta zu einem verhältnismäßig stärkeren vegetativen Wachstum des Pathogens und somit der DNA-Menge von $F$. graminearum im Vergleich zu den Mykotoxinmengen.

Resistentere Sorten wiesen in dieser Arbeit in allen Versuchen unter Freilandbedingungen eine signifikant geringere spezifische Mykotoxinbildung auf als anfälligere Sorten, was im Gegensatz zu bisherigen Ergebnissen aus der Literatur steht. In Feldversuchen sanken mit zunehmender Sortenresistenz die Mengen der Pilzbiomasse und der DON-Gehalte linear ab. Die Mykotoxinmengen verringerten sich dabei deutlich schneller, was zu der geringeren spezifischen Mykotoxinbildung in den resistenten Sorten führte. Unter kontrollierten Umweltbedingungen kehrte sich diese Tendenz jedoch um und führte $\mathrm{zu}$ höheren spezifischen Mykotoxinbildungen in den resistenteren Sorten. Als Konsequenz dieser distinkten Wechsel- 
wirkungen wurden zwei Modelle einerseits für Versuche unter kontrollierten Umweltbedingungen z.B. im Gewächshaus und andererseits für Feldversuche entwickelt, die den Verläufen der spezifischen Mykotoxinbildung Rechnung tragen.

Darüber hinaus zeigten die Pathogenitätstests der aus Zuckerrüben isolierten Fusarium-Arten, dass auch diese in der Lage waren Weizenähren zu besiedeln und erhebliche Mengen an Mykotoxinen in Körnern zu bilden. Klassische FHB-Bildner wie $F$. graminearum und $F$. culmorum besiedelten die inokulierten Ähren systemisch und führten zur Entwicklung der fusarientypischen weißlichen Schmachtkörner. Die Pathogense von F. tricinctum, F. equiseti, F. redolens und F. oxysporum blieb auf einzelne infizierte Ährchen beschränkt und verursachte dort atypische Verbräunungen an den Deck- und Hüllspelzen. Dort kam es auch zu der Ausbildung des sogenannten „Black Point“ Symptoms an ansonsten normal entwickelten Körnern. Im Vergleich zu symptomlosen Körnern wies diese Kornfraktion einen deutlich erhöhten Gehalt an Mykotoxinen auf.

Mit den Ergebnissen dieser Arbeit wird es in Zukunft möglich sein unter verschiedenen Witterungsszenarien den Einfluss agronomischer Faktoren wie der Vorfrucht, dem Standort und der Sortenresistenz auf die Pathogenentwicklung von F. graminearum und die Mykotoxingehalte im Getreidekorn exakter zu bewerten.

\section{Summary}

In the present study agronomic and climatic factors contributing to mycotoxin production in wheat ears by Fusarium spp. were examined under controlled and field conditions. Particular attention was paid to the amount of mycotoxins per unit Fusarium DNA, the so called specific mycotoxin production, which was calculated for all experiments. Previous studies have reported large variations in the ratio of fungal biomass and mycotoxin production in different experimental years, which were explained with the different weather conditions. In the present experiments under controlled conditions various environmental factors such as temperature and humidity were studied in order to explain the complex interactions between the amount of mycotoxins and fungal biomass.

The main factor influencing mycotoxin formation in the FAEN field trial was the effect of year, accounting for about $20 \%$ of total variation in grain mycotoxin content. A coincidence of wheat plants in susceptible growth stage of full anthesis and relatively long-lasting, warm, humid weather with precipitation events led to an occurrence of FHB. 
With $12 \%$ of total variation of DON content, the pre-crop represented the second most important influential factor. Besides boosting infections with $F$. graminearum, in all three years the pre-crop maize led to the highest mycotoxin contamination in harvested wheat products. Precrop effects for winter wheat and sugar beet were not consistent. Under low to medium infestation conditions a proper order seemed to be: maize > winter wheat > sugar beet. Whereas under high infestation conditions the order shifted to maize $>$ winter wheat $=$ sugar beet. Most likely, airborne infections via ascospores being prevalent in years with high disease pressure are a possible cause for these effects.

Mycotoxin levels of the variety Centrum differed significantly from cultivar Ritmo. The impact of cultivar resistance had a share of $8 \%$ of the total variance for all three experimental years. This was surprisingly low, compared to the empirical values of $40 \%$ from former studies. When each year was analysed individually the proportion of cultivar resistance to the total variance increased. In contrast, location and pre-crop had a significant influence on the mycotoxin level only in years with high disease pressure like in 2007 and 2009. Up to $70 \%$ of the annual variance of the deoxynivalenol content was explained by the four experimental factors, pre- crop, variety, location, and fungicide application.

The impact of fungicide applications on the total mycotoxin variation was negligible but this effect was significant across the three trial years. A foliar application of fungicides such as strobilurin that affect plant physiology, led to a slight increase of mycotoxins in grains. Under field conditions strobilurin treated plants showed delayed maturation and a delayed senescence. This might be one reason for an increasing DON accumulation. On the one hand on such plants the pathogen probably may grow for a longer period of time and therefore more mycotoxins can be produced. On the other hand more juvenile tissue could also act as a partial resistance factor against the necrotrophic Fusarium pathogens and thus lead to increased mycotoxin formation due to higher stress of the pathogen.

Specific mycotoxin formation was highly dependent on the season and weather effects. High levels of mycotoxins in grains were associated with low values of specific mycotoxin production. Particularly, the formation of fungal biomass seemed to be more responsive to environmental changes than the production of mycotoxins, which was confirmed in climate chamber experiments. Favorable environmental conditions enhanced vegetative growth of the pathogen in comparison to the amount of mycotoxins.

Under field conditions specific mycotoxin production in resistant cultivars was significantly lower than in susceptible ones, which was in contrast to results from earlier studies. In resis- 
tant varieties the amount of fungal biomass and DON level decreased linearly. DON content decreased significantly faster, resulting in a decreased specific mycotoxin formation in the more resistant cultivars. Under controlled environmental conditions, this trend reversed and therefore led to higher specific mycotoxin formation in the resistant varieties. As a consequence, two modified models for tests were developed, on the one hand under controlled environmental conditions and for field trials the other hand.

In addition pathogenicity tests with Fusarium spp. isolated from sugar beets showed that these were able to colonize wheat ears and produce large quantities of mycotoxins. FHB producers such as $F$. graminearum and $F$. culmorum colonized the inoculated ears systemically and led to the development of typical whitish scabby grains. Pathogenesis of F. tricinctum, F. equise$t i, F$. oxysporum and $F$. redolens remained limited to individual infected spikelets and caused atypical browning at the glumes. Infected grains showed formation of "black point" symptoms on normally developed grains. Compared with symptomless grains this fraction had a significant higher content of mycotoxins.

The results of this study will serve to predict the impact of agronomic factors such as precrop, location and type of resistance under different weather scenarios on FHB development and mycotoxin formation more accurately. 


\section{$6 \quad$ Literatur}

Adolf, B. 1998: Epidemiologie und Nachweis von Getreidefusariosen: Untersuchungen an Weizen und Gerste. Herbert Utz Verlag, München.

Ahl, Chr., 2002: Bodenkundliche Geländeübungen im Raum Göttingen, Skriptum zu Aspekte und Grundlagen der Bodenkunde, 5. Auflage, 47-48.

Anonymus, 2005: Verordnung (EG) Nr. 856/2005 der Kommission vom 6. Juni 2005 zur Änderung der Verordnung (EG) Nr. 466/2001 in Bezug auf Fusarientoxine, ABl. EG Nr. L $143,3$.

Anonymus, 2006: Beschreibende Sortenliste 2006 Getreide, Mais, Ölfrüchte, Legumiosen, Hackfrüchte. Bundesortenamt, Hannover.

Anonymus, 2009: Beschreibende Sortenliste 2009 Getreide, Mais, Ölfrüchte, Legumiosen, Hackfrüchte. Bundesortenamt, Hannover.

Appuhn, H., 2010: Persönliche Mitteilung 18.06.2010.

ASAE Standards, 1997: S352.2 Moisture measurement - unground grain and seeds. American Society of Agricultural and Biological Engineers, St. Joseph, Michigan.

Atanasoff, D., 1920: Fusarium-blight (scab) of wheat and other cereals. Journal of Agricultural Research 10, 1-33.

Bai, G. H., G. Shaner, 1994: Scab of wheat: Prospects for control. Plant Disease 78, 760-766.

Bai, G.H., G. Shaner, 1996: Variation in Fusarium graminerarum and cultivar resistance to wheat scab. Plant Disease 80, 975-979.

Beck, R. \& J. Lepschy, 2000: Ergebnisse aus dem Fusarium-Monitoring 1989-1999 - Einfluss der produktionstechnischen Faktoren Fruchtfolge und Bodenbearbeitung. Schriftenreihe der Bayerischen Landesanstalt für Bodenkultur und Pflanzenbau: Risiken durch den Ährenparasiten Fusarium graminearum, 39-47.

Bergstrom, G.C, D. Waxman, D.G. Schmalle III, C.A. Bradley, L.E. Sweets, S.N. Wegulo \& M.D. Keller, 2009: Effects of within-field corn debris in microplots on FHB and DON in ten U.S. winter wheat environments in 2009. in: Proceedings of the 2009 National Fusarium Head Blight Forum. University of Kentucky, 22. 
Birzele, B., A. Meier, H. Hindorf, J. Krämer \& H.W. Dehne, 2002: Epidemiology of Fusarium infection and deoxynivalenol content in winter wheat in Rhineland, Germany. European Journal of Plant Pathology 108, 667-673.

Bockmann, H., 1962: Künstliche Freilandinfektionen mit den Erregern der Fuß- und Ährenkrankheiten des Weizens. I. Vorbereitung und Durchführung der Feldinfektionen sowie deren Neben- und Nachwirkungen. Nachrichtenblatt des Deutschen Pflanzenschutzdienstes 14, 153-156.

Bockmann, H., 1963: Künstliche Freilandinfektionen mit den Erregern der Fuß- und Ährenkrankheiten des Weizens. II. Die Infektionswirkung und ihre Beurteilung nach dem Schadbild. Nachrichtenblatt des Deutschen Pflanzenschutzdienstes 3, 33-37.

Bockus, W.W., R.L. Bowden, R.M. Hunger, W.L. Morril, T.D. Murray and R.W. Smiley, 2010: Compendium of Wheat Diseases and Pests, Third Edition, APS Press, St.Paul.

Bottalico, A., 1998: Fusarium diseases of cereals: Species complex and related mycotoxin profiles in Europe. European Journal of Plant Pathology 80, 85-103.

Brandfass C., 2006: Establishment and application of real-time PCR-based methods to study the epidemiology of Fusarium Head Blight. Dissertation, Universität Göttingen.

Brandfass C. \& P. Karlovsky 2008: Upscaled CTAB-based-DNA extraction and real-time PCR assay for Fusarium culmorum and Fusarium graminearum in plant material with reduced sampling error. International Journal of Molecular Science 11, 2306-2321.

Brandfass C. \& J. Weinert, 2009: Ährenfusarien wieder ein Problem? Land + Forst 21, 16-19.

Brennan, J.M., B. Fagan, A. van Maanen, B.M. Cooke, F.M. Doohan, 2003: Studies on in vitro growth and pathogenicity of European Fusarium fungi. European Journal of Plant Pathology 109, 577-587.

Brennan, J.M., D. Egan, B.M. Cooke \& F.M. Doohan, 2005: Effect of temperature on head blight of wheat caused by Fusarium culmorum and F. graminearum. Plant Pathology 54, 156-160.

Burlakoti, R.R., R. Estrada, V.V. Rivera, A. Boddeda, G.A. Secor \& T.B. Adhikari, 2007: Real-time PCR quantification and mycotoxin production of Fusarium graminearum in wheat inoculated with isolates collected from potato, sugar beet and wheat. Phytopathology 97, 835-841. 
Bushnell, W.R., B.E. Hazen \& C. Pritsch, 2003: Histology and physiology of Fusarium head blight. In: Fusarium Head Blight of Wheat and Barley. Edited by K.J. Leonard \& W.R. Bushnell, APS Press, St. Paul, USA.

Champeil, A., J.F. Fourbet \& T. Dore, 2004: Effects of grain sampling procedures on Fusarium mycotoxin assays in wheat grains. Journal of Agricultural and Food Chemistry 52, 6049-6054.

Champeil, A.; T. Dore; J.F. Fourbet, 2004: Fusarium head blight: epidemiological origin of the effects of cultural practices on head blight attacks and the production of mycotoxins by Fusarium in wheat grains. Plant Science 166, 1389-1415.

Clark, M.F. \& A.N. Adams, 1977: Characteristics of the microplate method of enzyme-linked immunosorbent assay for the detection of plant viruses. Journal of General Virology 34, 475-483.

Cochrane, M.P., 1994: Observations of the germ aleurone of barley. Phenol oxidase and peroxidase activity. Annals of Botany 73, 121-128.

Conner, R.L., S.F. Hwang \& R.R. Stevens, 1996: Fusarium proliferatum: A new causal agent of black point in wheat. Canadian Journal of Plant Pathology 18, 419-423.

Covarelli, L., A.S. Turner \& P. Nicholson, 2004: Repression of deoxynivalenol accumulation and expression of Tri genes in Fusarium culmorum by fungicides in vitro. Plant Pathology 53, 22-28.

Cowger, C., J. Patton-Özkurt, G. Brown-Guedira \& L. Perugini, 2009: Post-Anthesis moisture increased Fusarium Head Blight and deoxynivalenol levels in North Carolina winter wheat. Phytopathology 99, 320-327.

Cumagun, C.J.R., F. Rabenstein \& T. Miedaner, 2004: Genetic variation and covariation for aggressiveness, deoxynivalenol production and fungal colonization among progeny of Gibberella zeae in wheat. Plant Pathology 53, 446-453.

Culler, M.D., J.E. Miller-Garvin \& R. Dill-Macky 2007: Effect of extendet irrigation and host resistance on deoxynivalenol accumulation in Fusarium-infected wheat. Plant Disease 91, 1464-1472.

Desjardins, A.E., R.H: Proctor, G.H. Bai, S.P. McCormick, G. Shaner, G. Bueckley \& T.M. Hohn, 1996: Reduced virulence of trichothecene-nonproducing mutants of Gibberella zeae in wheat field tests. Molecular Plant-Microbe Interactions 9, 775-781. 
Desjardins, A.E., 2006: Fusarium Mycotoxins. APS Press, St.Paul, USA.

Desjardins, A.E., M. Busman, R.H. Proctor, R. Stessman, 2007: Wheat kernel black point and fumonisin contamination by Fusarium proliferatum. Food Additives and Contaminants 24, 1131-1137.

Dill-Macky, R., R.K. Jones, 2000: The effect of previous crop residues and tillage on Fusarium Head Blight of wheat. Plant Disease 84, 71-76.

D`Mello, J.P.F., A.M.C. Macdonald, D. Postel, W.T.P. Dijksma, A. Dujardin \& C.M. Placinta, 1998: Pesticide use and mycotoxin production in Fusarium and Aspergillus phytopathogens. European Journal of Plant Pathology 104, 741-751.

D`Mello, J.P.F., A.M.C. Macdonald \& R. Rinna, 2001: Effects of azoxystrobin on mycotoxin production in a carbendazim-resistant strain of Fusarium sporotrichioides. Phytoparasitica 29, 431-440.

Domsch, K.H., W. Gams, \& E. Weber, 1968: Der Einfluss verschiedener Vorfrüchte auf das Bodenpilzspektrum in Weizenfeldern. Zeitschrift für Pflanzenernährung und Bodenkunde 119, 134-149.

Doohan, F.M., J. Brennan \& B.M. Cooke, 2003: Influence of climatic factors on Fusarium species pathogenic to cereals. European Journal of Plant Pathology 109, 755-768.

Edwards, S.G., 2004: Influence of agricultural practices on fusarium infection of cereals and subsequent contamination of grain by trichothecene mycotoxins. Toxicology Letters 153, 29-35.

Eisenthal, R. \& M.J. Danson, 1992: Enzyme Assays: A Practical Approach. Oxford University Press.

Ellner, F.M., 2005: Results of long-term field studies into the effect of strobilurin containing fungicides on the production of mycotoxins in several winter wheat varieties. Mykotoxin Research 21, 112-115.

Ellner, F.M. 2006: Einfluss von Fungiziden auf die Mykotoxinproduktion in Weizen - ein Kurzresümee der Arbeiten am Institut. Nachrichtenblatt des Deutschen Pflanzenschutzdienstes 58, 67-69.

Engle, J.S., L.V. Madden \& P.E. Lipps, 2003: Evaluation of inoculation methods to determine resistance reactions of wheat to Fusarium graminearum. Plant Disease 87, 1530-1535. 
Fernando, W.G.D., J.D. Miller, W.L. Seaman, K. Seifert \& T.C. Paulitz, 2000: Daily and seasonal dynamics of airborne spores of Fusarium graminearum and other Fusarium species sampled over wheat plots. Canadian Journal of Botany 78, 497-505.

Flor, H.H., 1971: Current status of the gene-for-gene concept. Annual Review of Phytopathology 9, 275-296.

Gareis, M., 1994: Maskierte Mykotoxine. Übersichten zur Tierernährung 22, 104-113.

Geisler, G., 1983: Ertragsphysiologie von Kulturarten des gemäßigten Klimas. Verlag Paul Parey, Hamburg.

Golinski, P., M. Kosteckt, I. Lasocka, H. Wisniewska, J. Chelkowski \& Z. Kaczmarek, 1996: Moniliformin accumulation and other effects of Fusarium avenaceum (Fr.) Sacc. on kernels of winter wheat cultivars. Journal of Phytopathology 144, 495-499.

Goswami, R.S. \& H.C. Kistler, 2004: Heading for disaster: Fusarium graminearum on cereal crops. Molecular Plant Pathology 5, 515-525.

Grossmann, K. \& G. Retzlaff, 1997: Bioregulatory effects of the fungicidal strobilurin Kresoxim-methyl in wheat (Triticum aestivum). Pesticide Science 50, 11-20.

Groth, J.V., E.A. Ozmon \& R.H. Busch, 1999: Repeatability and relationship of incidence and severity measures of scab of wheat caused by Fusarium graminearum in inoculated nurseries. Plant Disease 83, 1033-1038.

Hanson, E.W. \& J.J. Christensen, 1953: The blackpoint disease of wheat in the United States. University of Minnesota Technical Bulletin 206.

Hart, L.P., J.J. Pestka \& M.T. Liu, 1984: Effect of kernel development and wet periods on production of deoxynivalenol in wheat infected with Gibberella zeae. Phytopathology 74, 1415-1418.

Hart, L.P. \& O. Schabenberger, 1998: Variability of vomitoxin in truckloads of wheat in a wheat scab epidemic year. Plant Disease 82, 625-630.

Hart, L.P. \& O. Schabenberger, 2001: Early detection of dexynivalenol in wheat grain. in: Proceedings of the 2001 National Fusarium Head Blight Forum. Hrsg. S. Canty, A. Clark, J. Mundell, E. Walton, D. Ellis \& D. Van Sanford. University of Kentucky, 164167. 
Hanse, B., F. Tijink, 2010: Harvesting losses... How to yield this hidden financial potential. Tagungsbeitrag des 72. IIRB Kongress, Copenhagen.

Hettwer, U. \& P. Karlovsky, 2007: Multimethode zur Bestimmung von Fusarientoxinen. LaborPraxis 5, 1-3.

Hershman, D., 2008: Fungicidal control of Fusarium Head Blight (Head scab) and deoxynivalenol (DON) in Wheat. Wheat Science News 12, 3.

Hooker, D.C., A.W. Schaafsma \& L. Tamburic-Ilinic, 2002: Using weather variabels pre- and post-heading to predict deoxynivalenol content in winter wheat. Plant Disease 86, 611619.

Hope, R., D. Aldred \& N. Magan, 2005: Comparison of environmental profiles for growth and deoxynivalenol production by Fusarium culmorum and F. graminearum on wheat grain. Letters in Applied Microbiology 40, 295-300.

Houterman, P.M., M. Lisong, G. van Ooijen, M.J. de Vroomen, B.J.C. Cornelissen, F.L.W. Takken \& M. Rep, 2009: The effector protein Avr2 of the xylem-colonizing fungus $F u$ sarium oxysporum activates the tomato resistance protein I-2 intracellulary. Plant Journal 58, 970-978.

Jorgensen, L.N. \& J.E. Olesen, 2002: Fungicide treatments affect yield and moisture content of grain and straw in winter wheat. Crop Protection 21, 1023-1032.

Kang, Z. \& H. Buchenauer, 2000a: Cytology and ultrastructure of the infection of wheat spikes by Fusarium culmorum. Mycological Research 104, 1083-1093.

Kang, Z. \& H. Buchenauer, 2000b: Ultrastructure and cytochemical studies on cellulose, xylan and pectin degradation in wheat spikes infected by Fusarium culmorum. Journal of Phytopathology 148, 263-275.

Kang, Z., H. Buchenauer, L. Huang, Q. Han, H. Zhang, 2008: Cytological and immunochemical studies on responses of wheat spikes of the resistant chinese cv. Sumai 3 and the susceptible cv. Xiaoyan 22 to infection by Fusarium graminearum. European Journal of Plant Pathology 120, 383-396.

Kluth, C., 2010: Persönliche Mitteilung vom 20.06.2010

Koch, H.J., Ch. Pringas \& B. Maerlaender, 2006: Evaluation of environmental and management effects on Fusarium head blight infection and deoxynivalenol concentration in the grain of winter wheat. European Journal of Agronomy 24, 357-366. 
Kosiak B, M. Torp, U. Thrane, 1997: The occurrence of Fusarium spp. in Norwegian grain A survey. Cereal Research Communications 25, 595-596.

Krauthausen, H.J., J. Weinert, W. Bauermann \& G.A. Wolf, 2003: Mehrjährige Erhebung zum Vorkommen von Ährenfusarien und dem Mykotoxin Deoxynivalenol in Getreide aus Rheinland-Pfalz. Gesunde Pflanzen 55, 136-143.

Lancashire, P.D., H. Bleiholder, P. Langelüddecke, R. Stauss, T. van den Boom, E. Weber \& A. Witzenberger, 1991: An uniform decimal code for growth stages of crops and weeds. Annual applied Biology 119, 561-601.

Leslie, J.F., B.A. Summerell, 2006: The Fusarium Laboratory Manual. Blackwell Publishing, Oxford.

Lienemann, K., E.C. Oerke \& H.W. Dehne, 2003: Infektionen und Ausbreitung von Fusarium spp. an Weizen in Abhängigkeit der Anbaubedingungen im Rheinland. Landwirtschaftliche Fakultät der Universität Bonn, Schriftenreihe des Lehr- und Forschungsschwerpunktes USL, 104, 120 Seiten.

Liddell, C.M., 2003: Systematics of Fusarium species and allies associated with Fusarium head blight. In: Fusarium Head Blight of Wheat and Barley. Edited by K.J. Leonard \& W.R. Bushnell, APS Press, St. Paul, USA.

Liggitt, J., P. Jenkinson \& D.W. Parry, 1997:The role of saprophytic microflora in the development of Fusarium ear blight of winter wheat caused by Fusarium culmorum. Crop Protection 16, 679-685.

Lorenz, K., 1986: Effects of blackpoint on grain composition and baking quality of New Zealand wheat. New Zealand Journal of Agricultural Research 29, 711-718.

Lyr, H., 1995: Modern Selective Fungicides. Gustav Fischer Verlag, Berlin.

Machacek, J.E. \& F.J. Greaney, 1938: The black-point or kernel smudge disease of cereals. Candian Journal of Research 16, 84-113.

Magan, N., R. Hope, A. Colleate \& E.S. Baxter, 2002: Relationship between growth and mycotoxin production by Fusarium species, biocides and environment. European Journal of Plant Pathology 108, 685-690. 
Matthies, A., F. Walker, H. Buchenauer, 1999: Interference of selected fungicides, plant growth retardants as well as pieronyl butoxide and 1-aminobenzotriazole in trichothecene production of Fusarium graminearum (strain 4528) in vitro. Journal of Plant Disease and Protection 106, 198-212.

Matthies, A., H. Buchenauer, 2000: Effect of tebuconazole (Folicur®) and prochloraz (Sportak $®$ ) treatments on Fusarium head scab development, yield and deoxynivalenol (DON) content in grains of wheat following artificial inoculation with Fusarium culmorum. Journal of Plant Disease and Protection 107, 33-52.

Matthies, A. B.H. Menk \& H. Bleiholder, 2000: Untersuchungen zur Wirksamkeit von Strobilurin-haltigen Fungiziden im Vergleich $\mathrm{zu}$ Azolen auf den Gehalt an Deoxynivalenol (DON) in Weizenproben des Erntejahres 1999 -Erste Erkenntnisse-. Gesunde Pflanze 52, 26-32.

Mesterhazy, A., 1995: Types and components of resistance against Fusarium head blight of wheat. Plant Breeding 114, 377-386.

Mesterhazy, A., 2003: Breeding wheat for Fusarium Head Blight resistance in Europe. In: Fusarium Head Blight of Wheat and Barley. Edited by K.J. Leonard \& W.R. Bushnell, APS Press, St. Paul, USA.

Miedaner, T. \& C. Reinbrecht, 2001: Trichothecene content of rye and wheat genotypes inoculated with a deoxynivalenol- and a nivalenol-producing isolate of Fusarium culmorum. Journal of Phytopathology 149, 245-251.

Miller, J.D., 2008: Mycotoxins in small grains and maize: Old problems, new challenges. Food Additives and Contaminants 25, 219-230.

Mirocha, C.J., S.V. Pathre \& C.M. Chrisensen, 1977: Zearalenone. In: Mycotoxins in Human and Animal Health. Edited by J.V. Rodricks, C.W. Hesseltine \& M.A. Mehlmann, Park Forest, USA.

Nganje, W.E., D.A. Bangsund, F.L. Leistritz, W.W. Wilson \& N.M. Tiapo, 2002: Estimating the economic impact of a crop disease: the case of Fusarium Head Blight in U.S. wheat and barley.In: Proceedings of the 2002 National Fusarium Head Blight Forum. Michigan State University, 275-281. 
Nicholson, P., D.R. Simpson, G. Weston, H.N. Rezanoor, A.K. Lees, D.W. Parry and D. Joyce, 1998: Detection and quantification of Fusarium culmorum and Fusarium graminearum in cereals using PCR assays. Physiological and Molecular Plant Pathology 109, 17-37.

Nicholson, P., E. Chandler, R.C. Draeger, N.E. Gosman, D.R. Simpson, M. Thomsett \& A.H. Wilson, 2003: Molecular tools to study epidemiology and toxicology of Fusarium head blight of cereals. European Journal of Plant Pathology 109, 691-703.

Obst, A., 1994: Untersuchungen zur Epidemiologie und Bekämpfung des Ährenparasiten $F u$ sarium graminearum an Weizen. Mitteilungen der Biologischen Bundesanstalt für Land- und Forstwirtschaft, Berlin-Dahlem 301, 73.

Obst, A., 2000: Witterungsvoraussetzungen für den Ährenbefall des Weizens mit Fusarium graminearum. Schriftenreihe der Bayerischen Landesanstalt für Bodenkultur und Pflanzenbau: Risiken durch den Ährenparasiten Fusarium graminearum, 81-88.

Obst, A. \& P. Gammel, 2000: Fungizide gegen den Ährenparasiten Fusarium graminearum. Schriftenreihe der Bayerischen Landesanstalt für Bodenkultur und Pflanzenbau: Risiken durch den Ährenparasiten Fusarium graminearum, 89-98.

Paulitz, T.C., 1996: Diurnal release of ascospores by Gibberella zeae in inoculated wheat plots. Plant Disease 80, 674-678.

Pereyra, S.A., R. Dill-Macky, A.I. Sims, 2004: Survival and inoculum production of Gibberella zeae in wheat residue. Plant Disease 88, 724-730.

Parry, D. W., P. Jenkinson \& L. McLeod, 1995: Fusarium ear blight (scab) in small grains - a review. Plant Pathology 44, 207-238.

Pomeranz, Y., D.B. Bechter, D.B. Sauer, L.M. Seitz, 1990: Fusarium head blight (scab) in cereal grains. Advances in Cereal Science and Technology 10, 373-433.

Polle, A., K. Chakrabarti, W. Schürmann \& H. Rennenberg, 1990: Composition and properties of hydrogen peroxide decomposing systems in extracellular and total extracts from needles of norway spruce (Picea abies L., Karst). Plant Physiology 94, 312-319.

Prigozliev, S.R., S.G. Edwards, M.C. Hare \& P. Jenkinson, 2003: Strategies for the control of Fusarium head blight in cereals. European Journal of Plant Pathology 109, 731-742. 
Prochazkova, D., R.K. Sairam, G.C. Srivastava \& D.V. Singh, 2001: Oxidative stress and antioxidant activity as the basis of senescence in maize leaves. Plant Science 161, 765771.

Pugh, G.W., H. Johann, J.G. Dickinson, 1933: Factors affecting infection of wheat heads by Gibberella saubinettii. Journal of Agricultural Research 46, 771-797.

Reintke, H., 2010: persönliche Mitteilung am 25.11.2010

Riediger, N., 2008: Beteiligung systemischer Signale an der Symptomauslösung bei Brassica napus nach Infektion mit Verticillium longisporum und $V$. dahliae. Dissertation, Universität Göttingen.

Rintelen, J., 2000: Ist das starke Auftreten von Gibberella zeae (Fusarium graminearum) an Getreideähren auf die Zunahme des Maisanbaus zurückzuführen? Schriftenreihe der Bayerischen Landesanstalt für Bodenkultur und Pflanzenbau: Risiken durch den Ährenparasiten Fusarium graminearum, 11-15.

Schaafsma, A.W., L. Tamburic-Illinic, J.D. Miller, D.C. Hooker 2001: Agronomic consideration for reducing deoxynivalenol in wheat grain. Molecular and Physiological Pathology 23, 279-285.

Schilling, A.G., E.M. Moller and H.H. Geiger, 1996: Polymerase chain reaction- based assays for species-specific detection of Fusarium culmorum, $F$. graminearum and $F$. avenaceaum. Phytopathology 86, 515-522.

Schmidt-Heydt, M. N. Magan \& R. Geisen, 2008: Stress induction of mycotoxin biosynthesis genes by abiotic factors. FEMS Microbiology Letters 284, 142-149.

Schnerr, H., R.F. Vogel \& L. Niessen, 2002: Correlation between DNA of trichotheceneproducing Fusarium species and deoxynivalenol concentrations in wheat-samples. Letters in Applied Microbiology 35, 121-125.

Schroeder, H.W., J.J. Christensen, 1963: Factors affecting resistance of wheat to scab caused by Gibberella zeae. Phytopathology 53, 831-838.

Selye, H., 1936: A syndrome produced by diverse nocuous agents. Nature 138, 32.

Shaner, G., E.L. Stromberg, G.H. Lacy, K.R. Barker \& T.P. Pirone, 1992: Nomenclature and concepts of pathogenicity and virulence. Annual Review of Phytopathology 30, 47-66. 
Simpson, D.R., G.E. Weston, J.A. Turner, P. Jennings \& P. Nicholson, 2001: Differntial control of head blight pathogens of wheat by fungicides and consequences for mycotoxin contamination of grain. Europena Journal of Plant Pathology 107, 421-431.

Stack, R.W., M. McMullen, 1985: Head blighting potential of Fusarium species associated with spring wheat heads. Canadian Journal of Plant Pathology 7, 79-82.

Stack, R. W., and M. McMullen, 1998: A visual scale to estimate severity of Fusarium Head Blight in wheat. NDSU Extension Service: Small Grains Publications. Online Publication/PP-1095.

Stack, R.W., 1999: Return of an old problem: Fusarium Head Blight of small grains. APSnet feature Plant Pathology online http://www.apsnet.org/education/feature/fhb/.

Stein, J.M., L.E. Osborne, K.D. Bondalapati, K.D. Glover \& C.A. Nelson, 2009: Fusarium Head Blight severity and deoxynivalenol concentration in wheat in response to Gibberella zeae inoculum concentration. Phytopathology 99, 759-764.

Strange, R.N., A. Derano \& H. Smith, 1978: Virulence enhancement of Fusarium graminearum by choline and betaine and of Botrytis cinerea by other constituents of wheat germ. Transactions of the British Mycological Society 70, 201-207.

Sulyok, M., R. Krska \& R. Schumacher, 2007: A liquid chromatography/tandem mass spectrometric multi-mycotoxin method for the quantification of 87 analytes and its application to semi-quantitative screening of moldy food samples. Analytical and Bioanalytical Chemistry 389,1505-1523.

Sutton, J.C. 1982: Epidemiology of wheat head blight and maize ear rot caused by Fusarium graminearum. Canadian Journal of Plant Pathology 4, 195-209.

Tiemann, U. \& S. Dänicke, (2007): In vivo and in vitro effects of the mycotoxins zearalenone and deoxynivalenol on different non-reproductive and reproductive organs in female pigs: a review. Food Additives and Contaminants 24, 306-314.

Tschanz, A.T., R.K. Horst \& P.E. Nelson, 1975: Ecological aspects of ascospore discharge in Gibberella zeae. Phytopathology 65, 597-599.

Tschanz, A.T., R.K. Horst, P.E. Nelson 1976: The effect of environment on sexual reproduction of Gibberella zeae. Mycologia 68, 327-340.

Tu, D.S., 1950: Factors affecting the reaction of wheat varieties to head blight infection caused by Gibberella zeae. Ph.D. Thesis, Ohio State University, Colubus, Ohio, USA. 
USDA-GIPSA 1995: Program handbook-Book I: Grain Sampling. United States Department of Agriculture - Grain Inspection, Packers and Stockyards Administration, Washington D.C.

van Euwijk, F.A., A. Mesterhazy, Ch. Kling, P. Ruckenbauer, L. Sauer, H. Bürstmayr, M. Lemmens, L.C.P. Keizer, N. Maurin \& C.H.A. Snijders, 1995: Assessing nonspecificity of resistance in wheat to head blight caused by inoculation with European strains of Fusarium culmorum, F. graminearumand F. nivale using a multiplicative model for interaction. Theoratical Applied Genetics 90, 221-228.

Vesonder, R.F. \& C.W. Hesseltine, 1981: Vomitoxin: natural occurrence on cereal grains and significance as a refusal and emetic factor to swine. Process Biochemistry 16, 12/14$15 / 44$.

Vincent, P., F. Goubet, R. Carapito \& J.M. Jeltsch, 2009: Plant cell wall degradation with a powerful Fusarium graminearum enzymatic arsenal. Journal of Microbiology and Biotechnology 19, 573-581.

von Tiedemann, A., 2009: persönliche Mitteilung am 15.01.2009

Waalwijk, C., P. Kastelein, I. de Vries, Z. Kerenyi, T. van der Lee, T. Hesselink, J. Köhl \& G. Kema, 2003: Changes in Fusarium spp. in wheat in the Netherlands. Journal of Plant Pathology 109, $743-754$.

Wacker, P., 2000: Einfluss des Einsatzes von Fungiziden auf die Stoffeigenschaften von Winterweizen. Landtechnik 55, 119-121.

Wanyoike, M.W., K. Zhensheng \& H. Buchenauer, 2002: Importance of cell wall degrading enzymes produced by Fusarium graminearum during infection of wheat heads. European Journal of Plant Pathology 108, 803-810.

Weinert, J. \& G.A. Wolf, 1995: Gegen Ährenfusarien helfen nur resistente Sorten. Pflanzenschutzpraxis 2, 30-32.

Weinert, J., 2007: persönliche Mitteilung am 10.09.2007

Weinert, J., B. Kleinhenz \& A. von Tiedemann, 2007: Risiko richtig einschätzen. DLGMitteilungen 9, 48-51.

Wilcoxson, R.D., T. Kommedahl, E.A. Ozmon \& C.E. Windels, 1988: Occurrence of Fusarium species in scabby wheat from Minesota and their pathogenicity to wheat. Phytopathology 78, 586-589. 
Wilcoxson, R.D., R.H. Busch and E.A. Ozmon, 1992: Fusarium Head Blight resistance in spring wheat cultivars. Plant Disease 76, 658-661.

Williamson, P.M., 1997: Black Point of wheat: in vitro production of symptoms, enzymes involved, and association with Alternaria alternate. Australian Journal of Agricultural Resarch 48, 13-19.

Wollenweber, H.W., 1932: III. Hyphomyetes. - In: Sorauer, P., O. Appel \& L. Reh (Hrsg.), Handbuch der Pflanzenkrankheiten, Bd. III, Die pflanzlichen Parasiten, 2. Teil, 5. Auflage, Verlagsbuchhandlung Paul Parey, Berlin, 577-830.

Wu, Y.X. \& A. von Tiedemann, 2001: Physiological effects of azoxystrobin and epoxiconazol on senecence and the oxidative status of wheat. Pesticide Biochemistry and Physiology 71, 1-10.

www.apsnet.org/education/LessonsPlantPath/Fusarium/discycle.htm besucht am 20.07.2007

www.proplant.de besucht am 28.06.2010

www.wetterstation-goettingen.de die meteorologischen Daten wurden mit freundlicher Genehmigung von Andreas Vohl am 04.06.2010 zur Verfügung gestellt

Xu, X. 2003: Effects of environmental conditions on the development of Fusarium ear blight. European Journal of Plant Pathology 109, 683-689.

Xu, X.M., W. Monger, A. Ritieni \& P. Nicholson, 2007: Effect of temperature and duration of wetness during initial infection periods on disease development, fungal biomass and mycotoxin concentrations on wheat inoculated with single, or combinations of, Fusarium species. Plant Pathology 56, 943-956.

Yoshizawa, T. \& N. Morooka, 1973: Deoxynivalenol and its monoacetate: New mycotoxins from Fusarium roseum and moldy barley. Agricultural and Biological Chemistry 37, 2933-2934.

Zimmermann, P. \& U. Zentgraf, 2004: Der Zusammenhang zwischen oxidativen Stress und Blattseneszenz während der Entwicklung von Pflanzen. Gesunde Pflanzen 56, 208-217. 


\section{$7 \quad$ Anhang}

Tab. 27 Pflanzenbauliche Maßnahmen an den Standorten Torland und Gladebeck im FAEN-Versuch 2006-2007.

\begin{tabular}{|c|c|c|}
\hline & Gladebeck & Torland \\
\hline $\begin{array}{l}\text { Vorfrucht } \\
\text { Vorvorfrucht } \\
\text { 1.Stoppelbearbeitung } \\
\text { 2.Stoppelbearbeitung }\end{array}$ & $\begin{array}{l}\text { Winterweizen Drifter } \\
\text { 16.08.2006 Grubber (IFZ) }\end{array}$ & $\begin{array}{l}\text { Winterweizen } \\
\text { Winterweizen } \\
\text { 16.08.2006 Grubber (IFZ) }\end{array}$ \\
\hline $\begin{array}{l}\text { Parzellen markiert mit } \\
\text { Magneten }\end{array}$ & 13.09.2006 & 15.09.2006 \\
\hline $\begin{array}{l}\text { Bodenbearbeitung } \\
\text { Saatbettbereitung }\end{array}$ & $\begin{array}{l}\text { 10.10.2006 Spatenrollegge } \\
\text { 10.10.2006 Rototiller }\end{array}$ & $\begin{array}{l}\text { 10.10.2006 Spatenrollegge } \\
\text { 10.10.2006 Rototiller }\end{array}$ \\
\hline Aussaat & & 11.10.2006 Hege Parzellendrillmaschine( nach \\
\hline $\begin{array}{l}\text { Datum und Bedingungen } \\
\text { Technik }\end{array}$ & $\begin{array}{l}\text { 10.10.2006 } \\
\text { 11.10.2006 Hege Parzellendrillmaschine( nach } \\
\text { Rüben+Mais) }\end{array}$ & $\begin{array}{l}\text { Rüben) } \\
\text { 16.10.2006 Hassia Drillmaschine mit Rollscharen } \\
\text { (nach Mais und WW) }\end{array}$ \\
\hline $\begin{array}{l}\text { Saatgut (Menge und } \\
\text { Sorte) }\end{array}$ & $\begin{array}{l}\text { 16.10.2006 Hassia Drillmaschine mit } \\
\text { Rollscharen (nach WW) } \\
\text { "Centrum"170 kg/ha, } 300 \text { Kö./qm ; } 93 \text { \% KF ; } \\
52,8 \text { gr.:TKG nach Plan } \\
\text { "Ritmo"177 kg/ha, } 300 \text { Kö./qm ; } 80 \text { \% KF ; 47, } \\
\text { gr.:TKG(nach Plan) }\end{array}$ & $\begin{array}{l}\text { "Centrum"170 kg/ha, } 300 \text { Kö./qm ; } 93 \text { \% KF ; } \\
\text { 52,8 gr.:TKG nach Plan } \\
\text { "Ritmo"177 kg/ha, } 300 \text { Kö./qm ; } 80 \text { \% KF ; 47,1 } \\
\text { gr.:TKG(nach Plan) }\end{array}$ \\
\hline sonstiges & $\begin{array}{l}\text { 06.03.07 } \mathrm{N} \text {-min Probenahme } \\
\text { 14.03.2007 ausgemessen und abgesteckt }\end{array}$ & $\begin{array}{l}\text { 06.03.07 N-min Probenahme } \\
\text { 14.03.2007 ausgemessen und abgesteckt }\end{array}$ \\
\hline $\begin{array}{l}N-\text { Düngung } \\
\cdot N_{\text {min }} \\
\cdot 1 . N-\text { Düngung }\end{array}$ & 14.03.07 EC27: $60 \mathrm{~kg} \mathrm{~N} / \mathrm{ha}$ als AHL & 14.03.07 EC27: $60 \mathrm{~kg} \mathrm{~N} /$ ha als AHL \\
\hline 2.N-Düngung & 19.04.07 EC 31/32: $60 \mathrm{~kg} \mathrm{~N} / \mathrm{ha}$ als AHL & 19.04.07 EC 31/32: $60 \mathrm{~kg} \mathrm{~N} / \mathrm{ha}$ als AHL \\
\hline 3.N-Düngung & 14.05.07 EC 39: $65 \mathrm{~kg} \mathrm{~N} / \mathrm{ha}$ als AHL & 14.05.07 EC 39: $65 \mathrm{~kg} \mathrm{~N} / \mathrm{ha}$ als AHL \\
\hline $\mathrm{N}_{\text {gesamt }}\left(\right.$ ohne $\left.\mathrm{N}_{\min }\right)$ & $185 \mathrm{~kg} / \mathrm{ha} \mathrm{N}$ & $185 \mathrm{~kg} / \mathrm{ha} \mathrm{N}$ \\
\hline Pflanzenschutz & & \\
\hline - 2. Herbizid & 26.03.07 EC: $2960 \mathrm{gr} . / \mathrm{ha}$ Lexus Class & 26.03.07 EC: $2960 \mathrm{gr} . / \mathrm{ha}$ Lexus Class \\
\hline 1.Wachtumsregler & 26.03.07 EC: 291 l/ha CCC 720 & 26.03.07 EC: 291 l/ha CCC 720 \\
\hline 2.Wachtumsregler & 18.04.07 EC 31/32: 0,5 I/ha CCC 720 & 18.04.07 EC 31/32: 0,5 I/ha CCC 720 \\
\hline $\begin{array}{l}\text { 1.Fungizid } \\
\text { 2.Fungizid }\end{array}$ & $\begin{array}{l}\text { 18.04.07 EC 31/32: Fungizide nach Plan mit } \\
\text { Rückenspritze } \\
\text { 23.05.07 EC 51: Fungizide nach Plan mit } \\
\text { Rückenspritze }\end{array}$ & $\begin{array}{l}\text { 18.04.07 EC 31/32: Fungizide nach Plan mit } \\
\text { Rückenspritze } \\
\text { 23.05.07 EC 51: Fungizide nach Plan mit } \\
\text { Rückenspritze }\end{array}$ \\
\hline 1.Insektizid & 26.03.07 EC: 29 0,3 I/ha Bulldock & 26.03.07 EC: 29 0,3 l/ha Bulldock \\
\hline 2.Insektizid & 22.05.07 EC 51: $150 \mathrm{gr} . / \mathrm{ha}$ Trafo & 22.05.07 EC 51: $150 \mathrm{gr} . / \mathrm{ha}$ Trafo \\
\hline
\end{tabular}


Tab. 28 Pflanzenbauliche Maßnahmen an den Standorten Torland und Gladebeck im FAEN-Versuch 2007-2008.

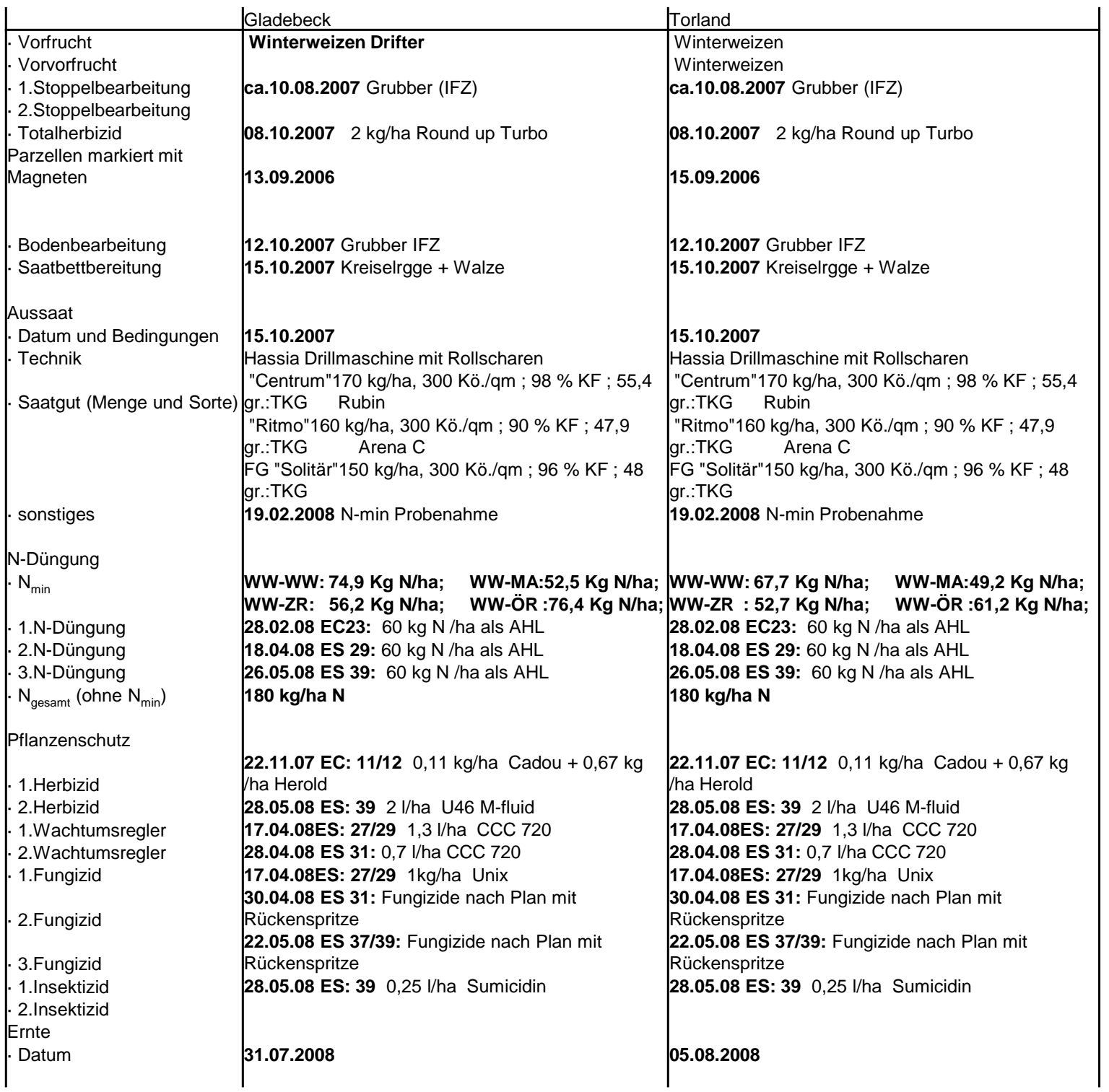


Tab. 29 Pflanzenbauliche Maßnahmen an den Standorten Torland und Gladebeck im FAEN-Versuch 2008-2009.

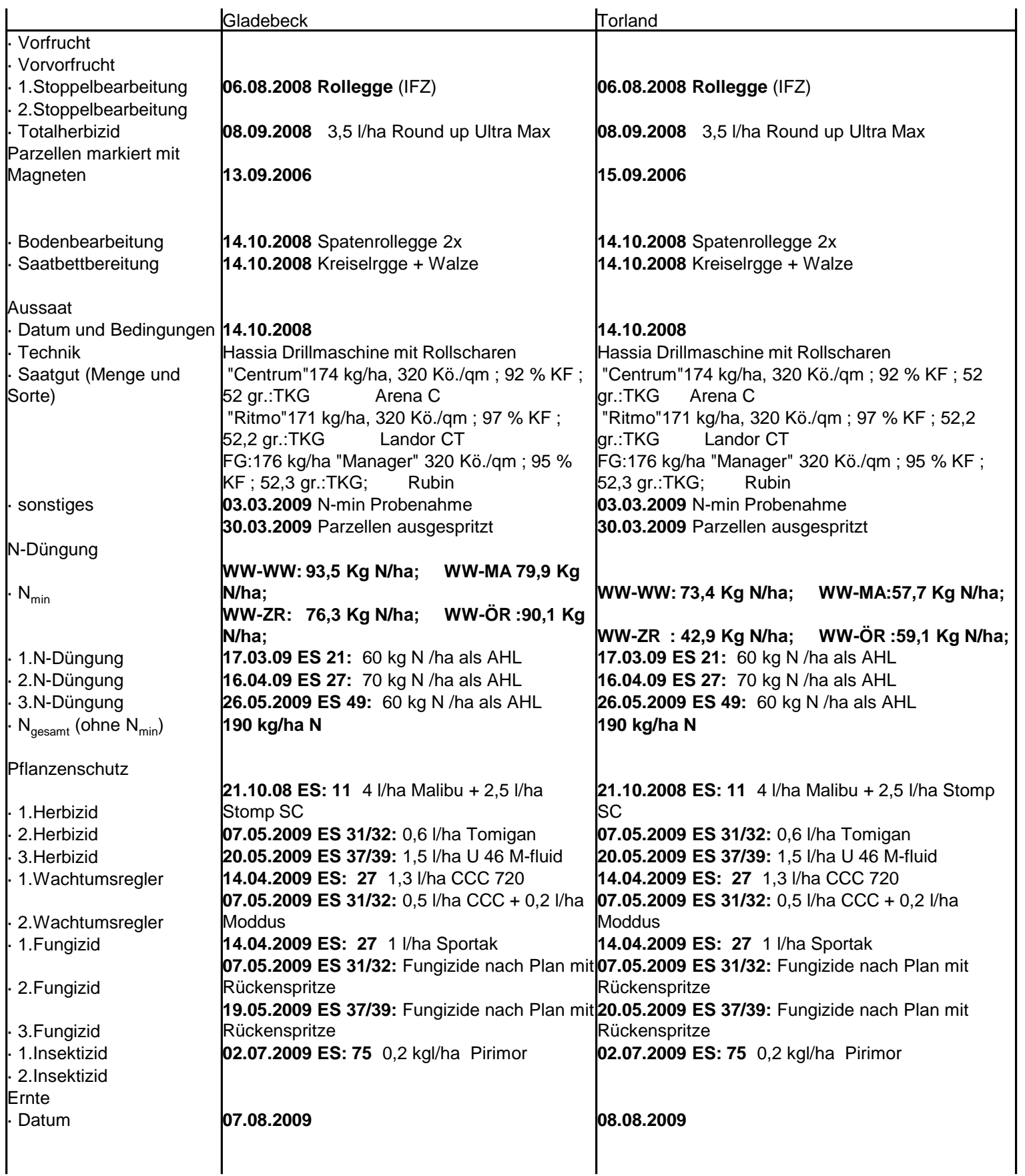


Tab. 30 Pflanzenbauliche Maßnahmen am Standort Weendelsbreite 2008-2009.

\begin{tabular}{|c|c|}
\hline & Weendelsbreite \\
\hline Vorfrucht & Ernte Winterweizen am 06.08.2008 \\
\hline 1.Stoppelbearbeitung & 19.08.2008 Rollegge \\
\hline 2.Stoppelbearbeitung & \\
\hline Totalherbizid & 02.09.2008 $5 \mathrm{l} / \mathrm{ha}$ Glyphogan \\
\hline - Grunddüngung Phosphor & \\
\hline - Grunddüngung Kali/Mg & \\
\hline Grunddüngung Kalk & \\
\hline Bodenbearbeitung & 11.09.2008 Grubber \\
\hline Saatbettbereitung & 27.09.2008 Kreiselegge+Walze \\
\hline Aussaat & \\
\hline Datum und Bedingungen & 27.09.2008 ( nach Plan ) \\
\hline Technik & Scheibenschaardrillmaschine "Hassia", $13.15 \mathrm{~cm}$ Reihe \\
\hline Saatgut (Menge und Sorte) & $\begin{array}{l}171 \text { kg/ha "Ritmo" } 320 \text { Kö./qm bei TKG } 52,2 \text { gr. u. 97\% Kf. } \\
174 \text { kg/ha "Centrum" } 320 \text { Kö./qm bei TKG } 52 \text { gr. u. 92\% Kf. }\end{array}$ \\
\hline Beizung & Centrum-Arena C; Ritmo-Landor CT \\
\hline Inokulation-Fusarium & 05.06.2009 ES:65 Sorte „Centrum“ \\
\hline & 08.06.2009 ES:65 Sorte „Ritmo“ \\
\hline sonstiges & 30.03.2009 Parzellen ausgespritzt \\
\hline N-Düngung & \\
\hline $\mathrm{N}_{\min }$ & \\
\hline 1.N-Düngung & 17.03.09 ES 27: $60 \mathrm{~kg} \mathrm{~N} / \mathrm{ha}$ als AHL \\
\hline 2.N-Düngung & 16.04.09 ES 27: $60 \mathrm{~kg} \mathrm{~N} / \mathrm{ha}$ als AHL \\
\hline 3.N-Düngung & 12.05.09 ES 39: $50 \mathrm{~kg} \mathrm{~N} /$ ha als AHL \\
\hline$\cdot \mathrm{N}_{\text {gesamt }}\left(\right.$ incl. $\left.\mathrm{N}_{\min }\right)$ & 170 kg/ha N (ohne N-min) \\
\hline Pflanzenschutz & \\
\hline 1 Herbizid & 01.04.2009 ES: 23 0,6 I/ha Axial + 1,8 I/ha FHS + 0,1 I/ha Primus \\
\hline 2. Herbizid & 07.04.2009 ES 27: 1 l/ha Loredo \\
\hline - 1.Wachstumsregler & 07.04.2009 ES 27: 1 l/ha CCC 720 \\
\hline 2.Wachstumsregler & 27.04.2009 ES 32: 0,7 I/ha CCC 720 \\
\hline 1. Fungizid & 27.04.2009 ES 32: Fungizide nach Plan mit Rückenspritze \\
\hline 2. Fungizid & 18.05.2009 ES 37/39: Fungizide nach Plan mit Rückenspritze \\
\hline - 2.Insektizid & \\
\hline Ernte & \\
\hline - Datum & 30.07 .2009 \\
\hline
\end{tabular}




\section{Danksagung}

Ich möchte mich ganz besonders bei Herrn Prof. Dr. Andreas von Tiedemann für die Überlassung des Themas, die Diskussions- und Hilfsbereitschaft sowie die gewährte Freiheit bei der Bearbeitung des Projektes bedanken. Danke, dass Sie nicht so häufig auf die Bremse getreten haben.

Herrn Prof. Dr. Petr Karlovsky danke ich für die Übernahme des Koreferates.

Herrn Dr. Birger Koopmann und Frau Dr. Nadine Riediger gilt mein Dank für die Unterstützung bei nahezu allen Problemen während der drei Versuchsjahre.

Herrn Dr. Joachim Weinert danke ich für das erste Jahr meiner Promotion, in dem er für die Grundlagen der Fusariosen und für klare Strukturen in meinem Kopf sorgte.

Bei meinen Projektpartnern im FAEN-Projekt bedanke ich mich herzlich für die konstruktive Zusammenarbeit, Daniela Christ für immer kritische Anmerkungen und Marie Kreuzberger für gutes Bonitieren und leckere Marmelade.

Meinem Büronachbarn Mark Winter danke ich für die spezielle Arbeitsatmosphäre und die Mitgliedschaft im ZDM, auch wenns hin und wieder mal lauter wurde.

Vielen Dank an Evelin Vorbeck, Hubertus Reintke und Eugen Hodyl für die tatkräftige Unterstützung im Feld und Gewächshaus. Bei Frank Gremmes und Herrn Kussatz danke ich für die technische Unterstützung jeglicher Art.

Bei Frau Martina Bode und Frau Evelin Kistner möchte ich mich für die pragmatische, unbürokratische Hilfe in allen administrativen Angelegenheiten bedanken.

Ich möchte mich bei den Zivildienstleistenden Ali Haydar Oezen, Matthias Meier und Sebastian Streit bedanken, ohne deren Hilfe die Versuche nicht möglich gewesen wären.

Bei den Mitarbeitern der KWS-Lochow GmbH bedanke ich mich für die hervorragenden Sortenversuche.

Den Kollegen in der Abteilung Allgemeine Pflanzenpathologie und Pflanzenschutz möchte ich für die herausragende Arbeitsatmosphäre und stetige Hilfsbereitschaft danken.

Mein besonderer Dank gilt Claudia Nordmann. Du warst einfach immer da, wenn ich dich gebraucht habe!

Abschließend möchte ich mich ganz besonders bei meinen Eltern und bei Sarah und Markus bedanken, die mich immer unterstützt haben und seis beim Bonitieren auf den Feldern. 


\section{Eidesstattliche Erklärung}

Hiermit erkläre ich, dass diese Arbeit weder in gleicher noch in ähnlicher Form bereits anderen Prüfungsbehörden vorgelegen hat.

Weiter erkläre ich, dass ich mich an keiner anderen Hochschule um einen Doktorgrad beworben habe.

Göttingen, den 


\section{Lebenslauf}

\section{Persönliche Daten:}

Name: $\quad$ Ruben Gödecke

Geburtsdatum: $\quad 31.05 .1979$ in Göttingen

Wohnort: $\quad$ Duderstädter Str. 4, 37434 Rhumspringe

\section{Schulausbildung:}

1985-1989 Grundschule Rhumspringen

1989-1991 Orientierungsstufe Gieboldehausen

1991-1998 Eichsfeldgymnasium Duderstadt

Abitur als Abschluss

Ausbildung:

1999-2001 Ausbildung zum Landwirtschaftlich-technischen Assistenten bei der KWS Saat AG/Einbeck

\section{Hochschulausbildung:}

2001-2005 Grund- und Bachelorstudium der Agrarwissenschaften an der Georg-AugustUniversität Göttingen. Thema der Bachelorarbeit: „Untersuchungen zur Sortenanfälligkeit von Winterraps gegenüber der kleinen Kohlfliege““

2006-2007 Masterstudium der Agrarwissenschaften an der Ohio State University, Columbus/USA und der Georg-August-Universität Göttingen. Thema der Masterarbeit: „Einfluss von Wurzelexudaten bei der wirtspezifischen Induktion der Mikrosklerotienkeimung von Verticillium longisporum“

Seit 2007 Doktorand am Department für Nutzpflanzenwissenschaften, Fachgebiet Pflanzenpathologie und Pflanzenschutz der Georg-August-Universität Göttingen. Dissertationsthema: „Einflussfaktoren der Mykotoxinbildung durch Ährenbefall mit Fusarium spp. in verschiedenen Winterweizenfruchtfolgen“ 